\title{
CRYOGENIC PROPERTIES OF INORGANIC INSULATION MATERIALS FOR ITER MAGNETS: A REVIEW
}

\section{N.J. Simon}

Materiais Reliability Division

Materials Science and Engineering Laboratory National Institute of Standards and Technology Boulder, Colorado 80303-3328

Sponsored by:

Department of Energy

Office of Fusion Energy

Washington, DC 20545

December 1994

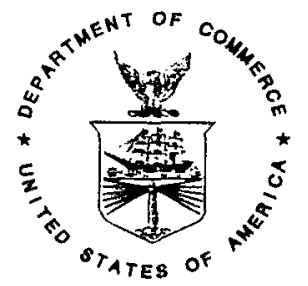

PROCESSED FROM BEST AVAILABLE COPY

U.S. DEPARTMENT OF COMMERCE, Ronald H. Brown, Secretary TECHNOLOGY ADMINISTRATION, Mary L. Good, Under Secretary for Technology NATIONAL INSTITUTE OF STANDARDS AND TECHNOLOGY, Arati Prabhakar, Director 


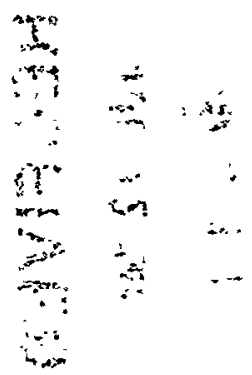




\section{DISCLAIMER}

This report was prepared as an account of work sponsored by an agency of the United States Government. Neither the United States Government nor any agency thereof, nor any of their employees, make any warranty, express or implied, or assumes any legal liability or responsibility for the accuracy, completeness, or usefulness of any information, apparatus, product, or process disclosed, or represents that its use would not infringe privately owned rights. Reference herein to any specific commercial product, process, or service by trade name, trademark, manufacturer, or otherwise does not necessarily constitute or imply its endorsement, recommendation, or favoring by the United States Government or any agency thereof. The views and opinions of authors expressed herein do not necessarily state or reflect those of the United States Government or any agency thereof. 


\section{DISCLAIMER}

Portions of this document may be illegible in electronic image products. Images are produced from the best available original document. 


\title{
CRYOGENIC PROPERTIES OF INORGANIC INSUIATION MATERIALS
}

\section{FOR ITER MAGNETS: A REVIEW}

\author{
N.J. Simon \\ National Institute of Standards and Technology \\ Boulder, Colorado 80303
}

\begin{abstract}
Results of a literature search on the cryogenic properties of candidate inorganic insulators for the ITER ${ }^{+} \mathrm{TF}^{\ddagger}$ magnets are reported. The materials investigated include: $\mathrm{Al}_{2} \mathrm{O}_{3}, \mathrm{AlN}, \mathrm{MgO}$, porcelain, $\mathrm{SiO}_{2}, \mathrm{MgAl}_{2} \mathrm{O}_{4}, \mathrm{ZrO}_{2}$, and mica. A graphical presentation is given of mechanical, elastic, electrical, and thermal properties between 4 and $300 \mathrm{~K}$. A companion report reviews the low temperature irradiation resistance of these materials.
\end{abstract}

Key words: cryogenic properties, electrical properties, inorganic insulation, ITER magnets, mechanical properties, thermal properties

FOREWORD

For insulator downselection and design, data are required on the 4-K compressive and shear strengths and the electrical breakdown strength. However, for most of these inorganic insulators, very few measurements of these and other 4-K properties were retrieved in the literature search, with the notable exception of thermal properties, which have been adequately measured for most of the candidate insulators. Using existing bibliographic data bases to locate cryogenic data is difficult, owing to the inadequate indexing of the data bases and the circumstance that much basic cryogenic information predates

\footnotetext{
*Materials Reliability Division, Materials Science and Engineering Laboratory. IITER - International Thermonuclear Experimental Reactor FTF - toroidal field

'Simon, N. J. 1994. Irradiation Damage in Inorganic Insulation Materials for ITER Magnets: A Review. NISTIR 5025, National Institute of Standards and Technology, Boulder, Co. 430 pp.
} 
the effective date of the databases. Therefore, additional "manual" searching was done, often with excellent yields, to supplement the on-line retrieval systems. However, these procedures are extremely time-consuming. Thus, when the statement is made in this report that no information on a particular property of a material was found in the literature search, it does not necessarily mean that the information does not exist, but, rather, that it could not be retrieved within the time period available.

\section{ACKNOWLEDGMENTS}

R. J. Deal has extracted data from the references with care and has expertly and accurately prepared the large number of graphs in this publication. A number of readers have assisted in removing errors and omissions from the text: R. P. Reed, D. R. Smith, M. Young, and M. E. DeWeese. Of course, the author is responsible for the imperfections that remain. Finally, the author is grateful to M. M. Cohen of the Office of Fusion Energy for sponsoring this work.

Trade names are used in this report solely to provide complete identification of specimens for scientific purposes. Such identification of products neither constitutes nor implies endorsement of the products. 
EXECUTIVE SUMMARY................................

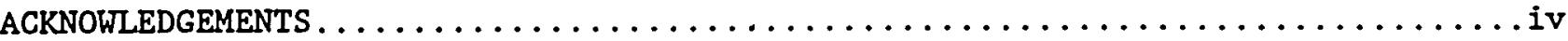

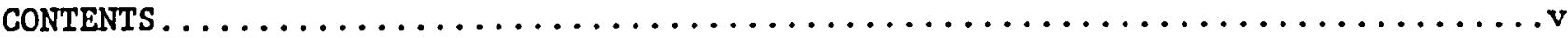

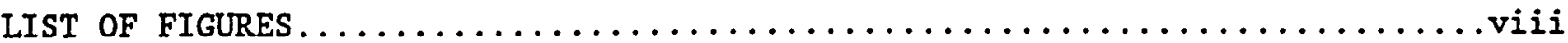

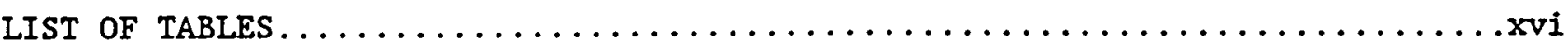

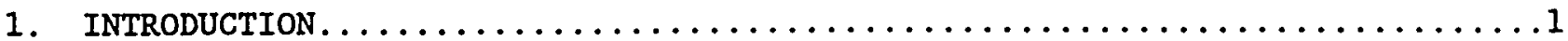

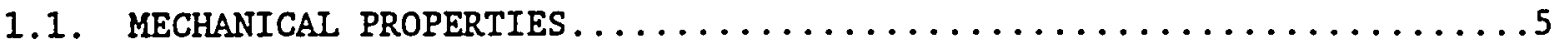

1.1.1. Effect of Microstructure on Compressive Strength

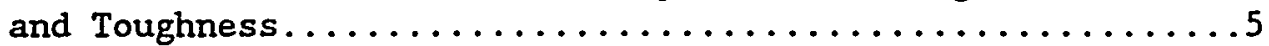

1.1.2. Effect of Temperature on Compressive Strength

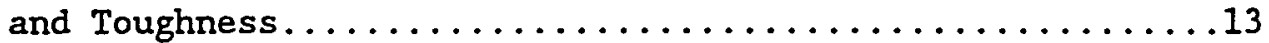

1.1.3. Measurements of Compressive Strength and Related

Properties............................... 14

1.1.4. Onset and Measurement of Microcracking under

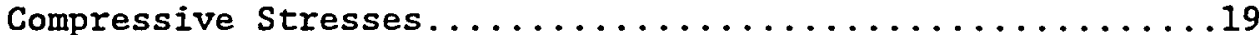

1.1.5. Measurement of Hardness..........................20

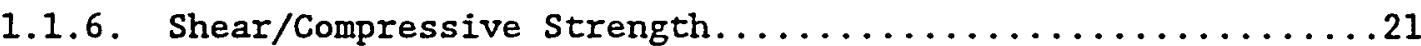

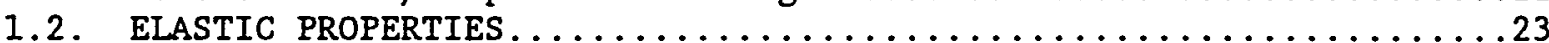

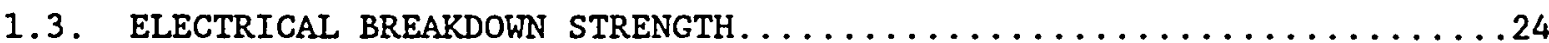

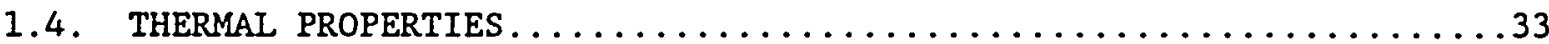

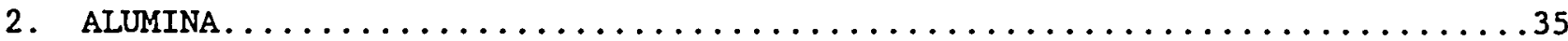

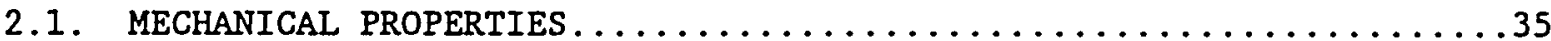

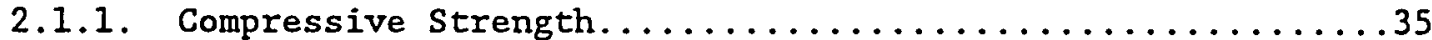

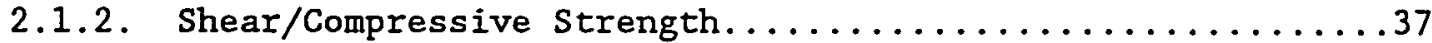

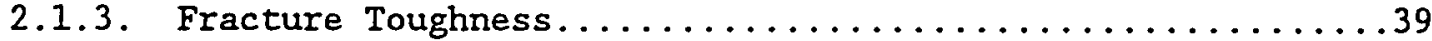

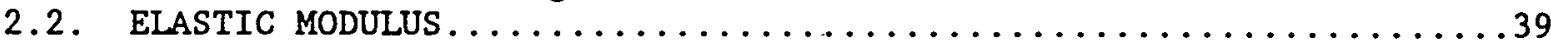

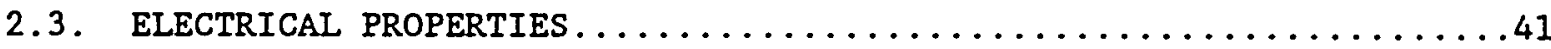

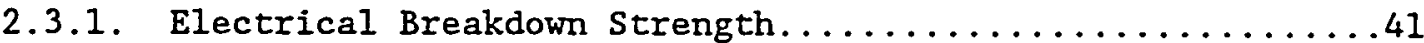

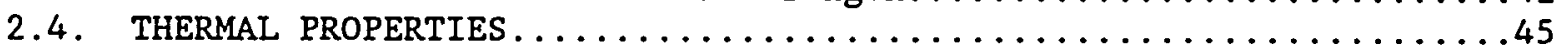

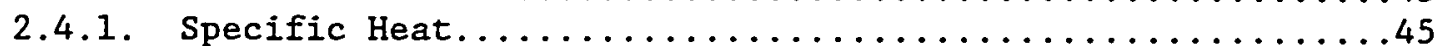

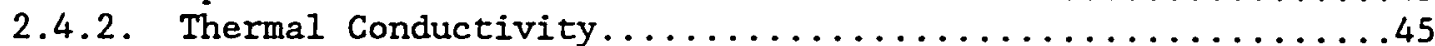

2.4.3. Thermal Expansion......................... 49

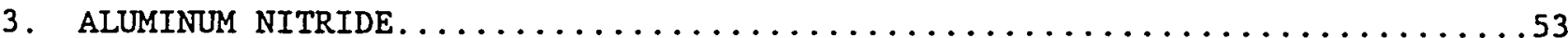

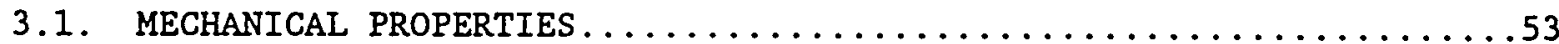

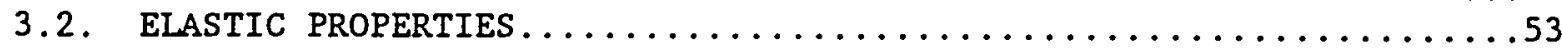

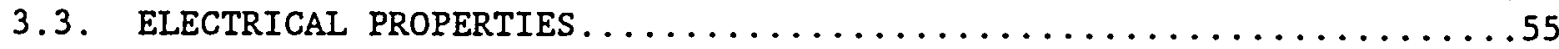

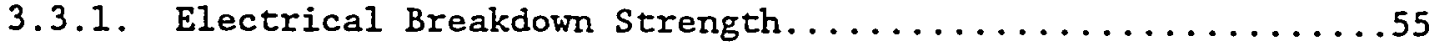

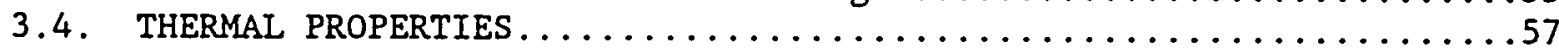

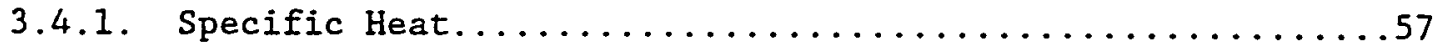

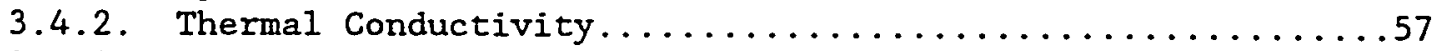

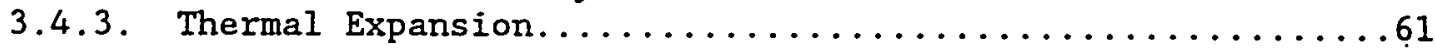




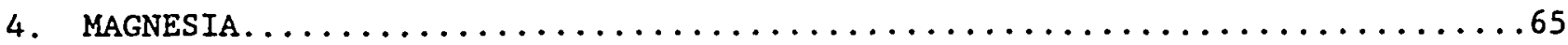

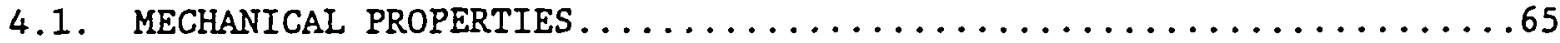

4.1.1. Effect of Temperature on Compressive and

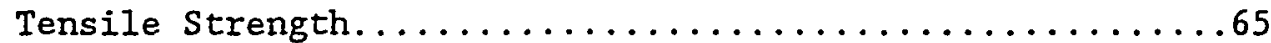

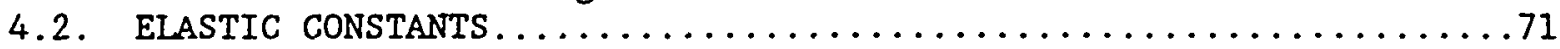

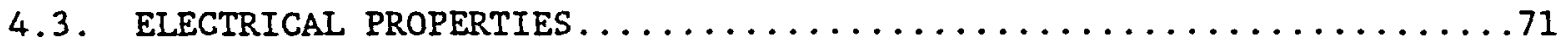

4.3.1. Electrical Breakdown Strength.................

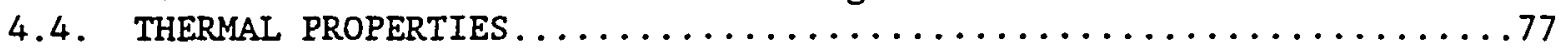

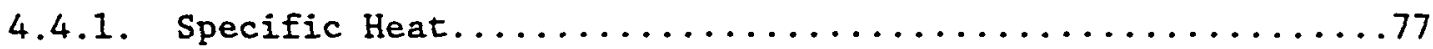

4.4.2. Thermal Conductivity.................

4.4.3. Thermal Expansion.......................

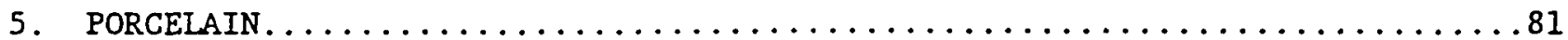

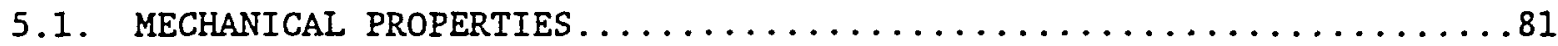

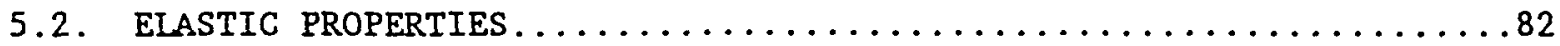

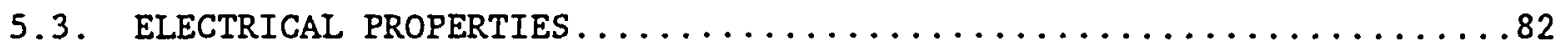

5.3.1. Electrical Breakdown Strength................. 82

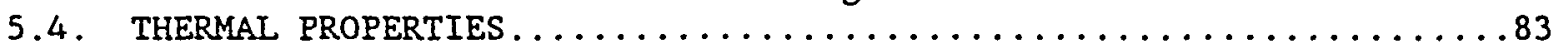

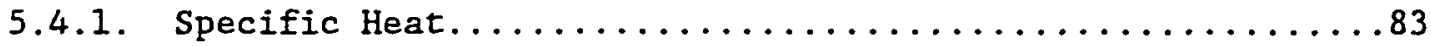

5.4.2. Thermal Conductivity....................

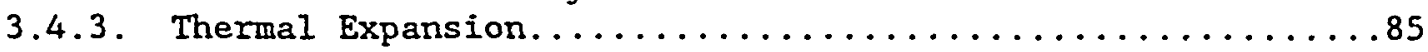

6. VITREOUS SILICA AND QUARTZ $\ldots \ldots \ldots \ldots \ldots \ldots \ldots \ldots \ldots \ldots \ldots \ldots \ldots \ldots \ldots \ldots$

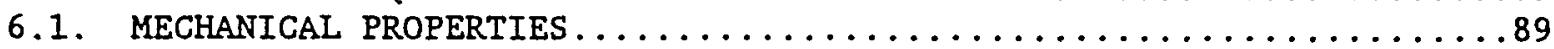

6.1.1. Compressive Strength....................... 89

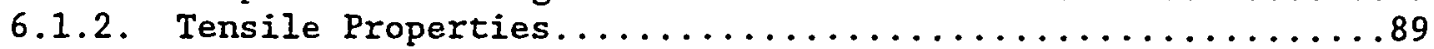

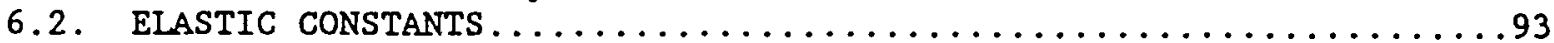

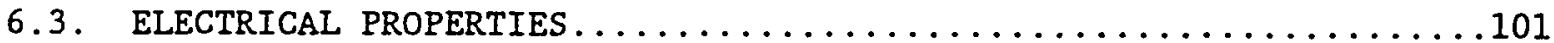

6.3.1. Electrical Breakdown Strength.......................

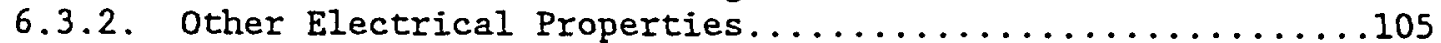

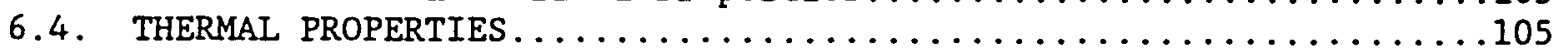

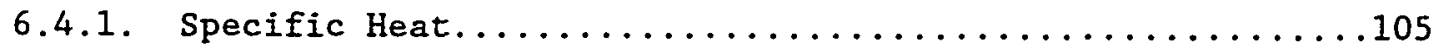

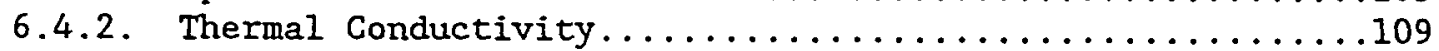

6.4.3. Thermal Expansion..........................

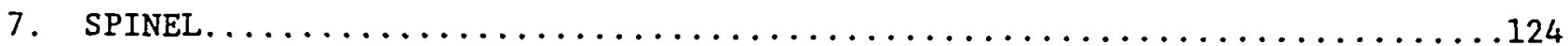

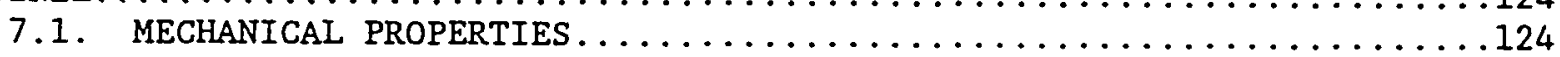

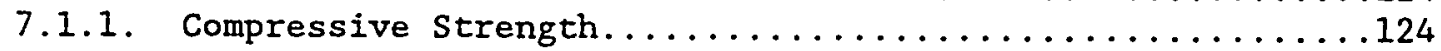

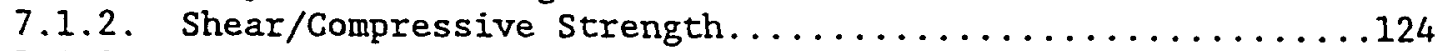

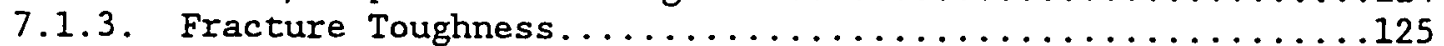

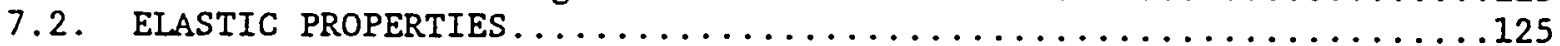

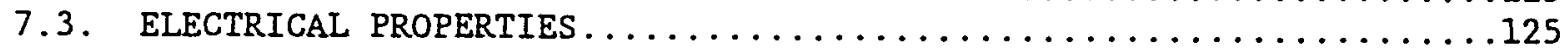

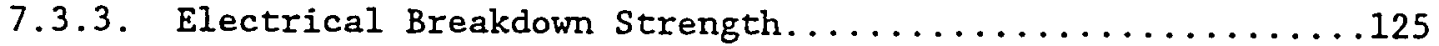

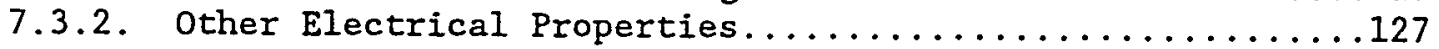

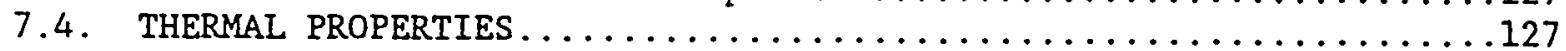

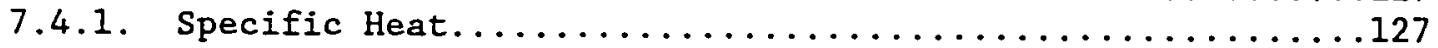

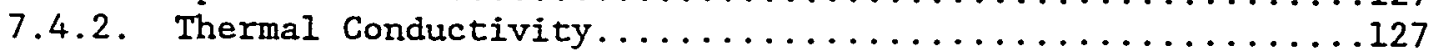

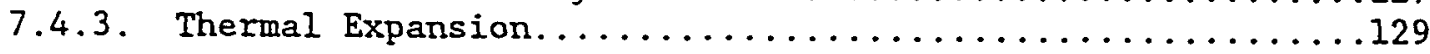

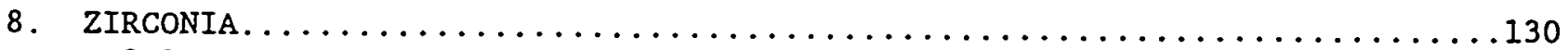

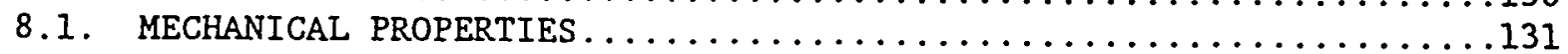

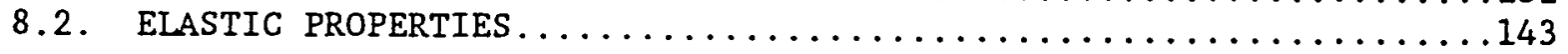




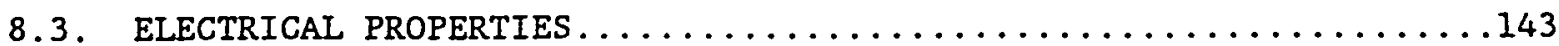

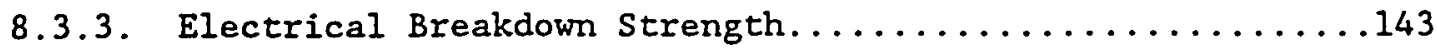

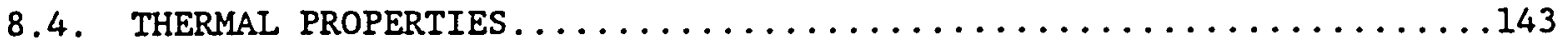

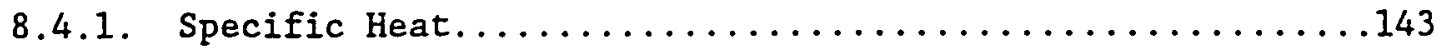

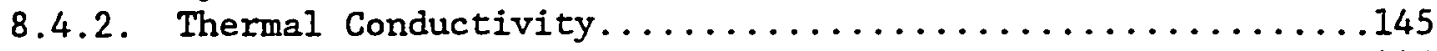

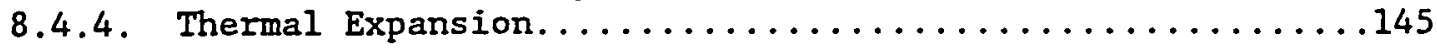

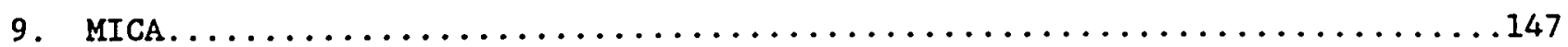

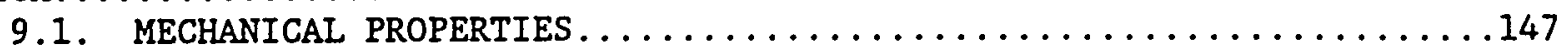

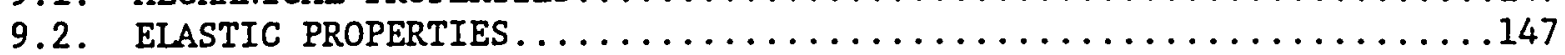

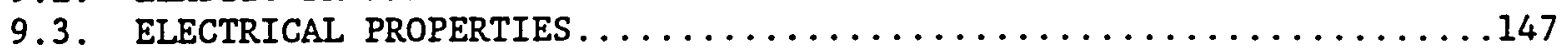

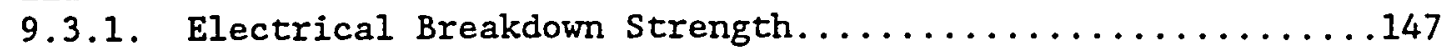

9.3.2. Other Electrical Properties.........................

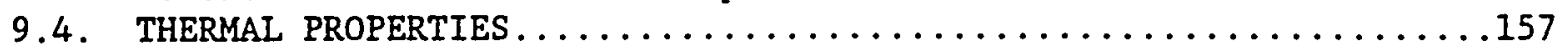

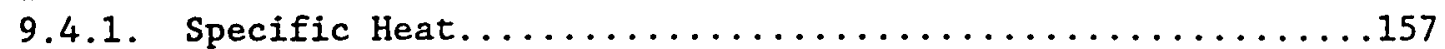

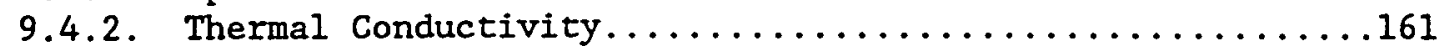

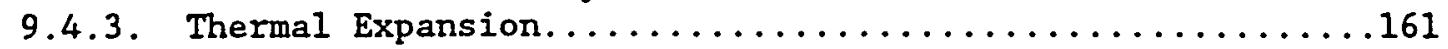

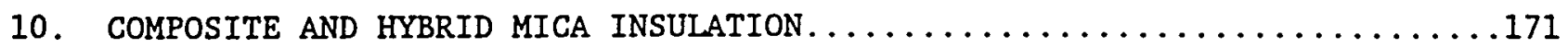

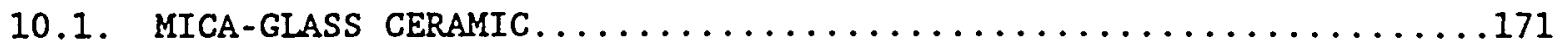

10.1.1. Mechanical Properties.......................171

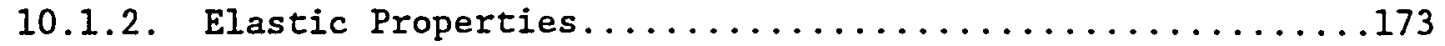

10.1.3. Electrical Properties....................... 173

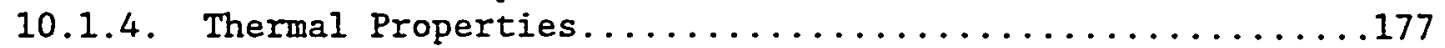

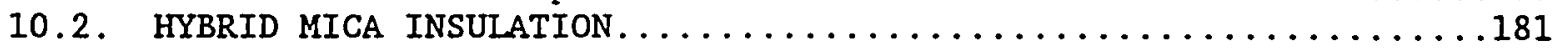

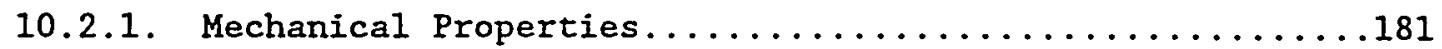

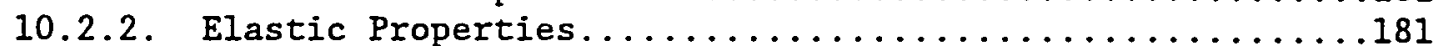

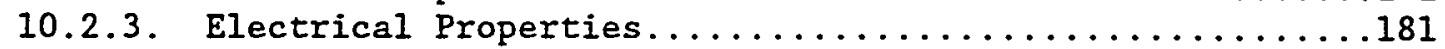

10.2.4. Thermal Properties......................... 185

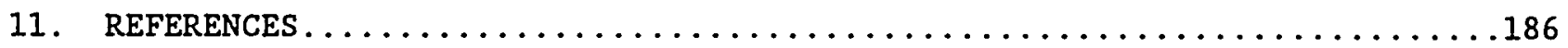




\section{LIST OF FIGURES}

Figure 1.0.1. Concept sketch of the TF magnet shear plates and conductor-incable configuration: "solid" rib option. From Reed [1993]..............

Figure 1.0.2. Concept sketch of the TF magnet shear plates and conductor-incable configuration: "bonded" rib option. From Reed [1993]..............4

Figure 1.1.1. Dependence of the compressive strength upon grain size for $\mathrm{Al}_{2} \mathrm{O}_{3}$.

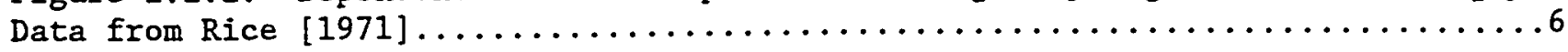

Figure 1.1.2. Dependence of the fracture toughness upon grain size in $\mathrm{Al}_{2} \mathrm{O}_{3}$.

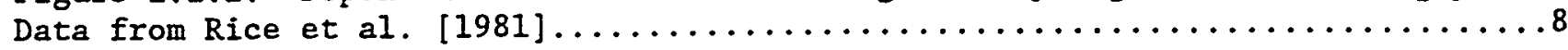

Figure 1.1.3. Dependence of the compressive strength upon the percent porosity for quartz ceramic. Data from Borodai and Suzdal'tsev [1975] .......10

Figure 1.1.4. Dependence of the compressive strength upon the percent porosity. The curves depict two theoretical predictions. Data from Nielsen

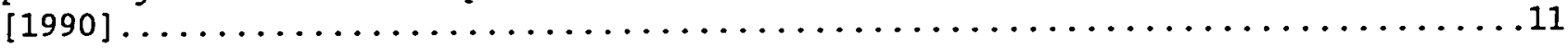

Figure 1.1.5. Effective fracture energy vs. temperature for polycrystalline $\mathrm{Al}_{2} \mathrm{O}_{3}$. Effective fracture energy is proportional to the square of the fracture stress at constant initial crack length. Data from Petch [1971] ...........12

Figure 1.1.6. Effect of hydrostatic pressure on the compressive strength of $\mathrm{Al}_{2} \mathrm{O}_{3}, \mathrm{AlN}$, and $\mathrm{MgO}$. Data from Heard and Cline $[1980] \ldots \ldots \ldots \ldots \ldots \ldots \ldots$

Figure 1.1.7. Compressive strength vs. strain rate for polycrystalline $\mathrm{Al}_{2} \mathrm{O}_{3}$.

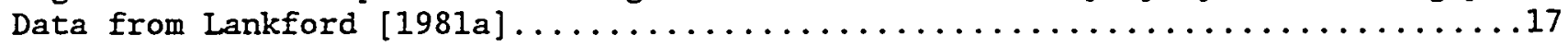

Figure 1.1.8. Compressive strength vs. strain rate for polycrystalline $\mathrm{Al}_{2} \mathrm{O}_{3}$.

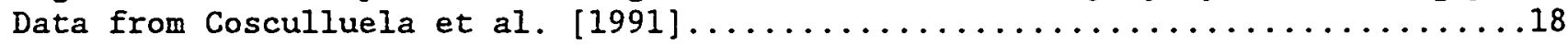

Figure 1.1.9. Failure curve obtained with shear/compression series test

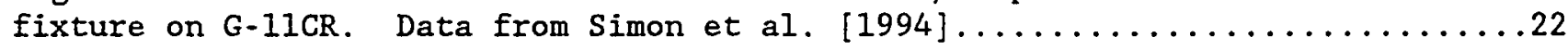

Figure 1.2.1. Young's modulus vs. porosity of SiC. Data from Dienst et al.

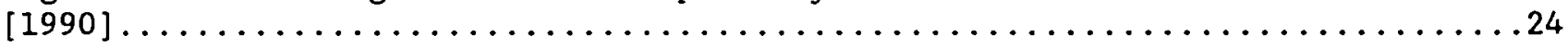

Figure 1.2.2. Young's modulus vs. porosity of quartz ceramic. Data from

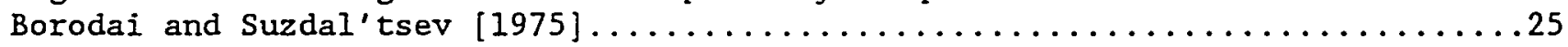

Figure 1.3.1. Diagrams of cup, flat, and recessed specimens for electrical

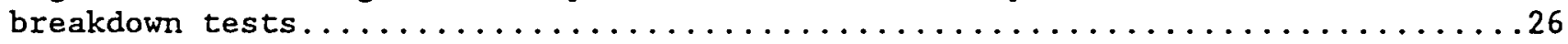

Figure 1.3.2. Chamber for dielectric breakdown measurements in an electron

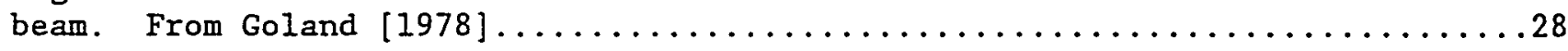

Figure 1.3.3. Dependence of electrical breakdown strength upon specimen thickness for several forms of $\mathrm{Al}_{2} \mathrm{O}_{3}$. Data from Morse and Hill [1970] .....29 
Figure 1.3.4. Dependence of electrical breakdown strength upon specimen density for hot-pressed $\mathrm{Al}_{2} \mathrm{O}_{3}$. Data from Morse and Hill [1970] ...........30

Figure 1.3.5. Theoretical effect of void size upon the dependence of electrical breakdown strength upon porosity. Data from Gerson and

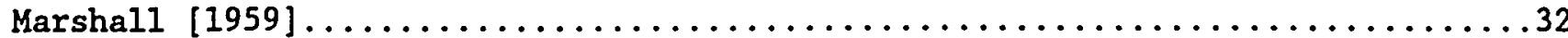

Figure 2.1.1. Flexural strength of single-crystal $\mathrm{Al}_{2} \mathrm{O}_{3}$ at 77 and $513 \mathrm{~K}$

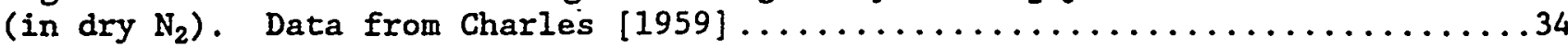

Figure 2.1.2. Compressive strength of polycrystalline $\mathrm{Al}_{2} \mathrm{O}_{3}$ vs. temperature from $77 \mathrm{~K}$ to $1800 \mathrm{~K}$. Data from Lankford [1981b].......................

Figure 2.1.3. Fracture toughness of polycrystalline $\mathrm{Al}_{2} \mathrm{O}_{3}$ at 77 and $298 \mathrm{~K}$ determined by the double cantilever beam technique. Data from Gupta and

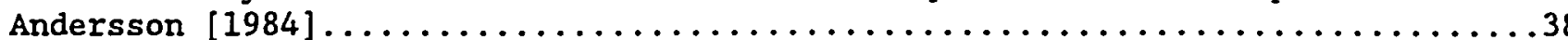

Figure 2.1.4. The ambient-temperature fracture toughness of plasma-sprayed $\mathrm{Al}_{2} \mathrm{O}_{3}$ coatings as a function of plasma gas, powder size range, and thickness. Thick coatings were about 500 to $600 \mu \mathrm{m}$; thin coatings were 200 to $260 \mu \mathrm{m}$.

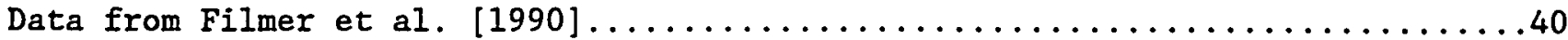

Figure 2.2.1. Young's modulus of polycrystalline $\mathrm{Al}_{2} \mathrm{O}_{3}, \mathrm{MgO}, \mathrm{MgAl}_{2} \mathrm{O}_{4}$, and $\mathrm{CaO}$-stabilized ZrO from ambient temperature to $1000^{\circ} \mathrm{C}$. Data from Wachtman

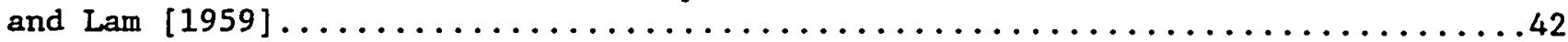

Figure 2.3.1. Summary of electrical breakdown voltages of single-crystal and polycrystalline $\mathrm{Al}_{2} \mathrm{O}_{3}$ vs. thickness at ambient temperature. Data from Yoshimura and Bowen $[1981$; citations therein $] \ldots \ldots \ldots \ldots \ldots \ldots \ldots \ldots \ldots \ldots \ldots$

Figure 2.4.1. Specific heat of $\mathrm{Al}_{2} \mathrm{O}_{3}$ vs. temperature. Data from Touloukian and Buyco [1970; citations therein] and Ditmars and Douglas [1971]........46

Figure 2.4.2. Thermal conductivity of polycrystalline $\mathrm{Al}_{2} \mathrm{O}_{3}$ vs. temperature. Data from Berman [1952], Berman et al. [1960], Alterovitz et al. [1975], Nemoto et al. [1985], and Touloukian et al. [1970; citations therein].......47

Figure 2.4.3. Thermal expansion coefficient of $\mathrm{Al}_{2} \mathrm{O}_{3}$ vs. temperature. Data from Burk [1962] and Touloukian et al. [1977; citations therein]..........48

Figure 2.4.4. Iinear expansion of $\mathrm{Al}_{2} \mathrm{O}_{3}$ vs. temperature. Data from Wachtman et al. [1962] and Touloukian et al. [1977; citations therein].............50

Figure 2.4.5. Comparison of thermal expansion coefficients of several

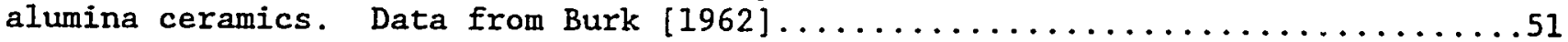

Figure 3.1.1. Vickers hardness of polycrystalline AlN vs. porosity. Data

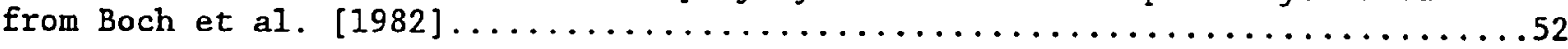

Figure 3.2.1. Elastic moduli and Poisson's ratio of polycrystalline AlN vs.

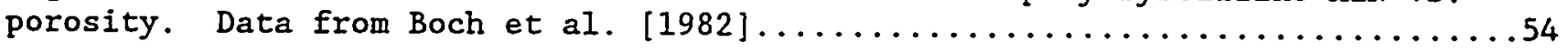


Figure 3.4.1. Specific heat of AlN from 53 to $300 \mathrm{~K}$. Data from Touloukian and Buyco [1970; citations therein], Demidenko et al. [1975], and Koschenko

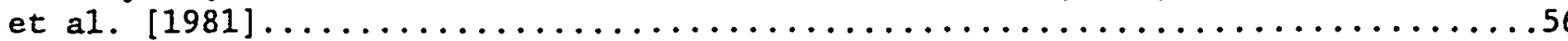

Figure 3.4.2. Thermal conductivity of high purity, single-crystal AlN vs. temperature and calculations for a ceramic with 1 - $\mu$ m grain size. Data from

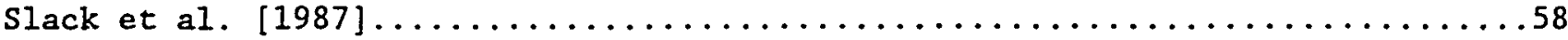

Figure 3.4.3. Thermal conductivity of both single-crystal and ceramic AlN.

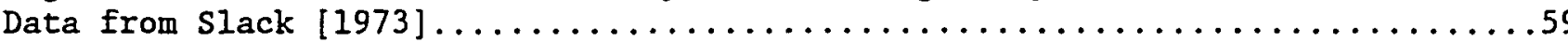

Figure 3.4.4. Comparative thermal conductivity above $300 \mathrm{~K}$ of $\mathrm{Al}_{2} \mathrm{O}_{3}, \mathrm{AlN}$,

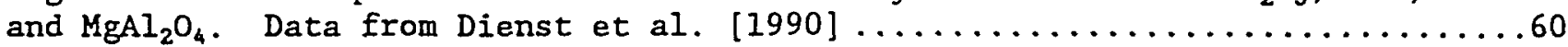

Figure 3.4.5. Comparative thermal expansion above $300 \mathrm{~K}$ of $\mathrm{Al}_{2} \mathrm{O}_{3}, \mathrm{AlN}$, and

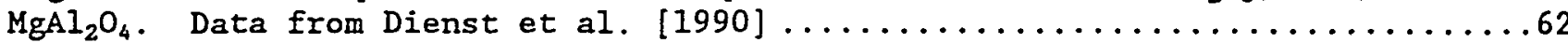

Figure 3.4.6. Thermal expansion vs. temperature of single-crystal AlN and recommended polycrystalline values. Data from Touloukian et a1. [1977;

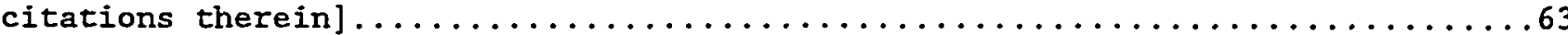

Figure 4.1.1. Single-crystal MgO compressive ultimate and yield strength vs. temperature. Data are fitted to curve that includes higher-temperature data (not shown). Data from Hulse and Pask [1960].......................64

Figure 4.1.2. Stress-strain curves of MgO single crystals under compressive deformation. The lack of smoothness in the curves is an artifact of the

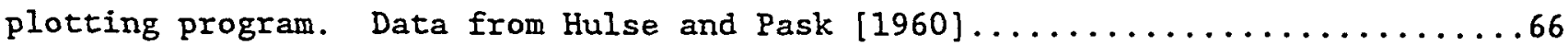

Figure 4.1.3. Compressive strength of single crystal MgO vs. temperature.

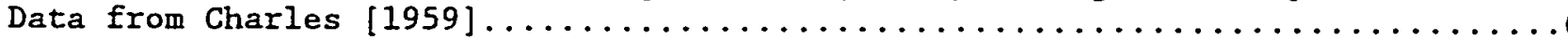

Figure 4.1.4. Yield strength from 4-point bending tests of single crystal MgO vs. temperature. Data from Thompson and Roberts [1960] on two specimens...68

Figure 4.1.5. Single crystal and polycrystalline compressive strengths of MgO vs. temperature. Data from Langdon and Pask [1971].................70

Figure 4.1.6. Compressive flow stress vs. temperature for single-crystal

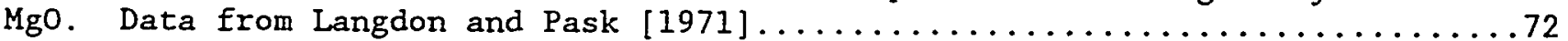

Figure 4.2.1. Young's modulus of MgO vs. temperature. Calculated from

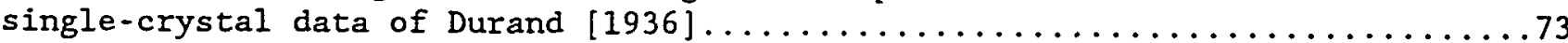

Figure 4.2.2. Shear modulus of MgO vs. temperature. Calculated from

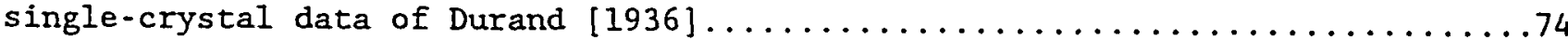

Figure 4.2.3. Poisson's ratio of MgO vs, temperature. Calculated from

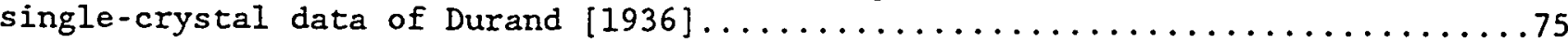

Figure 4.4.1. Specific heat of MgO vs. temperature. Data from Gmelin [1967; 1969] (sintered) and Barron et al. [1959] (single-crystal)..........76 
Figure 4.4.2. Thermal conductivity of two single-crystal Mgo specimens vs. temperature. Data from Slack $[1962] \ldots \ldots \ldots \ldots \ldots \ldots \ldots \ldots \ldots \ldots \ldots \ldots \ldots$

Figure 4.4.3. Thermal expansion coefficient of MgO vs. temperature. Data from Burk [1962] and Touloukian et al. [1977; citations therein]...........79

Figure 4.4.4. Linear thermal expansion of MgO vs. temperature. Data from Touloukian et al. [1977; citations therein] .....................

Figure 5.4.1. Specific heat of $80 \%$ porous ultraporcelain vs. temperature, from 80 to $300 \mathrm{~K}$. Data from Egorov et al. [1991] .................... 84

Figure 5.4.2. Thermal conductivity (in vacuum) of $80 \%$ porous ultraporcelain vs. temperature, from 100 to $300 \mathrm{~K}$. Data from Egorov et al. [1991] ........86

Figure 5.4.3. Linear thermal expansion, $\Delta \mathrm{L} / \mathrm{L}_{273} \mathrm{~K}$, vs. temperature for three grades of porcelain. Data from Ebert [1928] .....................87

Figure 6.1.1. Compressive strength of vitreous $\mathrm{SiO}_{2}$ at 77 and $513 \mathrm{~K}$. Data

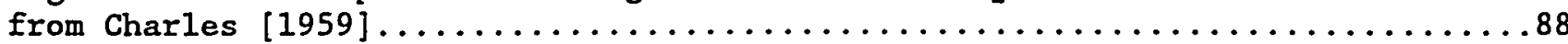

Figure 6.1.2. Compressive strength of quartz at 77 and $513 \mathrm{~K}$. Data from

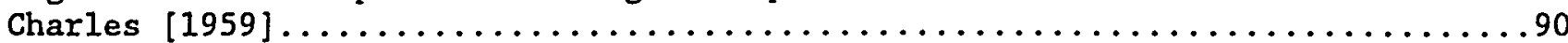

Figure 6.1.3. Breaking strength of annealed soda-lime glass rods vs. temperature for three periods of load application. Data from Vonnegut and

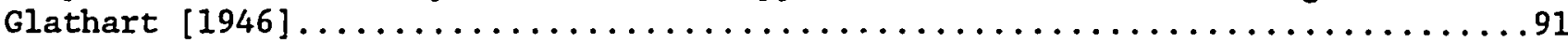

Figure 6.1.4. Breaking strength of unabraded glass specimens at 76 and $296 \mathrm{~K}$ at $5.5 \mathrm{MPa} / \mathrm{s}$ stress increase. Data from Kropschot and Mikesell [1960]......92

Figure 6.1.5. Breaking strength of abraded glass specimens at $296 \mathrm{~K}$ at $5.5 \mathrm{MPa} / \mathrm{s}$ stress increase. Data from Kropschot and Mikesell [1960].........994

Figure 6.1.6. Breaking strength of abraded glass specimens at $194 \mathrm{~K}$ at $5.5 \mathrm{MPa} / \mathrm{s}$ stress increase. Data from Kropschot and Mikesel1 [1960].........95

Figure 6.1.7. Breaking strength of abraded glass specimens at $76 \mathrm{~K}$ at $5.5 \mathrm{MPa} / \mathrm{s}$ stress increase. Data from Kropschot and Mikesell [1960]........96

Figure 6.1.8. Breaking strength of abraded glass specimens at $20 \mathrm{~K}$ at $5.5 \mathrm{MPa} / \mathrm{s}$ stress increase. Data from Kropschot and Mikesell [1960].........97

Figure 6.2.1. Young's modulus of vitreous $\mathrm{SiO}_{2}$ vs. temperature. Data from Fine et al. [1954], McSkimin [1953], and Spinner and Cleek [1960]..........98

Figure 6.2.2. Shear modulus of vitreous $\mathrm{SiO}_{2}$ vs. temperature. Data from Fine et al. [1954] and McSkimin [1953] ........................99

Figure 6.2.3. Poisson's ratio (calculated) of vitreous $\mathrm{SiO}_{2}$ vs. temperature.

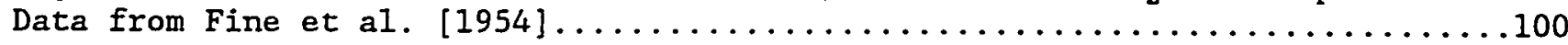

Figure 6.3.1. Electrical breakdown strength of $\mathrm{SiO}_{2}$ film 200-nm (2000-A) thick vs. temperature from 77 to $320 \mathrm{~K}$. Data from Korzo [1968]............102 
Figure 6.3.2. Electrical breakdown strength of $\mathrm{SiO}_{2}$ film vs. thickness at

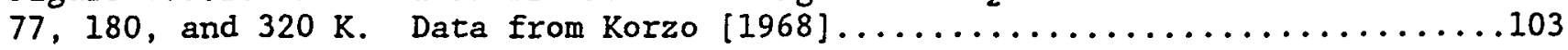

Figure 6.4.1. Specific heat of vitreous $\mathrm{SiO}_{2}$ vs. temperature. Data from Mamedov et al. [1985; 1987], Zeller and Pohl [1971], and Flubacher et al. [1959]....

Figure 6.4.2. Comparative data from Zeller and Pohl [1971; citations therein] on the specific heat of vitreous and crystalline $\mathrm{SiO}_{2}$ vs. temperature. Data on two commercial glasses are also shown............106

Figure 6.4.3. Specific heat of quartz vs. temperature. Data (points and curve) from Zeller and Pohl [1971; citations therein] and Touloukian and

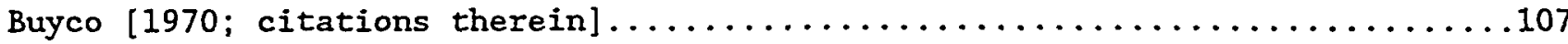

Figure 6.4.4. Recommended values for thermal conductivity of "high purity clear fused $\mathrm{SiO}_{2} . "$ From Touloukian et al. [1970] ................... 108

Figure 6.4.5. Measured thermal conductivity of vitreous $\mathrm{SiO}_{2}$ vs. temperature from 125 to $300 \mathrm{~K}$. Data from Damon [1973] and Ratcliffe [1963;

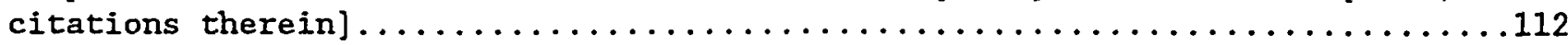

Figure 6.4.6. Thermal conductivity of crystalline and vitreous $\mathrm{SiO}_{2}$ vs. temperature. Data from Zeller and Pohl [1971] ....................114

Figure 6.4.7. Recommended values for thermal conductivity of pure, annealed crystalline quartz. From Touloukian et al. [1970].................. 115

Figure 6.4.8. Thermal expansion coefficient of various types of vitreous $\mathrm{SiO}_{2}$ vs. temperature. Data from White [1973; citations therein], Gibbons

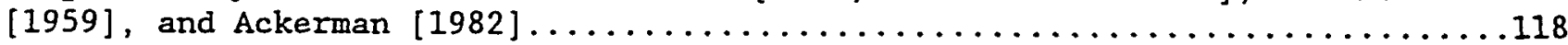

Figure 6.4.9. Comparison of the thermal expansion coefficient of various glasses with vitreous $\mathrm{SiO}_{2}$ vs. temperature. See text for $\mathrm{SiO}_{2}$ content.

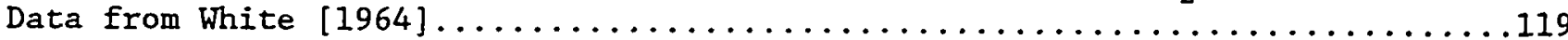

Figure 6.4.10. Linear thermal expansion of various types of vitreous $\mathrm{SiO}_{2}$ from 293 K. Data from Touloukian et al. [1977], Gibbons [1959; citations

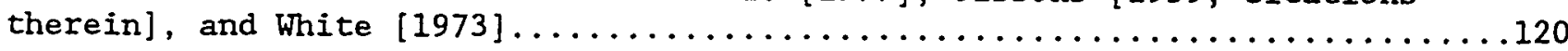

Figure 6.4.11. Thermal expansion coefficient of quartz $\perp$ and $\|$ to the optic (c) axis. Data from White [1964] and Touloukian et al. [1977; citations therein].

Figure 6.4.12. Recommended linear thermal expansion of quartz from $293 \mathrm{~K}$ from Touloukian et al. [1977]. Lower temperature data from White [1964] ....122

Figure 7.4.1. Specific heat of $\mathrm{MgAl}_{2} \mathrm{O}_{4}$ vs. temperature. Data from

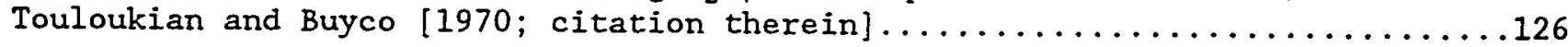

Figure 7.4.2. Thermal conductivity of single-crystal $\mathrm{MgAI}_{2} \mathrm{O}_{4}$ vs.

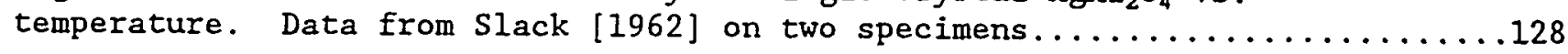


Figure 8.1.1. Flexural strength of $\mathrm{MgO}$-stabilized $\mathrm{ZrO}_{2}$ vs. temperature, for

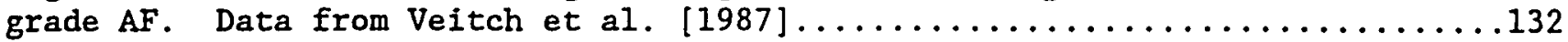

Figure 8.1.2. Flexural strength of $\mathrm{MgO}$-stabilized $\mathrm{ZrO}_{2}$ vs. temperature, for grade MS. Data from Veitch et al. [1987] ......................133

Figure 8.1.3. Flexural strength of Mgo-stabilized $\mathrm{ZrO}_{2}$ vs. temperature, for grade Ts. Data from Veitch et al. [1987] .......................134

Figure 8.1.4. Fracture toughness of MgO-stabilized $\mathrm{ZrO}_{2}$ vs. temperature for all grades, as measured by the critical stress intensity factor. Data from

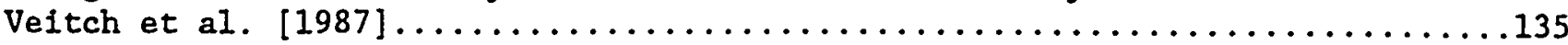

Figure 8.1.5. Fracture toughness of $\mathrm{Y}_{2} \mathrm{O}_{3}$-stabilized $\mathrm{ZrO}_{2}$ vs. temperature, as measured by the critical stress intensity factor. Data from Veitch et al.

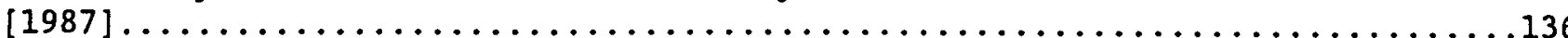

Figure 8.1.6. Flexural strength of $\mathrm{Y}_{2} \mathrm{O}_{3}$-stabilized $\mathrm{ZrO}_{2}$ vs. temperature.

Data from Veitch et al. [1987] .................................137

Figure 8.1.7. Flexural strength of $\mathrm{Y}_{2} \mathrm{O}_{3}$-stabilized $\mathrm{ZrO}_{2}$ and $\mathrm{CeO}_{2}$-stabilized

$\mathrm{ZrO}_{2}$. Data from Jikihara and Ishihara $[1990] \ldots \ldots \ldots \ldots \ldots \ldots \ldots \ldots \ldots \ldots$

Figure 8.1.8. Flexural strength and fracture toughness of $\mathrm{Y}_{2} \mathrm{O}_{3}$-stabilized

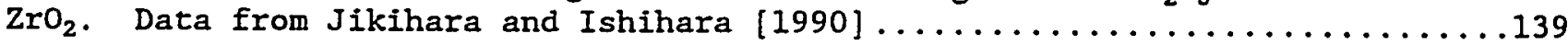

Figure 8.1.9. Fracture toughness of $\mathrm{Y}_{2} \mathrm{O}_{3}$-stabilized $\mathrm{ZrO}_{2}$ and $\mathrm{CeO}_{2}$-stabilized

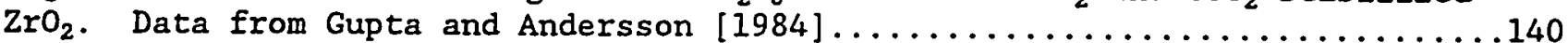

Figure 8.4.1. Specific heat of pure $\mathrm{ZrO}_{2}$ and $\mathrm{Y}_{2} \mathrm{O}_{3}$-stabilized $\mathrm{ZrO}_{2}$ vs.

temperature. Data from Kelley [1944], Nevitt et al. [1990], Lawless and

Gupta [1983], Lawless [1980], and Collins et al. [1985]..............142

Figure 8.4.2. Thermal conductivity of 8 mass $\mathrm{Y}_{2} \mathrm{O}_{3}-\mathrm{ZrO}_{2}$ vs. temperature.

Data from Ackerman et al. [1981] and Lawless and Gupta [1983] ............. 144

Figure 8.4.3. Thermal expansion coefficient of $\mathrm{Y}_{2} \mathrm{O}_{3}$-stabilized $\mathrm{ZrO}_{2}$ vs .

temperature. Data from Ackerman [1982] and Collins et al. [1985] .........146

Figure 9.3.1. Intrinsic electrical breakdown voltage of phlogopite and muscovite mica vs. thickness at ambient temperature. Data from Hackett and

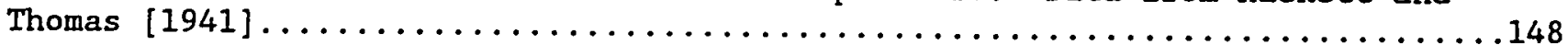

Figure 9.3.2. Intrinsic electrical breakdown strength of muscovite mica vs. temperature, from 78 to $-780 \mathrm{~K}$. Data from Hackett and Thomas [1941]........ 150

Figure 9.3.3. Electrical breakdown strength of mica crystals $<800$-nm thick from 4 to $520 \mathrm{~K}$. Data from Davidson and Yoffe [1968]................... 151

Figure 9.3.4. Dependence of electrical breakdown strength of muscovite mica upon thickness at ambient temperature. Data from Davidson and Yoffe [1965]......152 
Figure 9.3.5. Conduction current in micas vs. electrical field strength.

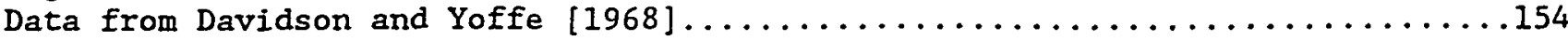

Figure 9.3.6. Conductivity in micas vs. the square root of electrical field strength at 295 and $100 \mathrm{~K}$. Data from Davidson and Yoffe [1968] ..........155

Figure 9.3.7. Deterioration of electrical breakdown strength of mica paper and mica-flake, layered insulation under static bending load, with respect to performance of polyimide film. Data from Aki et al. [1983] ...........156

Figure 9.3.8. Dielectric constant at $75 \mathrm{~Hz}$ of silicone-bonded mica product and polyimide vs. temperature. Data from Chant [1967] ...............158

Figure 9.3.9. Loss tangent at $75 \mathrm{~Hz}$ of silicone-bonded mica product and polyimide vs. temperature. Data from Chant $[1967] \ldots \ldots \ldots \ldots \ldots \ldots \ldots \ldots$.............

Figure 9.3.10. Loss tangent of silicone-bonded mica product and polyimide

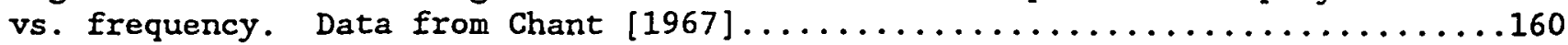

Figure 9.4.1. Specific heat of a hydrated form of muscovite mica from 52 to $298 \mathrm{~K}$. [citations, Touloukian and Buyco, 1970]. A value at $298 \mathrm{~K}$ for

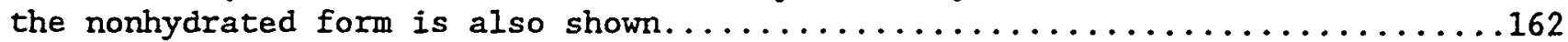

Figure 9.4.2. Thermal conductivity of muscovite and phlogopite mica along crystal planes vs. temperature. Data from Gray and Uher [1977] ..........163

Figure 9.4.3. Thermal conductivity of muscovite and phlogopite mica perpendicular to crystal planes vs. temperature. Data from Gray and Uher

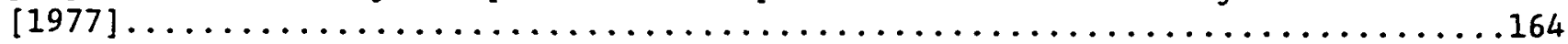

Figure 9.4.4. Anisotropy ratio of thermal conductivity of muscovite and phlogopite mica vs. temperature. Data from Gray and Uher [1977] ..........165

Figure 9.4.5. Thermal conductivity of powdered mica (density, $0.090 \mathrm{~g} / \mathrm{cm}^{3}$ )

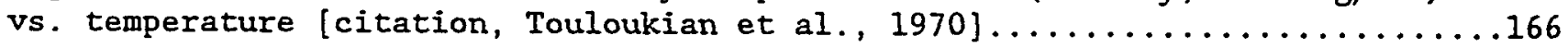

Figure 9.4.6. Difference in thermal conductivity of two samples of

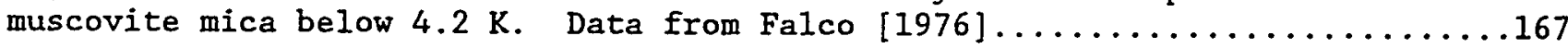

Figure 9.4.7. Change of lattice constant of muscovite mica with temperature between 123 and $423 \mathrm{k}$. Data from Goldstein and Post [1969].............168

Figure 9.4.8. Thermal expansion $\left(\Delta \mathrm{L} / \mathrm{L}_{273} \mathrm{~K}\right.$ ) of mica from 20 to $273 \mathrm{~K}$. Data

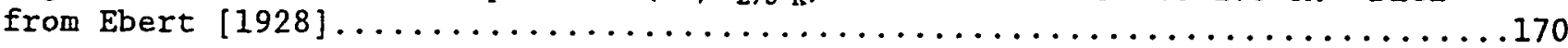

Figure 10.1.1. Flexural and compressive strength of mica-glass ceramics vs. mica flake diameter. Data from Chyung [1974]....................172

Figure 10.1.2. Dielectric constant and loss tangent at $1 \mathrm{kHz}$ of a micaglass ceramic vs. temperature. Data from Lawless $[1975] \ldots . . \ldots \ldots \ldots . . . . . .174$

Figure 10.1.3. Frequency dependence of the imaginary part of the dielectric constant, $\epsilon^{n}$, of a mica-glass ceramic at 4 and $77 \mathrm{~K}$. Data from Lawless

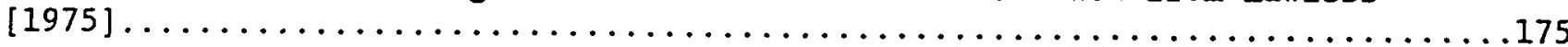


Figure 10.1.4. Frequency dependence of the loss tangent of a mica-glass

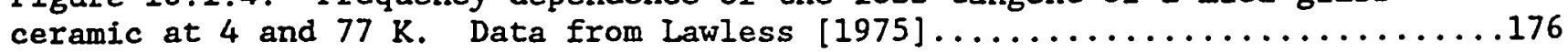

Figure 10.1.5. Specific heat of a mica-glass ceramic below $20 \mathrm{~K}$. Data from Lawless [1975] and Roth and Anderson [1976] .......................

Figure 10.1.6. Thermal conductivity of a mica-glass ceramic below $20 \mathrm{~K}$. Data from Lawless [1975] and Roth and Anderson [1976] . . . . . . . . . . . 179

Figure 10.1.7. Thermal expansion coefficient of a mica-glass ceramic vs. temperature from -8 to $30 \mathrm{~K}$. Data from white $[1976] \ldots \ldots \ldots \ldots \ldots \ldots \ldots \ldots$ 
Table 1.0.1. ITER concept insulation parameters for TF and CS magnets.

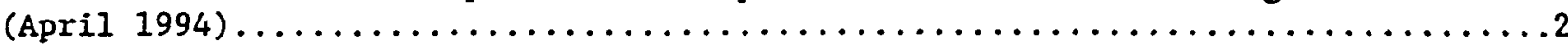

Table 6.5.1 Recommended thermal conductivity values for vitreous $\mathrm{SiO}_{2}$ from

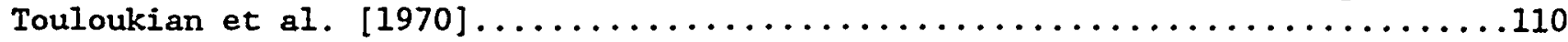

Table 6.4.2. Thermal conductivity data of Damon [1973] on synthetic

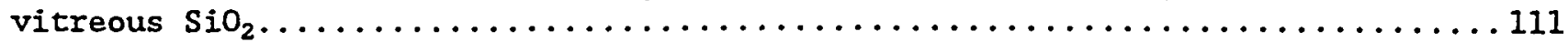

Table 6.4.3. Recommended values for the thermal conductivity of quartz from Touloukian et al. $[1970] \ldots \ldots \ldots \ldots \ldots \ldots \ldots \ldots \ldots \ldots \ldots \ldots \ldots \ldots \ldots \ldots, \ldots \ldots$

Table 10.2.1. Compressive strength of hybrid mica/epoxy/fiberglass insulation systems. Data from Fabian and Reed $[1994] \ldots \ldots \ldots \ldots \ldots \ldots \ldots \ldots \ldots \ldots$

Table 10.2.2. Short-beam shear strength of hybrid mica/epoxy/fiberglass insulation systems. Data from Fabian and Reed [1994] ................182

Table 10.2.3. Shear/compressive strength of hybrid mica/epoxy/fiberglass insulation systems. Data from Fabian and Reed [1994] ............... 183

Table 10.2.4. Electrical breakdown strength of hybrid mica/epoxy/fiberglass insulation systems. Data from Fabian and Reed [1994] ................ 183 


\section{INTRODUCTION}

This report presents the results of a literature search on properties from 4 to $300 \mathrm{~K}$ of inorganic insulators that are candidates for use in the ITER TF (toroidal-field) superconducting magnets. The insulators included are: alumina $\left(\mathrm{Al}_{2} \mathrm{O}_{3}\right)$, aluminum nitride $(\mathrm{AlN})$, magnesia ( $\left.\mathrm{MgO}\right)$, mica, porcelain, vitreous silica and quartz $\left(\mathrm{SiO}_{2}\right)$, spinel $\left(\mathrm{MgAl}_{2} \mathrm{O}_{4}\right)$, and zirconia $\left(\mathrm{ZrO}_{2}\right)$. Mechanical, elastic, electrical, and thermal properties are reviewed. A companion report presented a review of the available data on the lowtemperature radiation resistance of these insulators [Simon, 1994]. (Only the $\alpha-\mathrm{Al}_{2} \mathrm{O}_{3}$ structure is included in these reviews, unless otherwise noted.)

The information gathered in this literature search is intended to assist with insulation material downselection for ITER magnets. Using existing bibliographic data bases to locate cryogenic data is difficult, owing to the inadequate indexing of the data bases and the circumstance that much basic cryogenic information predates the effective date of the databases. Therefore, additional "manual" searching was done, often with excellent yields, to supplement the on-line retrieval systems. However, these procedures are extremely time consuming. Thus, when the statement is made in this report that no information on a particular property of a material was found in the literature search, it does not necessarily mean that the information does not exist, but, rather, that it could not be retrieved within a reasonable time period. If one or more of the materials reviewed here is selected, some additional searches for missing basic property information should probably be done before expensive measurement programs begin. Furthermore, this report contains only a basic presentation of the data unless analysis had already been performed. Analysis of temperature dependence of properties or of recommended values was considered premature before further material downselection.

Some current ITER design requirements for the TF and CS (central solenoid) magnets are given in Table 1.0 .1 and Figures 1.0 .1 and 1.0 .2 show possible configurations for the TF magnet insulation. As Table 1.0.1 indicates, data on the compressive strength and electrical breakdown strength at $4 \mathrm{~K}$ are needed for design of the ITER TF magnets; however, 4-K data on these 
Table 1.0.1. ITER concept insulation parameters for $T F$ and $C S$ magnets (April 1994).

\begin{tabular}{|c|c|c|c|c|c|c|c|}
\hline & \multicolumn{4}{|c|}{ TF coils ${ }^{a}$} & \multicolumn{3}{|c|}{$\mathrm{CS}^{\mathrm{b}}$} \\
\hline & $\begin{array}{l}\text { Turn } \\
\text { to } \\
\text { plate }\end{array}$ & $\begin{array}{l}\text { Plate } \\
\text { to } \\
\text { plate }\end{array}$ & Gnd. & Key & $\begin{array}{l}\text { Turn } \\
\text { to } \\
\text { turn }\end{array}$ & $\begin{array}{l}\text { Layer } \\
\text { (incl. } \\
\text { turn) }\end{array}$ & $\begin{array}{l}\text { Gnd. } \\
\text { (incl. } \\
\text { turn) }\end{array}$ \\
\hline Thickness, $\mathrm{mm}$ & 2.5 & 2 & 8 & 8 & 3 & 6 & 11.5 \\
\hline $\begin{array}{l}\text { Operating } \\
\text { voltage, } \mathrm{kV}\end{array}$ & 1.5 & 1.5 & 10 & 10 & 1 & 5 & 15 \\
\hline $\begin{array}{l}\text { Operating } \\
\text { stress, } \mathrm{MPa}- \\
\text { compression }\end{array}$ & 100 & 250 & 200 & 250 & 250 & 250 & 200 \\
\hline
\end{tabular}

- The TF coil insulation must be capable of experiencing fast $(>0.1 \mathrm{MeV})$ neutron fluence of $1 \times 10^{22} \mathrm{n} / \mathrm{m}^{2}$; the associated gamma radiation will be up to $1 \times 10^{7} \mathrm{~Gy}$.

b The CS coil insulation must be capable of experiencing fast $\left(>0.1 \mathrm{MeV}\right.$ ) neutron fluence of $1 \times 10^{20} \mathrm{n} / \mathrm{m}^{2}$; the associated gamma radiation will be about $1 \times 10^{4} \mathrm{~Gy}$.

c "Operating" is normal operating plus the inclusion of limited fault conditions for one breaker failure or a single ground fault.

d Operation is at $4 \mathrm{~K}$ in vacuum. CS total operational cycles $=8 \times 10^{4}$. TF compression cycles $=400 ;$ cool-down cycles $=40$. 


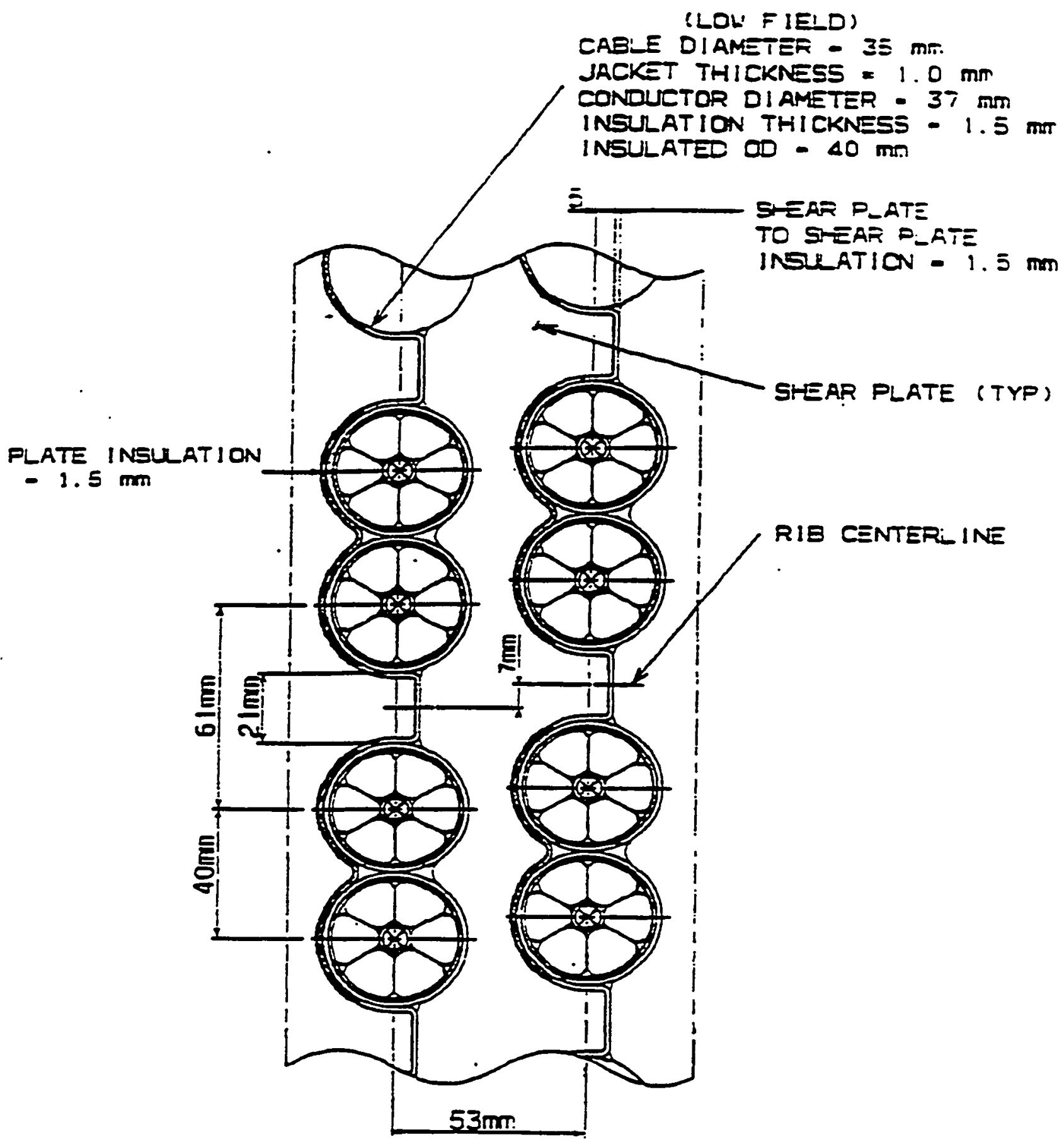

Figure 1.0.1. Concept sketch of the TF magnet shear plates and conductor-incable configuration: "solid" rib option. From Reed [1993]. 


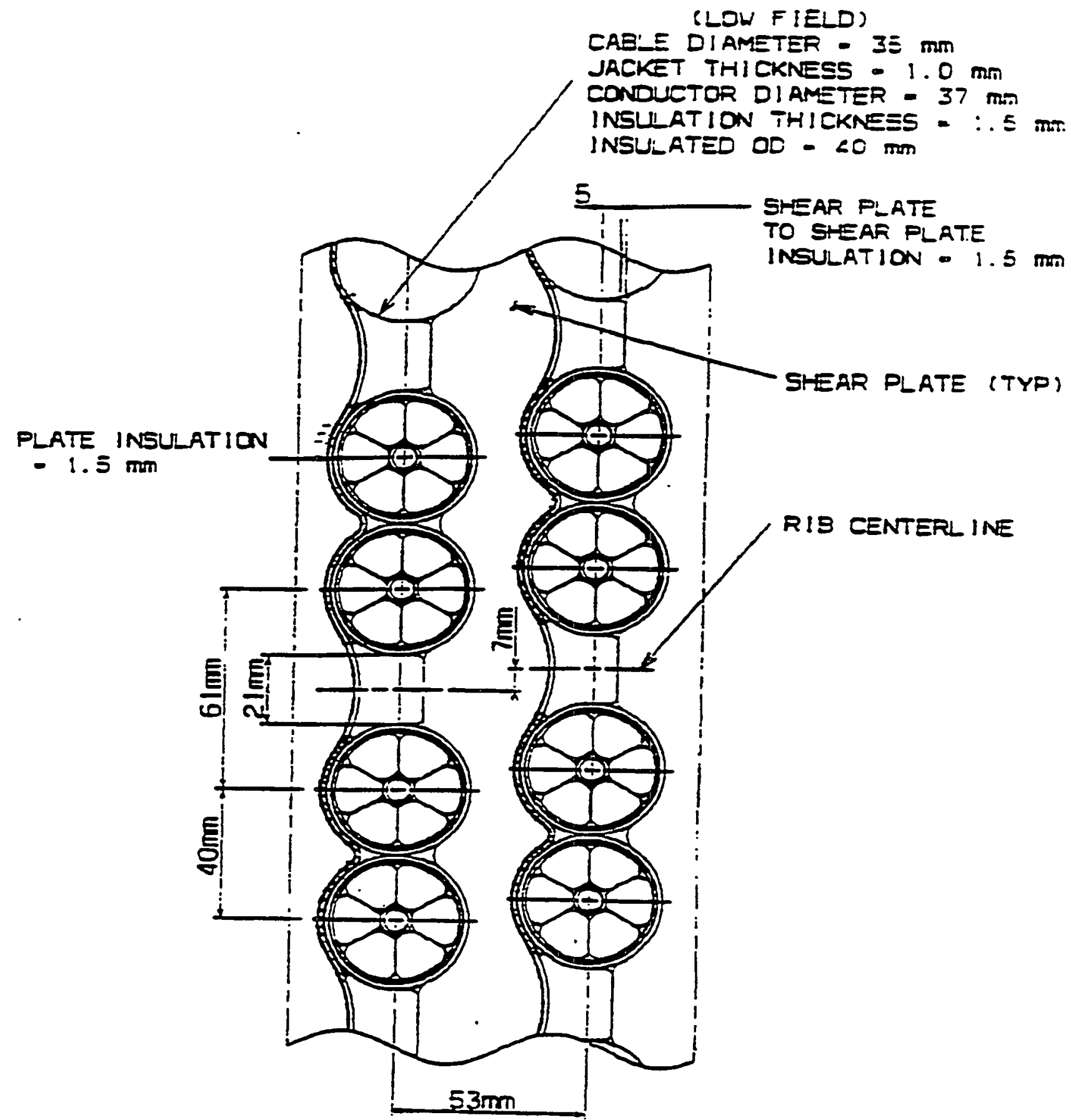

Figure 1.0.2. Concept sketch of the TF magnet shear plates and conductor-incable configuration: "bonded" rib option. From Reed [1993]. 
properties are generally not available in the literature. Fortunately, ITERrelated measurement programs are beginning to supply some of these data [e.g., Fabian et al., 1993; Fabian and Reed, 1994]. Since 4-K and other cryogenic temperature data are often not available, 295-K data are also supplied in this review. Furthermore, property variability with material parameters, such as porosity and grain size, has been studied primarily at ambient temperature rather than at $4 \mathrm{~K}$. Consequently, some of this ambient-temperature information is reviewed in this introductory section to give some perspective on the limitations of the cryogenic data base. Measurement techniques are also briefly reviewed in this introductory section.

\subsection{MECHANICAI PROPERTIES}

\subsubsection{Effect of Microstructure on Compressive Strength and Toughness}

Compressive strength and simultaneous shear/compressive strength are important mechanical properties for the current ITER design program (EDA, or Engineering Design Activity). In a review of the compressive strengths of ceramics, Rice [1971] discussed several theories that predicted that compressive strengths would be eight to several times the tensile strengths, and noted that since these predictions generally gave the correct order of magnitude of the compressive strength, they had encouraged the study of tensile strengths. For this reason, very little study of the effects of microstructure on compressive strength had been undertaken, and the orientation of research to tensilesensitive flaws left considerable uncertainty about the limit of compressive mechanical strengths as the qualities of ceramics were improved.

Although studies relating the compressive strength to microstructure are limited, Rice compiled single-crystal and polycrystalline data for $\mathrm{Al}_{2} \mathrm{O}_{3}$ and several other ceramics to show that the usual Petch relationship with the inverse square root of the grain size was followed. The data for $\mathrm{Al}_{2} \mathrm{O}_{3}$ are shown in Figure 1.1.1. (Some of the values were corrected for porosity, but the $2-\mu \mathrm{m}$ grain size strength corresponds to only 1 to $2 \%$ porosity.) The intercept for infinite grain size falls between reported single-crystal values, as expected. The grain size dependence of compressive strength is thought to imply microplastic fracture behavior, rather than brittle, strictly 


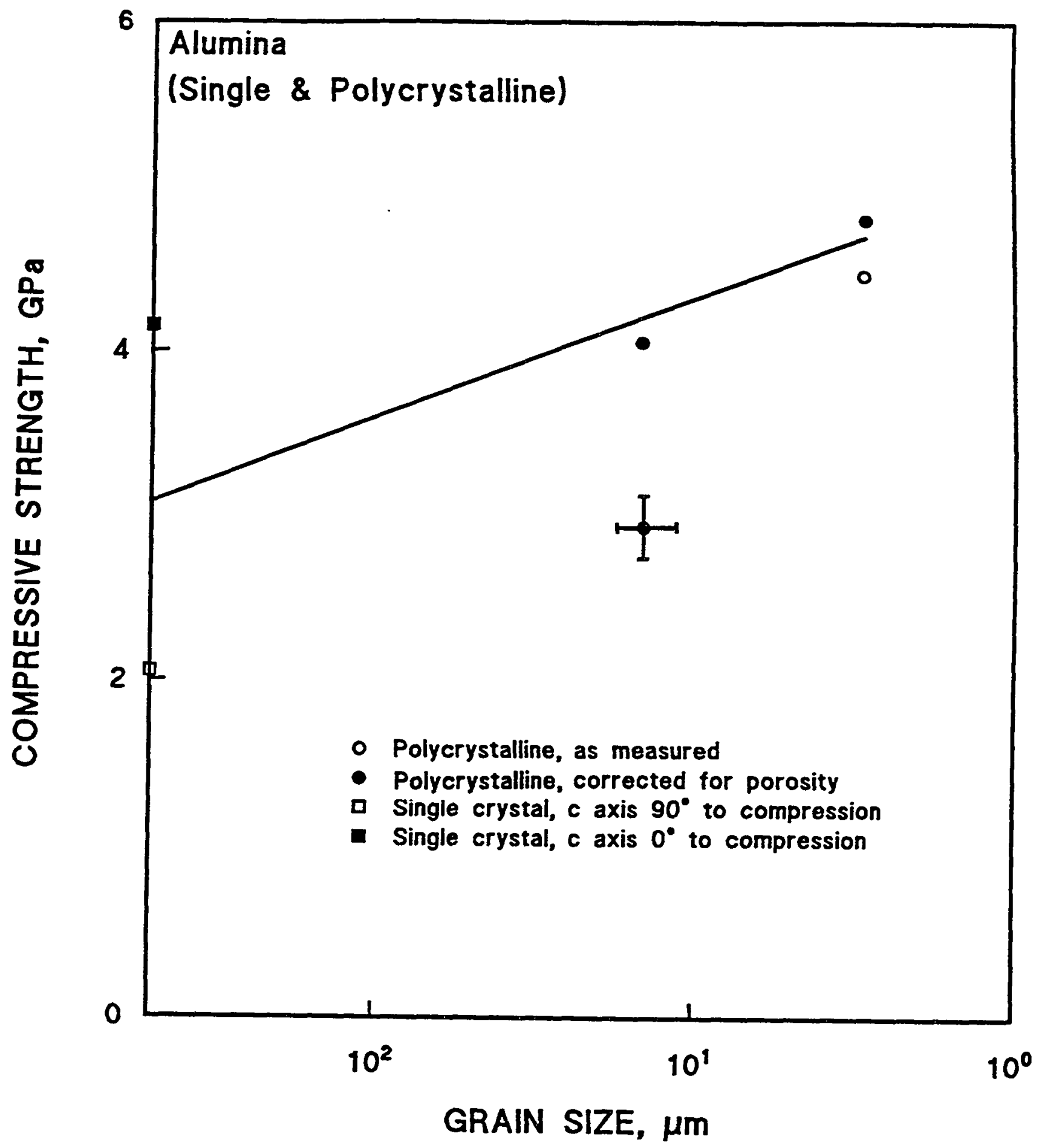

Figure 1.1.1. Dependence of the compressive strength upon grain size for $\mathrm{Al}_{2} \mathrm{O}_{3}$. Data from Rice [1971]. 
elastic behavior. However, Quinn [1991] suggested that in addition to microplasticity in the grains, compressive strength could depend on the square root of grain size simply because the size of defects may scale with the average grain size. In the brittle, Griffith theory of compressive failure, the compressive stress field is distorted at the tip of a flaw, allowing defects in the worst orientation ( $30^{\circ}$ to the axis) to experience a local tensile stress that is about one-eighth of the stress concentration experienced in tensile loading. This allows some stable crack growth until the crack becomes aligned with the compressive stress. Progressive accumulation of defects of this sort finally results in catastrophic failure in which the specimen is reduced to a powder. Thus, the compressive strength depends on the entire defect population, not on the largest, worst-oriented, most highly stressed defect. By this argument, compressive strength may then depend on the grain size simply because it sets the scale of defects.

Grain size has also been shown to affect the fracture toughness, mainly for non-cubic crystal structures [Rice et al., 1981]. The results of Rice et al. [1981] for $\mathrm{Al}_{2} \mathrm{O}_{3}$ shown in Figure 1.1 .2 are based on cantilever beam tests (see Amin [1991]). Evans and Fu [1984] discussed toughness by the microcrack process and obtained a theoretical explanation for the maximum in toughness shown for a particular range of grain sizes in Figure 1.1.2. Low values of toughness, -0.5 to $3 \mathrm{MPa} \cdot \sqrt{\mathrm{m}}$, are typical for traditional monolithic ceramics; reinforced ceramics can have toughness values that are a factor of 2 or more higher, and may also exhibit "R-curve" behavior in which a growing crack encounters greater resistance to propagation [Quinn, 1991].

As mentioned above, compressive strengths are predicted to be 8 times the tensile strength by the Griffith theory, and 3 to 5 times the tensile strength by the maximum tensile strength theory. These are brittle fracture-flaw theories. However, Rice cited several systematic studies that showed that the ratio of compressive to tensile strength varied with the grain size, with a smaller ratio occurring for small grain size and a larger ratio for large grain sizes. For $\mathrm{Al}_{2} \mathrm{O}_{3}$, a ratio of 4 corresponded to a grain size of $1 \mu \mathrm{m}$ and a ratio of 30 corresponded to $100 \mu \mathrm{m}$. For $\mathrm{MgAl}_{2} \mathrm{O}_{4}$, the ratio was 7 for a grain size of $1 \mu \mathrm{m}$. The grain size dependence of the ratios can be accounted for by microplastic mechanisms, discussed by Rice, but not by the brittle 


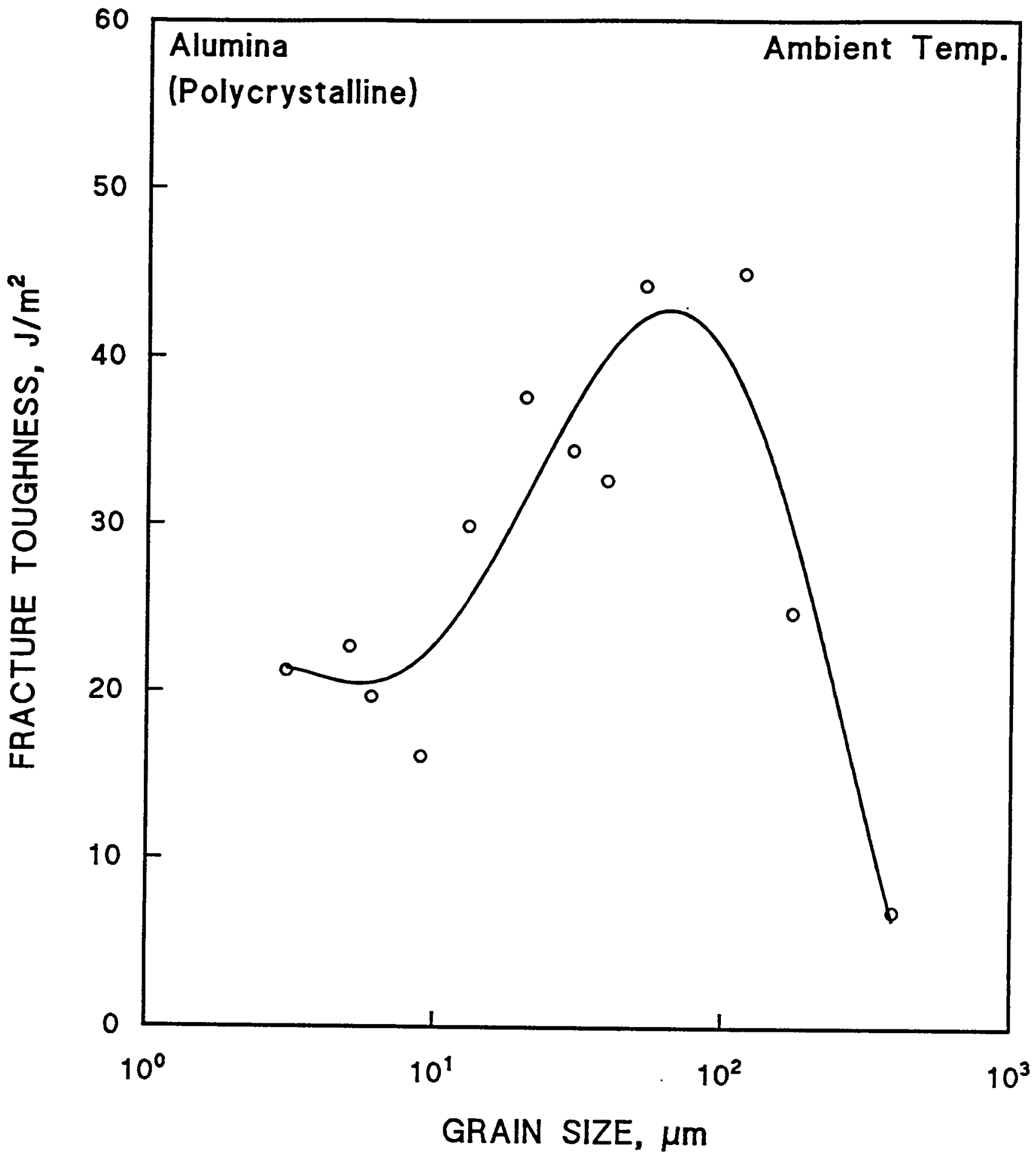

Figure 1.1.2. Dependence of the fracture toughness upon grain size in $\mathrm{Al}_{2} \mathrm{O}_{3}$. Data from Rice et al. [1981]. 
failure theories. Microplastic mechanisms include both slip and twinning, resulting in microscopic changes rather than generalized plastic flow, or macroscopic ductility, that is possible only at high temperatures or high confining pressures. The theory that plastic deformation is involved in the apparently brittle fracture of $\mathrm{Al}_{2} \mathrm{O}_{3}$ below $100^{\circ} \mathrm{C}$ is supported by TEM (transmission electron microscopy) observations of thin flakes collected from the fracture surface, which exhibit extensive twinning and dislocation generation [Petch, 1971]. The extent to which microplastic behavior may extend to cryogenic temperatures is discussed below, in $\$ 1.1 .2$.

Porosity is another feature of the microstructure that can lower compressive strength. Examples of smooth variations of compressive strength with porosity are given in Figure 1.1.3 (quartz ceramic) and Figure 1.1 .4 (calcium silicate system). In view of the predicted dependence of the compressive strength upon the defect population discussed above, perhaps this regular depencence should be expected. Nielsen [1990] presented predictive equations for the dependence of strength upon porosity. Extremes of pore size or volume might lead to brittle behavior. However, the distribution of porosity is important. Very fine pores within grains could act as sources of slip and have a beneficial effect, allowing more ductile behavior. This was shown in stress-strain curves of polycrystalline MgO with different microstructure by Langdon and Pask [1971]. Rice [1971] also cited evidence that porosity acted as a source of slip. Porosity at grain boundaries is generally not beneficial, especially if pores are large with respect to grain size, since they hinder the extension of slip bands across grain boundaries. Porosity also was shown to result in increased grain boundary cracking under irradiation [Simon, 1994, \$2.2]. Rice noted that experimental evidence indicated that compressive strength was more sensitive to porosity than was tensile strength.

Impurities can strengthen single-crystal ceramics, but in polycrystals, impurities can segregate to grain boundaries, causing weakened bonding, enhanced stress concentrations, and cracks. This can lead to brittle behavior. Impurities in solid solution or fairly homogeneous precipitation will encourage flow related brittle behavior, because slip and twinning is discouraged. 


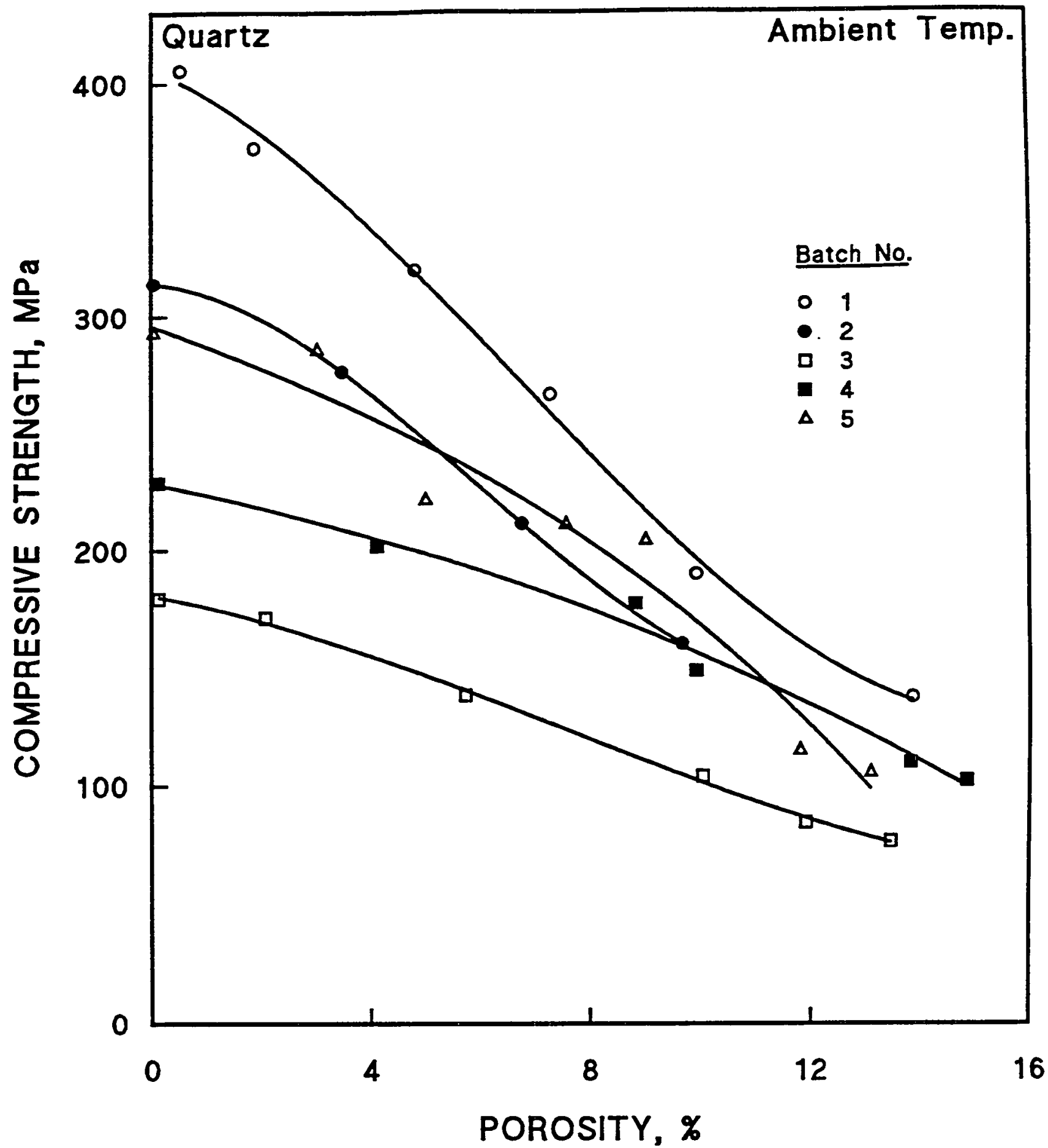

Figure 1.1.3. Dependence of the compressive strength upon the percent porosity for quartz ceramic. Data from Borodai and Suzdal'tsev [1975]. 


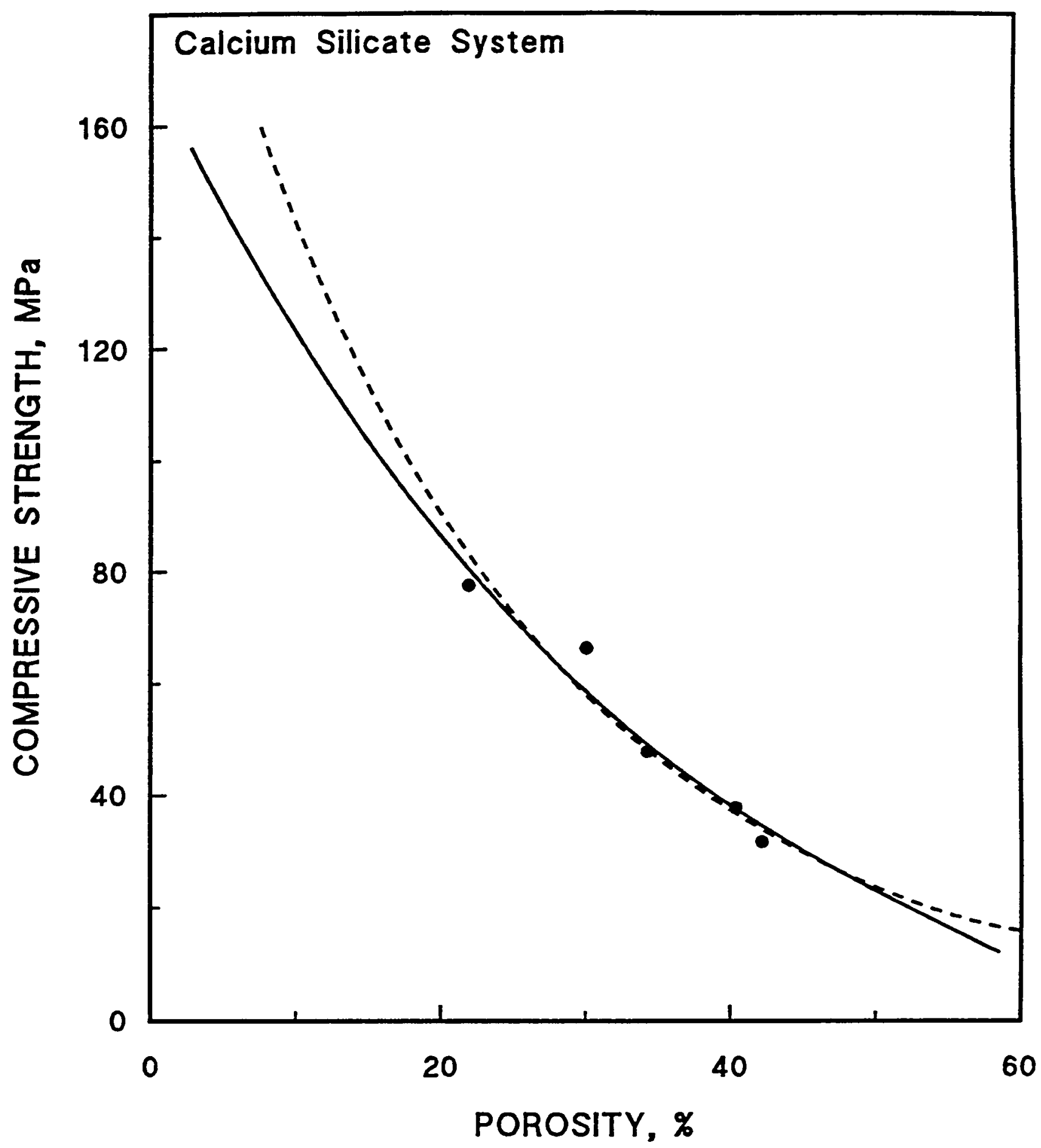

Figure 1.1.4. Dependence of the compressive strength upon the percent porosity. The curves depict two theoretical predictions. Data from Nielsen [1990]. 


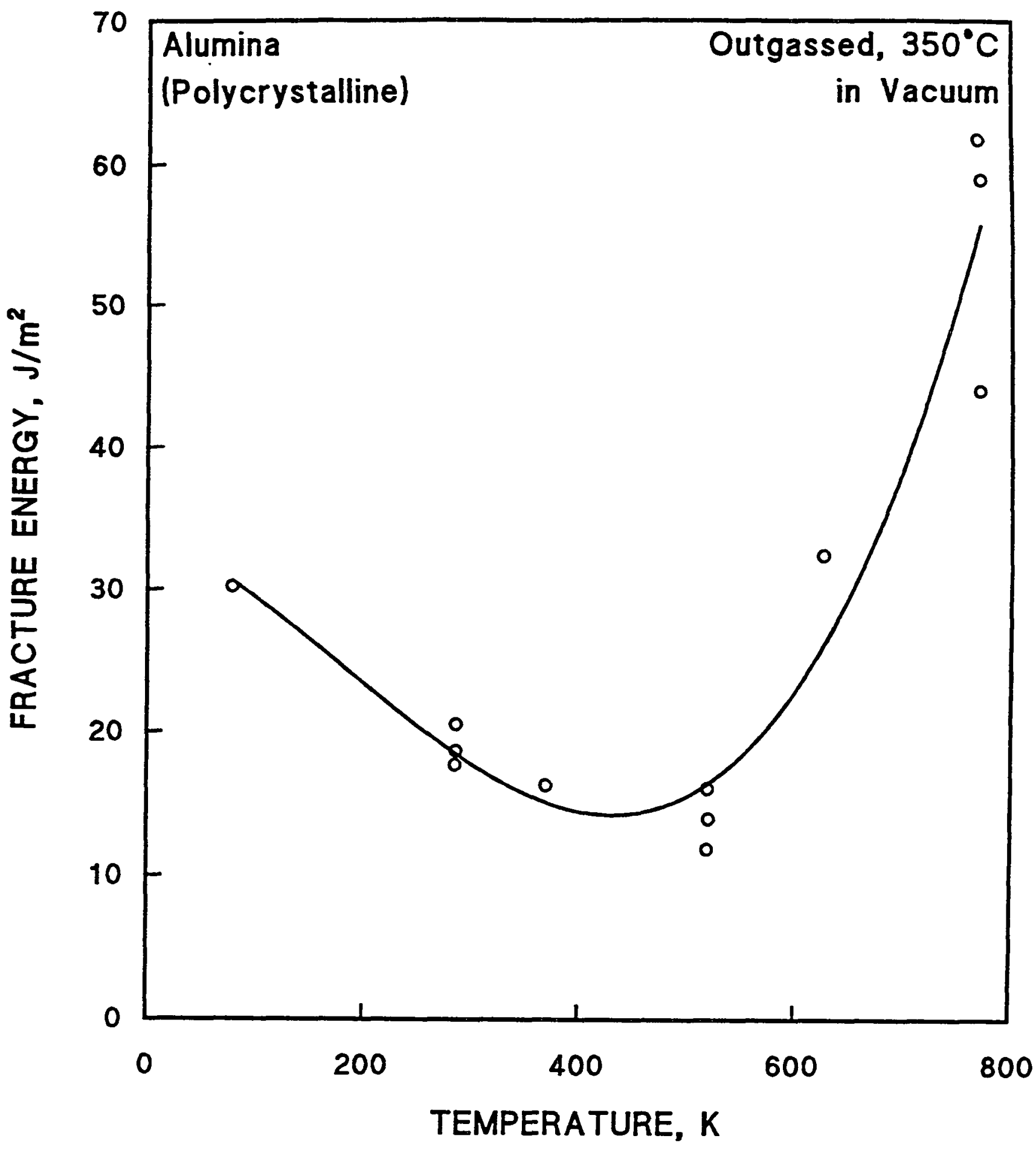

Figure 1.1.5. Effective fracture energy vs. temperature for polycrystalline $\mathrm{Al}_{2} \mathrm{O}_{3}$. Effective fracture energy is proportional to the square of the fracture stress at constant initial crack length. Data from Petch [1971]. 


\subsubsection{Effect of Temperature on Compressive Strength and Toughness}

Surface features influence strength owing to crack propagation by stress corrosion. Charles [1959] performed dynamic compression tests at $240^{\circ} \mathrm{C}$ on single-crystal $\mathrm{MgO}$ in saturated $\mathrm{H}_{2} \mathrm{O}$ vapor and in dry $\mathrm{N}_{2}$ with resulting failure stresses of 55 and $183 \mathrm{MPa}$, respectively. In fact, the apparent increase in strength of ceramics as the temperature is decreased (e.g., Figure 2.1.3, \$2.1) may be due to progressive inhibition of stress corrosion mechanisms. Rhodes et al. [1974] found nearly the same four-point bending strength for vacuum hot pressed and annealed $\mathrm{MgO}$ specimens in liquid $\mathrm{N}_{2}$ at $77 \mathrm{~K}$ as in $\mathrm{Ar}$ at $296 \mathrm{~K}$ after a $1-\mathrm{h}$ bakeout in $\mathrm{Ar}$ at $900^{\circ} \mathrm{C}$, since both environments were inert. As Figures 4.1.3, 6.1.1, and 6.1.2 in the following sections indicate for a number of materials, little apparent increase in compressive strengths in liquid $\mathrm{N}_{2}$ occurs, when comparison is made to higher temperature tests that were also performed in inert environments. However Lankford [1981b] found a temperature effect in the compressive strength of $\mathrm{Al}_{2} \mathrm{O}_{3}$, although the specimens used had fired surfaces and did not demonstrate the same sensitivity to environmental effects as ground specimens tested by De With [1986].

The effective fracture energy of polycrystalline $\mathrm{Al}_{2} \mathrm{O}_{3}$ was measured in vacuum as a function of temperature after outgassing at $350^{\circ} \mathrm{C}$ [Petch, 1971]. If the vacuum was adequate, it should have eliminated measurable surface stress corrosion effects, allowing observation of a true temperature effect, shown in Figure 1.1.5. (The effective fracture energy is proportional to the square of the fracture stress of the $\mathrm{Al}_{2} \mathrm{O}_{3}$ plate tested.) Petch suggested that the initial decrease in fracture stress with the rise of temperature above $77 \mathrm{~K}$ reflected the increasing ease of the plastic deformation necessary for fracture. Since accompanying plastic deformation will also occur around a growing crack, and dislocation movement will become easier as the temperature increases, the total fracture energy associated with crack extension may begin to increase with temperature. This may account for the rise in the curve above the minimum at about $473 \mathrm{~K}$. Other data cited by Petch indicated that the yield strength, as indicated by microhardness measurements (see $\$ 1.1 .3$ below), paralleled the fall in fracture strength up to $523 \mathrm{~K}$. 
Since data are scarce on the cryogenic temperature dependence of mechanical properties of ceramics, and the intrinsic temperature dependence is unclear, data on tensile properties, as well as hardness, as a function of temperature are reported in this review. As $\$ 1.1 .3$ below indicates, both tensile strength and hardness can serve, to some extent, as indicators of the maximum compressive strength.

\subsubsection{Measurements of Compressive Strength and Related Properties}

Rice [1971] related the limit of the compressive strength at ambient temperature to the yield stress, even under hydrostatic restraint. The increases in strength generally observed on application of a confining pressure should stop when general yielding begins, unless significant work-hardening occurs. Since hardness is about 3 times the yield stress (as in metals), Rice compared hardness-derived yield stresses to maximum observed compressive strengths and observed reasonable agreement. Lankford [1991] cited more recent data from an optimal uniaxial compressive configuration that further supported this relationship. To the extent that microplasticjty is the sole mechanism of forming indents at cryogenic temperatures also, hardness could serve as a compact, in situ screening test for radiation damage at $4 \mathrm{~K}$ of ceramic materials. (However, see the discussion of hardness measurements in $\$ 1.1 .5$ below.) Rice presented evidence for microplasticity at $295 \mathrm{~K}$ and Lankford [1991] cited more recent TEM evidence that dislocation activity was responsible for permanent indentations in strong ceramics.

The following discussion of compressive-strength measurement errors is taken chiefly from Rice [1971] and Lankford [1991]. In determining true compressive strengths, the most important problems are (1) nonparallel specimen ends or loading heads and (2) specimen-interface (and constraint) problems. Bending (tensile) stresses from nonparallel conditions can be quite high, but careful machining and the use of self-aligning heads can minimize these effects so that the errors from nonparallel conditions should not exceed a few percent. However, interfacial effects that arise from the combined effect of differential lateral (Poisson) expansion and friction between loading heads and the specimen can also result in substantial tensile stresses although these possible effects are often neglected. For example, the use of specimens of 
square cross section (owing to ease of experimental preparation) instead of comparable circular cross section can result in compressive strengths that are -15\% lower. Lankford [1991] presented a drawing showing the current optimum compression test specimen design ("dumbbell"). See also Tracy [1987] and Adams and Sines [1976] for descriptions of successful compressive tests on $\mathrm{Al}_{2} \mathrm{O}_{3}$. The use of a simple cylinder instead of a specimen with a reduced gauge section can result in strengths that are as much as $30 \%$ lower. Perhaps the use of optimized specimens will be necessary in radiation testing, to avoid large scatter that may obscure the results. However, all of these effects on non-optimal specimens are conservative, because they will cause the measured compressive strength to fall below the true compressive strength.

If the aspect ratio is low, however, the measured compressive strength may be higher than the true compressive strength. The aspect ratio is defined as the ratio of specimen gauge length in the compressive load direction to the specimen width perpendicular to that direction. But, since the insulation thickness in the TF magnets is small, $-2 \mathrm{~mm}$ (Table 1.0.1), while the extension of the insulation in the perpendicular direction is large, except at the keys, or notches, where it is $-21 \mathrm{~mm}$ (at this writing), measurements at very low aspect ratio should reflect usual insulation service conditions in ITER. Experimental observations of the change in measured compressive strength with aspect ratio were not found in this literature search; however, Figure 1.1 .6 shows the effect of a confining pressure (or hydrostatic restraint) for several of the materials considered in this review.

The influence of surface conditions upon the measured compressive strength can be sizable. For example, when polished porcelain specimens of identical aspect ratio (height $-3 \mathrm{x}$ diameter) were tested, specimens with a larger diameter of $20 \mathrm{~mm}$ had a $12 \%$ higher compressive strength than those of $6-\mathrm{mm}$ diameter [Dobrovl'skii et al., 1984]. This was attributed to the decreasing ratio of surface-damaged volume to total volume as the diameter increased.

Strain rate can also affect the measured compressive strength. Figure 1.1.7 shows the effect at ambient temperature in $\mathrm{Al}_{2} \mathrm{O}_{3}$; the total increase was less than $40 \%$ between strain rates of $10^{-6}$ to $10^{3} \mathrm{~s}^{-1}$ [Lankford, 1981a; 1977]. Figure 1.1.8 illustrates similar results published by Cosculluela et al. 


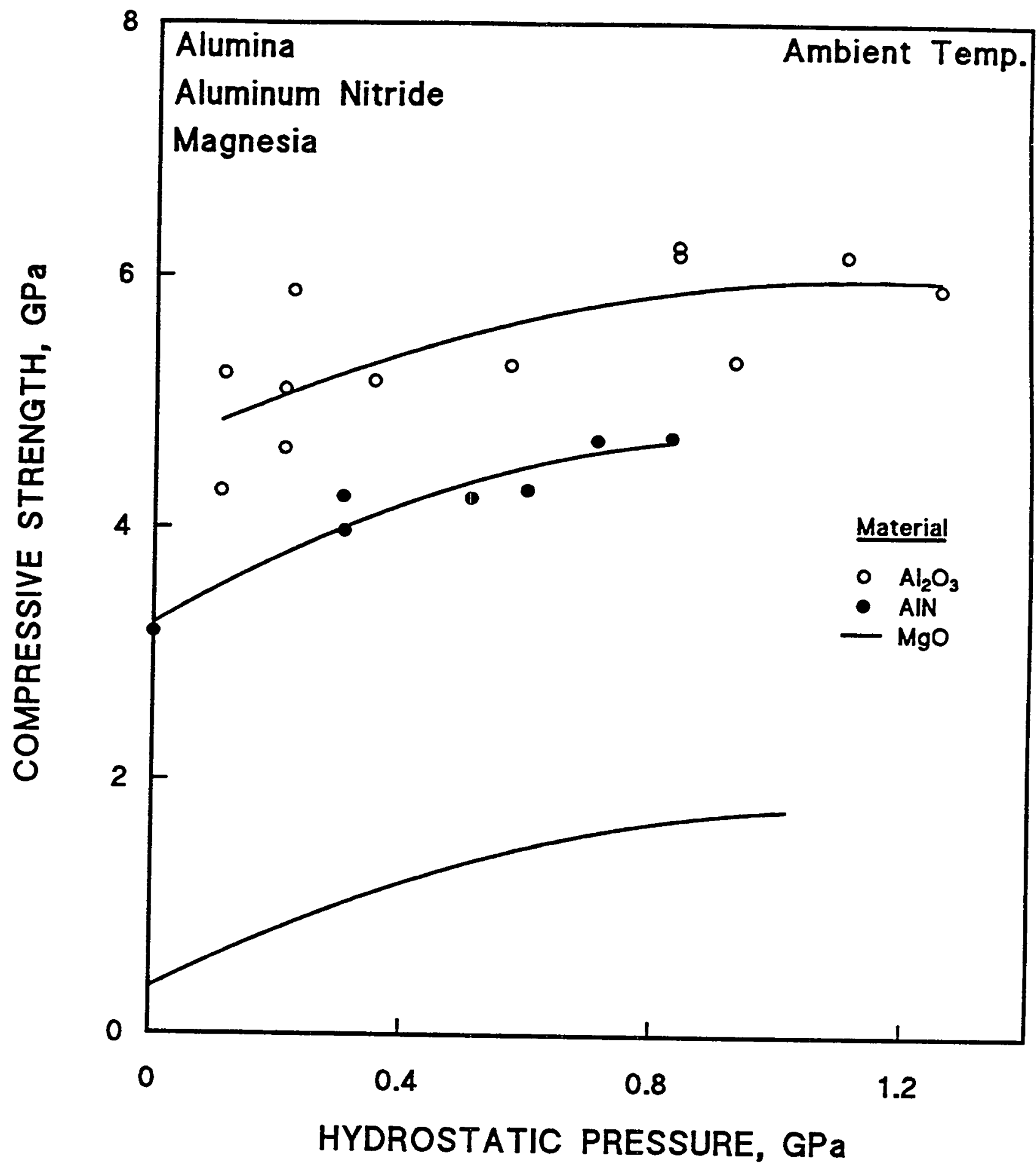

Figure 1.1.6. Effect of hydrostatic pressure on the compressive strength of $\mathrm{Al}_{2} \mathrm{O}_{3}, \mathrm{AlN}$, and $\mathrm{MgO}$. Data from Heard and Cline [1980]. 


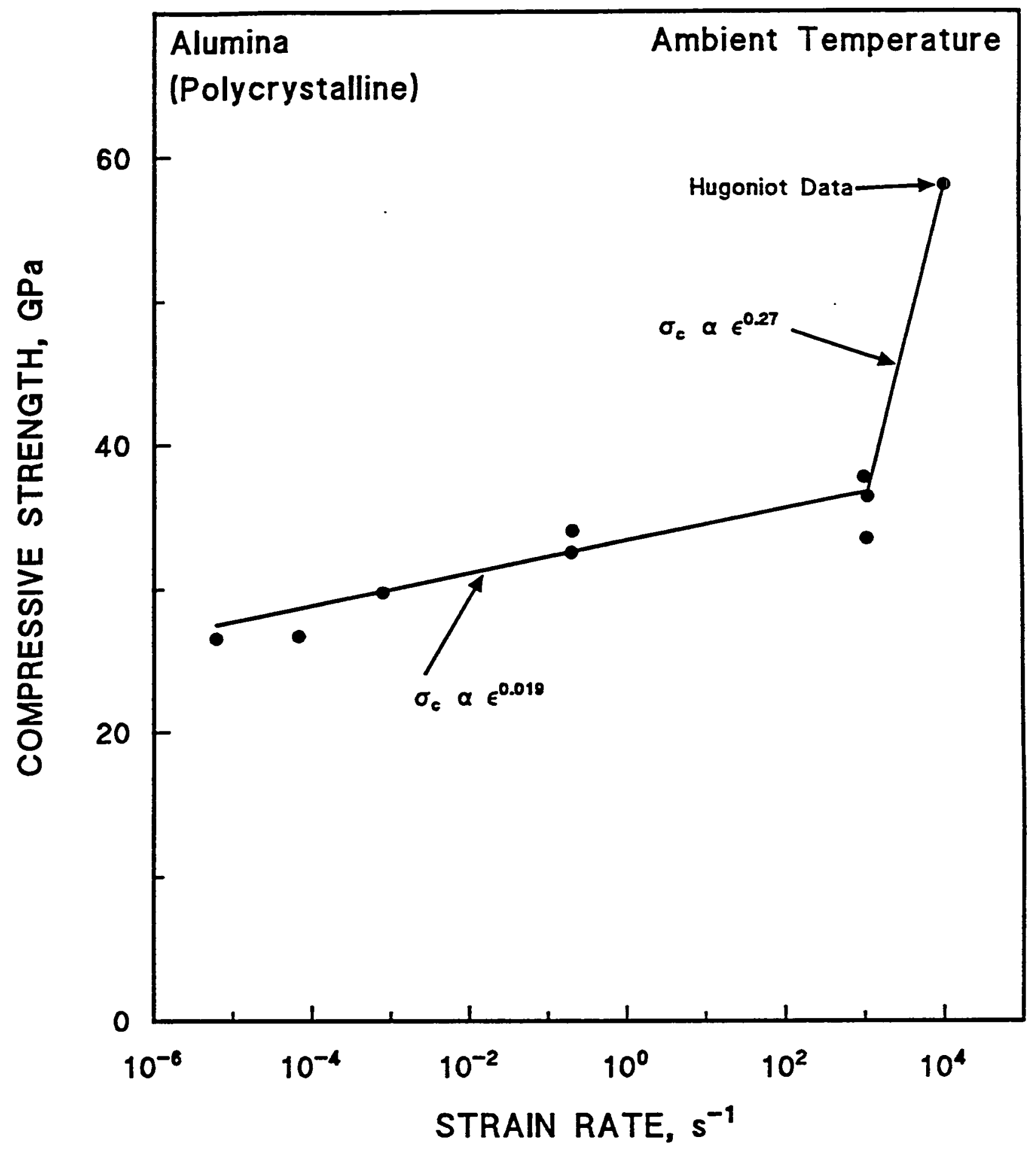

Figure 1.1.7. Compressive strength vs. strain rate for polycrystalline $\mathrm{Al}_{2} \mathrm{O}_{3}$. Data from Lankford [1981a]. 


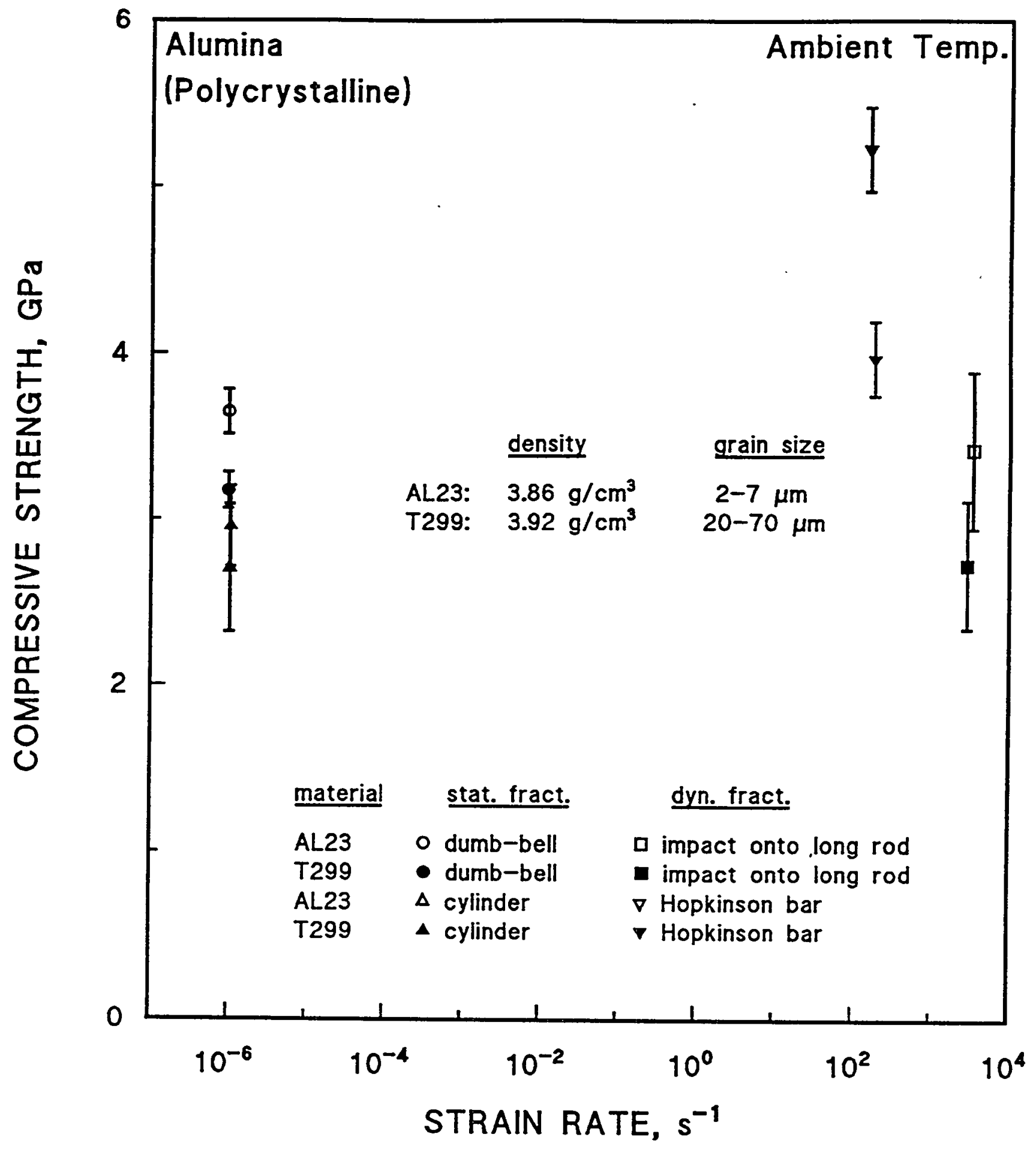

Figure 1.1.8. Compressive strength vs. strain rate for polycrystalline $\mathrm{Al}_{2} \mathrm{O}_{3}$. Data from Cosculluela et al. [1991]. 
[1991]. In both studies, shock wave techniques were used to attain very high strain rates. Cryogenic data on the effect of strain rate were not found in the literature search.

A large amount of scatter is typically observed in mechanical strength measurements of ceramic materials, presumably because the ceramics contain a random distribution of flaws that prevent them from achieving theoretical strength. The measure of the scatter most commonly used is the Weibull modulus, which is only useful if at least 10 or, preferably, 20 specimens are tested [Ibarra et al., 1992]. In this case, the failure probability, $F$, of the strength, $\sigma$, may follow the Weibull distribution, $F(\sigma)=1$ $-\exp \left[-\left(\sigma / \sigma_{0}\right)^{m}\right]$, where $m$ is the Weibull modulus. The value of $m$ is a measure of the scatter, since the distribution, $F$, broadens with decreasing $m$. If the number of specimens tested is low, the mean strength, $\sigma_{\mathrm{m}}$, is related to the Weibull distribution parameter, $\sigma_{0}$, by $\sigma_{\mathrm{m}}=\sigma_{0}(\ln 2)^{1 / \mathrm{m}}$. For $\mathrm{m} \approx 10, \sigma_{\mathrm{m}} \approx \sigma_{0}$. In many cases, examination of the Weibull modulus furnished useful information. For example, Dienst [1992] tested 10 to 20 bending specimens of $\mathrm{Al}_{2} \mathrm{O}_{3}$ before and after neutron irradiation, and found that the decrease in strength appeared to saturate after a particular fluence. However, he found that the Weibull modulus continued to decline with increasing fluence, indicating a larger percentage of specimens with very low strengths after high irradiation fluence. (See Figures 2.4.6 and 2.4.7 in Simon [1994].) Clearly, this additional information on scatter would be more useful to the designer than a report consisting only of the mean strengths after irradiation. Quinn [1991] also reviewed Weibull analysis. Although he suggested that compressive tests often have very low scatter and therefore may not require Weibull statistics, this assumption was based upon the use of highly developed compressive test techniques [Adams and Sines, 1976; Tracy, 1987] that may not be practical in the ITER irradiation program.

\subsubsection{Onset and Measurement of Microcracking under Compressive Stresses}

If the insulation component under compressive stress is required to serve as an electrical barrier (i.e., a wrap, such as polyimide film or mica is not also used), then the issue of microcracking before compressive failure arises, since microcracking could degrade the electrical breakdown strength. At 
ambient temperatures, microcrack nucleation in brittle materials such as $\mathrm{Al}_{2} \mathrm{O}_{3}$ begins at stresses below one-half of the compressive strength of the material. Crack extension from flaws was shown to begin at a stress of one-fourth the compressive strength in $\mathrm{Al}_{2} \mathrm{O}_{3}$ [Adams and Sines, 1977]. The evidence for microcracking at these stresses is based upon volumetric dilation and acoustic emission experiments [citations, Lankford, 1991]. Since hydrostatic pressure provides microcracking restraint, care must be taken in testing that such pressure conditions are similar to those that would obtain under service conditions. For example, when indentation methods are used, plastic deformation below the customary brittle-to-ductile transition temperature is possible because the large hydrostatic stress component beneath indenters prevents fracture [Hannink and Swain, 1984]. Also, information on the nucleation of microcracks at $4 \mathrm{~K}$ was not found in the current literature search. Since microplasticity was considered to have a negative influence on microcracking, because the available slip systems are too limited to permit the relaxation of crack-nucleating flaws (such as pores) and because dislocation activation contributes a population of microcracks to the intrinsic flaw-generated ensemble of cracks [Lankford, 1991], a change to less plastic behavior at or above $4 \mathrm{~K}$ could affect the stress level at which microcracking becomes important. However, even at higher temperatures, intrinsic geometric processing flaws nucleate a large fraction of the microcracks, so the presence of considerable microcracking in brittle ceramics at a stress below half of the compressive strength may be a temperature-independent phenomenon, to a first approximation. Electrical breakdown measurements and acoustic emission and dilation measurements can be used to detect the thresholds at which microcracking begins at $4 \mathrm{~K}$ and the threshold at which it impairs the usefulness of the material for ITER TF magnets.

\subsubsection{Measurement of Hardness}

This discussion of errors in hardness measurements is adapted from that of Rice [1971; citations therein] and is chiefly directed toward the use of hardness measurements as a screening test to predict compressive strengths. Under ambient conditions, moisture can decrease measured hardness to $-15 \%$ below that obtained with carefully dried surfaces. Machining, grinding, and mechanical polishing work harden surfaces, and result in hardness values that 
are higher than one-third the bulk compressive strength. Surface preparation by cleavage and chemical polishing can alleviate this problem.

To avoid cracking of ceramics, hardness tests are usually carried out with low loads (100-g mass); however, this results in hardness values that are higher by 20 to $40 \%$ owing to greater proportional amounts of elastic recovery and difficulties in determining smaller indent dimensions. Electron microscopy measurements give deeper indent values than optical measurements.

The Knoop indenter has a greater surface area than the Vickers indenter, leading to less local work hardening and hardness values that are lower by an average of $20 \%$.

Since hardness is not an isotropic property and variations of 40 to $50 \%$ are common between different crystal planes in anisotropic materials, such as those with the wurtzite structure, texture of polycrystalline specimens and orientation in single crystal specimens must also be taken into account in some cases. Even in cubic materials, hardness can vary by $20 \%$ or more between different crystal planes.

Grain size affects hardness; therefore, hardness values should be expected to correlate with compressive strength only for specimens of similar grain size. However, porosity will usually not affect the hardness as much as it does the compressive strength; therefore, hardness measurements on porous material, especially if the porosity is located primarily at the grain boundaries, may seriously overestimate the compressive strength. As the indent becomes larger or the porosity distribution becomes finer, porosity effects on the hardness are more observable, and the results may be a more accurate reflection of compressive strength.

\subsubsection{Shear/Compressive Strength}

Initially, strength upon simultaneous application of shear and.compressive stresses at cryogenic temperatures was obtained for organic composites [Simon et al., 1992; Drexler et al., 1992; Simon et al., 1994; citations therein]. (See also Aki et al. [1983] for an earlier application of this test.) A 


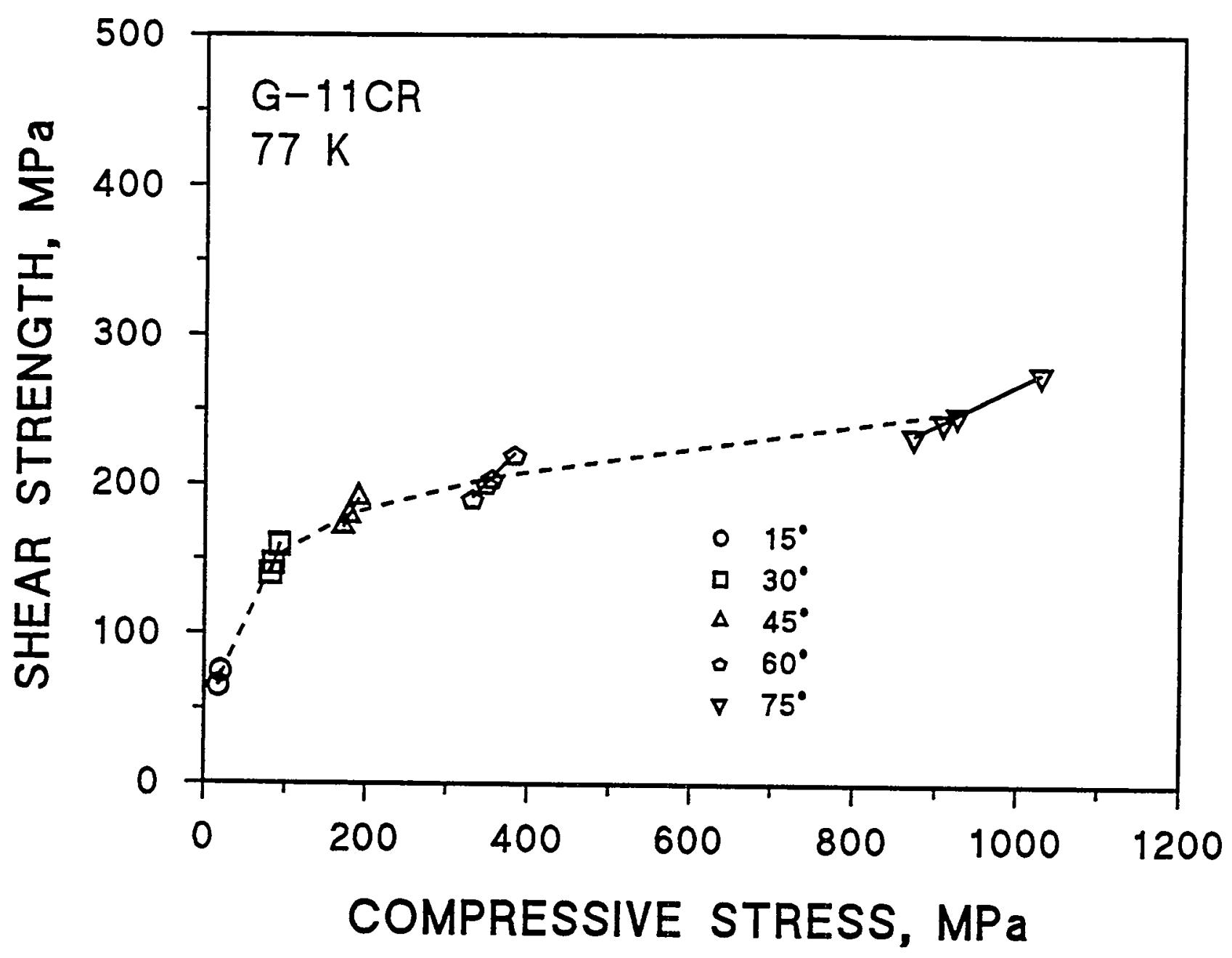

Figure 1.1.9. Failure curve obtained with shear/compression series test fixture on G-1ICR. Data from Simon et al. [1994]. 
series of uniaxial test fixtures was used in which the angle between the normal to the flat specimen and the axis of the load was varied, so that shear/compression failure envelope was generated, as shown in Figure 1.1.9. More recently, this test method has been applied to hybrid insulation consisting of ceramic coatings on metal chips, combined with an organic composite [Fabian and Reed, 1994]. However, it was not feasible to generate a failure envelope with the type of specimen employed, because failures occurred within different parts of the hybrid sandwich-type specimen at different shear/ compressive stress ratios. Specifically, at 15' (shear component $96 \%$ of load, compressive component $26 \%$ of load), failures occurred within the $\mathrm{Al}_{2} \mathrm{O}_{3}$ or $\mathrm{MgAl}_{2} \mathrm{O}_{4}$ coating or at the boundary of that coating with the organic constituent, but occurred within the organic component at $45^{\circ}$. No other examples of cryogenic shear/compression testing of inorganics were found in the literature.

\subsection{ELASTIC PROPERTIES}

Elastic moduli of ceramics can be measured accurately by ultrasonic pulse techniques, but sometimes the only values in the literature will be static measurements from stress-strain curves. Except for porosity, the effect of differences in microstructure is expected to be small [Dienst et al., 1990]. Examples of the effect of porosity are shown in Figures 1.2.1 and 1.2.2. The effect depicted in Figure 1.2.1 was described by an equation of the form $E$ - $E_{0}(1-p)^{3}$ where $E$ is the Young's modulus and $p$ is the fractional porosity. The effect of porosity upon the Young's modulus is similar to the effect upon the compressive strength, as shown in Figures 1.1 .3 and 1.1.4.

\subsection{ELECTRICAL BREAKDOWN STRENGTH}

Several types of specimens were tested by Heuse and Creyke [citation, Morse and Hill, 1970] in a study of the effects of sample shape on the electrical breakdown strength of porcelain. The specimen types are depicted in Figure 1.3.1. The cup specimen (A) allows application of the electric field to a large area of the specimen. Because there is a high probability that a flaw will be present in the field region, the values of breakdown strength tend to be low. However, the recessed region prevents surface flashover if the 


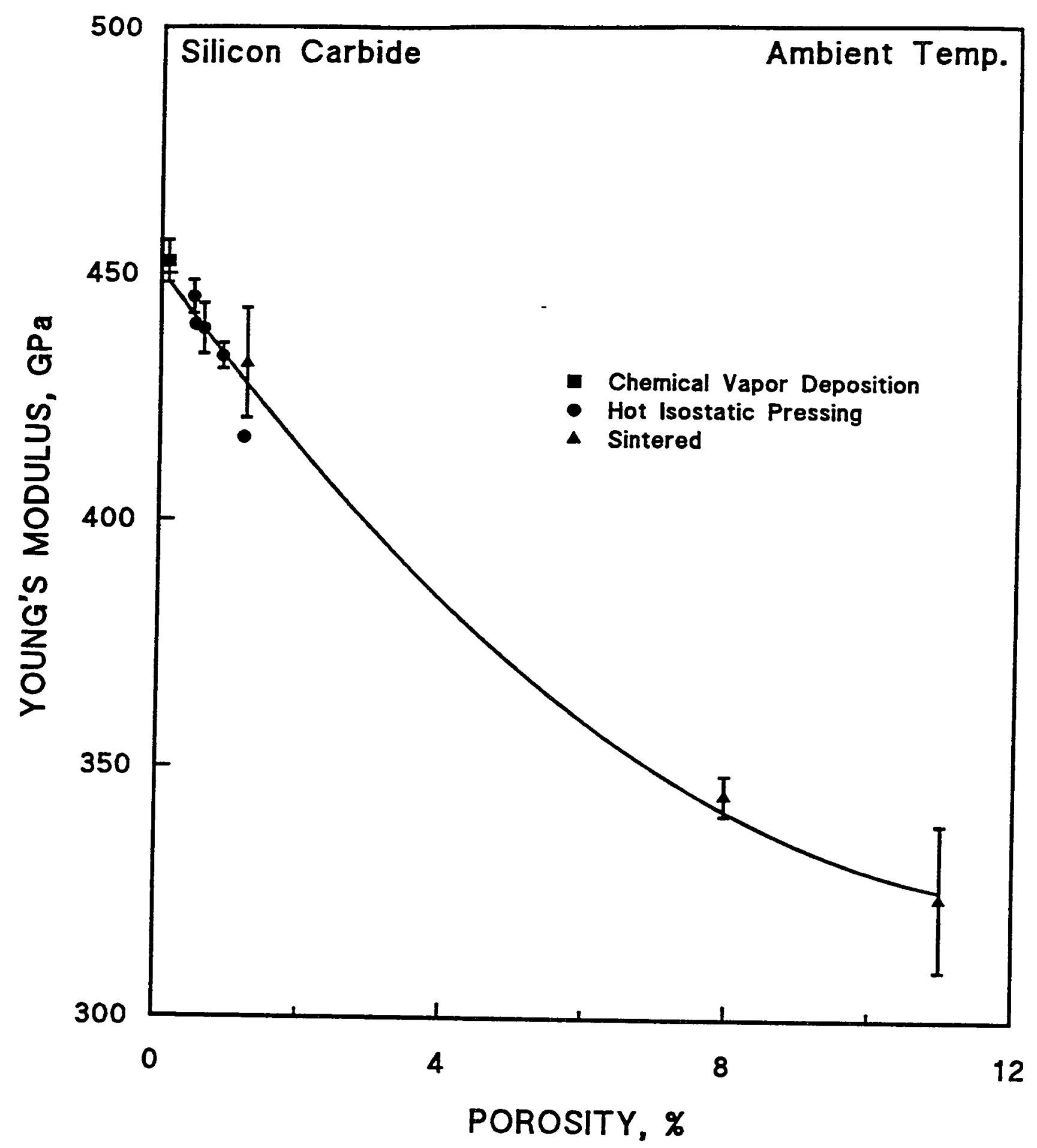

Figure 1.2.1. Young's modulus vs. porosity of SiC. Data from Dienst et al. [1990]. 


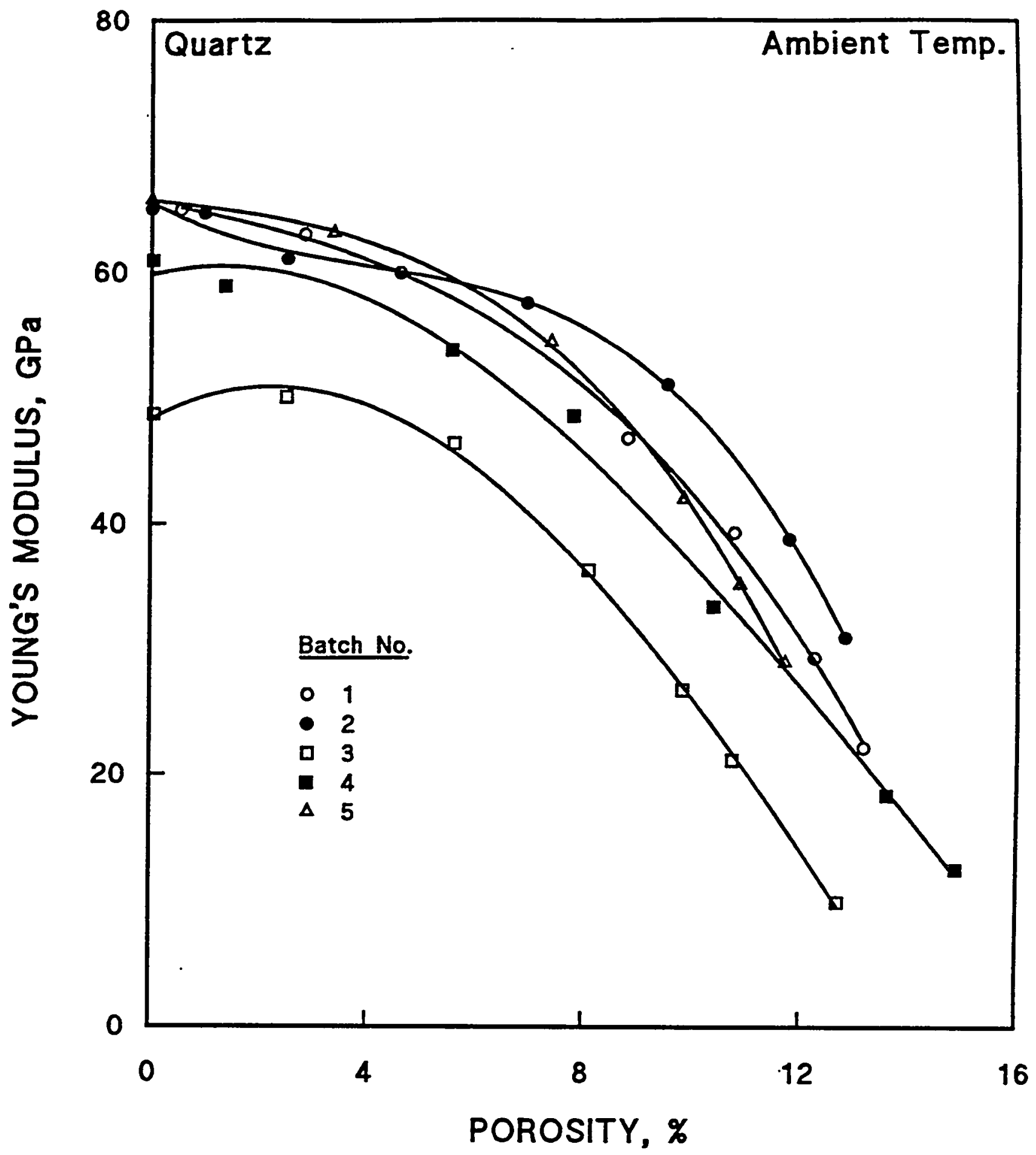

Figure 1.2.2. Young's modulus vs. porosity of quartz ceramic. Data from Borodai and Suzdal'tsev [1975]. 
A

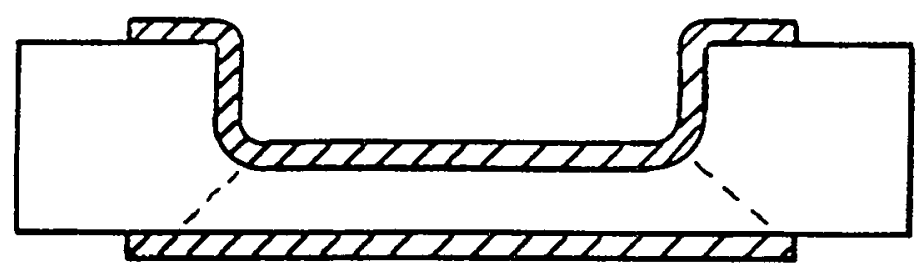

cup specimen

B

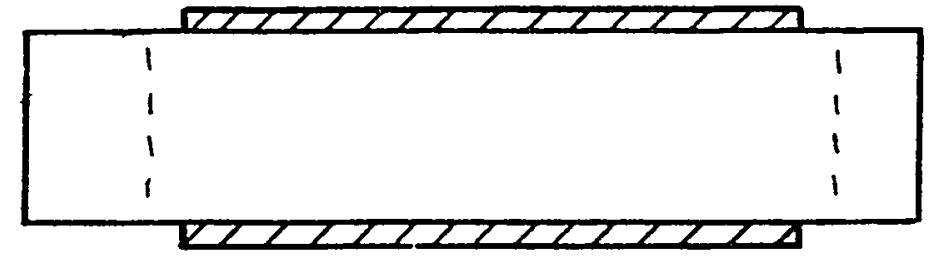

flat specimen

C

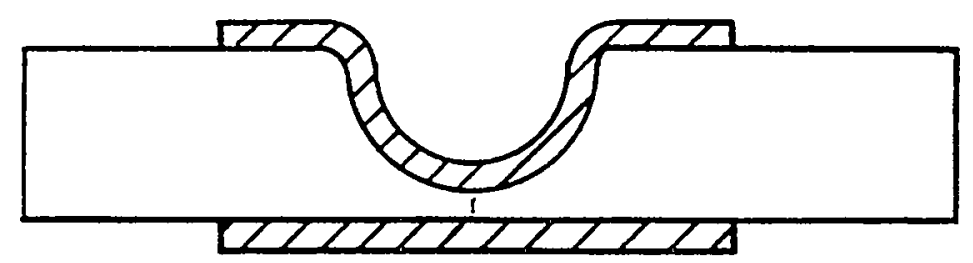

recessed specimen

Figure 1.3.1. Diagrams of cup, flat, and recessed specimens for electrical breakdown tests. 
dimensions are chosen correctly. Specimen type (B) also exposes a large volume of ceramic to the field, but breakdown often occurs at or near the edge of the electrode. This is usually the result of discharges in the surrounding medium, so that the measured values of breakdown strength are dependent upon properties of the medium. Specimen type (C) is known as the "intrinsic breakdown" specimen. Only the smali region below the hemispherical recess is exposed to a high field, so the probability of breakdown due to flaws is reduced. Heuse and Creyke found that this specimen type produced the highest, most reproducible measurements of electrical breakdown strength. While reproducibility is very important in both screening tests for material downselection and studies of the effects of radiation upon breakdown strength, additional measurements with cup specimen type (A) would be desirable to indicate minimum expected strengths from flaws. Goland [1978] used a tubular specimen of $\mathrm{Al}_{2} \mathrm{O}_{3}$ in an irradiation chamber designed for electrical breakdown measurements (see Figure 1.3.2).

The effect of thickness ( $t$ ) upon the measured electrical breakdown strength is well-established. Figure 1.3.3 demonstrates this effect with several different forms of commercial $\mathrm{Al}_{2} \mathrm{O}_{3}$ [Morse and $\mathrm{Hill}, 1970$ ]. The authors used specimen type $C$ for reproducibility. The expression $E_{b}=a t^{-0.3}$ fitted the data well and corresponds to results of other investigators. The power of $t$ usually varies within a fairly narrow range of -0.2 to 0.4 .

Morse and Hill noted that the breakdown strengths of both cold-pressed and sintered specimens obeyed the equation, despite differences in density and mode of fabrication. However, the series of hot-pressed specimens produced with variable pressing time indicated that a reduction in porosity achieved by increased pressing time increased the breakdown strength. Some of the change could have been due to changes in the grain size instead of porosity. In an additional experiment, Morse and Hill determined that a large difference in the grain size produced no appreciable change in breakdown strength; rather, the porosity, as indicated by the density, was the determining factor. Figure 1.3.4 illustrates the variation of breakdown strength of $\mathrm{Al}_{2} \mathrm{O}_{3}$ with density. The polycrystalline curve was extrapolated to the mean value for single crystal $\mathrm{Al}_{2} \mathrm{O}_{3}$ (the breakdown strength along the $c$ axis is $27 \%$ lower than that along the a axis). 


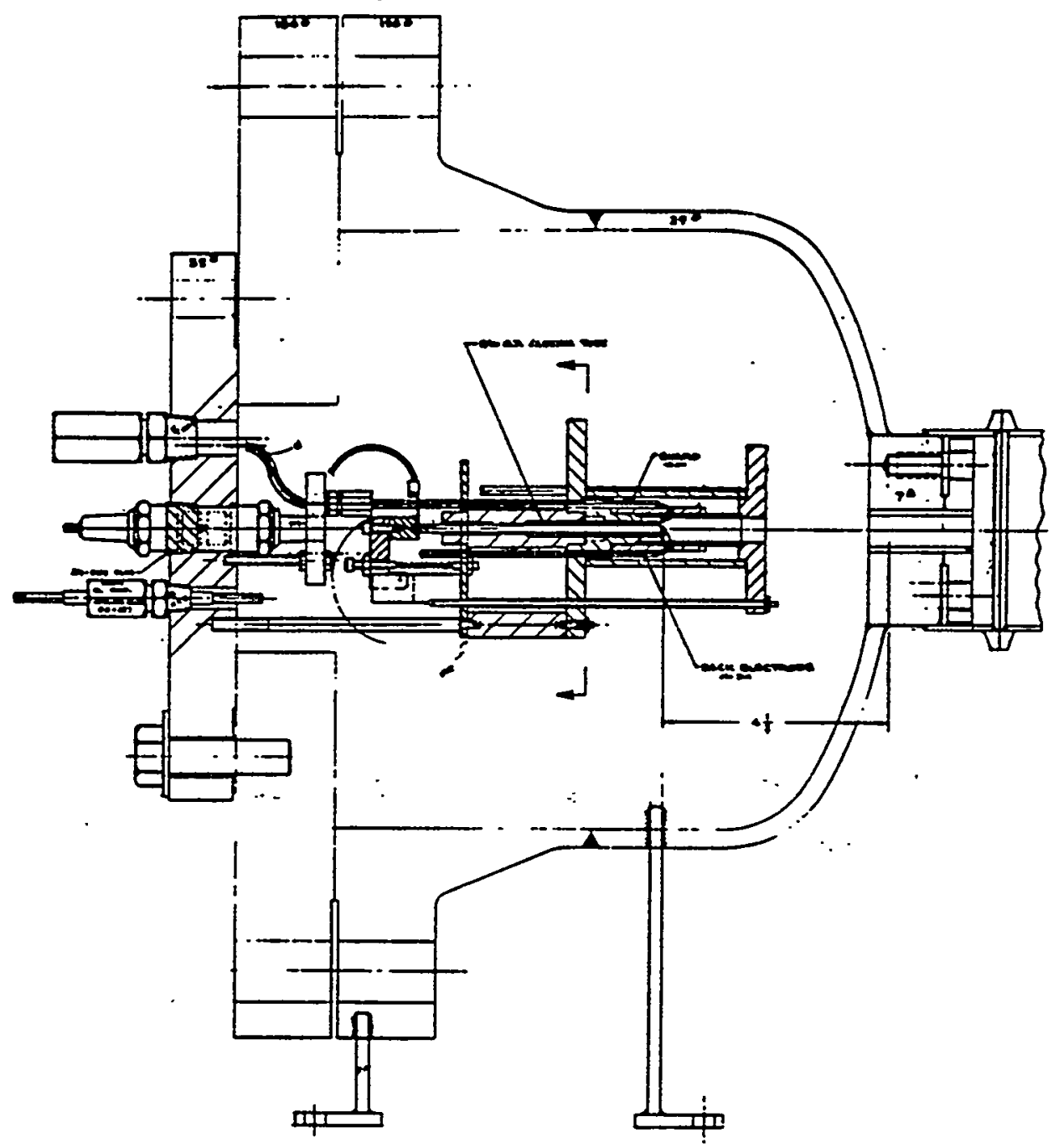

Figure 1.3.2. Chamber for dielectric breakdown measurements in an electron beam. From Goland [1978]. 


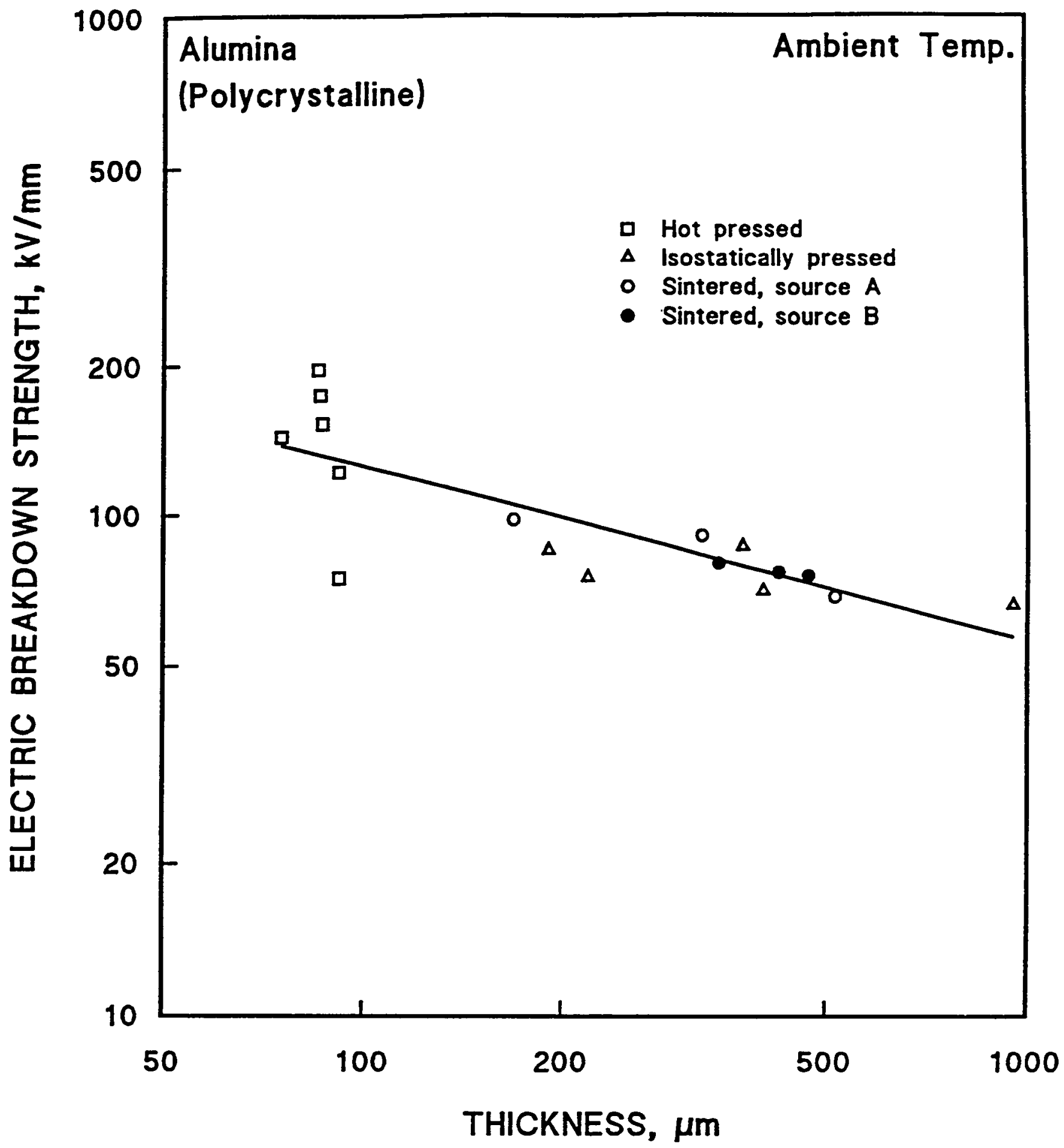

Figure 1.3.3. Dependence of electrical breakdown strength upon specimen thickness for several forms of $\mathrm{Al}_{2} \mathrm{O}_{3}$. Data from Morse and Hill [1970]. 


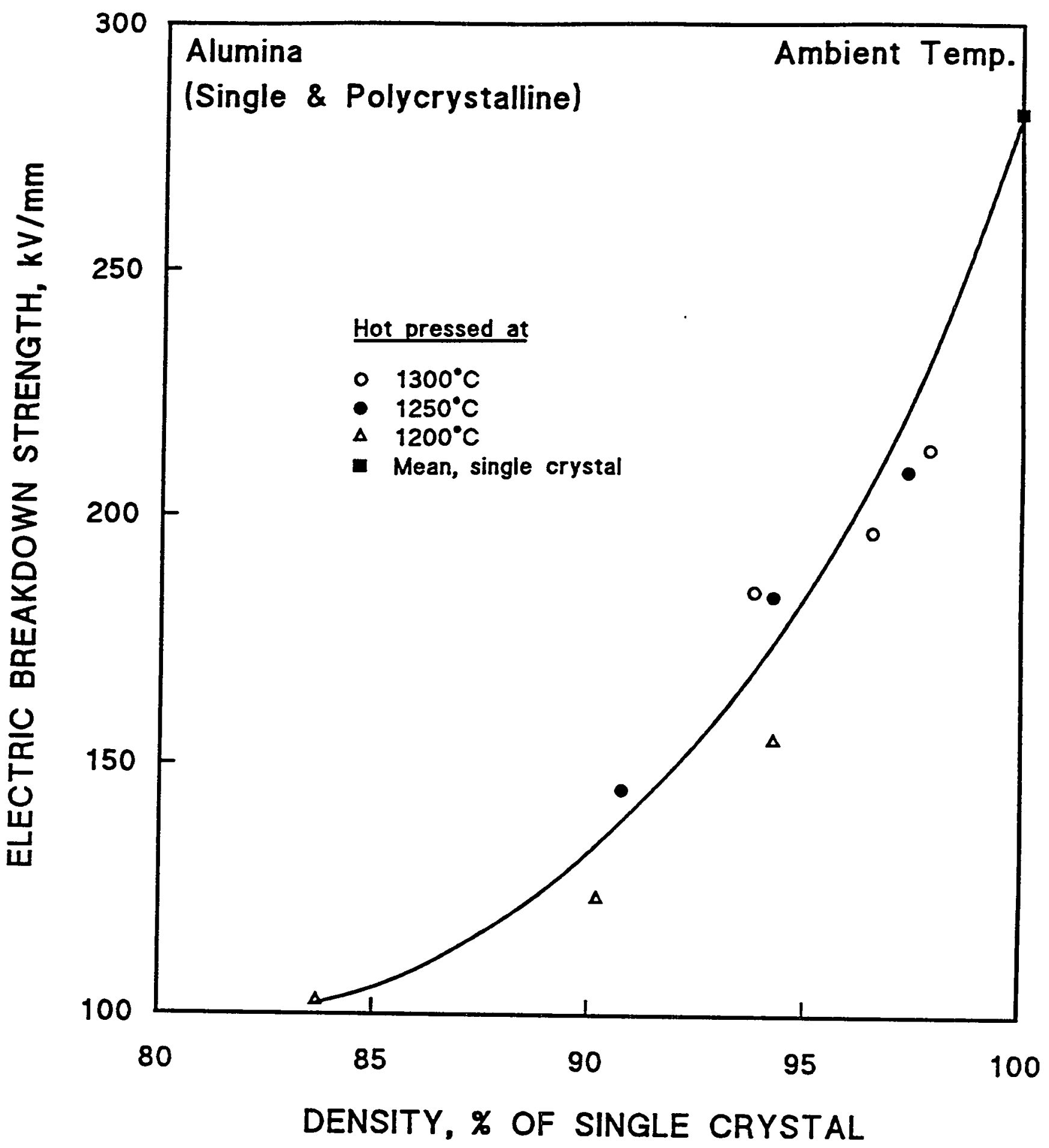

Figure 1.3.4. Dependence of electrical breakdown strength upon specimen density for hot-pressed $\mathrm{Al}_{2} \mathrm{O}_{3}$. Data from Morse and Hill [1970]. 
Gerson and Marshall [1959] used a statistical approach to determine the effect of void size in addition to that of porosity. Their theoretical result is shown in Figure 1.3.5.

Humidity has an effect upon the electrical breakdown strength when measurements are made at ambient temperature, and conditioning is often required to obtain reproducible results. The effects of trapped, frozen $\mathrm{H}_{2} \mathrm{O}$ upon the electrical breakdown strengths of various materials measured at cryogenic temperatures are not well known.

Ambient-temperature measurements are often made in oil, to prevent corona or surface flashover. Liquid $\mathrm{N}_{2}$ is a good dielectric, so measurements in this medium should not, in general, lower the breakdown strength from that of an intrinsic measurement in oil at ambient temperature. Liquid He, however, has a low dielectric constant and low breakdown voltage [Mathes, 1963]. The breakdown voltage of a polyimide-coated, glass fiber insulation was $1.32 \mathrm{kV}$ in liquid He and $11.3 \mathrm{kV}$ in liquid $\mathrm{N}_{2}$ [Mathes, 1963]. The dielectric strength of liquid He is affected by the presence of barely detectable, finely divided solid impurities, for example, solid air particles. Practical values of breakdown voltages of liquid $\mathrm{He}, \mathrm{H}, \mathrm{N}_{2}$, and air were measured by Mathes. The use of a high vacuum at $4 \mathrm{~K}$ instead of an environment of liquid He improved the breakdown voltage of polyimide and other polymer films [Bobo et al., 1968]. Partial discharge phenomena commonly occurred in the liquid He for voltages lower than one half of breakdown. The breakdown strength of liquid He as a function of temperature was studied by Kim et al. [1983].

Usually, electrical breakdown strength has been measured by applying a steadily increasing field and measuring the leakage current. However, Sprangle et al. [1992; citation therein] noted that oxides having a high trap density may absorb significant amounts of electric charge before breaking down, so that a constantly increasing field may have increased above the true breakdown voltage when breakdown conditions are evident. Also, since dielectrics exhibit time-dependent breakdown, precisely controlled stressing time is important, because the breakdown field is reduced as stressing time is increased. The stepped-field method avoids these problems by applying a constant electrical field for a fixed period of time. After each period of 


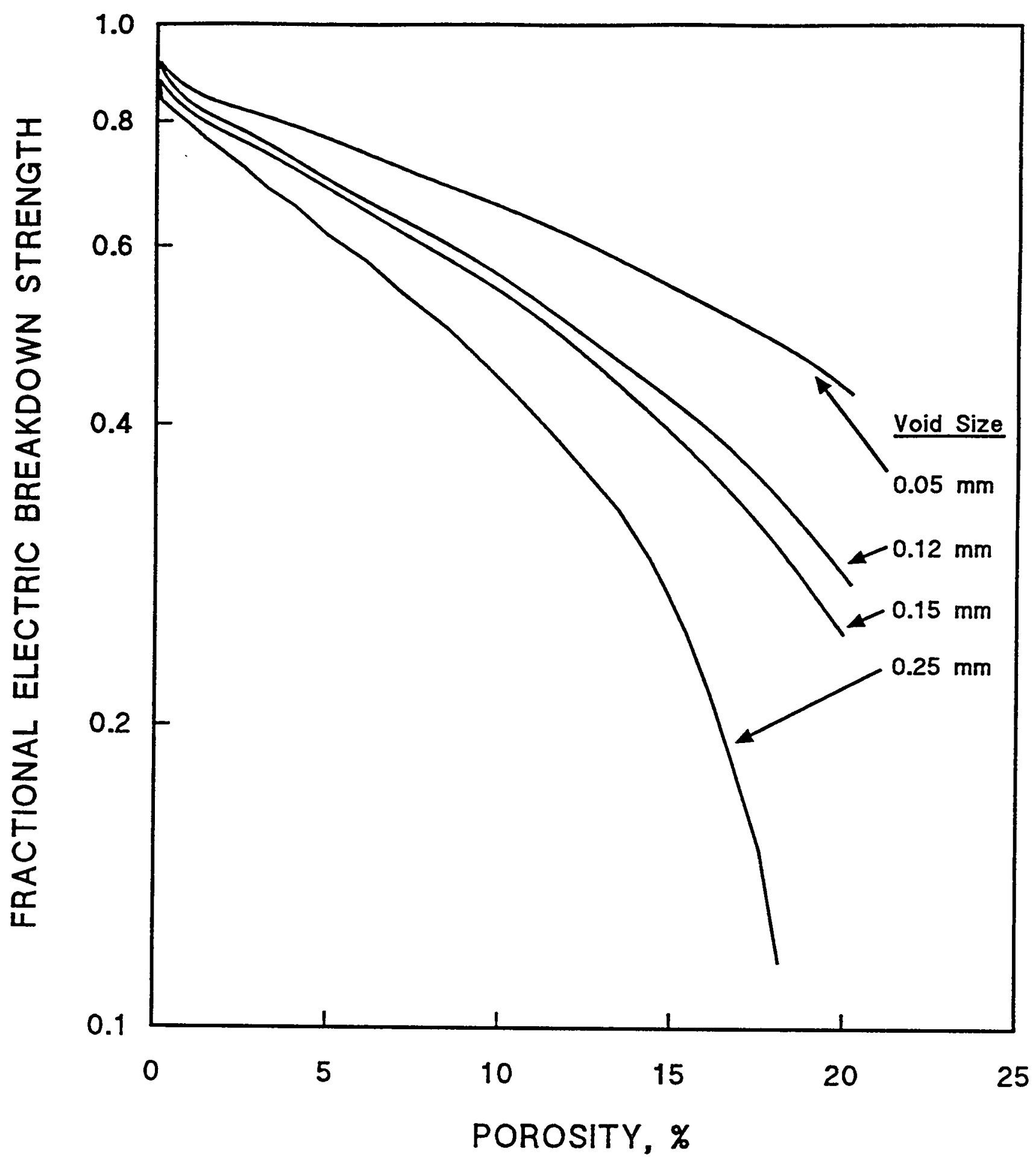

Figure 1.3.5. Theoretical effect of void size upon the dependence of electrical breakdown strength upon porosity. Data from Gerson and Marshall [1959]. 
stress, the field is reduced to a much lower test value to determine whether the leakage current has been significantly increased. A bimodal distribution of electrical breakdown strength for $\mathrm{SiO}_{2}$ was observed with this method [Sprangle et al., 1991; 1992].

To support the design data needs of the ITER magnets, data on electrical breakdown after appropriate mechanical stresses subsequent to (or, coincident with) 4-K neutron irradiation should be obtained. For example, the breakdown voltage of mica decreased significantly under a 300-MPa compressive stress (\$9.3). Fracture of materials in vacuum induced electrical breakdown in many materials, such as quartz, $\mathrm{Al}_{2} \mathrm{O}_{3}$, and epoxy, owing to the emission of particles when the fracture occurs [Klakken et al., 1984].

\subsection{THERMAI PROPERTIES}

Nearly all of the cryogenic-temperature data base on inorganic insulations pertains to their thermal properties, especially for temperatures below $77 \mathrm{k}$. In most cases, cryogenic measurements of thermal properties of inorganic materials are relatively straightforward, in comparison to measurements of mechanical properties and electrical breakdown strength. For further information and references on thermal conductivity measurement techniques of nonmetallics, Touloukian et al. [1970] may be consulted. Measurement techniques for the specific heat of nonmetallics are reviewed by Touloukian and Buyco [1970], and a similar introduction to the measurement of thermal expansion of nonmetaliics is also available from the same group [Touloukian et al., 1977]. The theoretical basis of cryogenic thermal property measurements has been presented in a form accessible to the non-specialist by Rosenberg [1963]. 


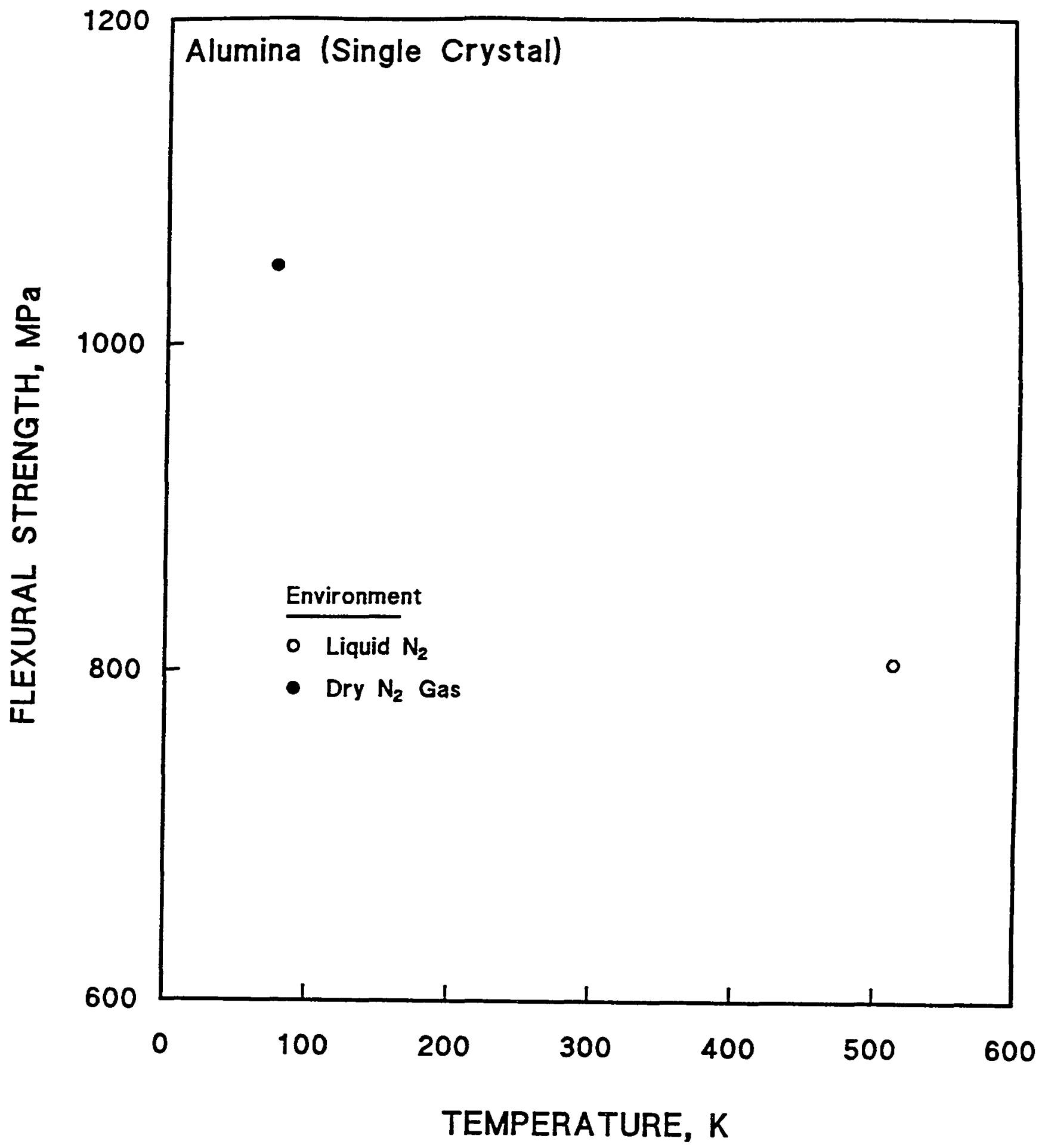

Figure 2.1.1. Flexural strength of single-crystal $\mathrm{Al}_{2} \mathrm{O}_{3}$ at 77 and $513 \mathrm{~K}$ (in dry $\mathrm{N}_{2}$ ). Data from Charles [1959]. 


\section{AITMINA}

\subsection{MECHANICAL PROPERTIES}

\subsubsection{Compressive Strength}

Considerable development of $\mathrm{Al}_{2} \mathrm{O}_{3}$ ceramics has occurred with reduction in grain size; with this reduction, the ambient-temperature compressive strength has increased considerably, to about $4.5 \mathrm{GPa}$ for a 2- $\mu \mathrm{m}$ grain size, as Figure 1.1.1 indicates. However, a more typical uniaxial, ambient-temperature compressive strength of a commercial, dense, sintered $\mathrm{Al}_{2} \mathrm{O}_{3}$ (grain size 5 to $10 \mu \mathrm{m}$ ) is about $2.4 \mathrm{GPa}$ [Aghajanian et al., 1989; citations therein]. Even rather impure alumina ceramics had ambient compressive strengths of about 1.8 to $2.1 \mathrm{GPa}$ [De With, 1986]. Handbook values range from $2.5 \mathrm{GPa}$ (90\% pure) to 2.5 and $3.8 \mathrm{GPa}$ for specimens that were $99.9 \%$ pure [Miyayama et al., 1991]

By testing single-crystal $\mathrm{Al}_{2} \mathrm{O}_{3}$ in tension, both at $240^{\circ} \mathrm{C}\left(513 \mathrm{~K}\right.$ ) in dry $\mathrm{N}_{2}$ gas and at $77 \mathrm{~K}$ in liquid $\mathrm{N}_{2}$, Charles [1959] found an apparent large intrinsic increase in tensile strength at the lower temperature. The use of dry $\mathrm{N}_{2}$ gas at the higher temperature should have eliminated stress corrosion effects. Figure 2.1.1 shows this result. However, compressive tests that Charles did in dry $\mathrm{N}_{2}$ gas on other materials, shown below in Figures 4.1.3, 6.6.1, and 6.1.2, indicated smaller strength increases at low temperatures.

The intrinsic temperature dependence of compressive strength in polycrystalline $\mathrm{Al}_{2} \mathrm{O}_{3}$ between 77 and $1800 \mathrm{~K}$ was probably obtained by Lankford [1981b], because the cylinders of the translucent commercial material used (Lucalox) were tested in the as-fired condition, and other work indicated that these specimens did not exhibit strong effects of the testing environment [De With, 1986]. The density of flaws on the outer surface of as-fired specimens is greatly reduced, compared to surface flaws in ground or machined specimens; hence, sensitivity to temperature-dependent stress corrosion effects is much reduced. Lankford's test results for three strain rates are shown in Figure 2.1.2. These tests were detailed, in that failed specimens were studied fractographically in an SEM (scanning electron microscope) and the onset of microcracking was monitored for the lowest strain rate with acoustic emission 


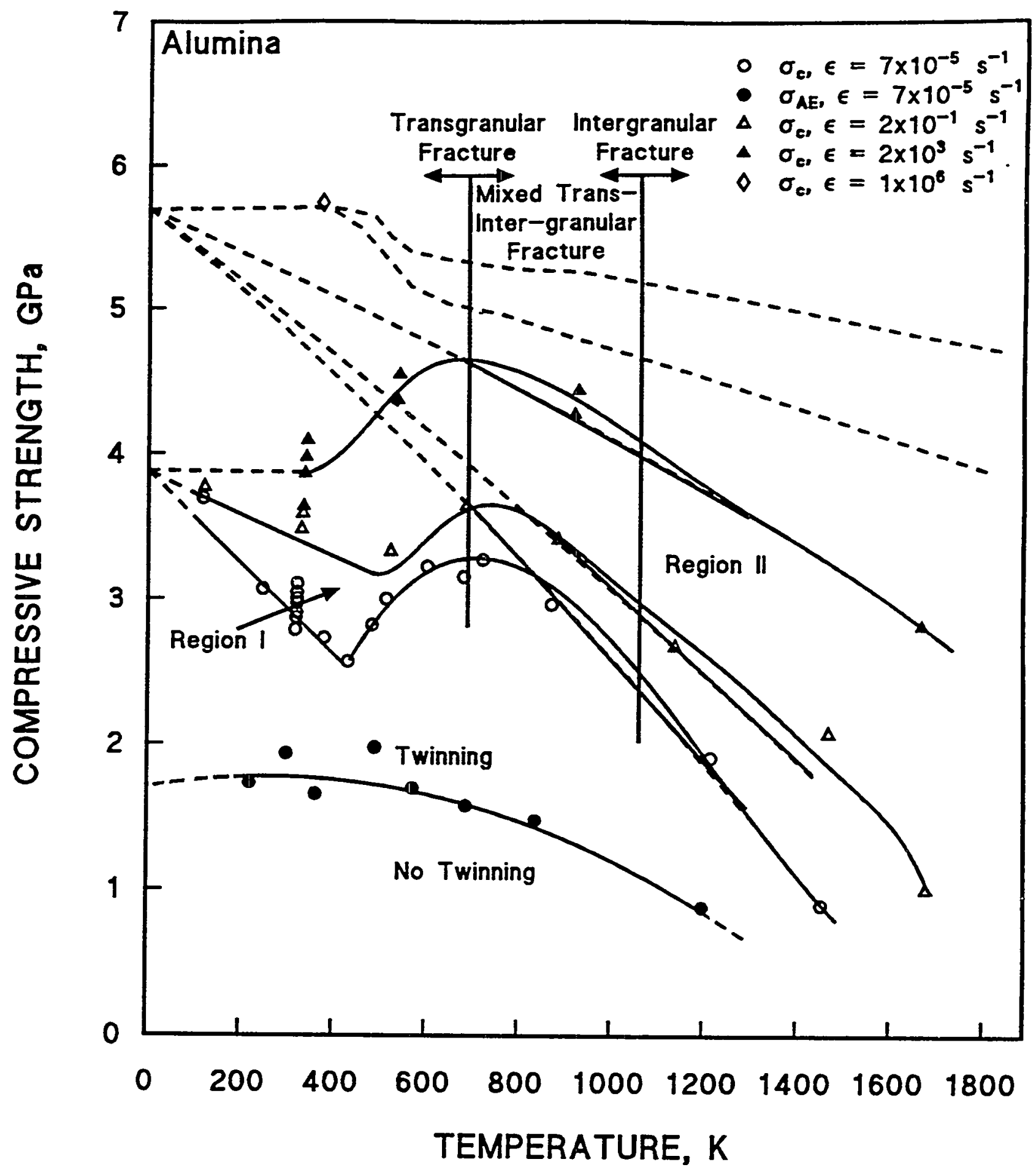

Figure 2.1.2. Compressive strength of polycrystalline $\mathrm{Al}_{2} \mathrm{O}_{3}$ vs. temperature from $77 \mathrm{~K}$ to $1800 \mathrm{~K}$. Data from Lankford [1981b]. 
(AE) techniques. The lower curve in Figure 2.1.2 indicates the much lower stress at which microcracking initiates $\left(\sigma_{\mathrm{AE}}\right)$ and is in agreement with the statements of $\$ 1.1 .4$ that this phenomenon begins at a stress about half of the macroscopic failure strength. As noted there also, electrical breakdown strength may start to degrade at this stress.

The low temperature stress for twinning is also indicated in Figure 2.1.2. Twinning was determined by SEM observation, and was found to be essentially athermal. The fracture mode is also indicated in the figure, and was also determined by SEM. At $77 \mathrm{~K}$, the fracture surface is principally transgranular, with only occasional intergranular features, while at $743 \mathrm{~K}$, somewhat more intergranular fracture is present, and at much higher temperatures, e.g., $1560 \mathrm{~K}$, fracture is almost entirely intergranular. Lankford [1981b; citations therein] noted that bending (tensile) tests carried out over about the same temperature range yielded nearly identical fractographic observations, the principal difference being that compressive failure involved multiple cracks, whereas tensile fracture occurred though the action of a single dominant crack. Twinning, which occurs at least down to $77 \mathrm{~K}$, is evidence for microplasticity in the cryogenic temperature range. The twins nucleate microcracks. Lankford asserted that the process of microcracking itself also represented a form of plasticity. The predominant microcrack orientation observed, regardless of temperature or strain rate, was nearly axial; that is, the plane of the crack tended to include the axis of compression. For materials like Mgo, that can deform plastically at relatively low temperatures (\$4.1) and nucleate slip band cracks, a thermally activated crack nucleation mechanism may be superimposed upon that of subcritical crack growth.

\subsubsection{Shear/Compressive Strength}

At an angle of $15^{\circ}$ (see Figure $1.1 .9, \$ 1.1 .6$ ) at $76 \mathrm{~K}$, plasma-sprayed $\mathrm{Al}_{2} \mathrm{O}_{3}$ coatings exhibited a shear strength of $83.5 \pm 9.0 \mathrm{MPa}$ with an accompanying compressive stress of $22.4 \pm 2.4 \mathrm{MPa}$ [Fabian and Reed, 1994]. At $4 \mathrm{~K}$, the shear strength at $15^{\circ}$ was $85.9 \pm 7.8 \mathrm{MPa}$, with an accompanying compressive stress of $23.0 \pm 2.1 \mathrm{MPa}$. This indicated that there was no temperature effect, between 76 and $4 \mathrm{~K}$, within the standard deviation. Three tests were 


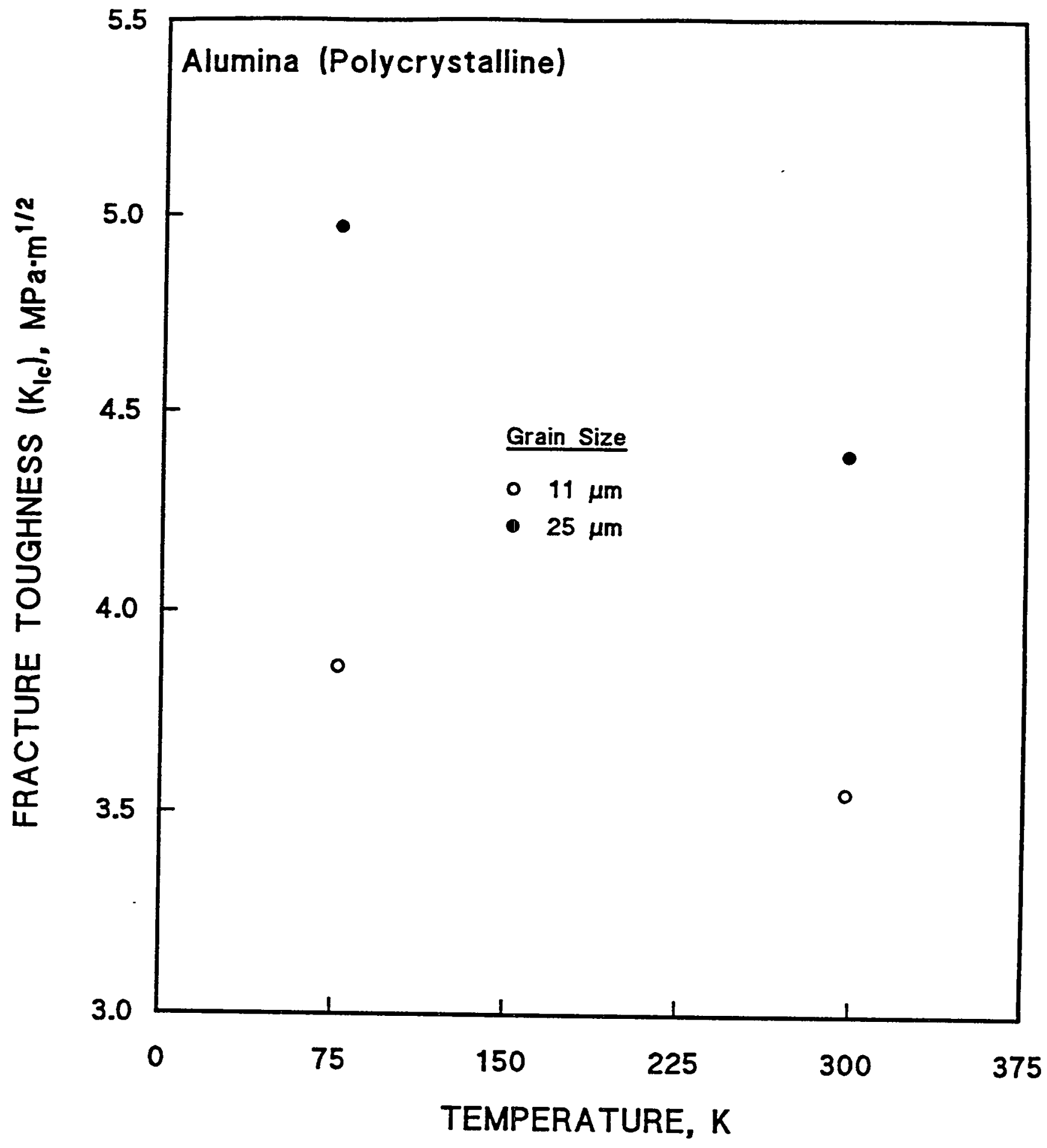

Figure 2.1.3. Fracture toughness of polycrystalline $\mathrm{Al}_{2} \mathrm{O}_{3}$ at 77 and $298 \mathrm{~K}$ determined by the double cantilever beam technique. Data from Gupta and Andersson [1984]. 
done at each temperature on hybrid insulation, sandwich-type specimens with a fiberglass reinforced, DGEBA epoxy. Tests at an angle of $45^{\circ}$ (equal compressive and shear stresses) at $76 \mathrm{~K}$ resulted in failure within the fiberglassepoxy layer at a shear or compressive stress of $174 . \pm 7 \mathrm{MPa}$. Results at $4 \mathrm{~K}$ were similar: the failure stress was $172 \pm 8.7 \mathrm{MPa}$. Thus, the $45^{\circ}$ shear/ compressive strength of the $\mathrm{Al}_{2} \mathrm{O}_{3}$ coating is greater than about $173 \mathrm{MPa}$, but the failure envelope for the coating itself cannot be obtained, owing to the specimen type used.

\subsubsection{Fracture Toughness}

Increases in the 77-K fracture toughness of polycrystalline $\mathrm{Al}_{2} \mathrm{O}_{3}$ over that at $300 \mathrm{~K}$ were found by Gupta and Andersson [1984], but were attributed to the stress corrosion effect, rather than to an intrinsic temperature dependence, since the $300-\mathrm{K}$ measurements were evidently done in air. The increases of $13 \%$ for a grain size of $25 \mu \mathrm{m}$ and $9 \%$ for a grain size of $11 \mu \mathrm{m}$ are shown in Figure 2.1.3. The fracture toughness was determined by the double cantilever beam technique. Specimens measured $1.0 \times 15.0 \times 30.0 \mathrm{~mm}$ and had a natural crack at the end of a $16.0-\mathrm{mm}$ long groove machined from one edge parallel to the $30.0 \mathrm{~mm}$ length at the midpoint of the 15.0 -mm edge. The number of specimens on which each result was based was not reported.

The fracture toughness of plasma-sprayed coatings of $\mathrm{Al}_{2} \mathrm{O}_{3}$ was measured by Filmer et al. [1990] at ambient temperature only. (Measurements of the electrical breakdown strength were also made and are reviewed below, in \$2.3.) The results are shown in Figure 2.1.4. The coatings produced by the $\mathrm{Ar} / \mathrm{H}_{2}$ plasma gas usually had a higher fracture toughness than those produced with the $\mathrm{N}_{2} / \mathrm{H}_{2}$ plasma gas. No clear trend for the effect of particle size or coating thickness is seen. A scratch test method was used to evaluate the fracture toughness [citation, Filmer et al., 1990].

\subsection{ELASTIC MODULUS}

Although the Young's modulus of polycrystalline $\mathrm{Al}_{2} \mathrm{O}_{3}$ increases rapidly as the temperature decreases to $300 \mathrm{~K}$ [Wachtman and Lam, 1959], the temperature dependence of the modulus at lower temperatures was not found in the 


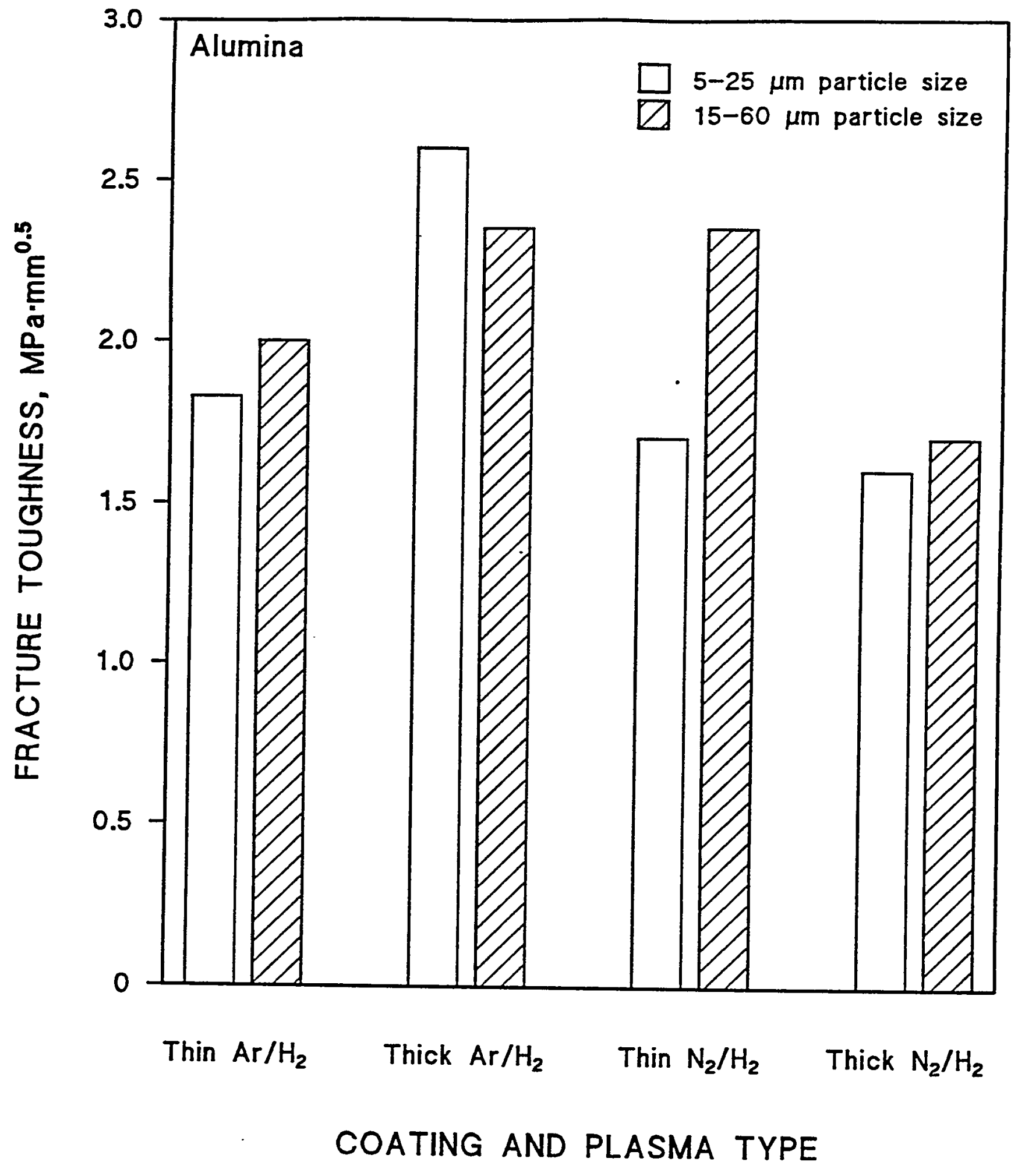

Figure 2.1.4. The ambient-temperature fracture toughness of plasma-sprayed $\mathrm{Al}_{2} \mathrm{O}_{3}$ coatings as a function of plasma gas, powder size range, and thickness. Thick coatings were about 500 to $600 \mu \mathrm{m}$; thin coatings were 200 to $260 \mu \mathrm{m}$. Data from Filmer et al. [1990]. 
literature search. Figure 2.2.1 shows this rapid increase of Young's modulus for several materials covered in this survey and the relative magnitude of the moduli at ambient temperature. The sintered $\mathrm{Al}_{2} \mathrm{O}_{3}$ had a density of $3.71 \mathrm{~g} / \mathrm{cm}^{3}$, the $\mathrm{MgO}$ was pressed and fired to a density of $3.50 \mathrm{~g} / \mathrm{cm}^{3}$, the sintered $\mathrm{MgAl}_{2} \mathrm{O}_{4}$ had a density of $2.50 \mathrm{~g} / \mathrm{cm}^{3}$, and the sintered, $5 \% \mathrm{CaO}-$ stabilized $\mathrm{ZrO}_{2}$ had a density of $4.93 \mathrm{~g} / \mathrm{cm}^{3}$. The magnitude of the Young's modulus is about 3.8 times that of $\mathrm{MgAl}_{2} \mathrm{O}_{4}$, according to these data of Wachtman and Lam. However, Dienst et al. [1990] reported a higher Young's modulus for $\mathrm{Al}_{2} \mathrm{O}_{3}$ of $380 \mathrm{GPa}$ and a value of $270 \mathrm{GPa}$ for the modulus of $\mathrm{MgAl}_{2} \mathrm{O}_{4}$, considerably above the $0.81 \mathrm{GPa}$ reported by Wachtman and Lam and closer to common handbook values. Dynamic measurement techniques were used by both groups. The densities of the materials measured by Wachtman and Lam are considerably below the maximum values of about $3.95 \mathrm{~g} / \mathrm{cm}^{3}$ for $\mathrm{Al}_{2} \mathrm{O}_{3}$ and $3.58 \mathrm{~g} / \mathrm{cm}^{3}$ for $\mathrm{MgAl}_{2} \mathrm{O}_{4}$. However, their modulus values may give useful estimates for less dense materials, such as those obtained by plasma spraying. More typical values for high density, polycrystalline $\mathrm{Al}_{2} \mathrm{O}_{3}$ are about $400 \mathrm{GPa}$ for the Young's modulus and $160 \mathrm{GPa}$ for the shear modulus [Wachtman et al., 1960].

\subsection{ELECTRICAI PROPERTIES}

\subsubsection{Electrical Breakdown Strength}

Cryogenic data on the electrical breakdown strength of $\mathrm{Al}_{2} \mathrm{O}_{3}$ were not found in the literature search. However, the electrical breakdown strength at $76 \mathrm{~K}$ of 0.343-mm thick plasma-sprayed coatings on stainless steel disks was recently measured [Fabian and Reed, 1994]. A value of $48.2 \pm 4.9 \mathrm{kV} / \mathrm{mm}$ was found.

Figure 2.3.1. shows a summary of thick $\mathrm{Al}_{2} \mathrm{O}_{3}$ single-crystal, film, and polycrystalline (ceramic) breakdown strengths at ambient temperatures obtained by various investigators [citations, Yoshimura and Bowen, 1981]. Test frequencies were dc or 50 or $60 \mathrm{~Hz}$. The dependence of electrical breakdown strength of $\mathrm{Al}_{2} \mathrm{O}_{3}$ on thickness and density (or porosity) was shown above, in Figures 1.3.3 and 1.3.4. Additional thick specimen data at $50 \mathrm{~Hz}$ from Owate and Freer [1988] are available. The usual exponential dependence on thickness was found, in which the breakdown strength of plano-concave specimens decreased 


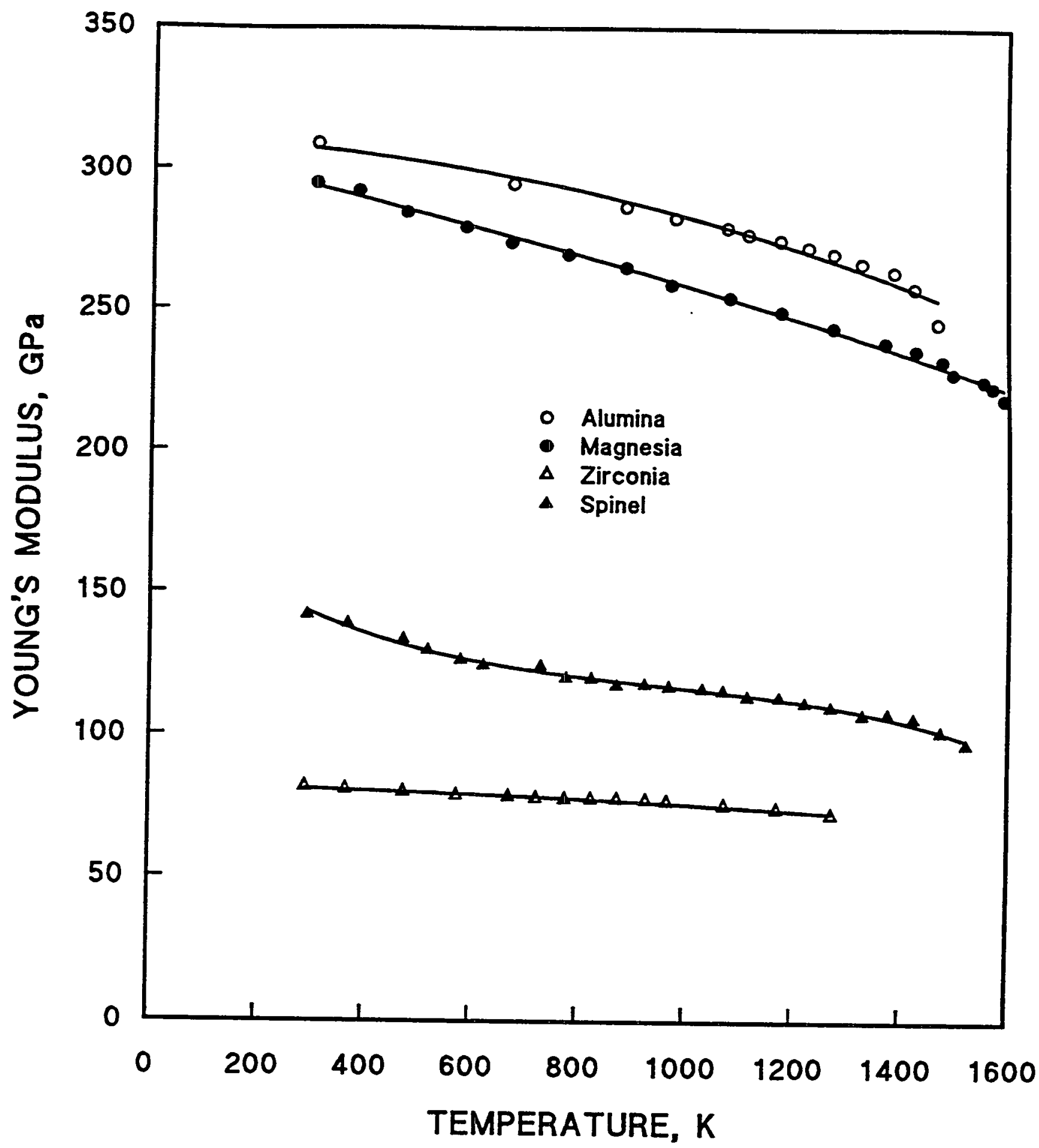

Figure 2.2.1. Young's modulus of polycrystalline $\mathrm{Al}_{2} \mathrm{O}_{3}, \mathrm{MgO}, \mathrm{MgAl}_{2} \mathrm{O}_{4}$, and $\mathrm{CaO}$ stabilized ZrO from ambient temperature to $1000^{\circ} \mathrm{C}$. Data from Wachtman and Lam [1959]. 


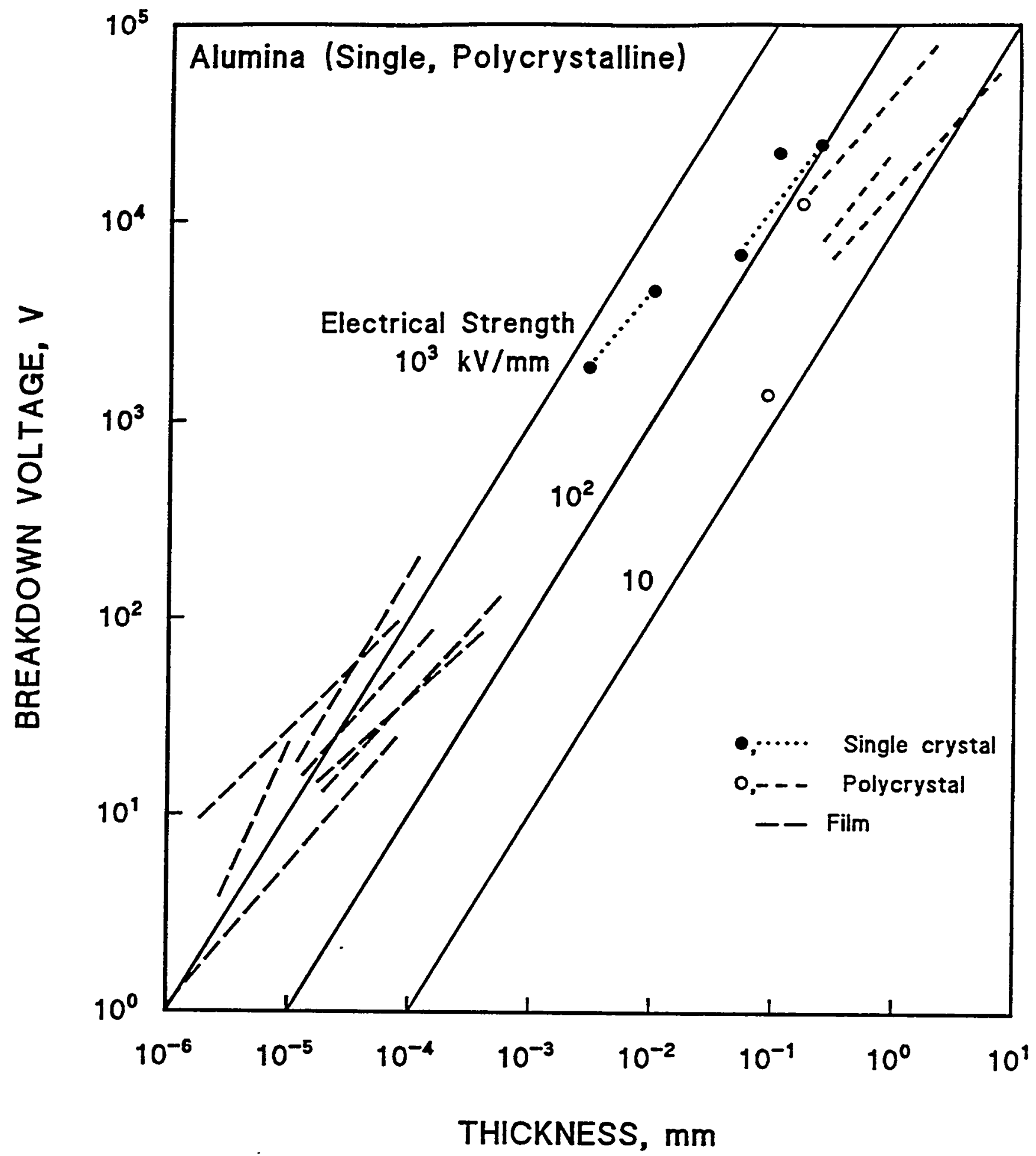

Figure 2.3.1. Summary of electrical breakdown voltages of single-crystal and polycrystalline $\mathrm{Al}_{2} \mathrm{O}_{3}$ vs. thickness at ambient temperature. Data from Yoshimura and Bowen [1981; citations therein]. 
from $-50 \mathrm{kV} / \mathrm{mm}$ at $-0.1 \mathrm{~mm}$ to $-25 \mathrm{kV} / \mathrm{mm}$ at $2 \mathrm{~mm}$. Breakdown strengths were lower for planar specimens. A continuous steady-state voltage rise of $2 \mathrm{kV} / \mathrm{s}$ was applied to the specimens under oil. Higher strengths were found for specimens of high density, low porosity, and good surface finish. A shortpulse breakdown strength of $>180 \mathrm{kV} / \mathrm{mm}$ was measured for a specimen of $\mathrm{Al}_{2} \mathrm{O}_{3}$ neutron-irradiated to $12 \mathrm{dpa}$ (displacements per atom) that contained 9-nm voids. Calculations indicated that $100-\mathrm{nm}$ or larger pores should be necessary to support an avalanche sufficiently energetic to produce such ionization events with a $10 \mathrm{kV} / \mathrm{mm}$ field [citations, Clinard and Hobbs, 1986].

Since $\mathrm{Al}_{2} \mathrm{O}_{3}$ may be used for ITER insulation in the form of a plasma-sprayed coating, ambient-temperature measurements of the breakdown strengths of such coatings are surveyed here. An interesting result noted by Pawlowski [1988] was that $\mathrm{X}$-ray analysis of plasma-sprayed $\mathrm{Al}_{2} \mathrm{O}_{3}$ coatings indicted that the major phase was $\gamma-\mathrm{Al}_{2} \mathrm{O}_{3}$, owing to rapid solidification of the liquid droplets during spraying. This indicates that conclusions about radiation damage from test of the $\alpha-\mathrm{Al}_{2} \mathrm{O}_{3}$ structure may not apply to plasma-sprayed coatings, and in fact, the apparently easier amorphization of plasma-sprayed material [Simon, 1994, \$7.3] may be related to the structural change or to the lack of structural homogeneity. Although Naguib and Kelly [1975] reported that $\gamma-\mathrm{Al}_{2} \mathrm{O}_{3}$ remained crystalline at higher ion irradiation fluences than those that caused amorphization of $\alpha-\mathrm{Al}_{2} \mathrm{O}_{3}$, the microstructure of the plasma-sprayed coating is apparently a mixture of $\gamma$ - and $\alpha-\mathrm{Al}_{2} \mathrm{O}_{3}$. Also, $\gamma-\mathrm{Al}_{2} \mathrm{O}_{3}$ is characterized by a network of pores having a diameter and a mutual distance of the order of $10 \mathrm{~nm}$ (100 A) [Singh et al., 1981], although, as discussed above, such a network of pores may not affect electrical breakdown strength significantly.

Pawlowski [1988] found that the breakdown strength of his coatings depended upon the porosity and varied from 9 to $18 \mathrm{kV} / \mathrm{mm}$. These values are considerably below the bulk values of $70 \mathrm{kV} / \mathrm{mm}$. Open porosity varied from 5.5 to 7.9\%. Coating thicknesses were 0.5 and $1 \mathrm{~mm}$. Apparently, the coatings were tested in an $\mathrm{Al}_{2} \mathrm{O}_{3}$ cell in air since corona discharge was mentioned as a problem. Dudko et al. [1982] found similar values of electrical breakdown strength, 6 to $12 \mathrm{kV} / \mathrm{mm}$, for plasma-sprayed coatings that were 0.1 - to 1.0-mm thick. Measurements were apparently made in air. In both the investigations 
of Pawlowski and of Dudko et al., dc voltage was applied to the ceramic surface by a spherical or hemispherical electrode.

Plasma-sprayed $\mathrm{Al}_{2} \mathrm{O}_{3}$ coatings about $0.35-\mathrm{mm}$ thick for the vacuum vessel of the NET (Next European Torus) reactor were found to have an electrical breakdown strength, in vacuum, of $11 \mathrm{kV} / \mathrm{mm}$ (ac) or $24 \mathrm{kV} / \mathrm{mm}$ (dc) at $20^{\circ} \mathrm{C}$ [European Community representatives, 1993]. Additions of Tio to the coatings were found to improve the breakdown strength and the performance under distributed compressive loads.

Thinner, sputtered $\mathrm{Al}_{2} \mathrm{O}_{3}$ films were measured by Bhatia et al. [1989]. For the largest thickness of $0.45 \mu \mathrm{m}$, the breakdown strength was $60 \mathrm{kV} / \mathrm{mm}$. Measurements (apparently in air) for a given sample were reported to be highly reproducible, perhaps owing to the $\mathrm{Hg}$ probe that reduced the effects of contact pressure. Mäntylä et al. [1985] also measured the electrical breakdown of sputtered $\mathrm{Al}_{2} \mathrm{O}_{3}$ coatings. These were thicker $(5 \mu \mathrm{m})$, but the breakdown strengths of 50 to $200 \mathrm{kV} / \mathrm{mm}$ ( in air) were somewhat higher.

\subsection{THERMAL PROPERTIES}

\subsubsection{Specific Heat}

Specific heat data on $\mathrm{Al}_{2} \mathrm{O}_{3}$ from several sources were obtained from the compilation by Touloukian and Buyco [1970]. These data are plotted in Figure 2.4.1, which also includes recommended values from a National Bureau of Standards publication [Ditmars and Douglas, 1971].

\subsubsection{Thermal Conductivity}

Thermal conductivity data on polycrystalline $\mathrm{Al}_{2} \mathrm{O}_{3}$ from several sources were obtained from the compilation by Touloukian et al. [1970]. The data are plotted in Figure 2.4.2, with other, more recent data on polycrystalline material. The specimens of Berman [1952] and of Alterovitz et. al. [1975] were sintered and the ceramic specimens of Nemoto et al. [1985] apparently had a purity of $99.6 \%$ (or, possibly 96\%). The data from a commercial specimen were from the manufacturer of Lucalox. The thermal conductivity of single crystal 


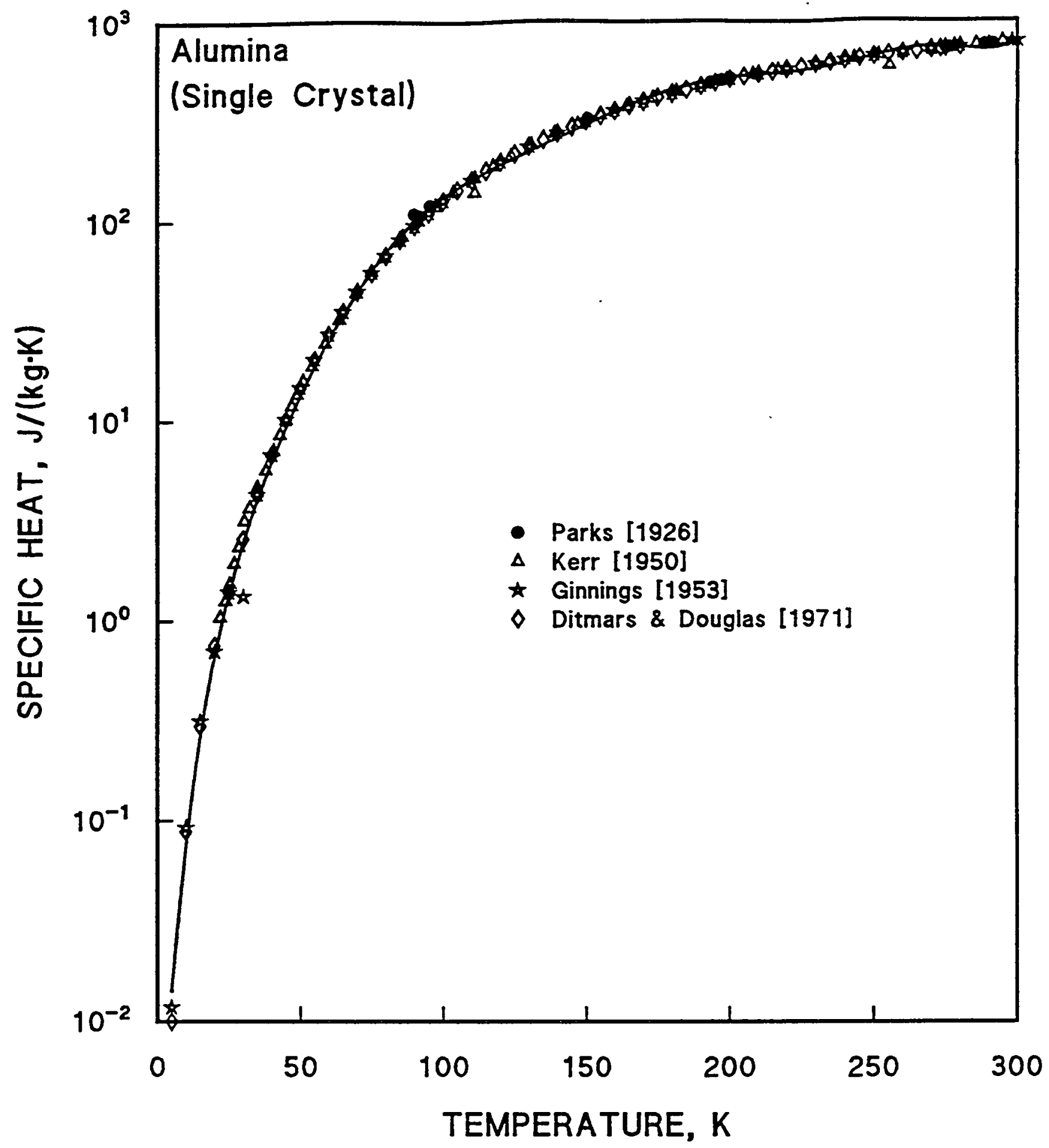

Figure 2.4.1. Specific heat of $\mathrm{Al}_{2} \mathrm{O}_{3}$ vs. temperature. Data from Touloukian and Buyco [1970; citations therein] and Ditmars and Douglas [1971]. 


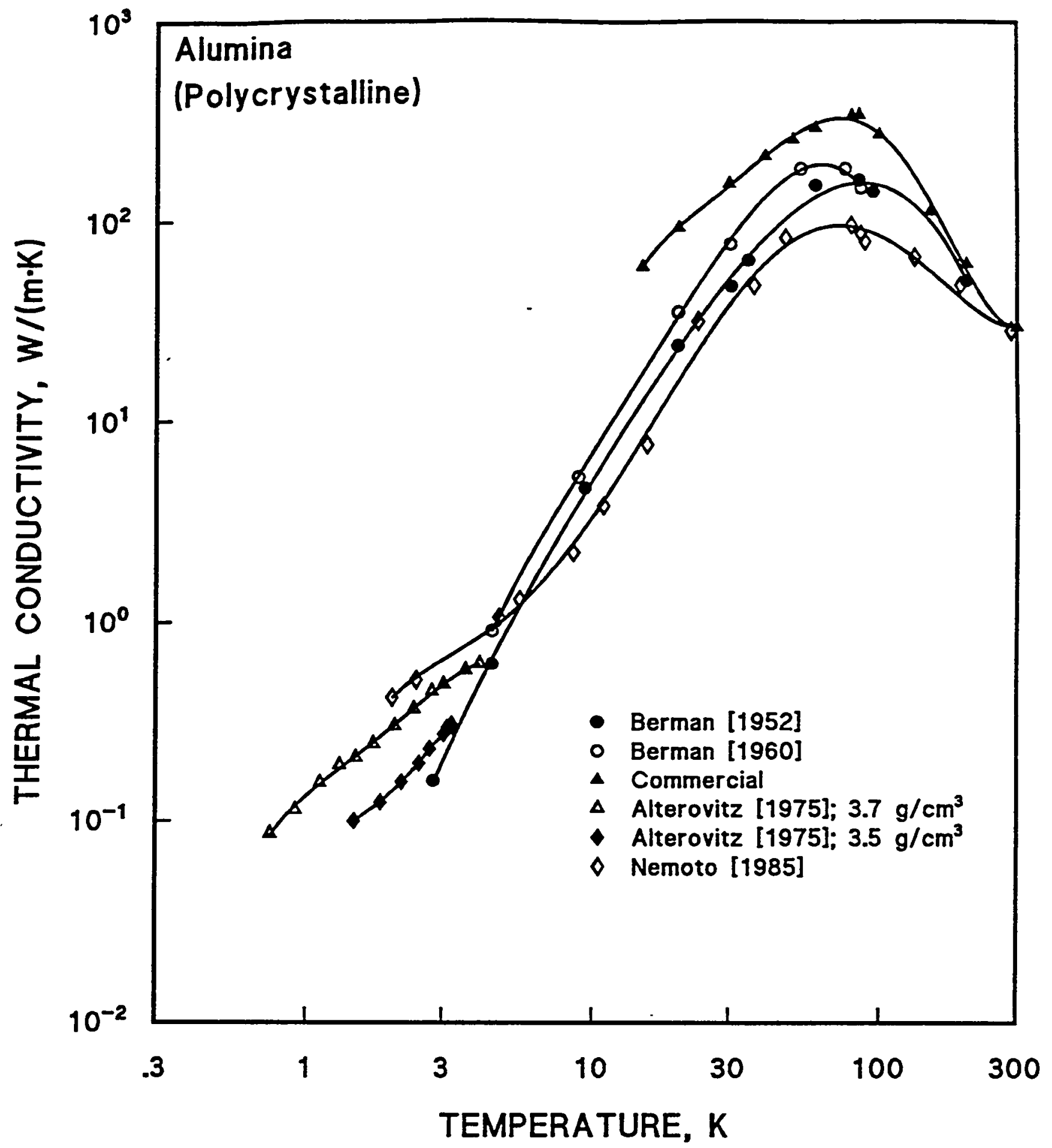

Figure 2.4.2. Thermal conductivity of polycrystalline $\mathrm{Al}_{2} \mathrm{O}_{3}$ vs. temperature. Data from Berman [1952], Berman et al. [1960], Alterovitz et al. [1975], Nemoto et al. [1985], and Touloukian et al. [1970; citations therein]. 


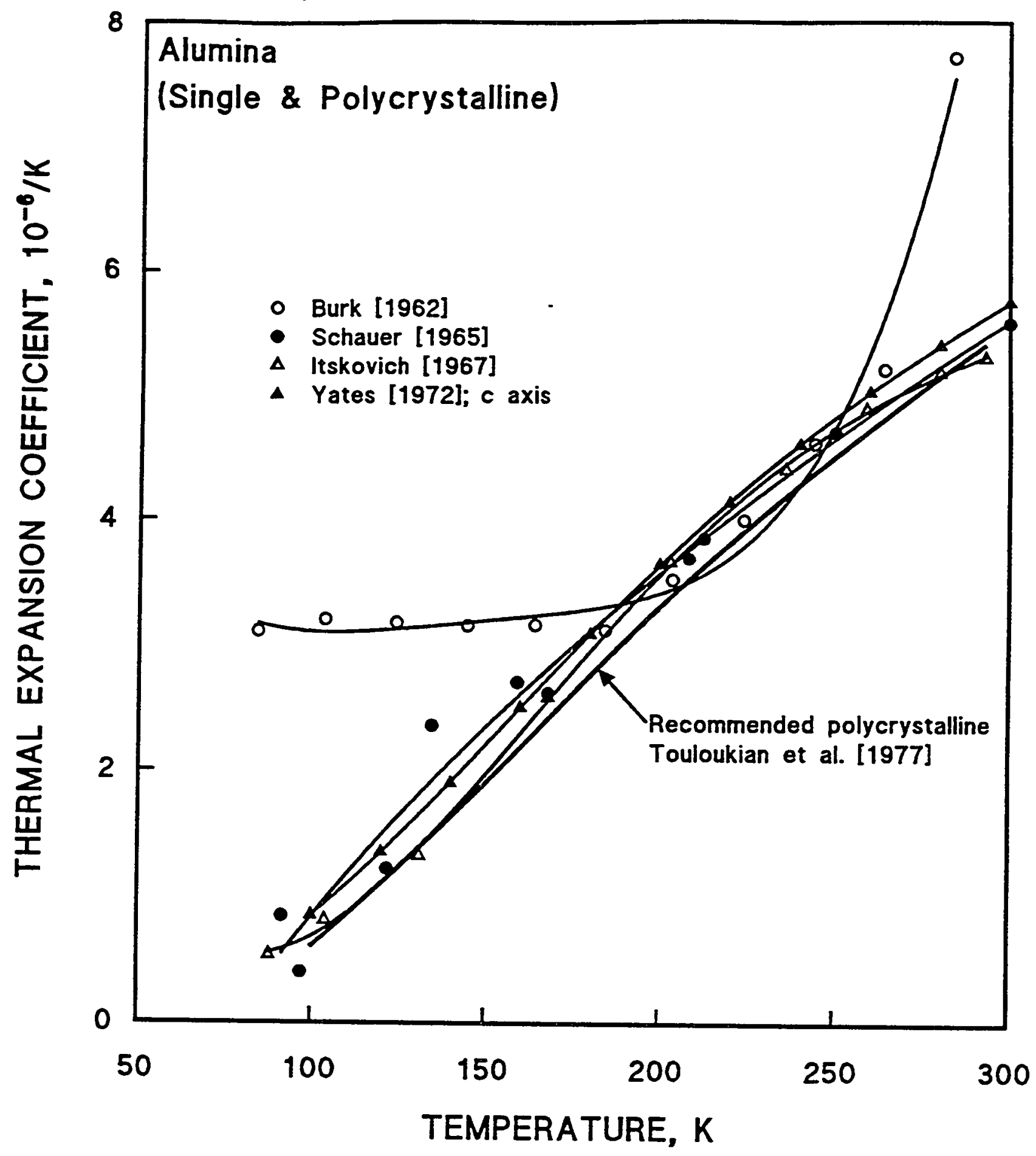

Figure 2.4.3. Thermal expansion coefficient of $\mathrm{Al}_{2} \mathrm{O}_{3}$ vs. temperature. Data from Burk [1962] and Touloukian et al. [1977; citations therein]. 
$\mathrm{Al}_{2} \mathrm{O}_{3}$ can be more than an order of magnitude higher below $100 \mathrm{~K}$, as indicated, for example, by Berman [1952]. (Data on the thermal conductivity of singlecrystal $\mathrm{B}-\mathrm{Al}_{2} \mathrm{O}_{3}$ below $300 \mathrm{~K}$ were obtained by Anthony and Anderson [1976].)

\subsubsection{Thermal Expansion}

Data on the thermal expansion coefficient of single-crystal and polycrystalIine $\mathrm{Al}_{2} \mathrm{O}_{3}$ are presented in Figure 2.4.3, together with a recommended curve for the expansion coefficient of polycrystalline material from Touloukian et al. [1977]. Data on the linear thermal expansion, $\Delta L / L_{293} \mathrm{~K}$, are given in Figure 2.4.4, again with a recommended curve from Touloukian et al. [1977] on polycrystalline material. Figure 2.4 .5 gives some indication of differences in the thermal expansion coefficients of less pure alumina ceramics from the expansion coefficient of $100 \% \mathrm{Al}_{2} \mathrm{O}_{3}$ [Burk, 1962]. However, as indicated in Figure 2.4.3, the data of Burk on pure $\mathrm{Al}_{2} \mathrm{O}_{3}$ differ considerably from those of other investigators. Data on single-crystal $\mathrm{Al}_{2} \mathrm{O}_{3}$ from Arp et al. [1962] are not included in these graphs because data from Wachtman et al. [1962] were presumed to be more accurate. White [1984] noted that the cryogenic thermal expansion data of polycrystalline ceramics, such as $\mathrm{Al}_{2} \mathrm{O}_{3}$, that were made from powders were more reproducible than those of some pure metals, such as $\mathrm{Ti}$, which easily developed a preferred texture. The polycrystalline expansion of $\mathrm{Al}_{2} \mathrm{O}_{3}$ can be calculated to within a few percent from single-crystal data, using $\alpha=\left(\alpha_{1}+2 \alpha_{1}\right) / 3$, where $\alpha$ is the thermal expansion coefficient. 


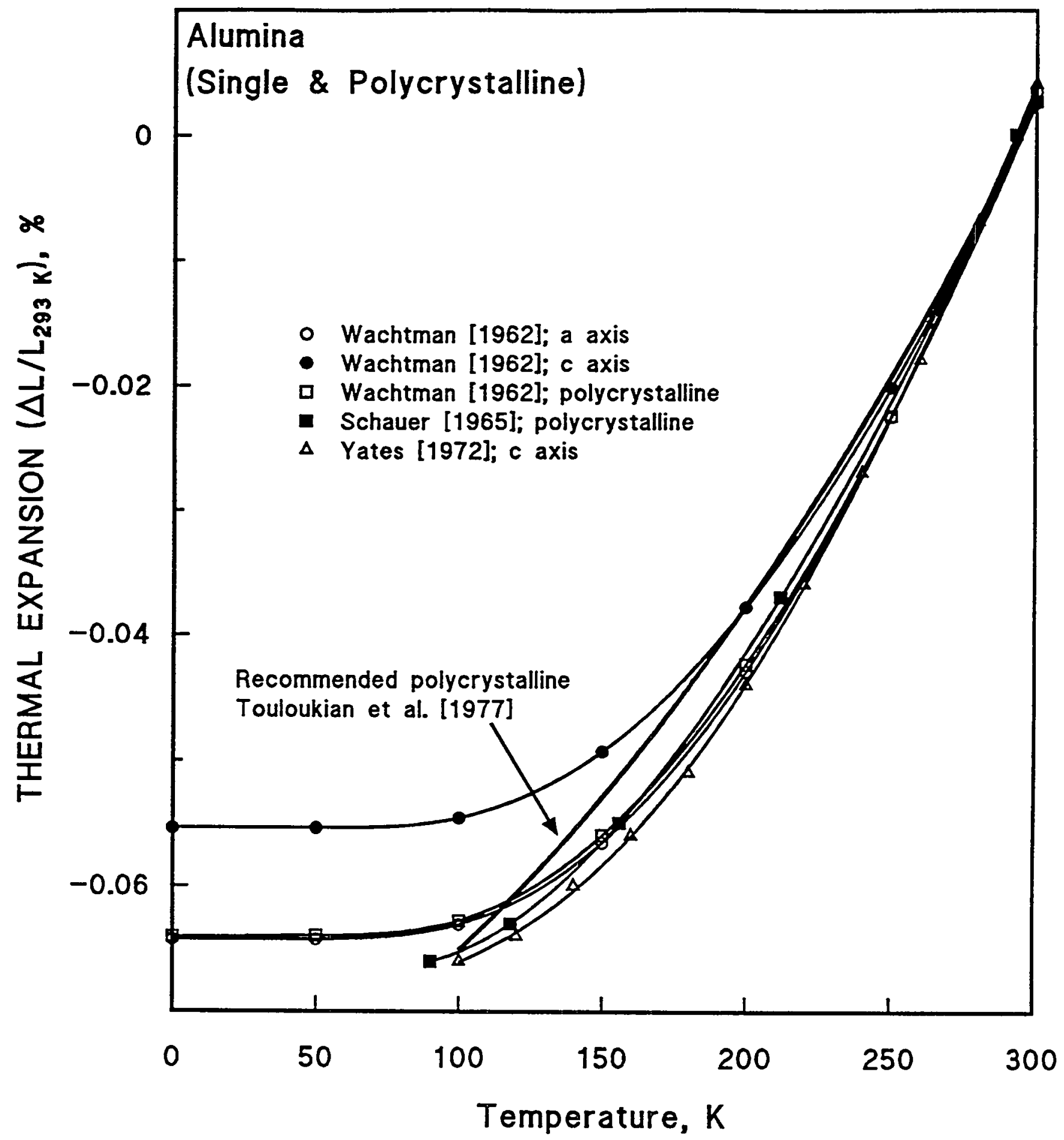

Figure 2.4.4. Linear expansion of $\mathrm{Al}_{2} \mathrm{O}_{3}$ vs. temperature. Data from Wachtman et al. [1962] and Touloukian et al. [1977; citations therein]. 


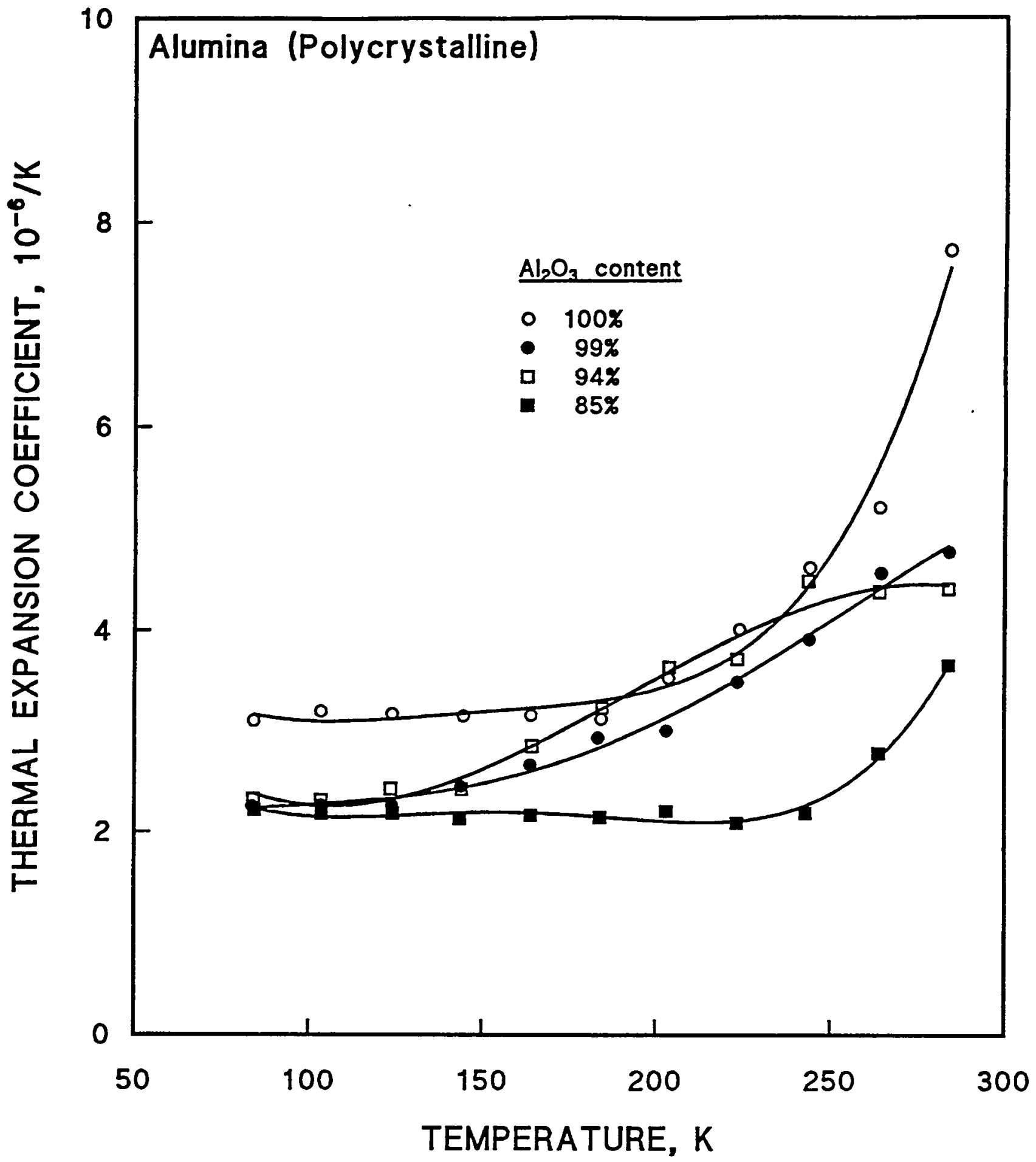

Figure 2.4.5. Comparison of thermal expansion coefficients of several alumina ceramics. Data from Burk [1962]. 


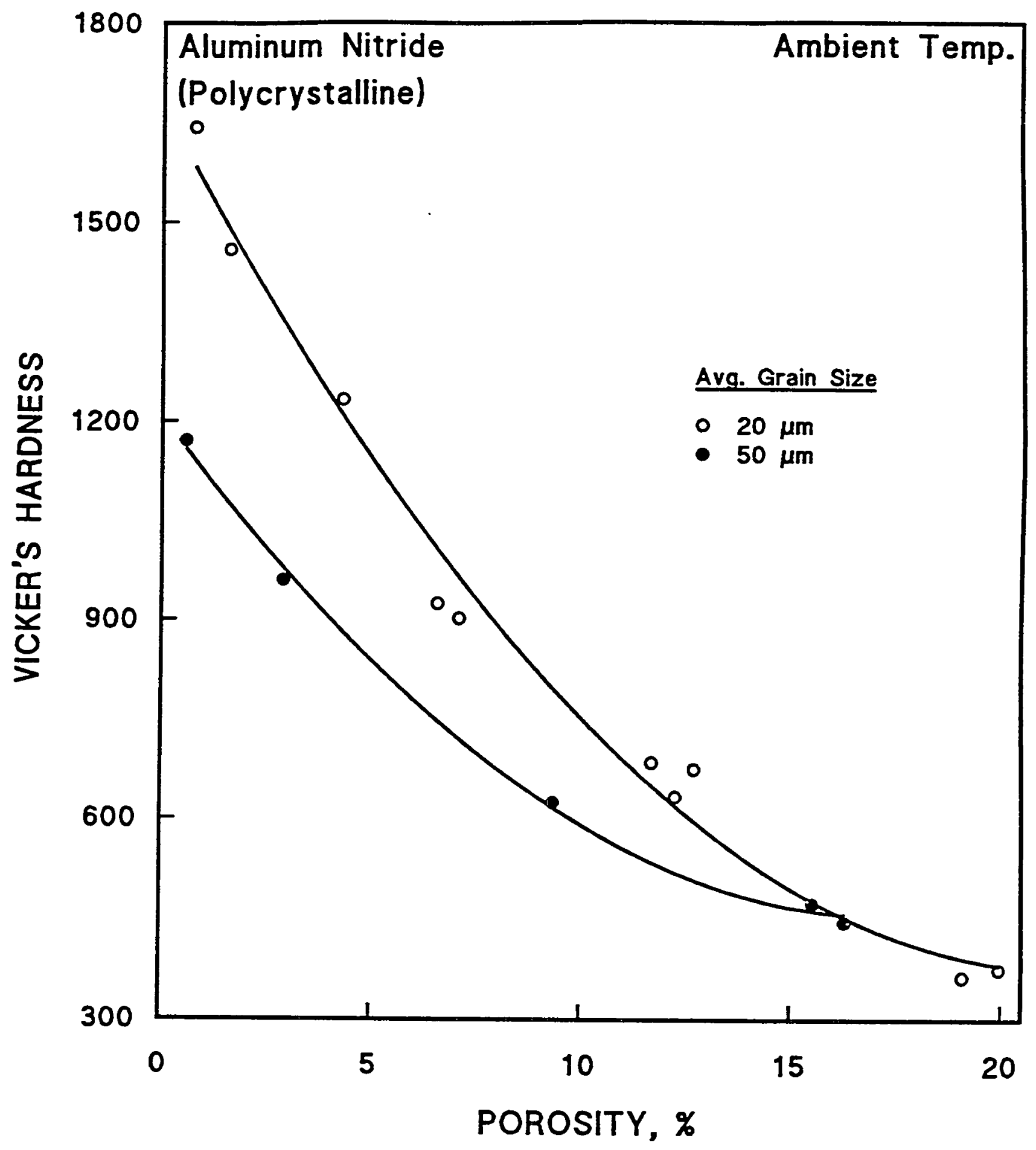

Figure 3.1.1. Vickers hardness of polycrystalline AlN vs, porosity. Data from Boch et al. [1982]. 


\section{AIUMINUM NITRIDE}

\subsection{MECHANICAL PROPERTIES}

Cryogenic measurements of mechanical properties of AlN were not found in the literature search. An ambient-temperature value of $2.07 \mathrm{GPa}$ for the compressive strength was given by Rice [1971] in a comparative table. This value is intermediate between the values for $\mathrm{MgO}$ and $\mathrm{MgAl}_{2} \mathrm{O}_{4}$, and is close to values for quartz and $\mathrm{CaO}_{4}$-stabilized $\mathrm{ZrO}_{2}$ (see Table 12.4.2, Simon [1994]).

The dependence of hardness upon porosity is illustrated in Figure 3.1.1 for material prepared by hot pressing a fine powder $(<20 \mu \mathrm{m})$ [Boch et al., 1982]. A 10-N load was used on disk-shaped specimens that were $30 \mathrm{~mm}$ in diameter and 3-mm thick. To obtain the brightness needed for the test, specimens were polished and then coated by metallic paint or cathodic sputtering of Au, Pt, $\mathrm{Ag}$, or $\mathrm{Al}$. Each value shown is the mean of 100 measurements performed over the entire surface of the sample. The figure also shows that the hardness increases as the mean grain size decreases, as was found for the compressive strength of $\mathrm{Al}_{2} \mathrm{O}_{3}$ (e.g., Figure 1.1.1).

\subsection{ELASTIC PROPERTIES}

The cryogenic temperature dependence of the elastic constants of AIN was not found in the literature search. An ambient-temperature, handbook range for Young's modulus is 260 to $350 \mathrm{GPa}$ [Moore, 1991]. Comparative values of Young's modulus derived from ultrasonic measurements were reported by Dienst et al. [1990]. These values were: $\mathrm{AlN}(320 \mathrm{GPa}) ; \mathrm{Al}_{2} \mathrm{O}_{3}(380 \mathrm{GPa}) ; \mathrm{MgAl}_{2} \mathrm{O}_{4}$ $(270 \mathrm{GPa})$. The dependence of the Young's modulus, shear modulus, and Poisson's ratio upon porosity is given in Figure 3.2.1 [Boch et al., 1982]. Specimens were prepared by hot pressing a fine powder $(<20 \mu \mathrm{m})$ without additives. A resonance method was used.

Gerlich et al. [1986] reviewed previous measurements of the ambienttemperature Young's modulus of AlN. Values varied from 294 to $392 \mathrm{GPa}$. They obtained $308 \mathrm{GPa}$ with two dynamic techniques on specimens of density 


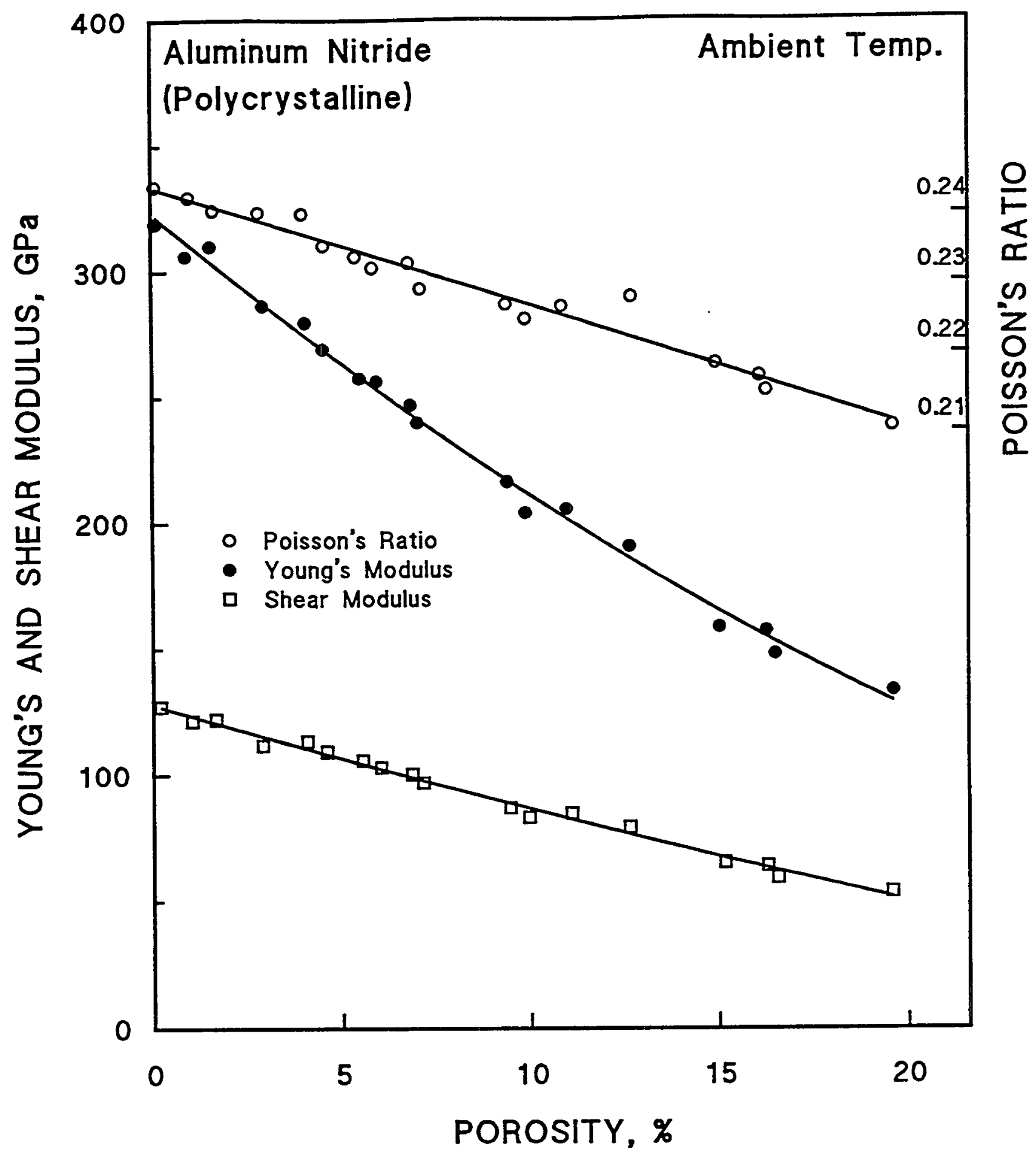

Figure 3.2.1. Elastic moduli and Poisson's ratio of polycrystalline AlN vs. porosity. Data from Boch et al. [1982]. 
$3.27 \mathrm{~g} / \mathrm{cm}^{3}$. The value of 0.179 that Gerlich et al. obtained for Poisson's ratio was lower than that of Boch et al., which was 0.245 [citation, Gerlich et al., 1986].

\subsection{ELECTRICAL PROPERTIES}

\subsubsection{Electrical Breakdown Strength}

Cryogenic data on the electrical breakdown strength of AlN were not found in the literature search. At ambient temperature, the most useful data found are those of Owate and Freer [1989], obtained on bulk ceramic AlN of $98 \%$ nominal purity, for a range of grain sizes and densities. (The major impurity was $-2 \%$ $\mathrm{Y}_{2} \mathrm{O}_{3}$ ) ) At a test frequency of $50 \mathrm{~Hz}$, the measured breakdown strengths ranged from 7 to $16 \mathrm{kV} / \mathrm{mm}$. Hemispherically ended electrodes were applied to planar disk specimens of $26-\mathrm{mm}$ diameter in a bath of transformer oil that had been cleaned, degassed, and dried. A continuous steady-state voltage rise of $2 \mathrm{k} / \mathrm{s}$ was applied to the specimens up to the breakdown point. At a thickness of about $1.6 \mathrm{~mm}$, the breakdown strength was about $11 \mathrm{kV} / \mathrm{mm}$; at $3.2 \mathrm{~mm}$, it was about $8 \mathrm{kV} / \mathrm{mm}$. The variation with thickness was linear on a $\log -\log$ plot. At the highest density of $3.87 \mathrm{~g} / \mathrm{cm}^{3}$ ( $14 \pm 3 \%$ porosity), the breakdown strength was about $17 \mathrm{kV} / \mathrm{mm}$; at the lowest density of $2.43 \mathrm{~g} / \mathrm{cm}^{3}$ ( $26 \pm 3 \%$ porosity) it was $7 \mathrm{kV} / \mathrm{mm}$. The variation with density was linear. Improvements in surface finish increased the breakdown strength, perhaps because the electrical field was distributed more uniformly, owing to improved contact between the specimen and the electrodes. Specimens with visible cracks and surface defects had lower breakdown strengths and were omitted from the analysis. In all cases, the breakdown process was associated with a single irregular puncture channel that terminated in a crater at the surface of the specimen.

Thin film data on AlN were obtained by Mangalaraj et al. [1982]. The specimens were formed by ion plating. At the highest film thickness of $200 \mathrm{~nm}$ $(2000 \AA)$, the dc breakdown strength was about $140 \mathrm{kV} / \mathrm{mm}$, in accord with cited studies on sputtered AlN films. 


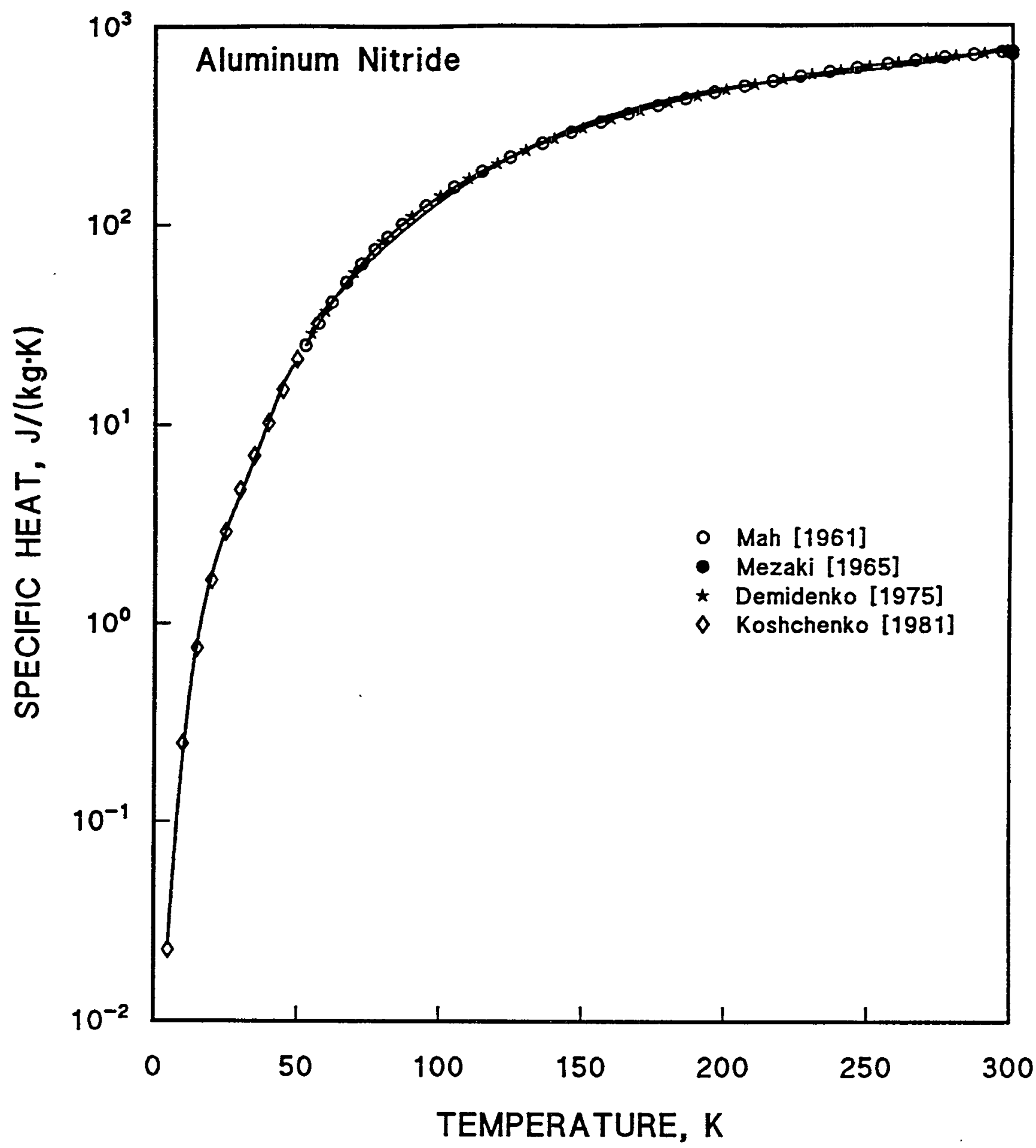

Figure 3.4.1. Specific heat of AIN from 53 to $300 \mathrm{~K}$. Data from Touloukian and Buyco [1970; citations therein], Demidenko et al. [1975], and Koschenko et al. [1981]. 


\subsection{THERMAL PROPERTIES}

\subsubsection{Specific Heat}

Data on the specific heat of AIN from 5 to $300 \mathrm{~K}$ are presented in Figure 3.4.1 [Touloukian and Buyco, 1970; Demidenko et al., 1975; Koschenko et al., 1981]. The data from different observers overlap only at $300 \mathrm{~K}$, where there is reasonable agreement, although the data extending down to $5 \mathrm{~K}$ were obtained on material of composition $98.2 \mathrm{AlN}, 1.08 \% \mathrm{Al}_{2} \mathrm{O}_{3}$, whereas the other data points at $300 \mathrm{~K}$ were from higher purity $\mathrm{AlN}$. A handbook value for the specific heat at $298 \mathrm{~K}$ is $800 \mathrm{~J} /(\mathrm{kg} \cdot \mathrm{K})$ [Moore, 1991].

\subsubsection{Thermal Conductivity}

Figure 3.4.2 presents thermal conductivity data on a high-purity, single crystal of AlN (heat flow along the $c$ axis) and also a calculation by the same authors of the expected cryogenic thermal conductivity of an AlN ceramic of $1-\mu \mathrm{m}$ grain size [Slack et al., 1987]. Figure 3.4 .3 gives additional thermal conductivity data on less pure crystals and data on ceramic specimens [Slack, 1973].

Since comparative cryogenic data from the same investigator are not available, the comparative thermal conductivity of $\mathrm{AlN}, \mathrm{Al}_{2} \mathrm{O}_{3}$, and $\mathrm{MgAl}_{2} \mathrm{O}_{4}$ above ambient temperature is presented in Figure 3.3.3 for two forms of AlN: hot isostatically pressed (HIP) and commercial, sintered materials [Dienst et al., 1990]. The lower conductivity of the $\mathrm{HIP}$ grade may be due to a $5 \% \mathrm{Al}_{2} \mathrm{O}_{3}$ content, but even so, the conductivity is substantially above the conductivities of $\mathrm{Al}_{2} \mathrm{O}_{3}$ and $\mathrm{MgAl}_{2} \mathrm{O}_{4}$. Aluminum nitride is known as a high thermal conductivity ceramic. The ambient-temperature conductivity of single crystal AlN is about $320 \mathrm{~W} /(\mathrm{m} \cdot \mathrm{K})$ [Slack, 1973], about $80 \%$ that of $\mathrm{Cu}$. However, it is difficult to process AIN ceramics and achieve this value, because impurities are often added to assist sintering. The dependence of the ambient thermal conductivity upon common additives was measured by Ichinose and Hazeyama [1990]. See also slack et al. [1987]. 


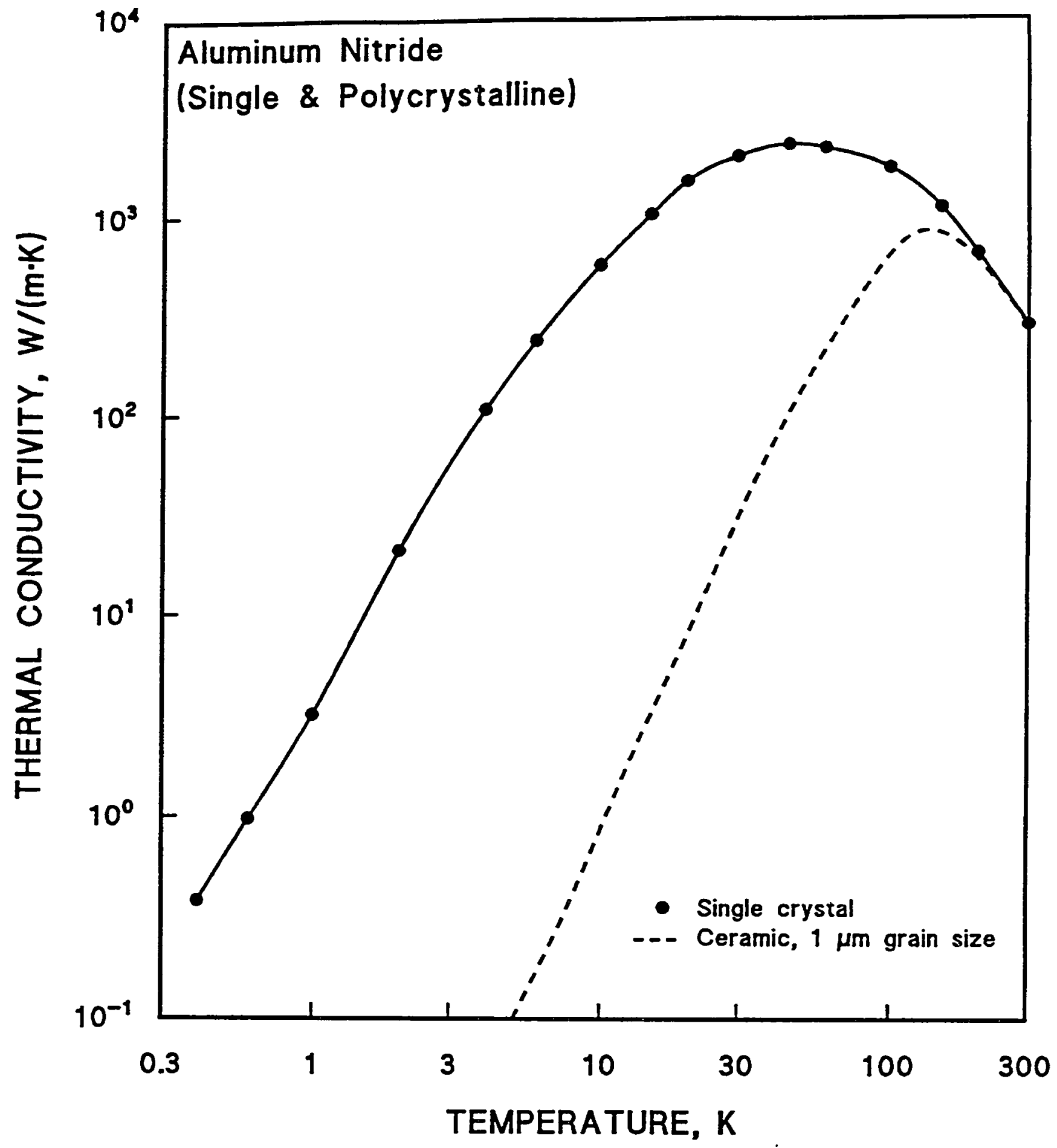

Figure 3.4.2. Thermal conductivity of high purity, single-crystal AlN vs. temperature and calculations for a ceramic with $1-\mu \mathrm{m}$ grain size. Data from slack et al. [1987]. 


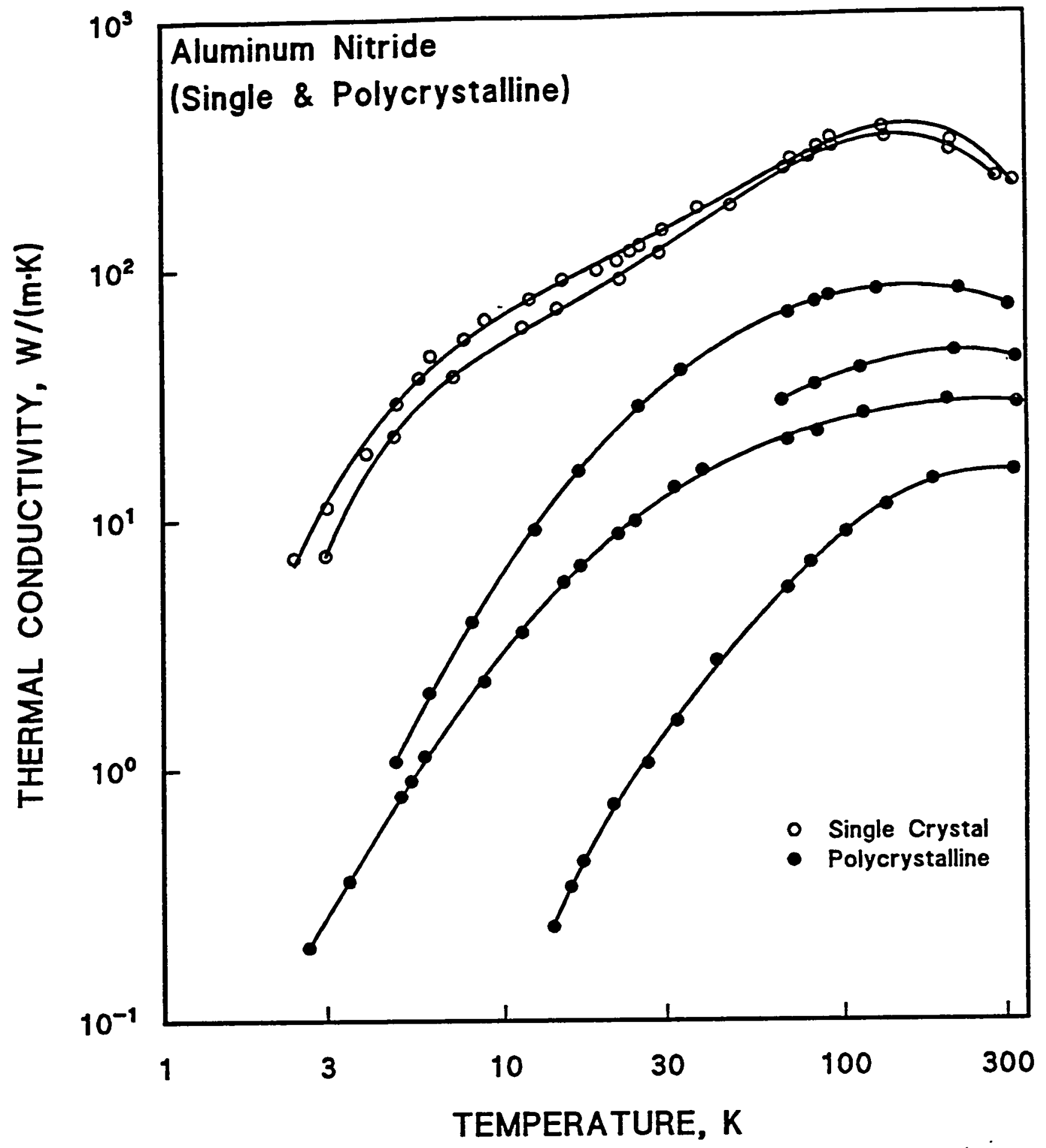

Figure 3.4.3. Thermal conductivity of both single-crystal and ceramic AlN. Data from Slack [1973]. 


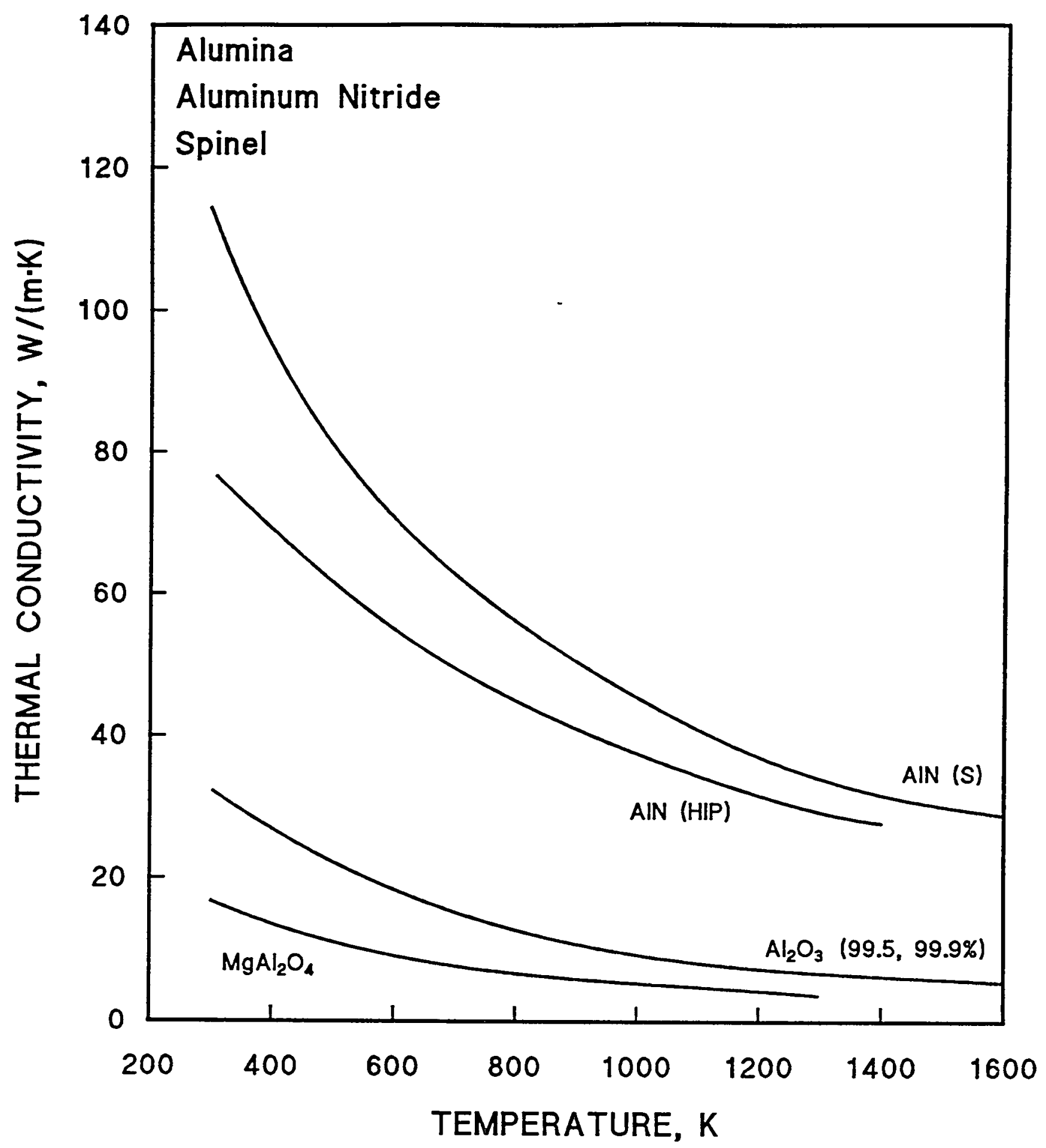

Figure 3.4.4. Comparative thermal conductivity above $300 \mathrm{~K}$ of $\mathrm{Al}_{2} \mathrm{O}_{3}$, $\mathrm{AlN}$, and $\mathrm{MgAl}_{2} \mathrm{O}_{4}$. Data from Dienst et al. [1990]. 


\subsubsection{Therma1 Expansion}

The comparative thermal expansion of three compounds in the same temperature range as that of the comparative thermal conductivity (Figure 3.4.4) is illustrated in Figure 3.4.5 from Dienst et al. [1990] (only the commercial, polycrystalline form of AlN is included). The thermal expansion of AlN at above-ambient temperature is about one half that of $\mathrm{Al}_{2} \mathrm{O}_{3}$ and $\mathrm{MgAl}_{2} \mathrm{O}_{4}$. A handbook range of the average thermal expansion of AlN from 25 to $1000^{\circ} \mathrm{C}$ was reported to be 4.4 to $5.7 \times 10^{-6} / \mathrm{K}$ [Moore, 1991].

Cryogenic thermal expansion data down to $77 \mathrm{~K}$ are presented in Figure 3.4.6, along with a recommended curve for polycrystalline AlN [Touloukian et al., 1977]. The recommended polycrystalline thermal expansion coefficients are: $2.5(293 \mathrm{~K}), 2.0(250 \mathrm{~K}), 1.9(200 \mathrm{~K}), 0.9(150 \mathrm{~K}), 0.5(100 \mathrm{~K})$, and 0.3 $\times 10^{-6} / \mathrm{K}(75 \mathrm{~K})$. The recommended percent polycrystalline thermal expansions are: $0(293 \mathrm{~K}),-0.010(250 \mathrm{~K}),-0.019(200 \mathrm{~K}),-0.026(150 \mathrm{~K}),-0.029$ $(100 \mathrm{~K})$, and $-0.030(75 \mathrm{~K})$. At $238 \mathrm{~K}$, Chanchani and Hall [1990] reported a thermal expansion coefficient of about $2.2 \times 10^{-6} / \mathrm{K}$ for commercially available, tape-cast, $99.5 \% \mathrm{AIN}$. This is fairly consistent with the data of Figure 3.4.6. 


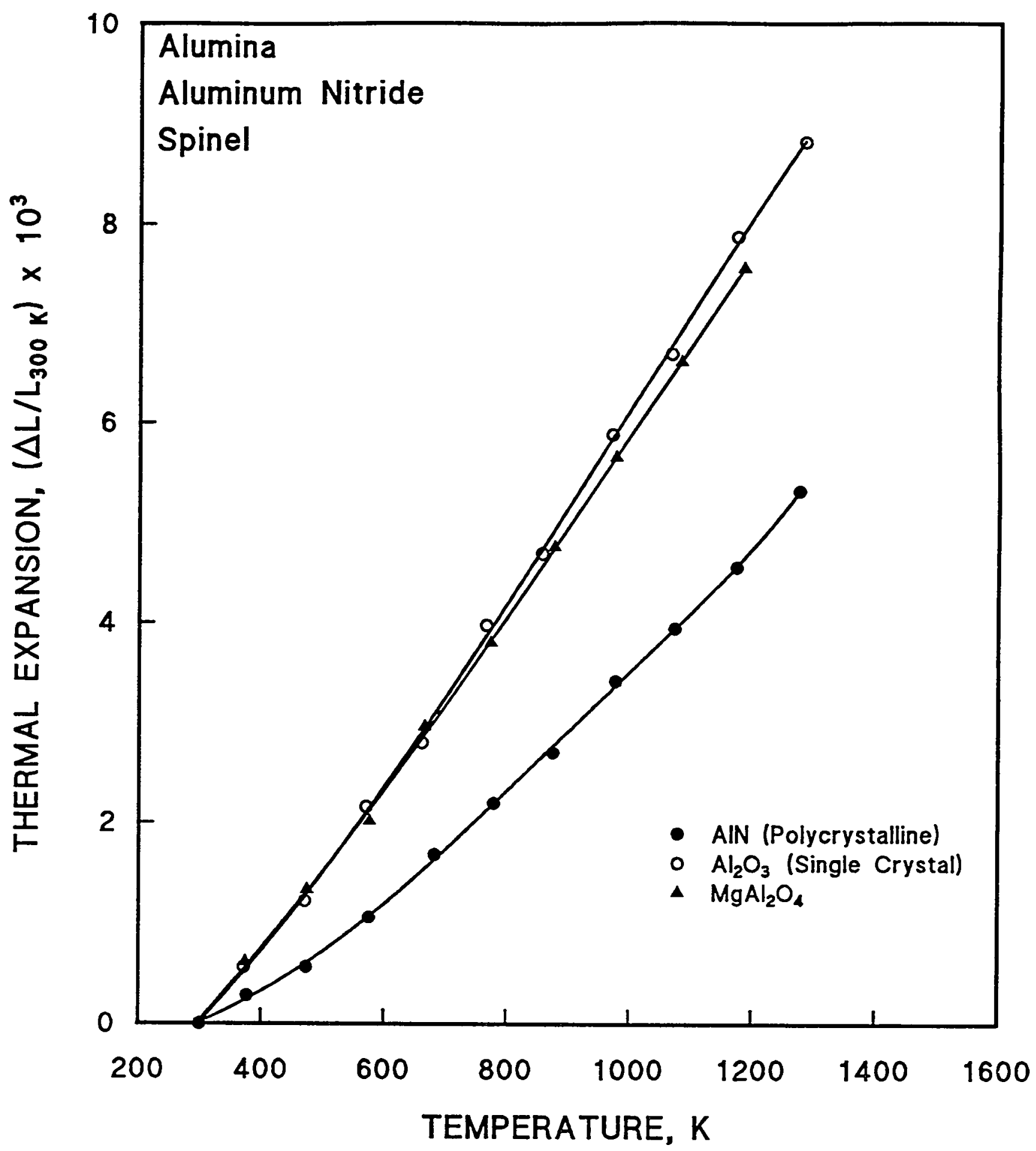

Figure 3.4.5. Comparative thermal expansion above $300 \mathrm{~K}$ of $\mathrm{Al}_{2} \mathrm{O}_{3}, \mathrm{AlN}$, and $\mathrm{MgAl}_{2} \mathrm{O}_{4}$. Data from Dienst et al. [1990]. 


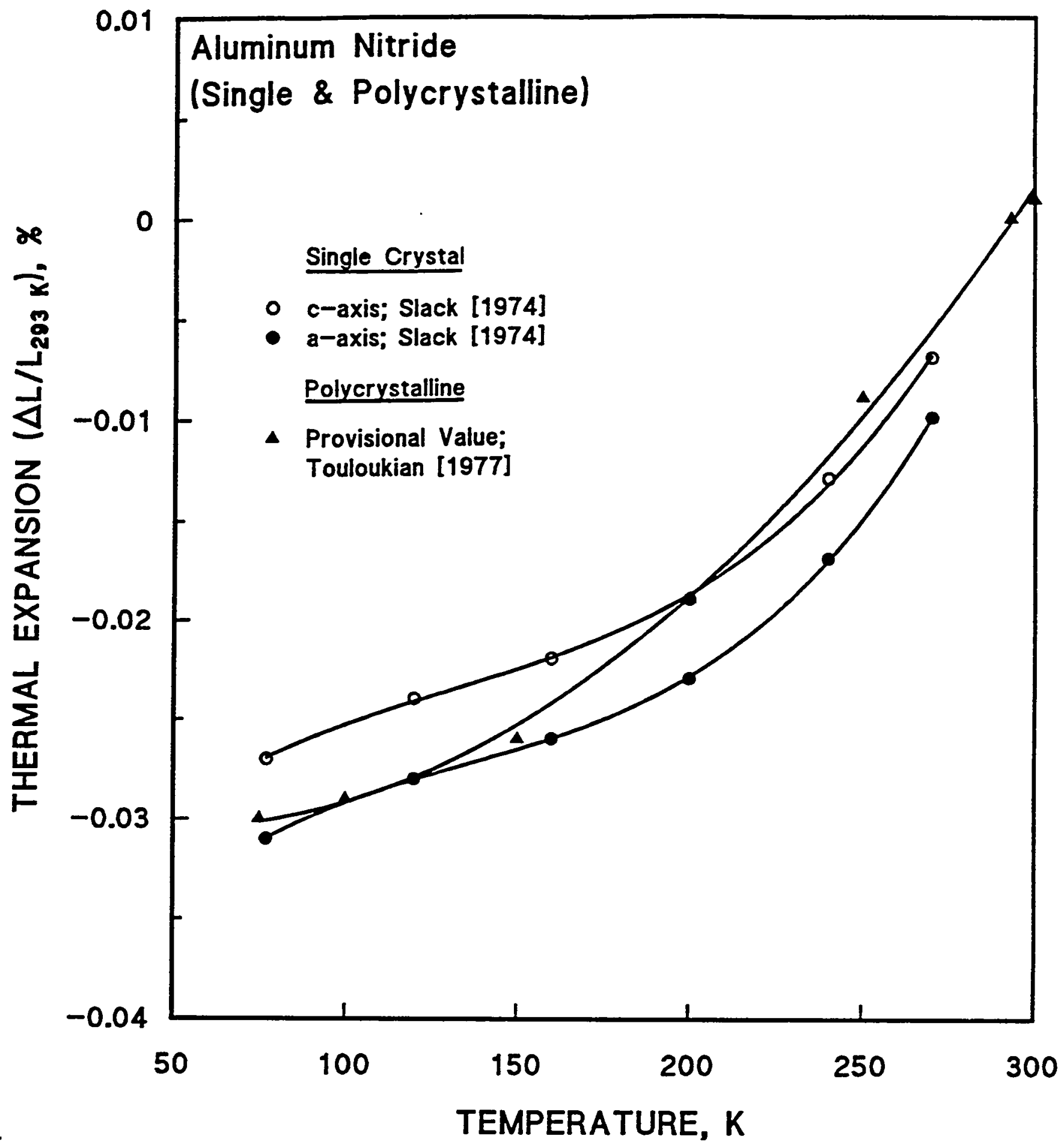

Figure 3.4.6. Thermal expansion vs. temperature of single-crystal A1N and recommended polycrystalline values. Data from Touloukian et al. [1977; citations therein]. 


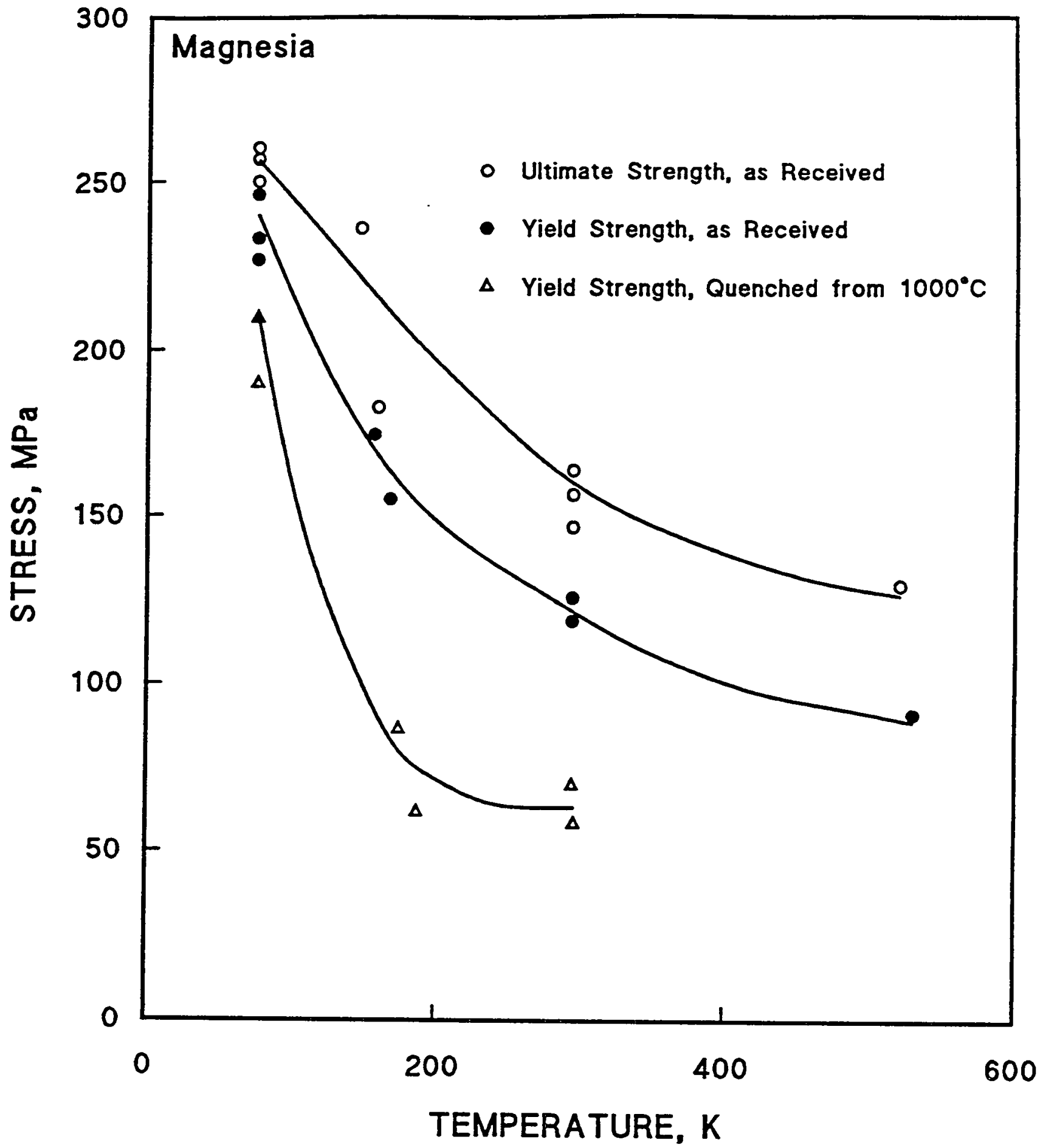

Figure 4.1.1. Single-crystal MgO compressive ultimate and yield strength vs. temperature. Data are fitted to curve that includes higher-temperature data (not shown). Data from Hulse and Pask [1960]. 


\section{MAGNESIA}

\subsection{MECHANICAL PROPERTIES}

The ductile behavior of $\mathrm{MgO}$ at ambient temperature has stimulated testing, and clear evidence was presented for a dislocation mechanism of crack nucleation in single-crystal Mgo. However, the mechanism of dynamic fracture in polycrystalline MgO has been controversial [citations, Rhodes et al., 1974], and fracture may be caused by the elastic propagation of existing flaws (Griffith criteria), or by mobile dislocations interacting with other defects. As noted in $\S 1$, microstructural features, such as the distribution of porosity (within grains or at grain boundaries), strength of grain boundaries related to impurity segregation, and possibilities for interpenetrating slip can have significant effects on the strength of polycrystalline MgO. Both Rhodes et al. [1974] and Langdon and Pask [1971] discussed the effects of microstructure and presented cryogenic measurements of single-crystal and polycrystalline Mgo properties.

\subsubsection{Effect of Temperature on Compressive and Tensile Strength}

Figure 4.1.1 shows the behavior with temperature of both the compressive yield and ultimate strength of single-crystal MgO tested along the [100] axis by Hulse and Pask [1960]. Crystals quenched from $1000^{\circ} \mathrm{C}$ had lowered yield strength. Some stress-strain curves at different temperatures of these crystals deformed along the [100] direction are shown in Figure 4.1.2. Rectangular blocks $(28 \times 8 \times 8 \mathrm{~mm})$ were cleaved along (100) faces and the compressive load was applied perpendicular to parallel loading faces polished free of cleavage steps. However, these results were obtained in air at the higher temperatures and in liquid $\mathrm{N}_{2}$ at $77 \mathrm{~K}$. Charles [1959] tested single crystals of $\mathrm{MgO}$ in compression in various environments and demonstrated that saturated water vapor could lower the strength significantly at $240^{\circ} \mathrm{C}(513 \mathrm{~K})$. When measurements at higher temperatures in dry $\mathrm{N}_{2}$ are compared with measurements in liquid $\mathrm{N}_{2}$, Figure 4.1 .3 indicates that the simple monotonic temperature dependence of Hulse and Pask may not always be observed, and high temperature tests in inert atmospheres may give strengths that are similar to those obtained in the inert cryogenic atmosphere. Specimens were cleaved 


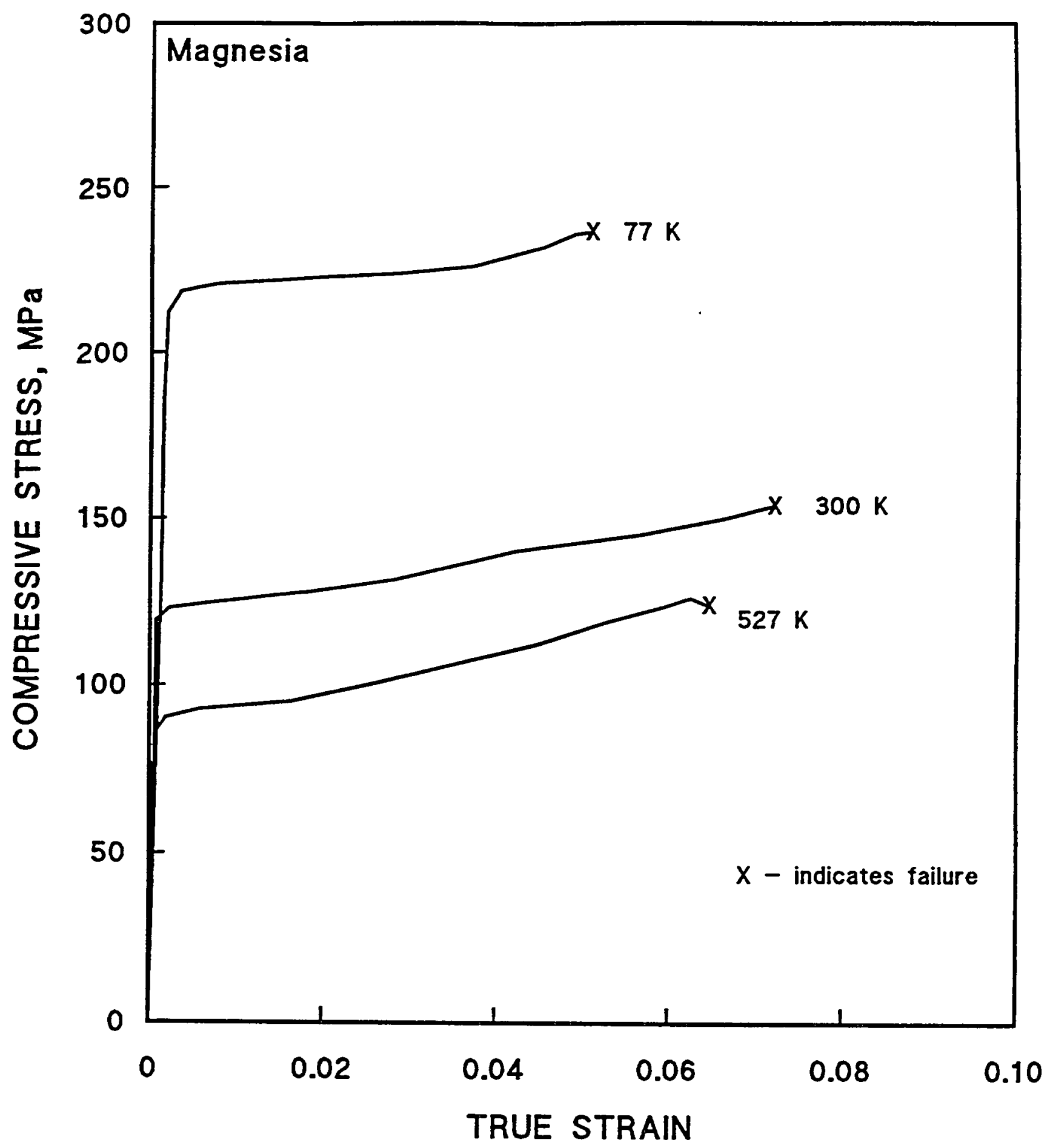

Figure 4.1.2. Stress-strain curves of Mgo single crystals under compressive deformation. The lack of smoothness in the curves is an artifact of the plotting program. Data from Hulse and Pask [1960]. 


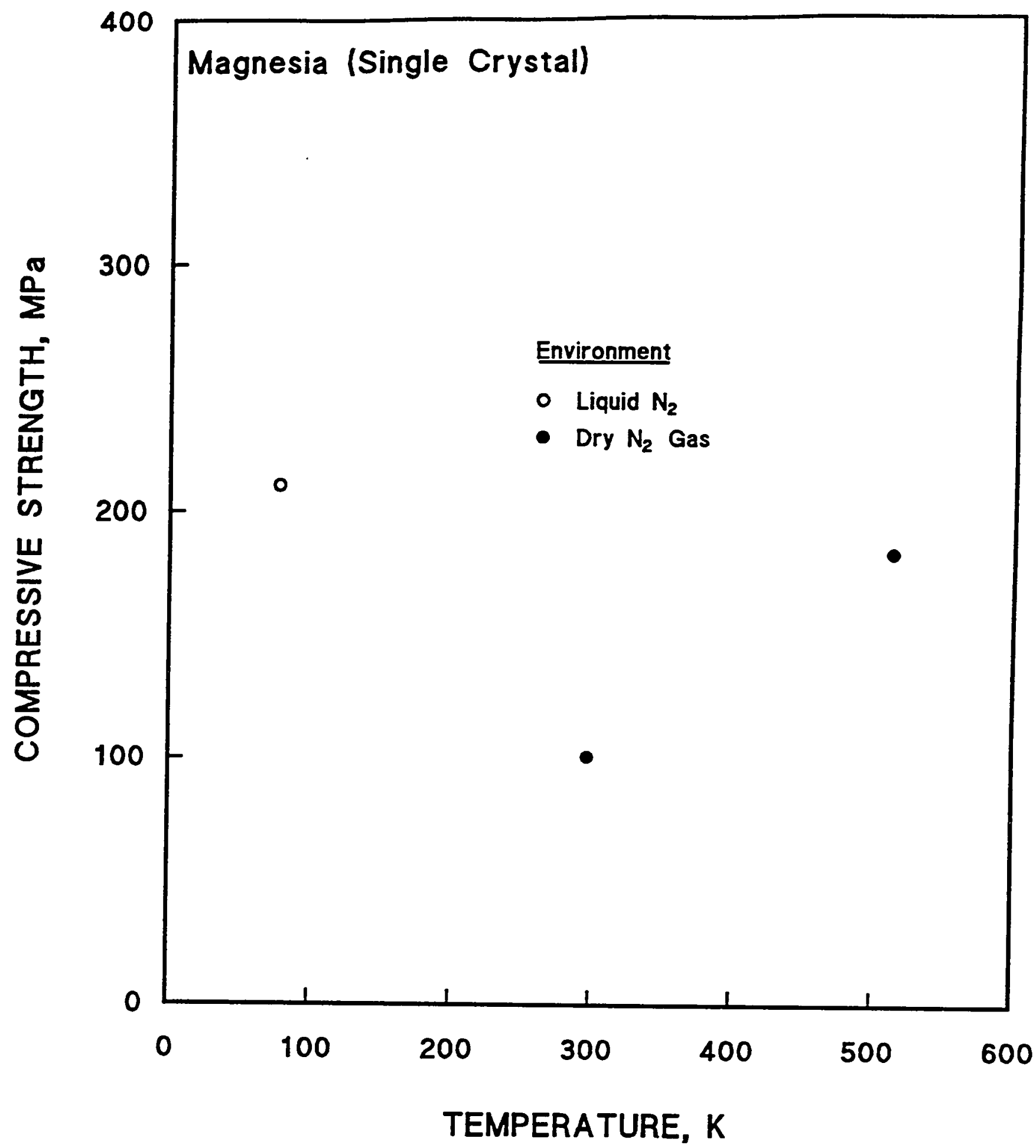

Figure 4.1.3. Compressive strength of single crystal MgO vs. temperature. Data from Charles [1959]. 


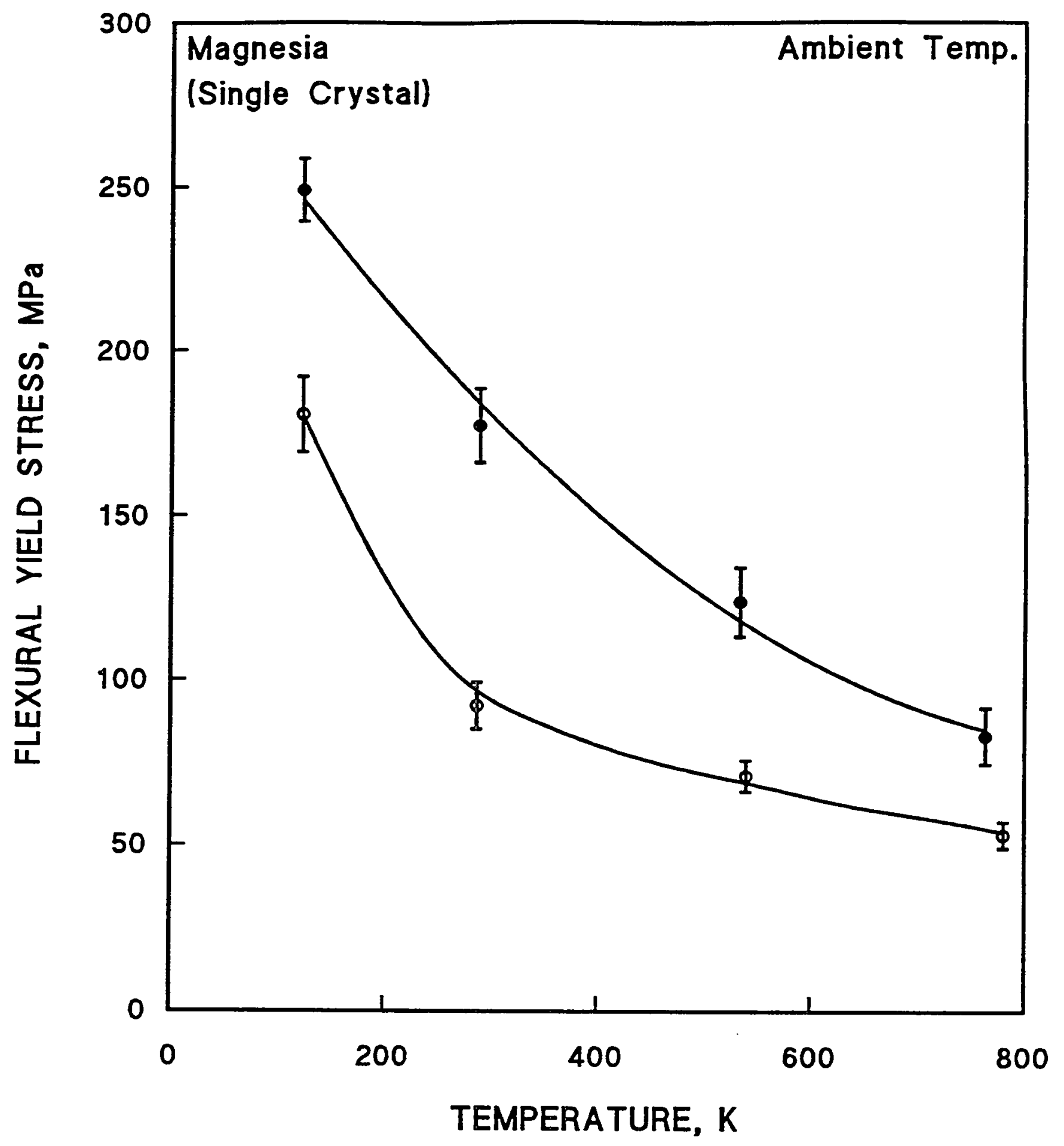

Figure 4.1.4. Yield strength from 4-point bending tests of single crystal MgO vs. temperature. Data from Thompson and Roberts [1960] on two specimens. 
cubes that were stressed parallel to the $\{100\}$ cleavage planes. Figures 6.1 .1 and 6.1 .2 on vitreous $\mathrm{SiO}_{2}$ and quartz, and other compression data of Charles indicate a similar effect of atmosphere, even though some atmospheric $\mathrm{H}_{2} \mathrm{O}$ vapor may have diffused into the specimens before testing in the inert atmospheres, which would tend to confound the results.

In four-point bending tests of single-crystal, cleaved MgO bars in unspecified atmospheres and in liquid $N_{2}$, Thompson and Roberts [1960] also reported a steep increase in the strength as the temperature deceased. This is illustrated for two specimens in Figure 4.1.4. Specimen size was $2.5 \times 0.25$ $\times 0.025 \mathrm{~cm}$. Noticeable differences were also observed on the ambienttemperature stress-strain curves of specimens cleaved from different crystals. However, Rhodes et al. [1974] also tested $\mathrm{MgO}$ in four-point bending tests in liquid $\mathrm{N}_{2}$ and at ambient temperature. The specimens tested at ambient temperature in air had a strength of $183 \mathrm{MPa}$; whereas, specimens tested in $\mathrm{Ar}$ at ambient temperature after a $900^{\circ} \mathrm{C}$ Ar anneal for $1 \mathrm{~h}$ had a strength of 210 $\pm 9.6 \mathrm{MPa}$, essentially equivalent to the $77-\mathrm{K}$ result of $209 \mathrm{MPa}$. Machined and ground specimens were vacuum-hot pressed and annealed, $100 \%$ of theoretical density, $99.6 \%$ pure, and had a grain size of $30 \mu \mathrm{m}$. Although these tests were carried out on polycrystalline, rather than single-crystal MgO specimens, the results are similar to those of Charles and indicate that the confounding factor of stress corrosion effects must be eliminated before the intrinsic temperature effect can be accurately assessed. In practical terms, if it is desired to extrapolate the results of ambient-temperature tests in air to cryogenic temperatures, it will probably be correct to assume that the cryogenic strengths are higher, but it is risky to estimate the amount from the available data, since stress corrosion and other confounding factors are dependent upon surface preparation.

As noted above, strengths of polycrystalline specimens are very dependent upon purity and microstructural factors. Other MgO specimens of slightly lower purity and density with different grain sizes had ambient-temperature strengths in the four-point bending test that were as much as. $30 \%$ lower, even in the Ar-controlled testing conditions. Figure 4.1.5 from Langdon and Pask [1971] shows that high temperature compressive strengths of polycrystalline MgO often fell between the results of single-crystal tests along different 


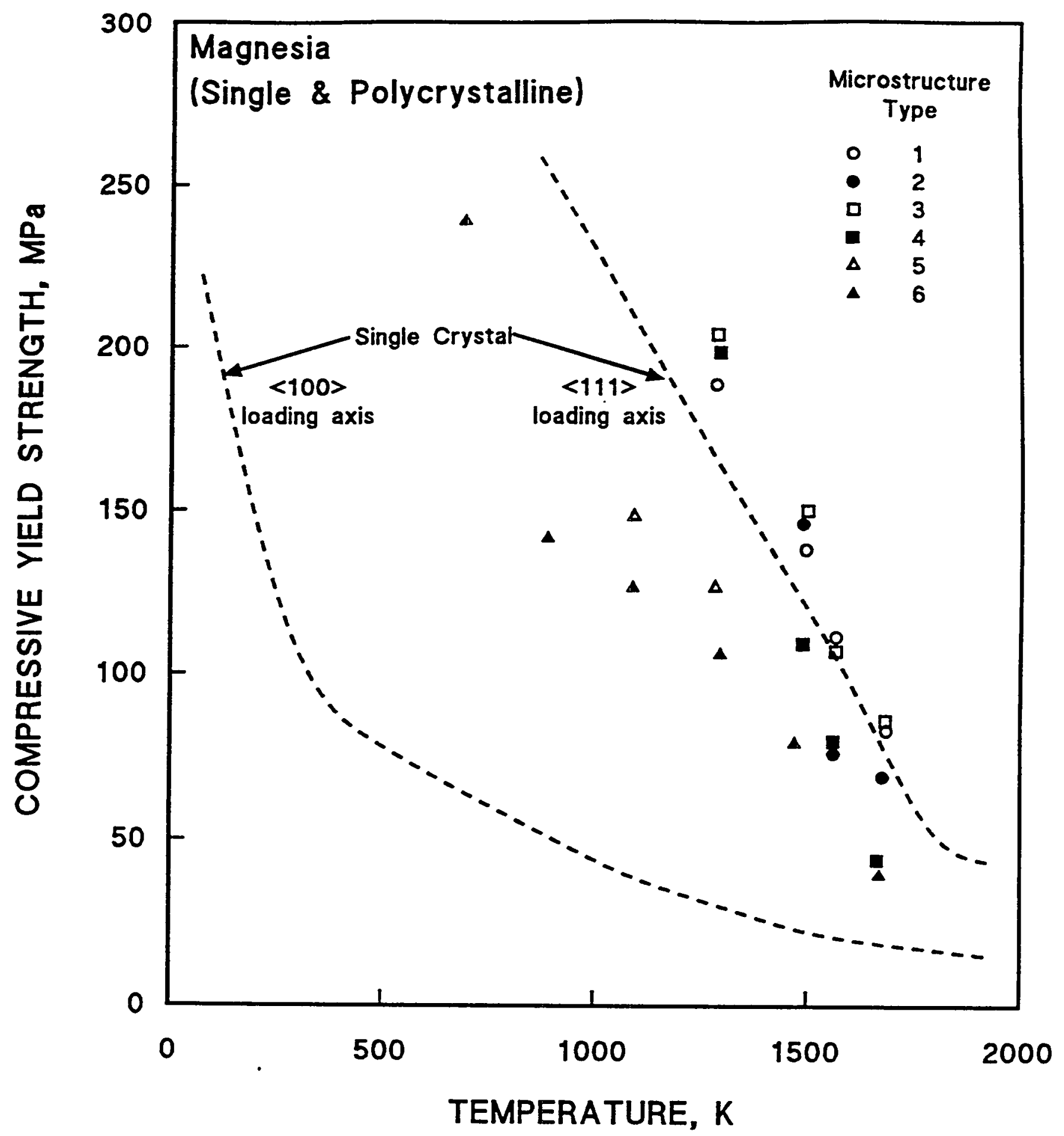

Figure 4.1.5. Single crystal and polycrystalline compressive strengths of MgO vs. temperature. Data from Langdon and Pask [1971]. 
axes, but considerable variation with microstructural type was evident. Unfortunately, compressive strength measurements of polycrystalline MgO at $4 \mathrm{~K}$ (or even $77 \mathrm{~K}$ ), were not obtained in this literature search. Figure 4.1 .6 shows the strain rate dependence of the compressive flow stress of single crystals tested by Langdon and Pask [1971], again mostly at higher temperatures.

\subsection{ELASTIC CONSTANTS}

The elastic compliances, $S_{1 j}$, of single-crystal $\mathrm{MgO}$ between 80 and $560 \mathrm{~K}$ were determined by Durand [1936] using a resonance technique. Since MgO is cubic, the values of the elastic compliances were converted to the Young's modulus, E, the shear modulus, G, and Poisson's ratio by the following equations; E $-1 / S_{11} ; G=1 / 2\left(S_{11}-S_{12}\right) ;$ and $\nu=-S_{12} / S_{11}$. These results are plotted in Figures 4.2.1 through 4.2.3. An increase of $5 \%$ in $E$ occurs between 300 and $80 \mathrm{~K}$, as would be expected from the data above ambient temperature presented in Figure 2.2.1. As the temperature approaches $0 \mathrm{~K}$, the slope of the curves shown in the figures must decrease to 0 ; therefore, a sizable portion of the increase in modulus at $4 \mathrm{~K}$ has already occurred by $80 \mathrm{~K}$.

\subsection{ELECTRICAL PROPERTIES}

\subsubsection{Electrical Breakdown Strength}

Cryogenic data on the electrical breakdown strength of MgO were not found in the literature search. Electrical breakdown strengths of $157 \mathrm{kV} / \mathrm{mm}$ were obtained at ambient temperature from chemically polished single-crystal MgO specimens [Beauchamp, 1971]. Disk specimens with a cylindrical cavity (with a bottom radius) were prepared to eliminate corona. The test voltage was applied as a ramp rising at 50 to $100 \mathrm{kV} / \mu \mathrm{s}$ across a thickness of $1.3 \mathrm{~mm}$. Polycrystalline MgO specimens of very small grain size, $-3 \mu \mathrm{m}$, had a similar electrical breakdown strength, but the strength declined to about half this value, or $70 \mathrm{kV} / \mathrm{mm}$, with an increase in the grain size to $100 \mu \mathrm{m}$. An increase in porosity to about $4 \%$ resulted in a similar decrease in breakdown strength, for specimens with a grain size of 1 to $3 \mu \mathrm{m}$. Specimens with a grain size of 50 to $100 \mu \mathrm{m}$ had an electrical breakdown strength of only about $37 \mathrm{kV} / \mathrm{mm}$ at $3 \%$ 


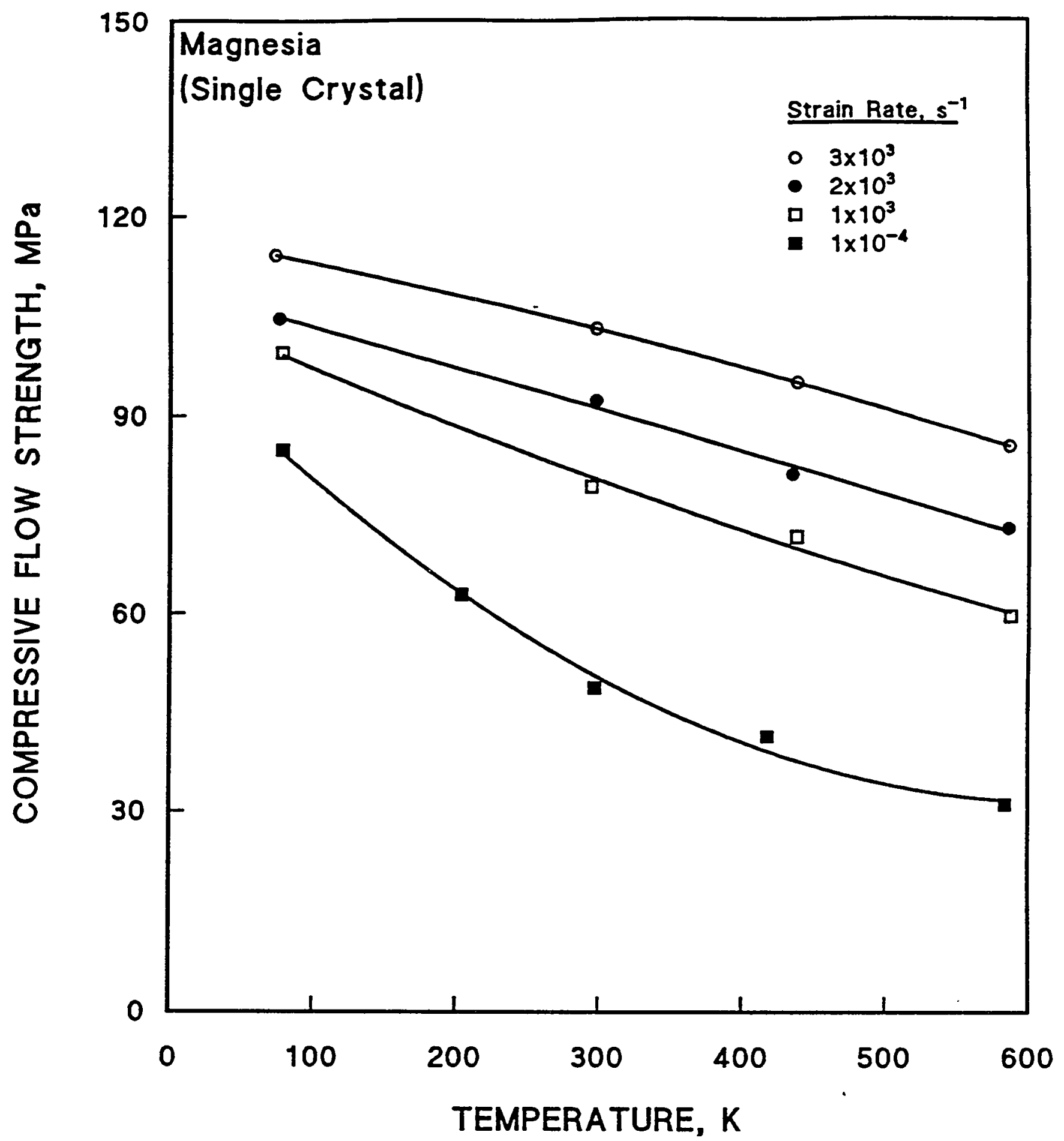

Figure 4.1.6. Compressive flow stress vs. temperature for single-crystal Mgo. Data from Langdon and Pask [1971]. 


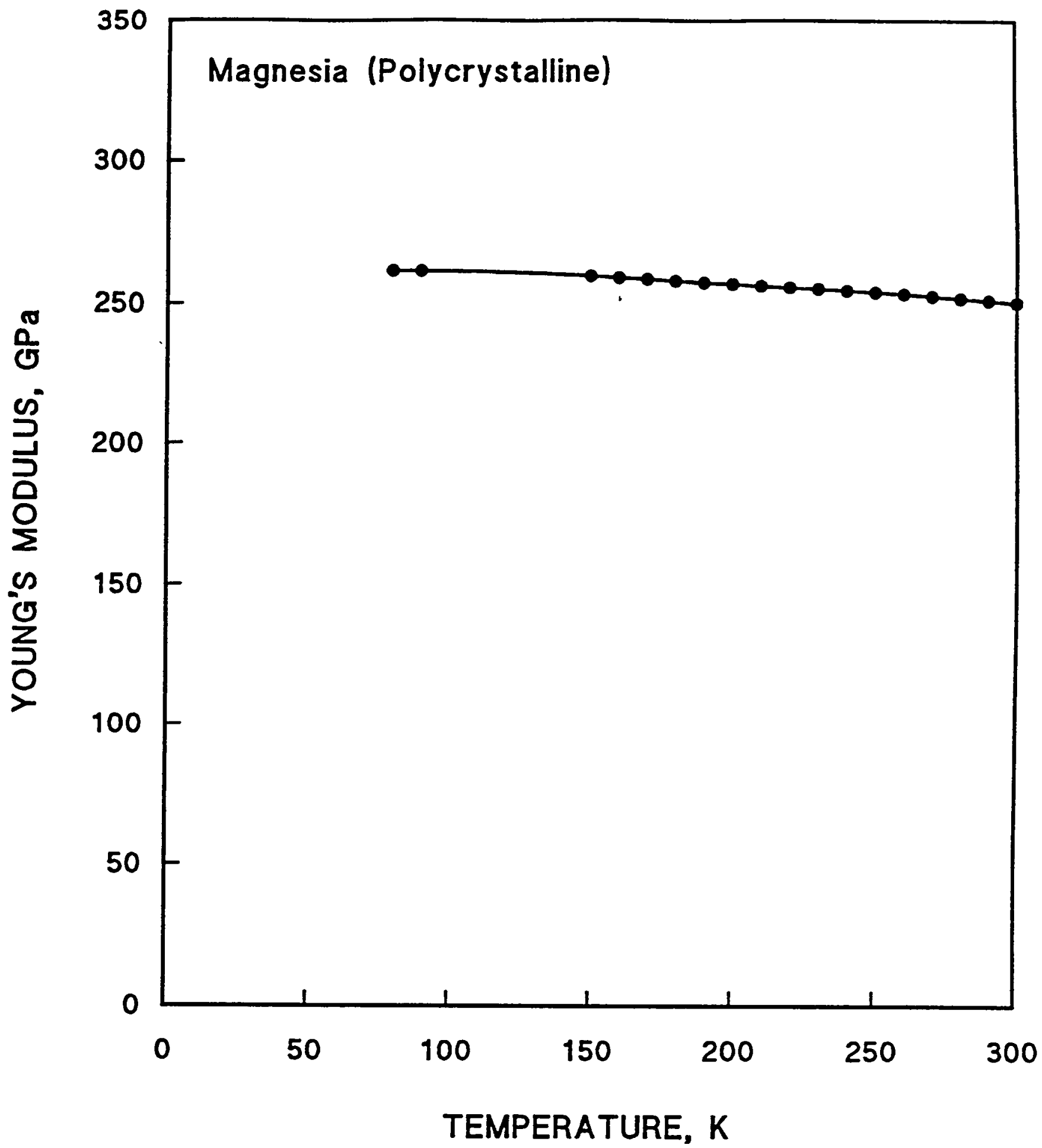

Figure 4.2.1. Young's modulus of MgO vs. temperature. Calculated from single-crystal data of Durand [1936]. 


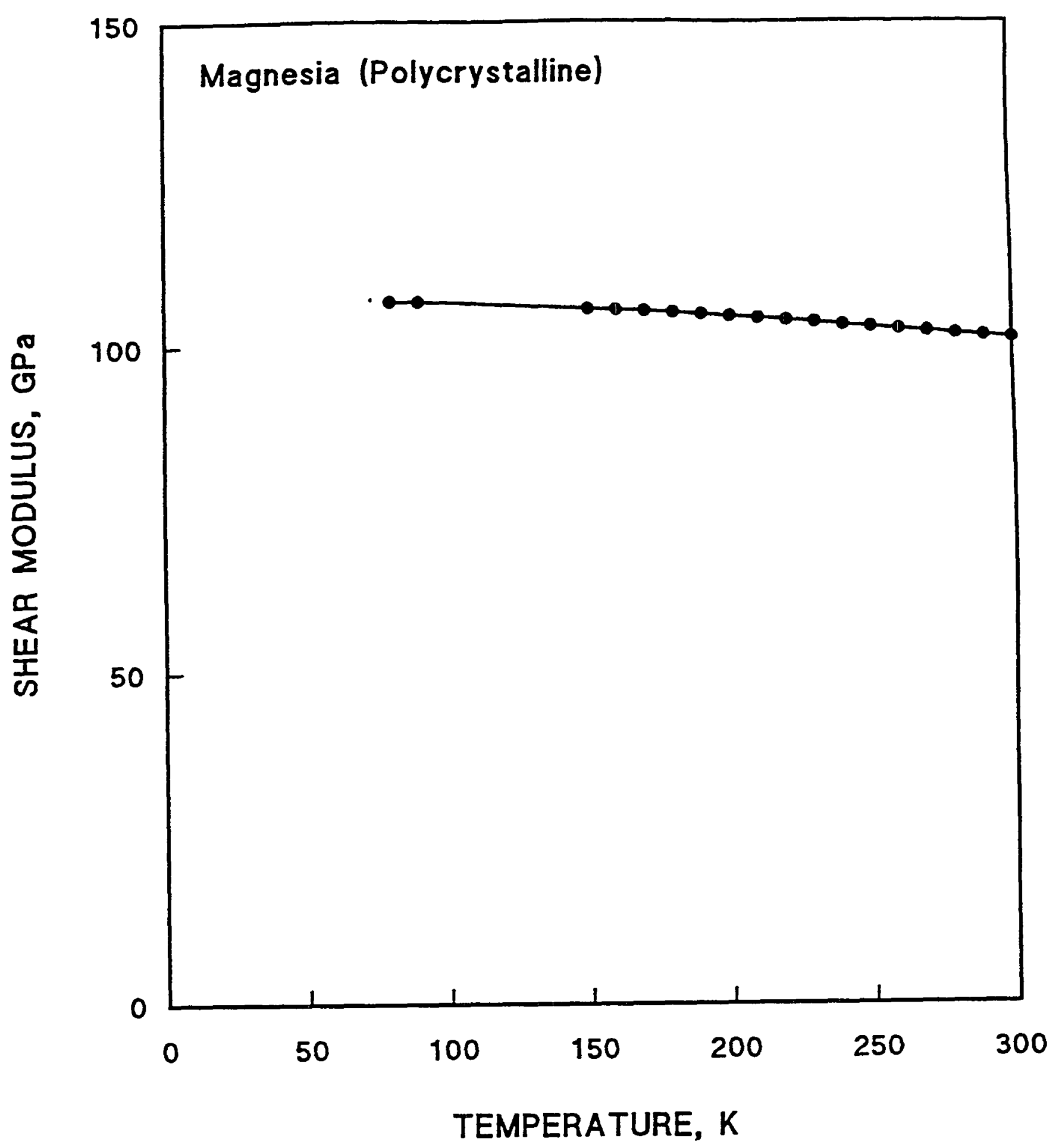

Figure 4.2.2. Shear modulus of MgO vs. temperature. Calculated from singlecrystal data of Durand [1936]. 


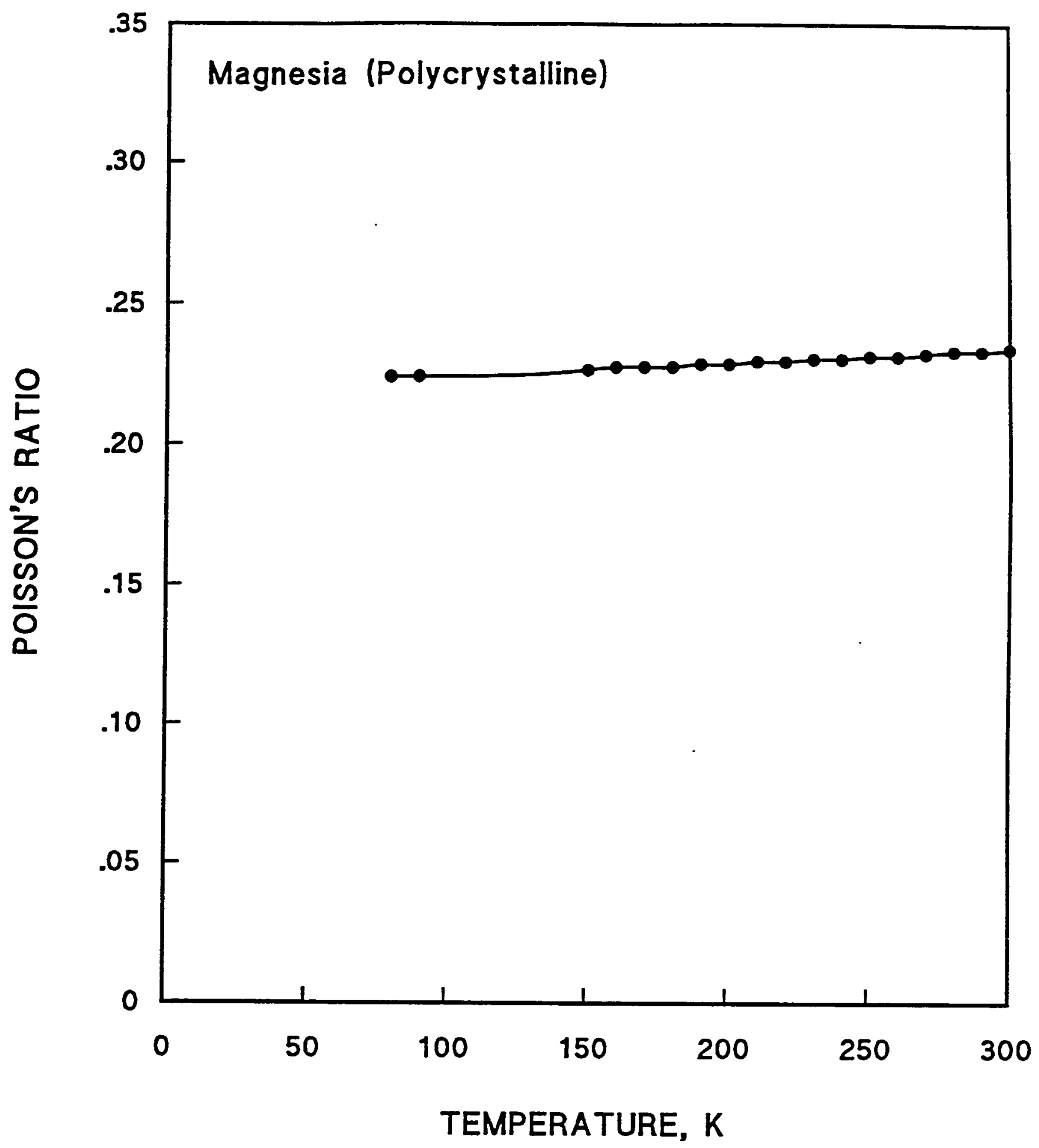

Figure 4.2.3. Poisson's ratio of MgO vs. temperature. Calculated from single-crystal data of Durand [1936]. 


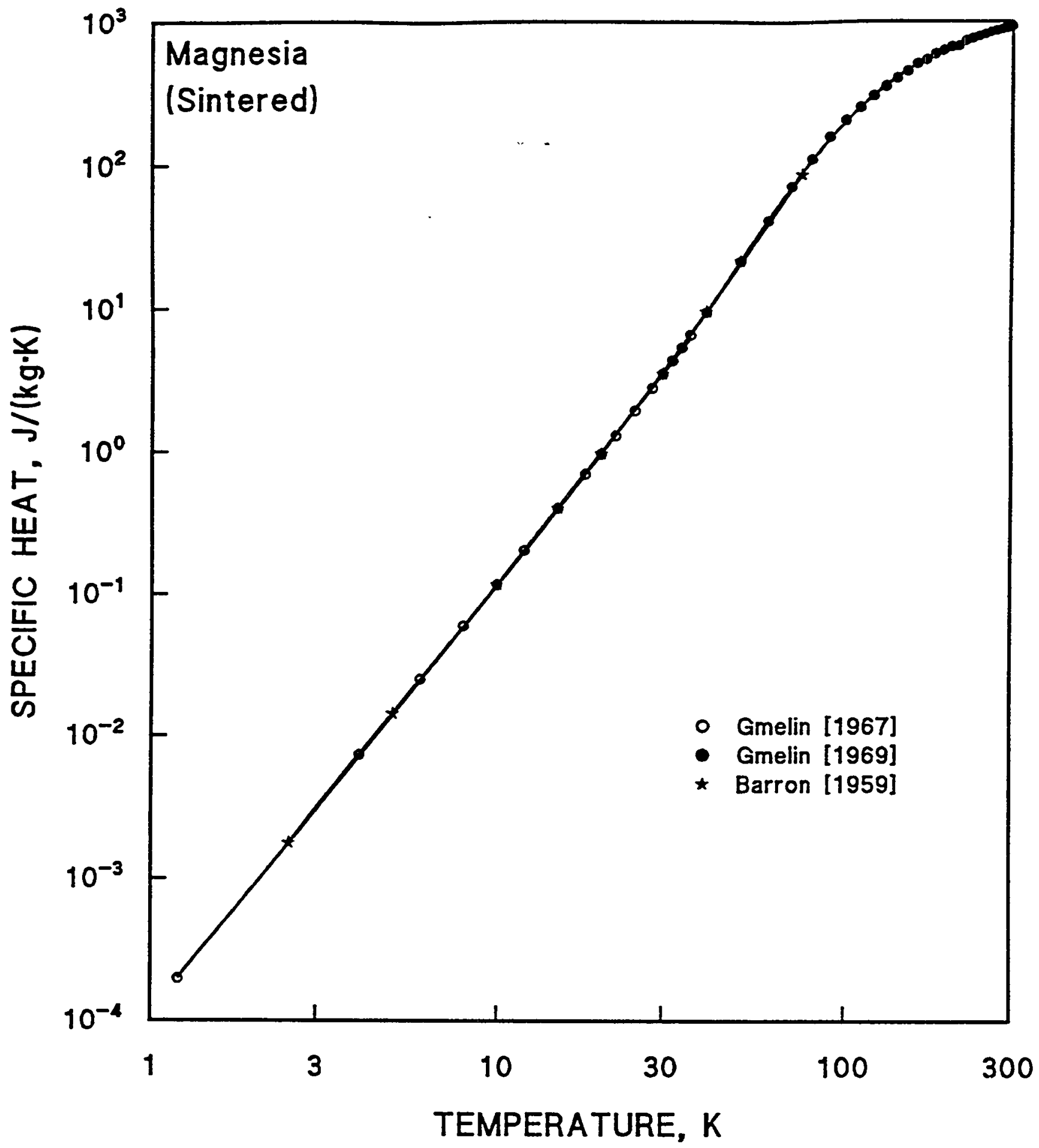

Figure 4.4.1. Specific heat of MgO vs. temperature. Data from Gmelin [1967; 1969] (sintered) and Barron et al. [1959] (single-crystal). 
porosity. These polycrystalline specimens had an addition of 0.3 mass\% LiF. Failure in these specimens usually occurred approximately $2 \mu$ s after the start of the pulse, but in very porous specimens, a precursor signal of small amplitude noise occurred just before the final breakdown. Punctures propagated mainly along grain boundaries, at least in large-grained specimens.

A frequency effect in thin MgO films of 5.0- to 7.0-nm thickness was reported by singh [1983]. A sinusoidal voltage was applied. The electrical breakdown strength remained constant at about $2 \mathrm{MV} / \mathrm{mm}$ up to $I \mathrm{kHz}$, and then declined to about one half of this value by $10^{5} \mathrm{~Hz}$. However, the breakdown strength of these films is quite high, and the results may not apply to thicker material.

\subsection{THERMAL PROPERTIES}

\subsubsection{Specific Heat}

The specific heat data of Gmelin [1967; 1969] and Barron et al. [1959] are presented in Figure 4.4.1. Data of Giauque and Archibald [1937] were not included, because they show a systematic deviation to higher specific heat of up to $100 \%$ near $40 \mathrm{~K}$ that has been attributed to an effect of particle size [citation, Gmelin, 1969]. Figure 4.4.1 shows good agreement between measurements on sintered specimens (Gmelin) and single crystals (Barron et al.).

\subsubsection{Thermal Conductivity}

The only available cryogenic thermal conductivity data appear to be those of Slack [1962] on two single-crystal specimens of MgO. As Figure 4.4.2 indicates, these data show a pronounced peak between 10 and $50 \mathrm{~K}$ that would not occur for a polycrystaline material.

\subsubsection{Thermal Expansion}

Data on the coefficient of thermal expansion of $\mathrm{MgO}$ are presented in Figure 4.4.3. Values recommended by Touloukian et al. [1977] are also shown. The linear thermal expansion, $\Delta \mathrm{L} / \mathrm{L}_{293} \mathrm{x}$, is illustrated in Figure 4.4.4. Again, values recommended by Touloukian et al. [1977] are also given. 


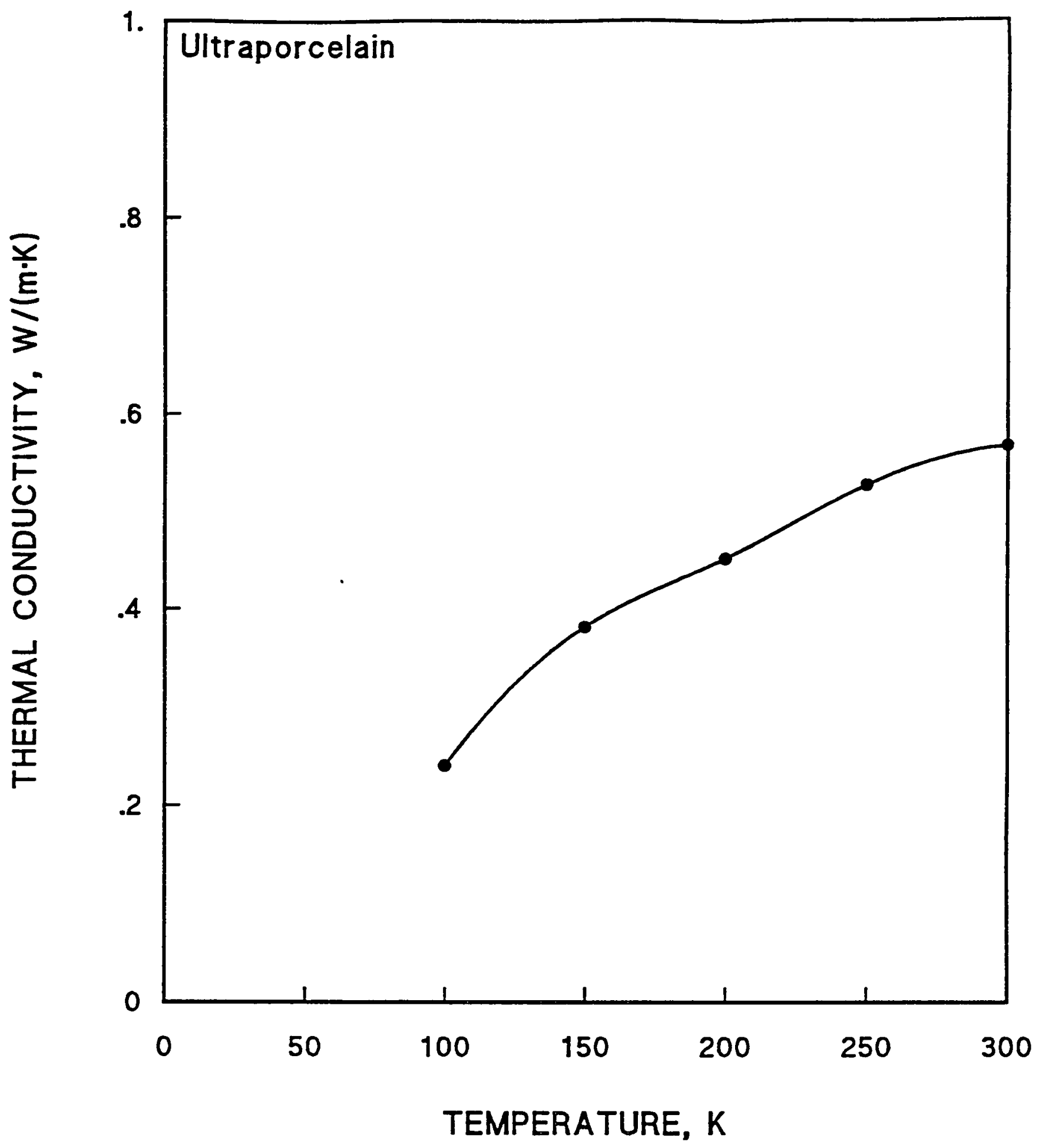

Figure 5.4.2. Thermal conductivity (in vacuum) of 808 porous ultraporcelain vs. temperature, from 100 to $300 \mathrm{~K}$. Data from Egorov et al. [1991]. 


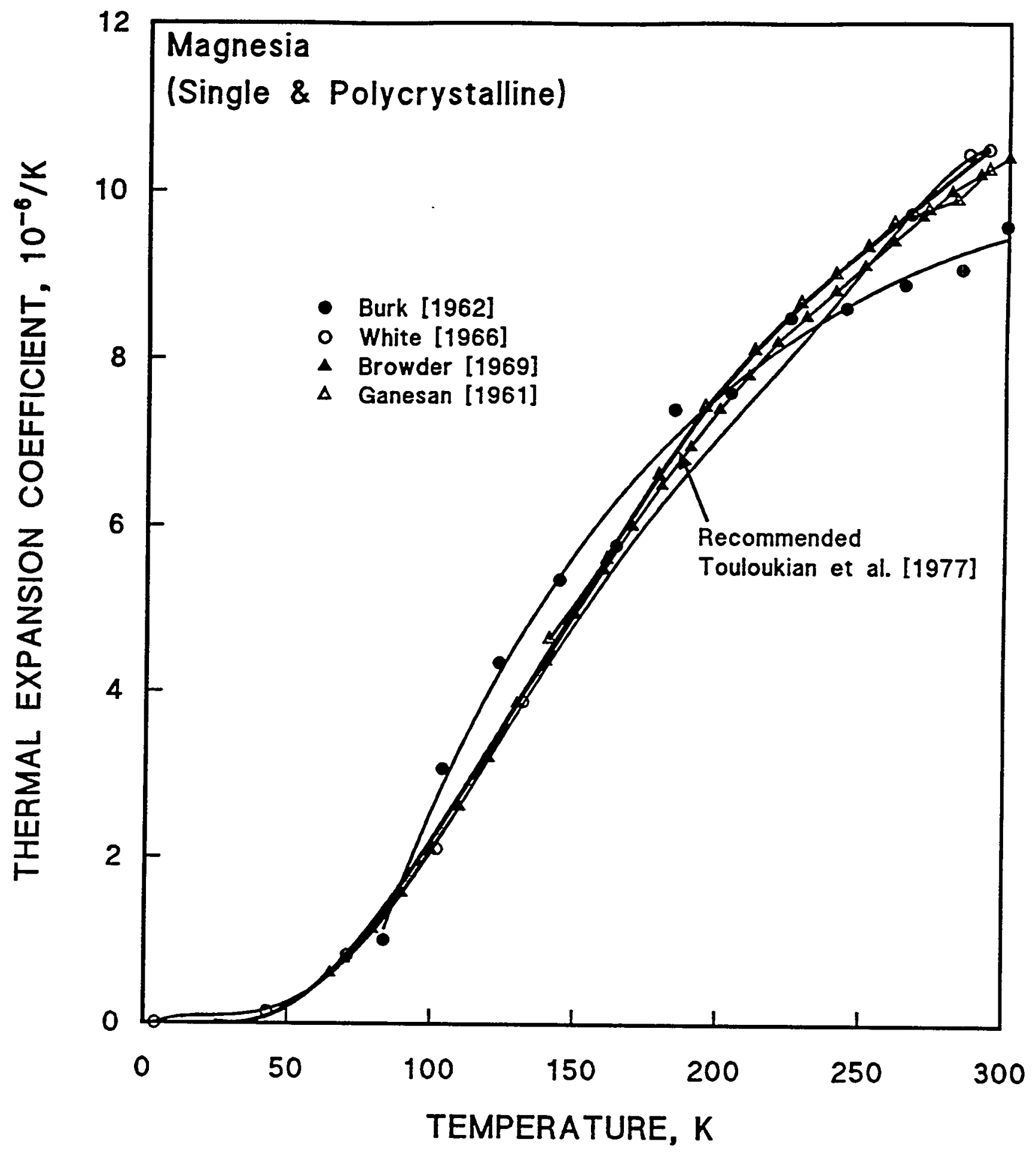

Figure 4.4.3. Thermal expansion coefficient of Mgo vs. temperature. Data from Burk [1962] and Touloukian et al. [1977; citations therein]. 


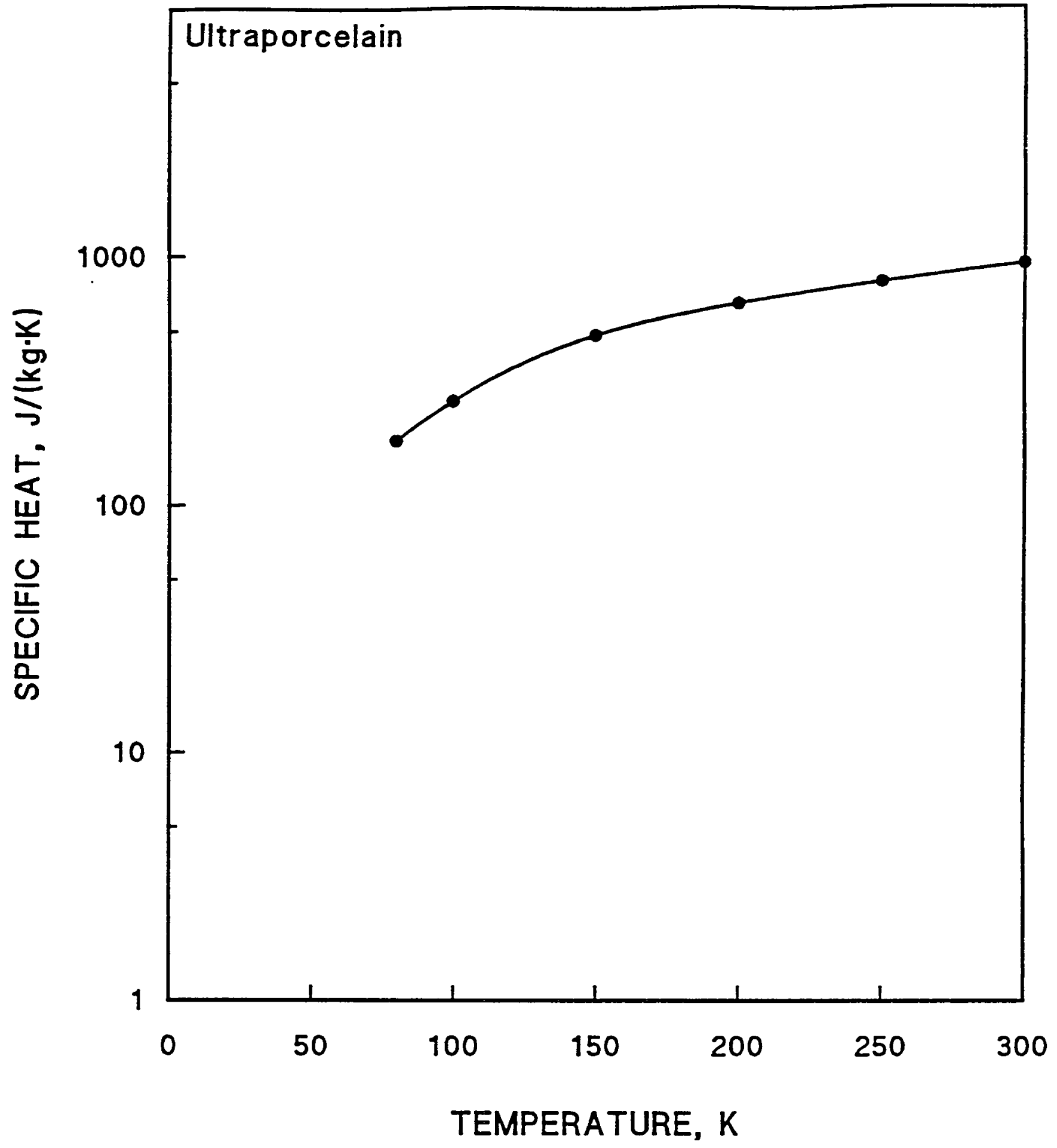

Figure 5.4.1. Specific heat of 808 porous ultraporcelain vs. temperature, from 80 to $300 \mathrm{~K}$. Data from Egorov et al. [1991]. 


\section{PORCELAIN}

\subsection{MECHANICAL PROPERTIES}

No cryogenic data on the mechanical properties of porcelain were found in the literature search. Limited recent cryogenic data on the shear/compressive strength of a porcelain coating are discussed below.

For standard electrical porcelain, the typical ambient temperature compressive strength is $345 \mathrm{MPa}$, but by optimizing the amount and size of acicular mullite crystals and reducing the amount of porosity, Schroeder and Guertin [1978] were able to attain values from 0.66 to $>1.38 \mathrm{GPa}$ (the limit of the test machine). It was necessary to surface-grind the ends of the test rods flat and parallel to obtain good results. The porosity was <1\%, whereas typical triaxial electrical porcelains showed a closed porosity of 6 to $10 \%$ (see also Schroeder [1978]). If external hydrostatic pressure is present, the measurements and calculation of Okhrimenko [1984] on the compressive strength of electrical porcelain may be of use. Controlling the grain size of the quartz in porcelain has been found to improve the bending strength, probably because most failures originated at quartz grain interfaces [Hamano et al., 1991a,b; Carlström and Carlsson, 1986]. Replacing the feldspar in porcelain with crystallizing glasses improved bending strength [Maiti and Kumar, 1992].

The applicability of fracture mechanics technology to porcelain ceramics was investigated by Clark and Logsdon [1974]. The effects of test specimen geometry, crack length, and notch radius on the nominal fracture toughness of electrical porcelain were evaluated. Carlström and Carlsson [1986] published a fractographic study of electrical porcelains that contained $\mathrm{Al}_{2} \mathrm{O}_{3}$.

Stainless steel chips that had been coated with a porcelain enamel were tested as part of a hybrid glass-reinforced epoxy system in simultaneous shear and compression (\$1.1.6) [Fabian and Reed, 1994]. Tests with three or four specimens each were done at an angle of $45^{\circ}$ (equal shear and compressive stresses) at 76 and $4 \mathrm{~K}$. At $76 \mathrm{~K}$, the shear strength was $155 \pm 42 \mathrm{MPa}$; at $4 \mathrm{~K}$, the shear strength was $162 \pm 18 \mathrm{MPa}$. Failures were most commonly interlaminar, 
adjacent to the ceramic layer. Mixed adhesive/cohesive failure at the ceramic interface and failure at the ceramic surface were also reported.

\subsection{ELASTIC PROPERTIES}

No cryogenic data on elastic properties of porcelain were found in the literature search. Clark and Logsdon [1974; citation therein] quote an ambienttemperature value of $58.6 \mathrm{GPa}$ for the Young's modulus. A value of about $78 \mathrm{GPa}$ was given by Maiti and Kumar [1992].

\subsection{ELECTRICAL PROPERTIES}

\subsubsection{Electrical Breakdown Strength}

No cryogenic data on the electrical breakdown strength of porcelain were found in the literature search. Recent dc measurements gave a value of 32.6 $\pm 6.4 \mathrm{kV} / \mathrm{mm}$ at $76 \mathrm{~K}$ in liquid $\mathrm{N}_{2}$ for a thin coating $(0.229-\mathrm{mm}$ thick) of a porcelain enamel on a stainless steel disk [Fabian and Reed, 1994]. (Values for other ceramic coatings measured by this technique were similar.) Specimens were measured between electrodes of 1.27-mm-diameter with 6.4-mm flats.

Ambient-temperature tests were carried out on porcelain under oil using 10 specimens with a hemispherical recess for each porcelain type [Cooper et al., 1972]. The wall thickness from the bottom of the recess to the plane face was $1.5 \mathrm{~mm}$ and the measurement frequency was $50 \mathrm{~Hz}$. The mean puncture strengths were between 24 and $30 \mathrm{kV} / \mathrm{mm}$ and no correlation was found with chemical composition, such as the use of $\mathrm{Na}$ or $\mathrm{K}$ feldspars. The dc breakdown strengths were also measured under similar conditions but with only seven specimens of each type. The dc strengths ranged between 30 and $35 \mathrm{kV} / \mathrm{mm}$. As expected, the dc values are somewhat higher than the $50-\mathrm{Hz}$ strengths.

Using porcelain disk specimens of several compositions and 8-mm thickness under oil, Soliman et al. [1972] found effects of the chemical composition upon the electrical breakdown strength. Their highest electrical breakdown strength was $7.25 \mathrm{kV} / \mathrm{mm}$ at $2.4 \%$ porosity. This is lower than a cited, typical value of 10 to $16 \mathrm{kV} / \mathrm{mm}$ at $6.4 \mathrm{~mm}$ (1/4 in) thickness. These authors also 


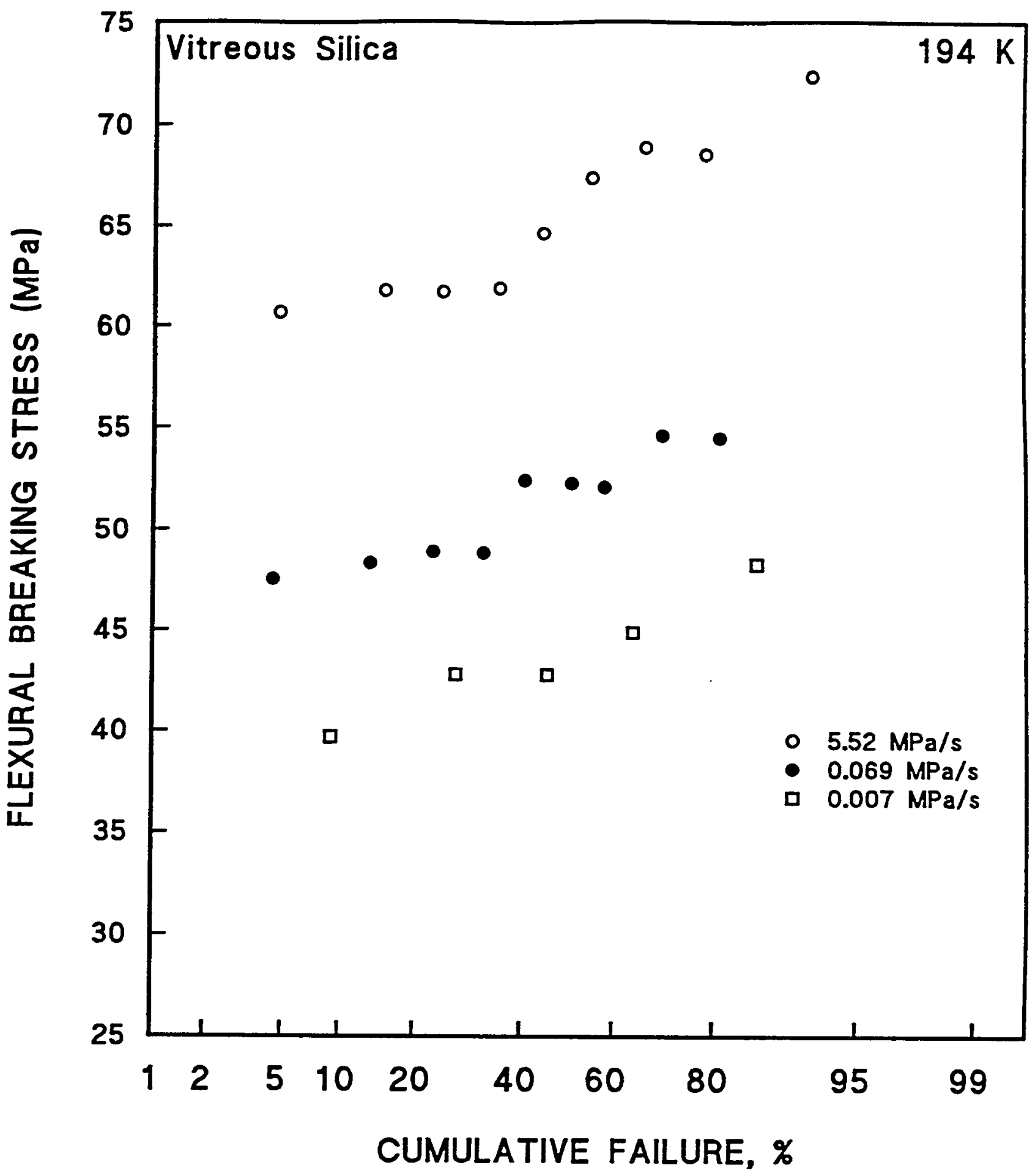

Figure 6.1.6. Breaking strength of abraded glass specimens at $194 \mathrm{~K}$ at

$5.5 \mathrm{MPa} / \mathrm{s}$ stress increase. Data from Kropschot and Mikesell [1960]. 


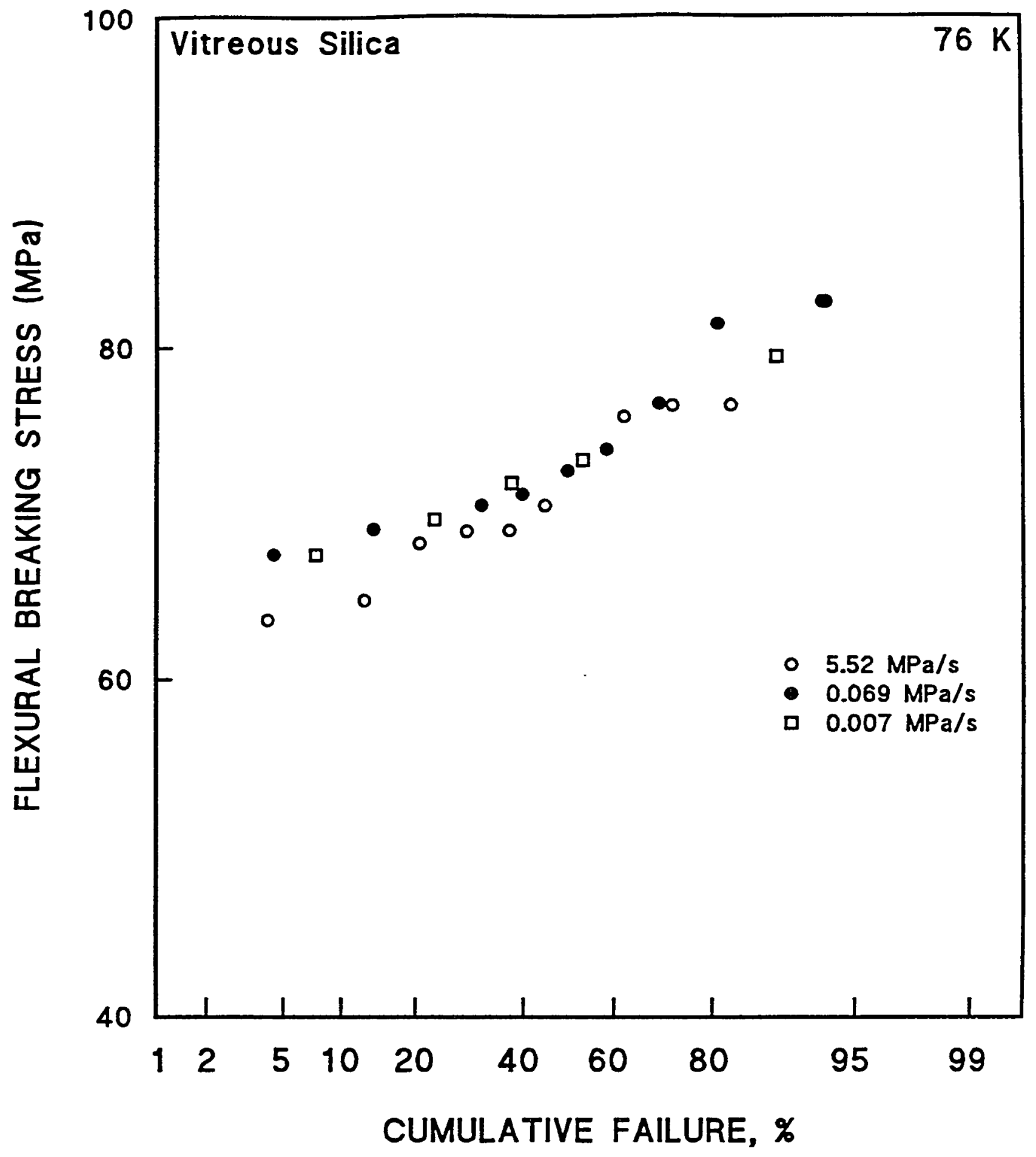

Figure 6.1.7. Breaking strength of abraded glass specimens at $76 \mathrm{~K}$ at $5.5 \mathrm{MPa} / \mathrm{s}$ stress increase. Data from Kropschot and Mikesel1 [1960]. 


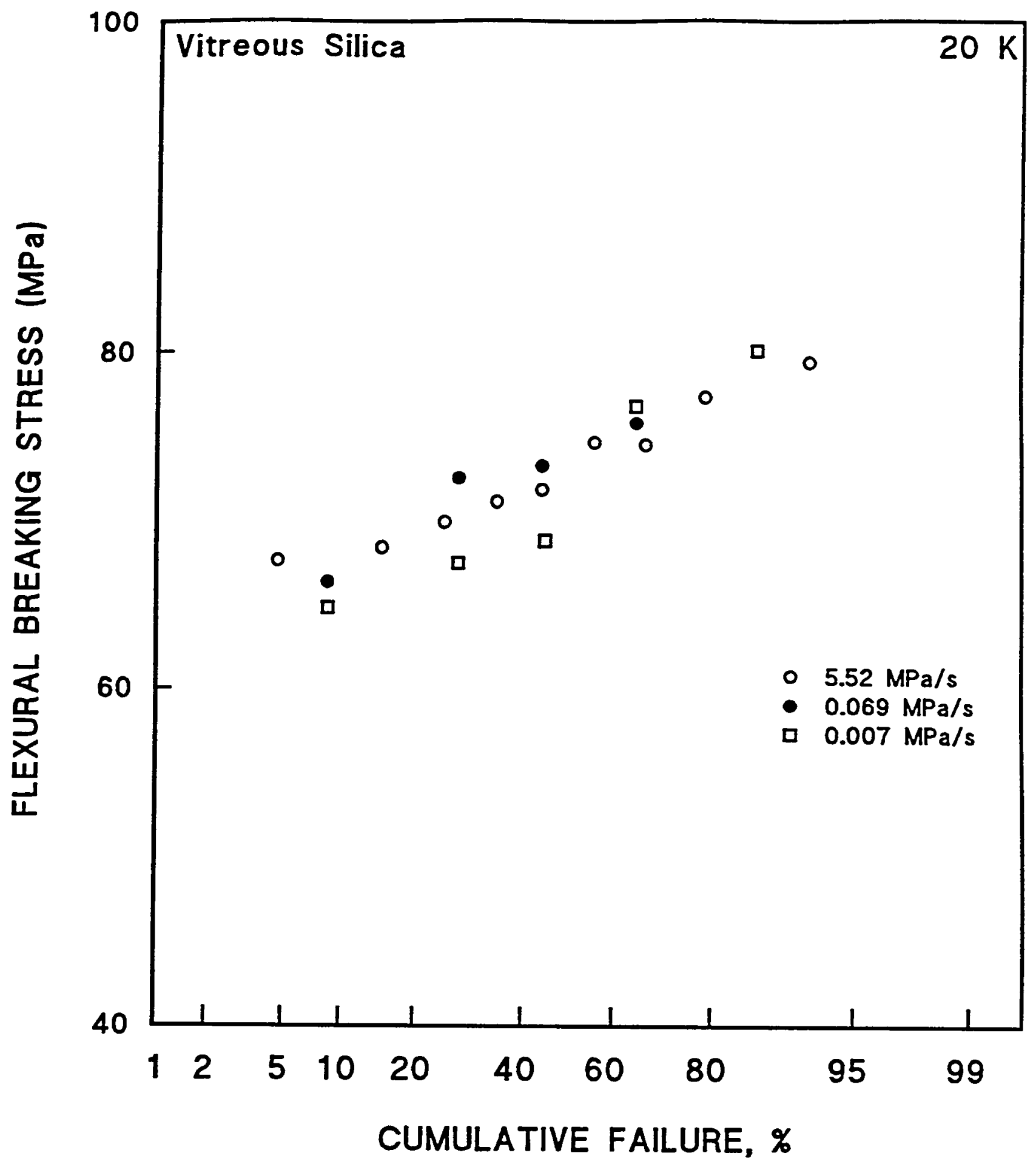

Figure 6.1.8. Breaking strength of abraded glass specimens at $20 \mathrm{~K}$ at $5.5 \mathrm{MPa} / \mathrm{s}$ stress increase. Data from Kropschot and Mikese11 [1960]. 


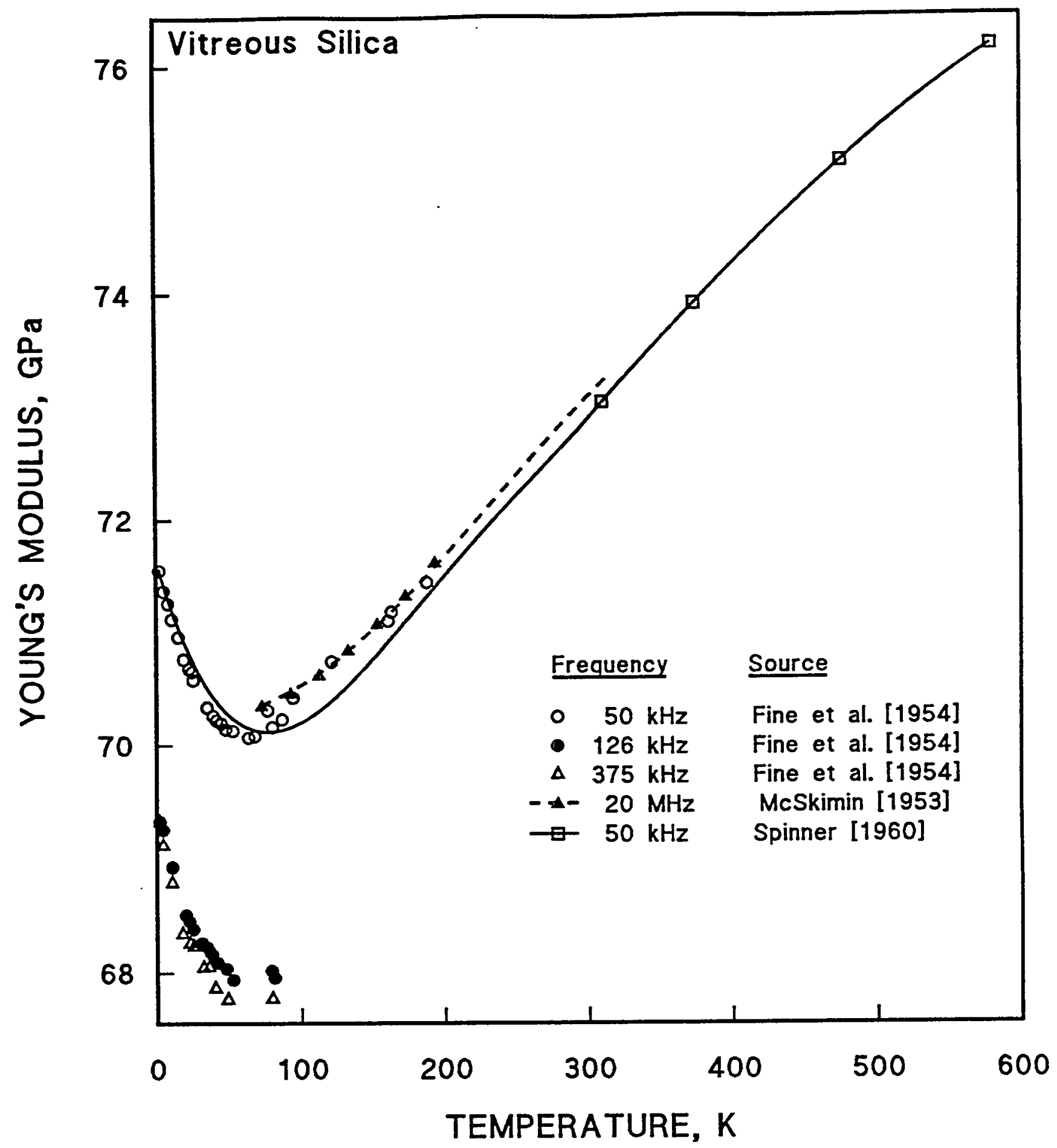

Figure 6.2.1. Young's modulus of vitreous $\mathrm{SiO}_{2}$ vs. temperature. Data from Fine et al. [1954], McSkimin [1953], and Spinner and Cleek [1960]. 


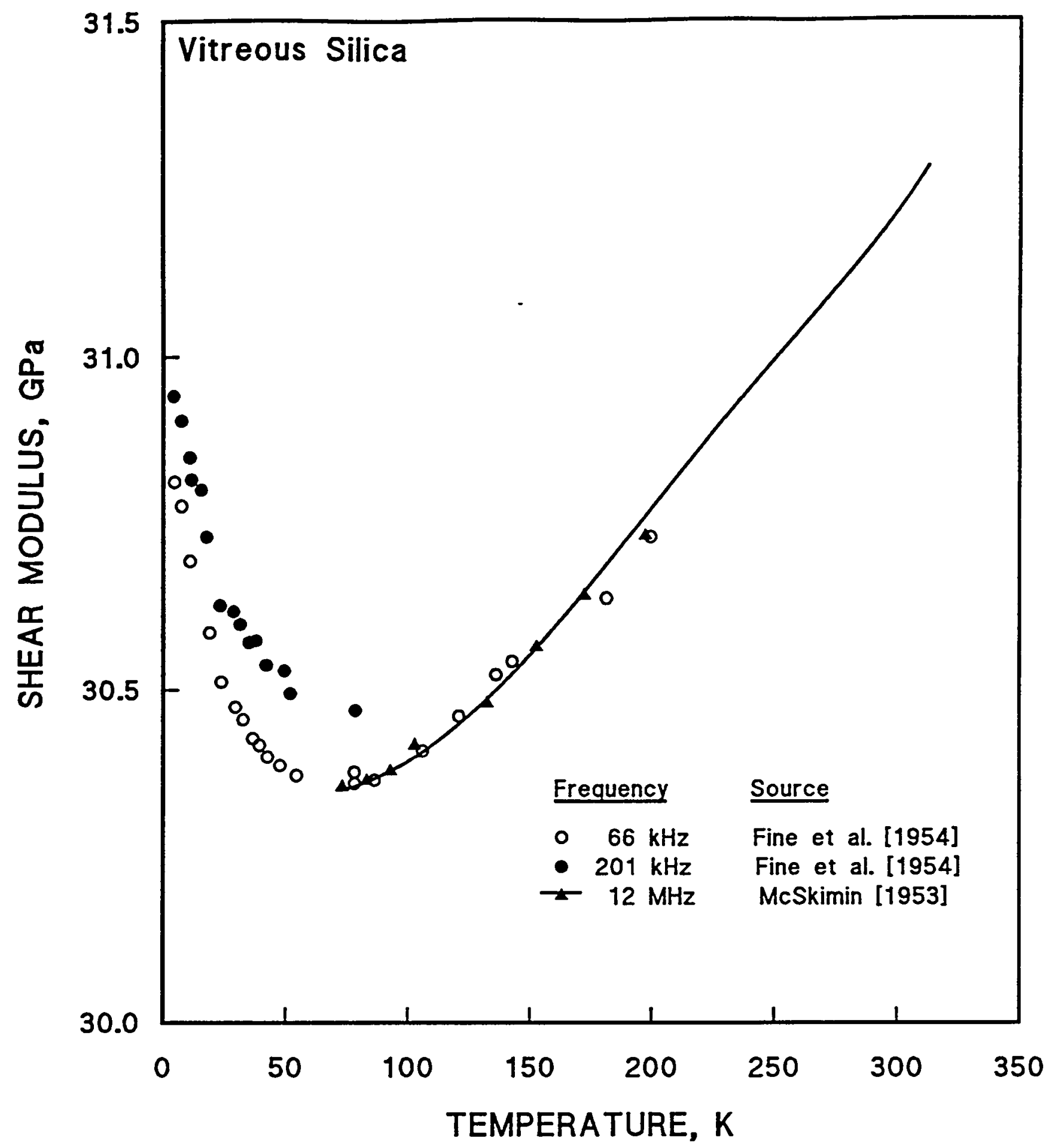

Figure 6.2.2. Shear modulus of vitreous $\mathrm{SiO}_{2}$ vs. temperature. Data from Fine et al. [1954] and McSkimin [1953]. 


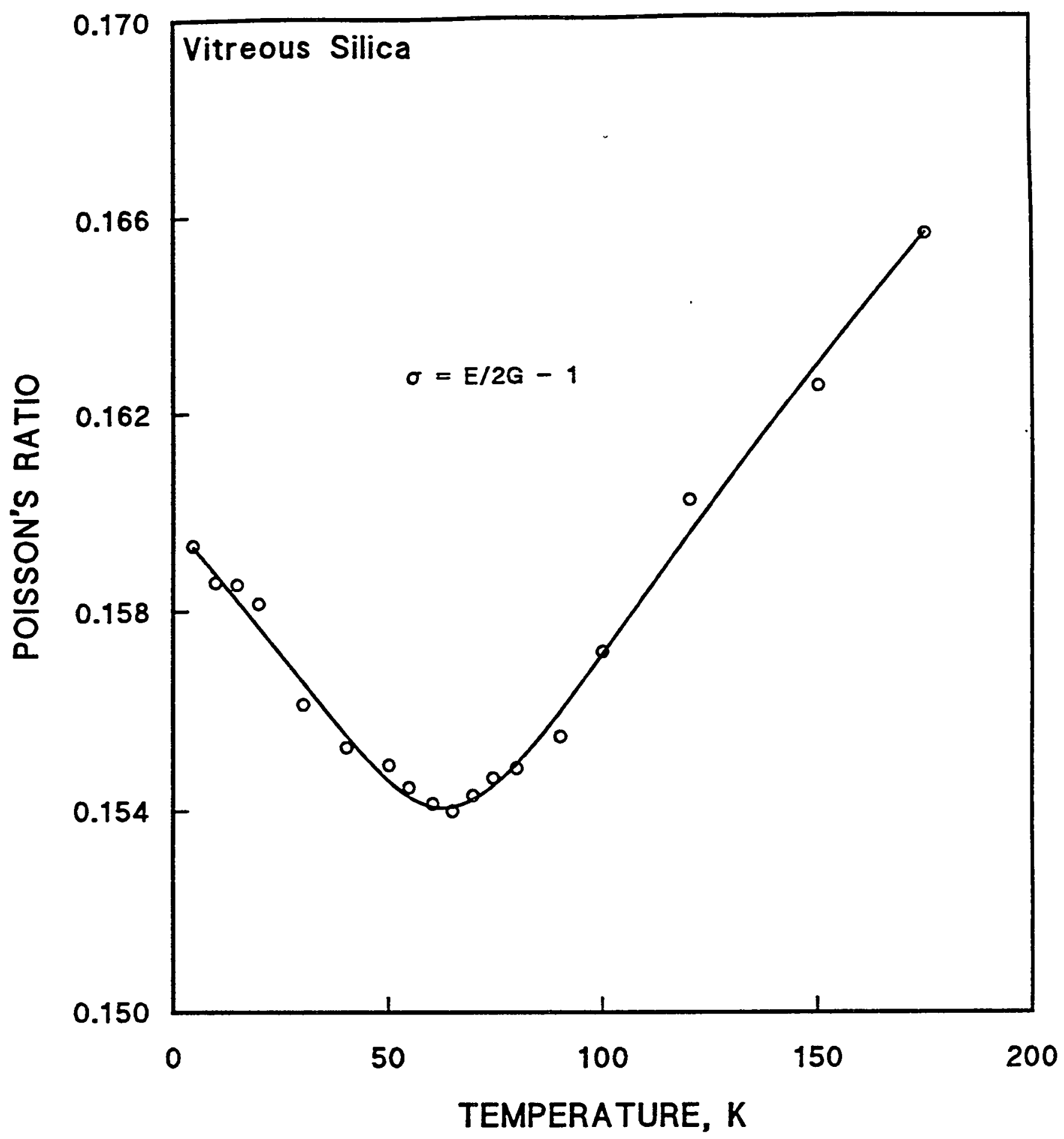

Figure 6.2.3. Poisson's ratio (calculated) of vitreous $\mathrm{SiO}_{2}$ vs. temperature. Data from Fine et al. [1954]. 
in Figure 6.2.1; if a different magnitude is chosen, the temperature dependence can be obtained from the graph by taking ratios.

The dependence of the ambient-temperature Young's modulus of quartz ceramic upon porosity was shown above, in Figure 1.2.2. The values for different batches of zero porosity ranged from about 49 to $68 \mathrm{GPa}$.

\subsection{ELECTRICAL PROPERTIES}

\subsubsection{Electrical Breakdown Strength}

Cryogenic data on the electrical breakdown strength of bulk quartz and vitreous $\mathrm{SiO}_{2}$ were not found in the literature search. However, some cryogenic data on chemically grown, amorphous $\mathrm{SiO}_{2}$ films is available [Korzo, 1968]. The electrical measurements were made in a vacuum of about $6.7 \times 10^{-3} \mathrm{~Pa}(5$ $\times 10^{-5}$ Torr). Figure 6.3 .1 for a film thickness of $200 \mathrm{~nm}$ (2000 $\AA$ ) shows that the electrical breakdown strength becomes significantly lower as the temperature decreases to $77 \mathrm{~K}$. Figure 6.3 .2 indicates that the curves of breakdown strength vs. thickness shift to higher values of both breakdown strength and thickness as the temperature becomes higher. Since the temperature dependence of the ionic mobility is thought to be exponential [0'Dwyer, 1967], whereas the temperature effect illustrated in Figure 6.3.1 is much less than exponential, the data imply that there is, at most, a very small contribution from ionic conduction to the overall mechanism of breakdown in $\mathrm{SiO}_{2}$ films at cryogenic temperatures.

Additional data on electrical breakdown are available at ambient temperature. Measurements of the breakdown strength of single-crystal quartz (electrical field parallel to the optic axis) gave a value of $670 \mathrm{kV} / \mathrm{mm}$ (Austen and Whitehead, 1940]. The electrical breakdown strength of bulk vitreous $\mathrm{SiO}_{2}$ was found to be $540 \mathrm{kV} / \mathrm{mm}$ [Austen and Whitehead, 1940]. Recessed specimens were probably used. Sputtered quartz films with thicknesses from 40 to $900 \mathrm{~nm}$ (400 to $9000 \AA$ ) had breakdown strengths ranging from 1100 to $200 \mathrm{kV} / \mathrm{mm}$ [Pratt, 1968]. The average value for 90 samples was $400 \mathrm{kV} / \mathrm{mm}$, which compares well with the bulk value of $540 \mathrm{kV} / \mathrm{mm}$ reported earlier by Austen and Whitehead and with the ambient-temperature value of $-300 \mathrm{kV} / \mathrm{mm}$ (Figure 6.3.1). These 


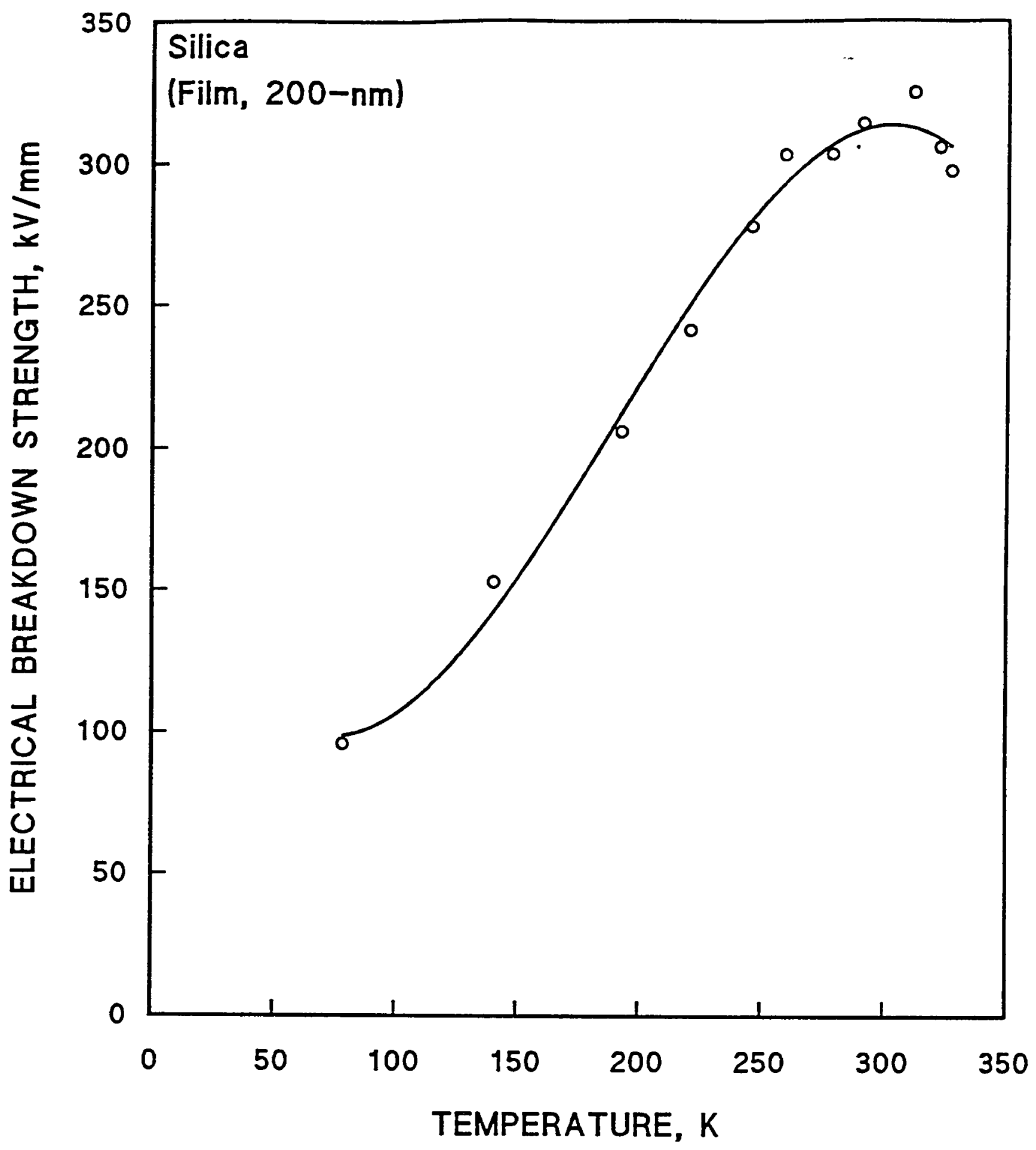

Figure 6.3.1. Electrical breakdown strength of $\mathrm{SiO}_{2}$ film 200-nm (2000- $\AA$ ) thick vs. temperature from 77 to $320 \mathrm{~K}$. Data from Korzo [1968]. 


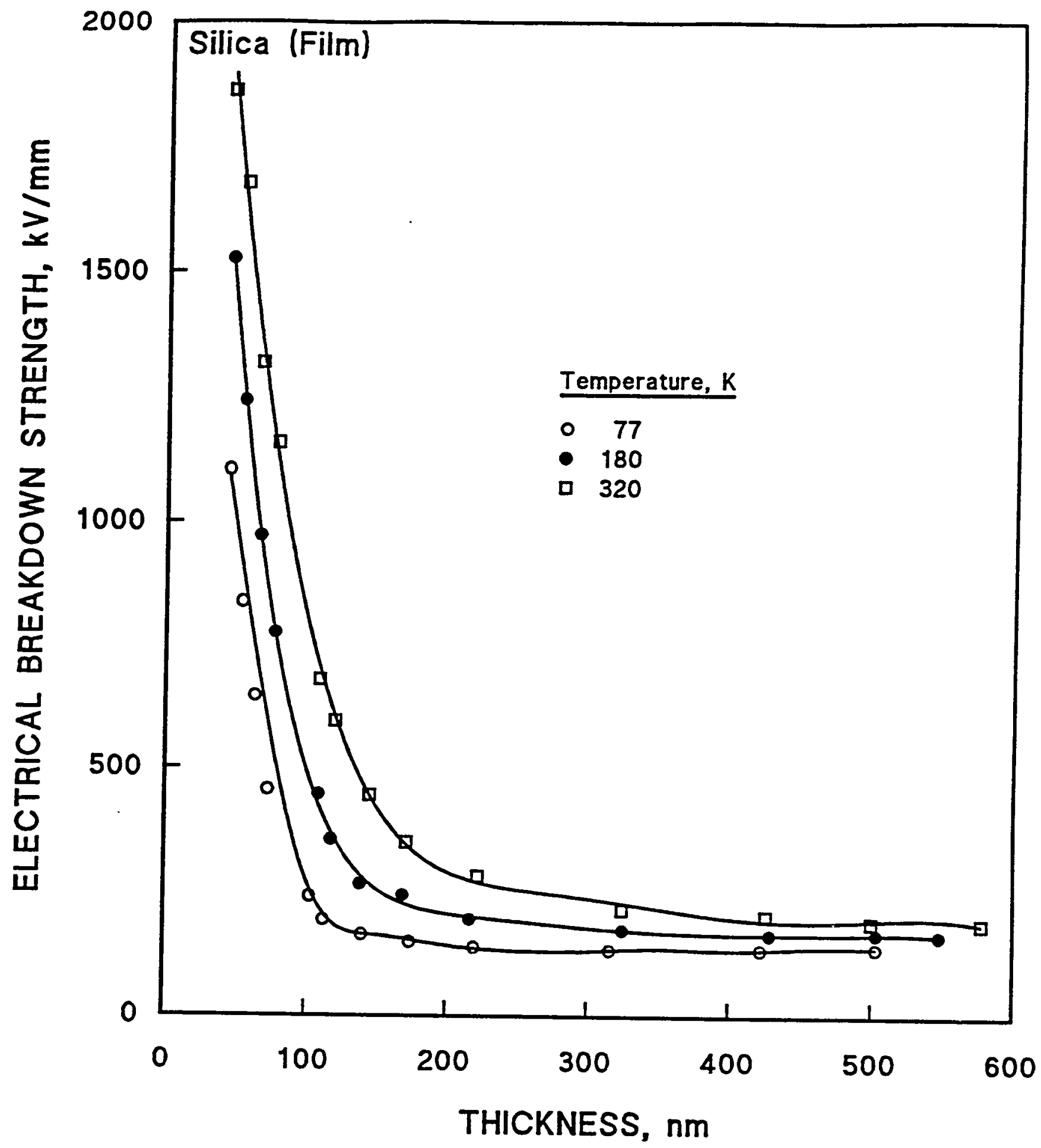

Figure 6.3.2. Electrical breakdown strength of $\mathrm{SiO}_{2}$ film vs. thickness at 77 , 180 , and $320 \mathrm{~K}$. Data from Korzo [1968]. 


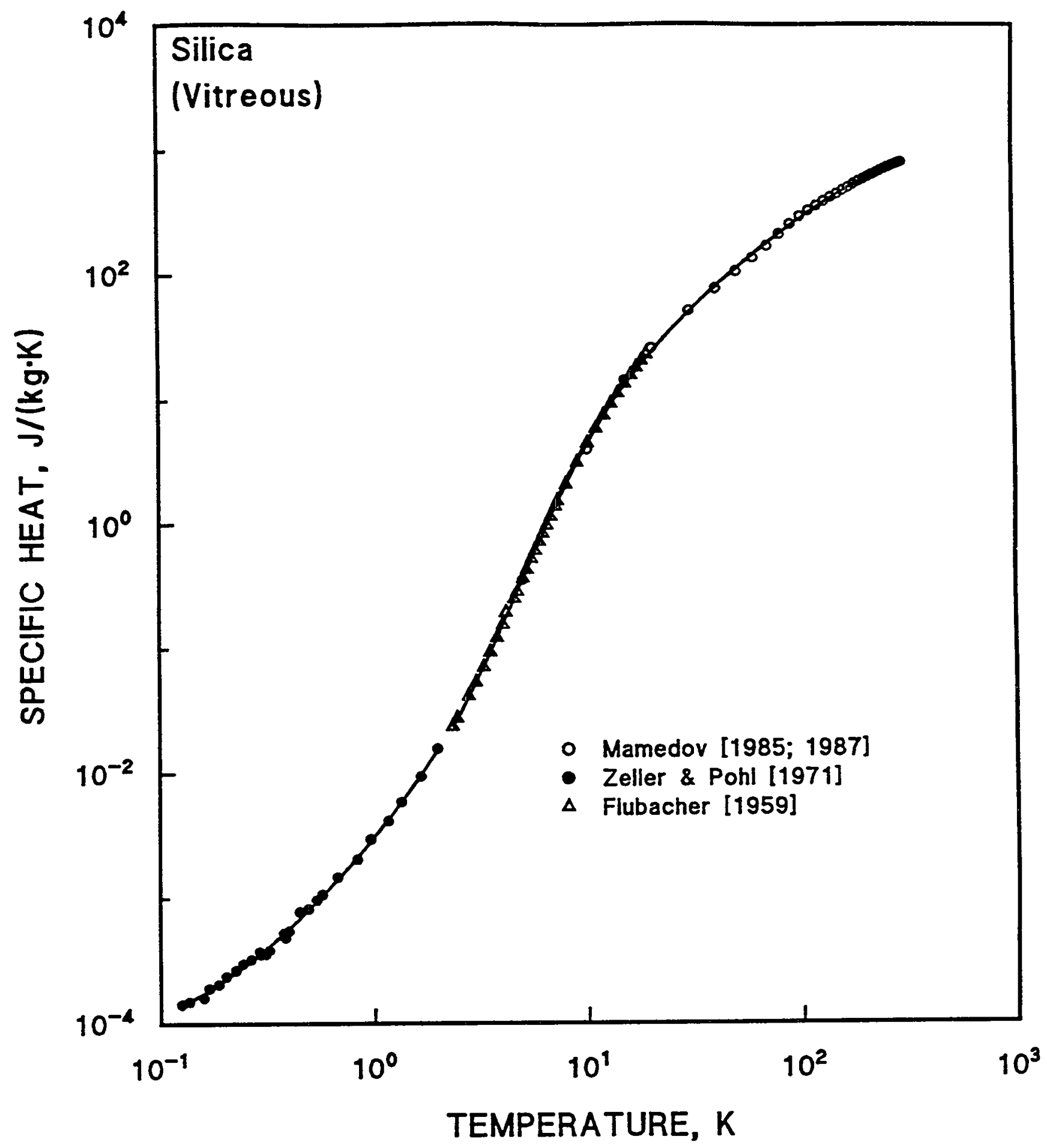

Figure 6.4.1. Specific heat of vitreous $\mathrm{SiO}_{2}$ vs. temperature. Data from Mamedov et al. [1985; 1987], Zeller and Pohl [1971], and Flubacher et al. [1959]. 
specimens were tested with capacitor structures. Slaoui et al. [1992] found a similar range of values for $\mathrm{SiO}_{2}$ films about $600-\mathrm{nm}(6000-\AA)$ thick: films deposited at $20^{\circ} \mathrm{C}$ had maximum breakdown strengths of 200 to $300 \mathrm{kV} / \mathrm{mm}$, perhaps owing to a high concentration of $\mathrm{OH}$ in the oxide, whereas samples annealed after deposition had higher breakdown strengths of 400 to $800 \mathrm{kV} / \mathrm{mm}$.

A calculated value for the breakdown field in quartz is $1000 \mathrm{kV} / \mathrm{mm}$ [Lynch, 1972; citations therein]. The intrinsic electron-induced, as opposed to defect-induced, breakdown strength in $\mathrm{SiO}_{2}$ has been shown to be 800 to 1000 $\mathrm{kV} / \mathrm{mm}$ [citations, Lynch, 1972]. More recently, Olivo et al. [1987] showed that interface defects, rather than bulk phenomena, affected their $\mathrm{SiO}_{2}$, thinfilm breakdown results.

\subsubsection{Other Electrical Properties}

Data on the loss tangent of a variety of quartz specimens between 14 and $150 \mathrm{~K}$ are given by Volger et al. [1955]. Quartz crystals in general have much smaller loss factors than glasses. Electron and X-ray irradiation caused pronounced changes in the loss curves of a synthetic quartz at $32 \mathrm{~Hz}$ as temperature ranged from 14 to $150 \mathrm{~K}$.

\subsection{THERMAL PROPERTIES}

\subsubsection{Specific Heat}

There are not many recent measurements of the cryogenic specific heat of vitreous $\mathrm{SiO}_{2}$, except over limited, very low temperature ranges. Touloukian and Buyco [1970] presented the earlier data on unirradiated specimens (before 1921). More recent data from Mamedov et al. [1985; 1987] from 5 to $300 \mathrm{~K}$ are given in Figure 6.4.1. Additional data for Flubacher et al. [1959] from 2 to $19 \mathrm{~K}$ and of Zeller and Pohl [1971] from 0.05 to $100 \mathrm{~K}$ are in reasonable agreement, as the figure indicates. At low cryogenic temperatures, $<8$ to $20 \mathrm{~K}$, data are available that indicate the variability of the specific heat with $\mathrm{OH}$ concentration [Ahmad and Matiullah, 1990] and with annealing treatment [Löhneysen et al., 1985]. At very low temperatures, the state of strain in vitreous $\mathrm{SiO}_{2}$ was shown not to affect the specific heat [Wenger et al., 1976]. 


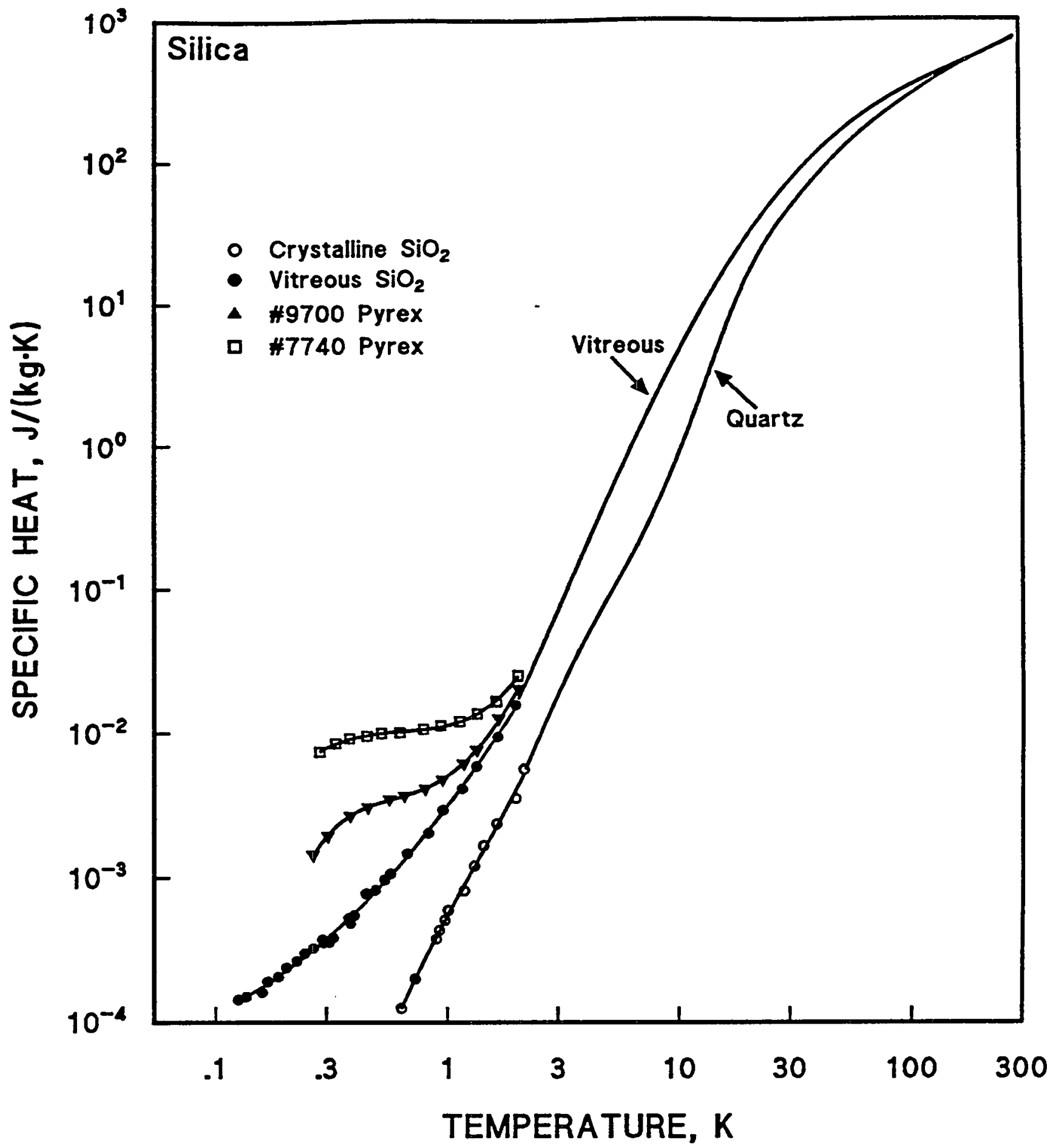

Figure 6.4.2. Comparative data from Zeller and Pohl [1971; citations therein] on the specific heat of vitreous and crystalline $\mathrm{SiO}_{2}$ vs. temperature. Data on two commercial glasses are also shown. 


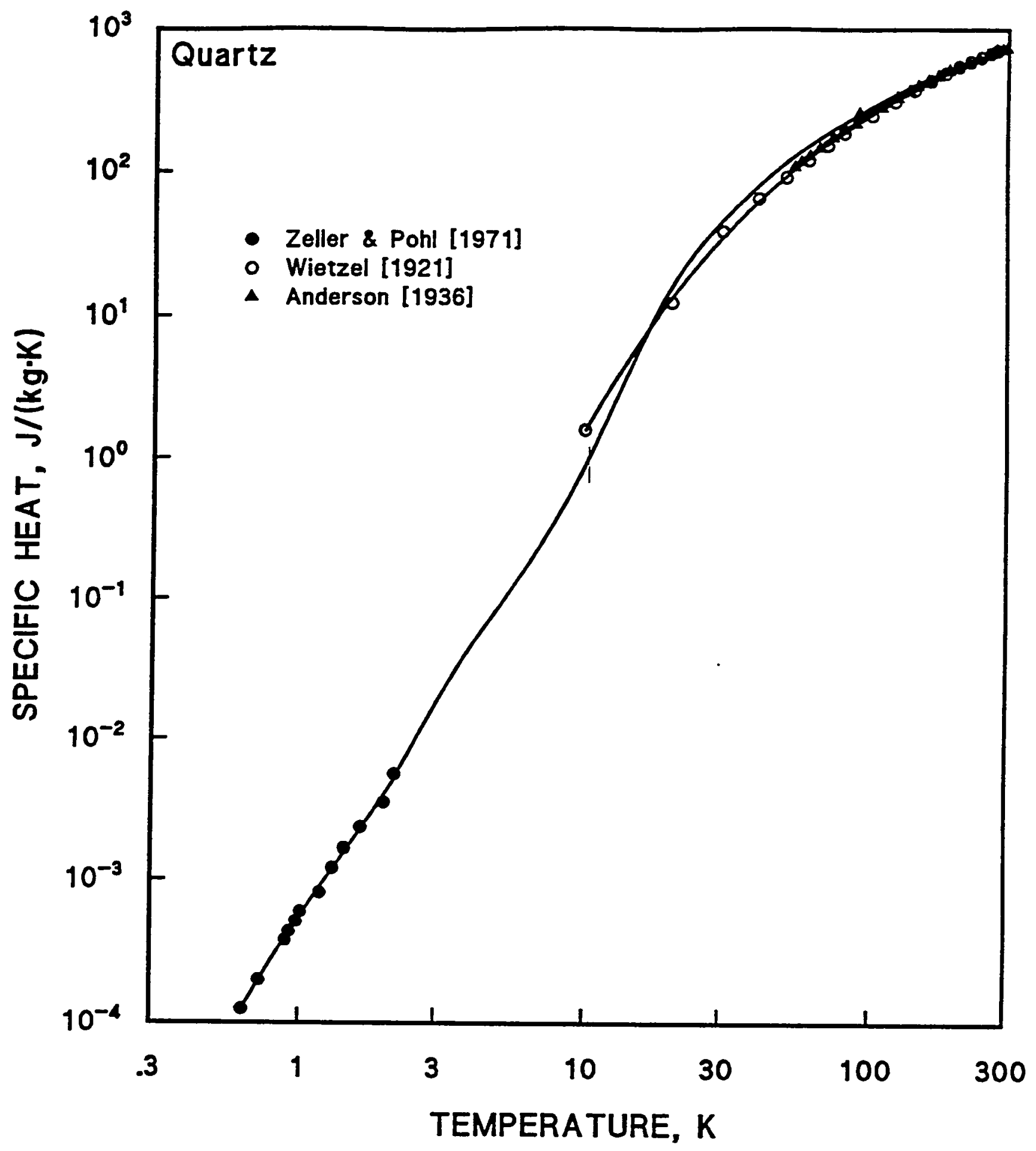

Figure 6.4.3. Specific heat of quartz vs. temperature. Data (points and curve) from Zeller and Pohl [1971; citations therein] and Touloukian and Buyco [1970; citations therein]. 


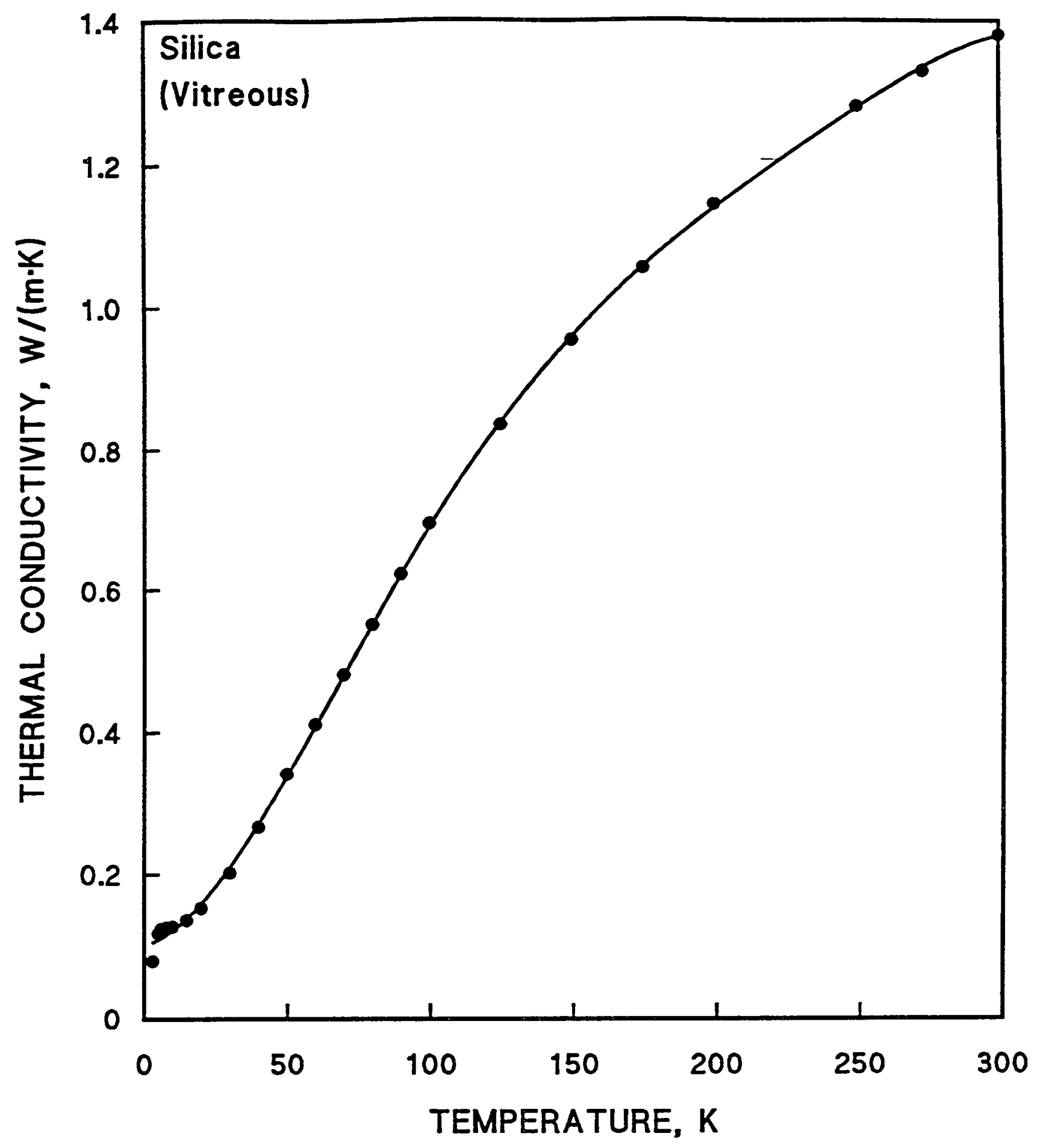

Figure 6.4.4. Recommended values for thermal conductivity of "high purity clear fused $\mathrm{SiO}_{2} . "$ From Touloukian et al. [1970]. 
The specific heats of vitreous $\mathrm{SiO}_{2}$ and quartz at low temperatures are compared in Figure 6.4.2 [Zeller and Pohl, 1971]. At low temperatures, the specific heat of the vitreous material is higher than that of the crystalline quartz. At about $0.3 \mathrm{~K}$, the specific heat of vitreous $\mathrm{SiO}_{2}$ is lower than that of two commercial glasses, but the specific heat approaches that of two other commercial glasses at about $2 \mathrm{~K}$. Above about $80 \mathrm{~K}$, the specific heats of both vitreous and crystalline $\mathrm{SiO}_{2}$ also become similar. Figure 6.4.3 again presents the data of Zeller and Pohl [1971; citations therein] on quartz together with much earlier data (from 1921 and 1936) at higher cryogenic temperatures [citations, Touloukian and Buyco, 1970]. Data from Gurevich and Khlyustov [1979] from 9 to $300 \mathrm{~K}$ agree with these values within a few percent.

\subsubsection{Thermal Conductivity}

Touloukian et al. [1970] compiled data on a large number of thermal conductivity measurements of vitreous $\mathrm{SiO}_{2}$ and published recommended values (Table 6.4.1 and Figure 6.4.4) The recommended values apply to "high purity, clear fused $\mathrm{SiO}_{2}$." There are basically two different ways to prepare vitreous $\mathrm{SiO}_{2}$, either by oxidation of $\mathrm{SiCl}_{4}$ or another compound (synthetic $\mathrm{SiO}_{2}$ ) or by grinding and then fusing natural rock quartz (fused quartz). Damon [1973] carried out measurements that identified the difference in cryogenic thermal conductivity of the two forms of vitreous $\mathrm{SiO}_{2}$. At low temperatures, -1.5 to $20 \mathrm{~K}$, the synthetic silicas all have a similar thermal conductivity that is lower than that of fused quartz. In this temperature range, the values of thermal conductivity of fused quartz exhibit a variation of up to $-20 \%$, and show no clear correlation with chemical impurity. The recommended values of Touloukian et al. apply more closely to the fused-quartz measurements, and the quoted uncertainty at $10 \mathrm{~K}$ of $\pm 15 \%$ probably covers this variability fairly accurately. Table 6.4.2 gives the results of Damon for synthetic $\mathrm{SiO}_{2}$ in this temperature range.

The measurements of Damon on a number of specimens of vitreous $\mathrm{SiO}_{2}$ from seven different sources also corroborate the flattening of the thermal conductivity curve over a region of low temperatures from about 2 to $30 \mathrm{~K}$ (see Figure 6.4.4 and, also, Figure 6.4 .6 below). This phenomenon has received considerable attention from theorists. The phonon mean free path in glasses and amorphous 
Table 6.4.1. Recommended Thermal conductivity values for vitreous $\mathrm{SiO}_{2}$ from Touloukian et al. [1970].

\begin{tabular}{|c|c|}
\hline Temperature, $\mathrm{K}$ & Thermal Conductivity, $\mathrm{W} /(\mathrm{m} \cdot \mathrm{K})$ \\
\hline 3 & 0.080 \\
\hline 5 & 0.118 \\
\hline 6 & 0.124 \\
\hline 8 & 0.126 \\
\hline 10 & 0.127 \\
\hline 15 & 0.136 \\
\hline 20 & 0.153 \\
\hline 30 & 0.202 \\
\hline 40 & 0.266 \\
\hline 50 & 0.340 \\
\hline 60 & 0.41 \\
\hline 70 & 0.48 \\
\hline 80 & 0.55 \\
\hline 90 & 0.62 \\
\hline 100 & 0.69 \\
\hline 125 & 0.83 \\
\hline 150 & 0.95 \\
\hline 175 & 1.05 \\
\hline 200 & 1.14 \\
\hline 250 & 1.28 \\
\hline 273.2 & 1.33 \\
\hline 300 & 1.38 \\
\hline
\end{tabular}


Table 6.4.2. Thermal conductivity data of Damon [1973] on synthetic vitreous $\mathrm{SiO}_{2}$.

\begin{tabular}{cc}
\hline Temperature, $K$ & Thermal conductivity, $W /(\mathrm{m} \cdot \mathrm{K})$ \\
\hline 1.45 & 0.0262 \\
1.61 & 0.0311 \\
1.84 & 0.0371 \\
2.20 & 0.0468 \\
2.35 & 0.051 \\
2.79 & 0.062 \\
3.38 & 0.074 \\
4.14 & 0.083 \\
6.92 & 0.093 \\
8.50 & 0.095 \\
8.79 & 0.095 \\
10.1 & 0.098 \\
12.61 & 0.105 \\
15.95 & 0.115 \\
16.24 & 0.116 \\
19.0 & 0.124 \\
\hline
\end{tabular}




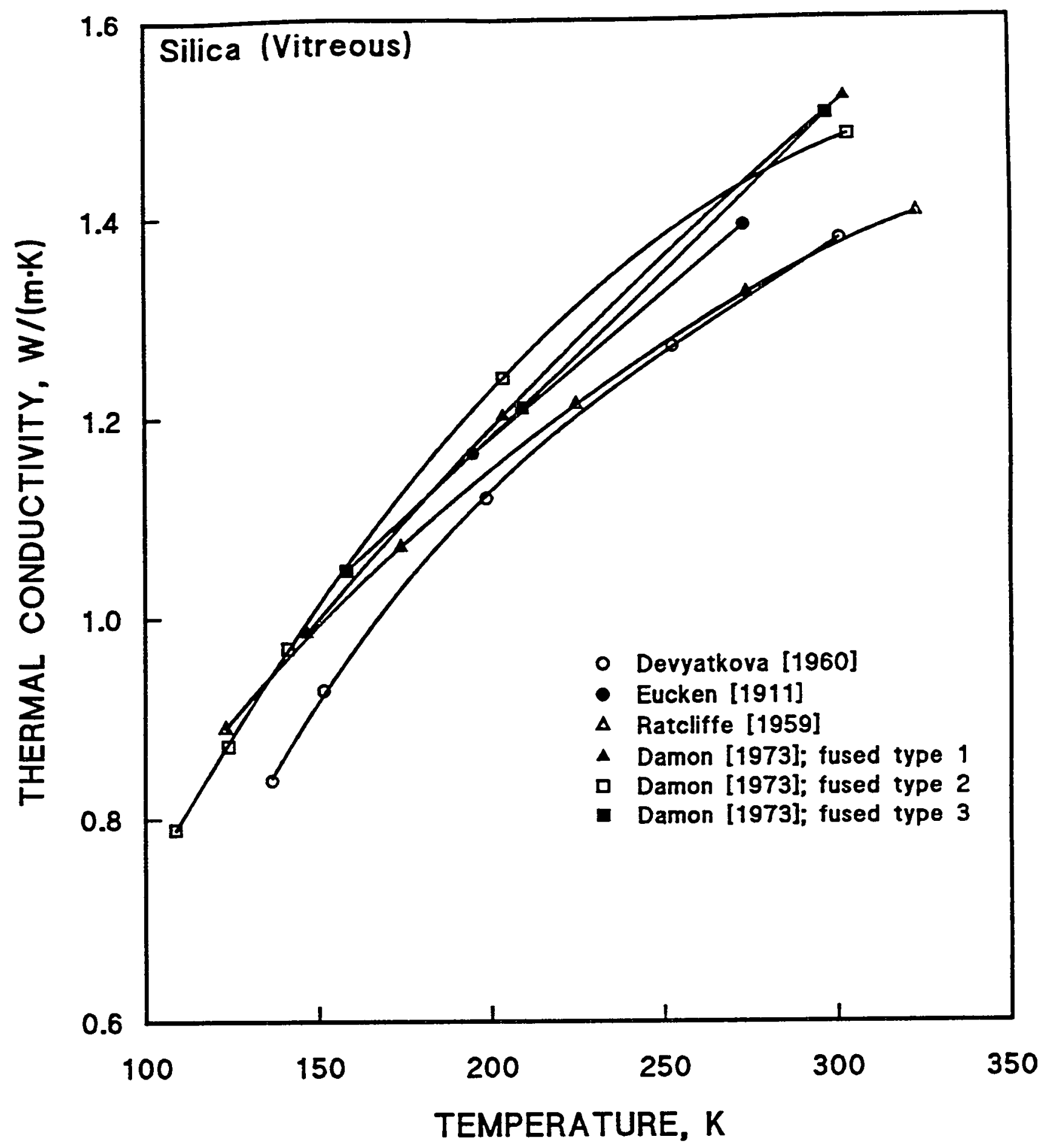

Figure 6.4.5. Measured thermal conductivity of vitreous $\mathrm{SiO}_{2}$ vs. temperature from 125 to $300 \mathrm{~K}$. Data from Damon [1973] and Ratcliffe [1963; citations therein]. 
polymers is thought to be strongly frequency dependent above $-10^{11} \mathrm{~Hz}$. This strong frequency dependence means that amorphous materials act as low pass filters for phonons so that at temperatures above about $30 \mathrm{~K}$, the heat is carried by phonons that have a longer wavelength that is more characteristic of - I K than of $30 \mathrm{~K}$. Hsieh et al. [1981] tested this theory by measuring the thermal conductivity of porous vitreous $\mathrm{SiO}_{2}$ that was obtained by leaching a commercial material. If long wavelength phonons are indeed present, then diffractive scattering of them by the holes should be reduced. Hsieh et al. were able to explain their results by assuming a strong frequency dependence of phonon scattering for bulk vitreous $\mathrm{SiO}_{2}$ and adding the scattering caused by pores. This reference may also be consulted for data on the thermal conductivity of porous, vitreous $\mathrm{SiO}_{2}$.

Above $65 \mathrm{~K}$, Damon [1973] found that the thermal conductivities of five types of vitreous $\mathrm{SiO}_{2}$ were in good agreement within experimental error. However, his values were somewhat higher than others in the literature and about 6 to 8\% higher than the recommended values in Table 6.4.1. Some data in this temperature range are plotted in Figure 6.4.5, which indicates the uncertainty. Probably, the uncertainty of the tabular values from 200 to $300 \mathrm{~K}$ should be considered to be about $6 \%$, rather than the $\pm 3 \%$ quoted by Touloukian et al. [1970].

Figure 6.4.6 shows the considerable difference between the cryogenic thermal conductivity of crystalline $\mathrm{SiO}_{2}$ (quartz) and vitreous $\mathrm{SiO}_{2}$. Figure 6.4.7 shows the recommended curve of Touloukian et al. [1970] for quartz and Table 6.4.3 gives the recommended values. However, both the figure and the table are based upon early measurements by Eucken, and there are many other measurements of crystalline $\mathrm{SiO}_{2}$ in the literature that lie between, and in fact, fill nearly all the space between the two curves shown in Figure 6.4.6. The values measured for the peak at about 10 to $15 \mathrm{~K}$ and even $4-\mathrm{K}$ values span nearly three decades and have not been well-correlated with impurity levels and other factors, although annealing was shown to increase the peak conductivity. Thus, there is considerable uncertainty in the cryogenic thermal conductivity of crystalline $\mathrm{SiO}_{2}$, and measurement of a selected material is probably necessary. Above 100 to $200 \mathrm{~K}$, the values approach those recommended by Touloukian et al. [1970] more closely. 


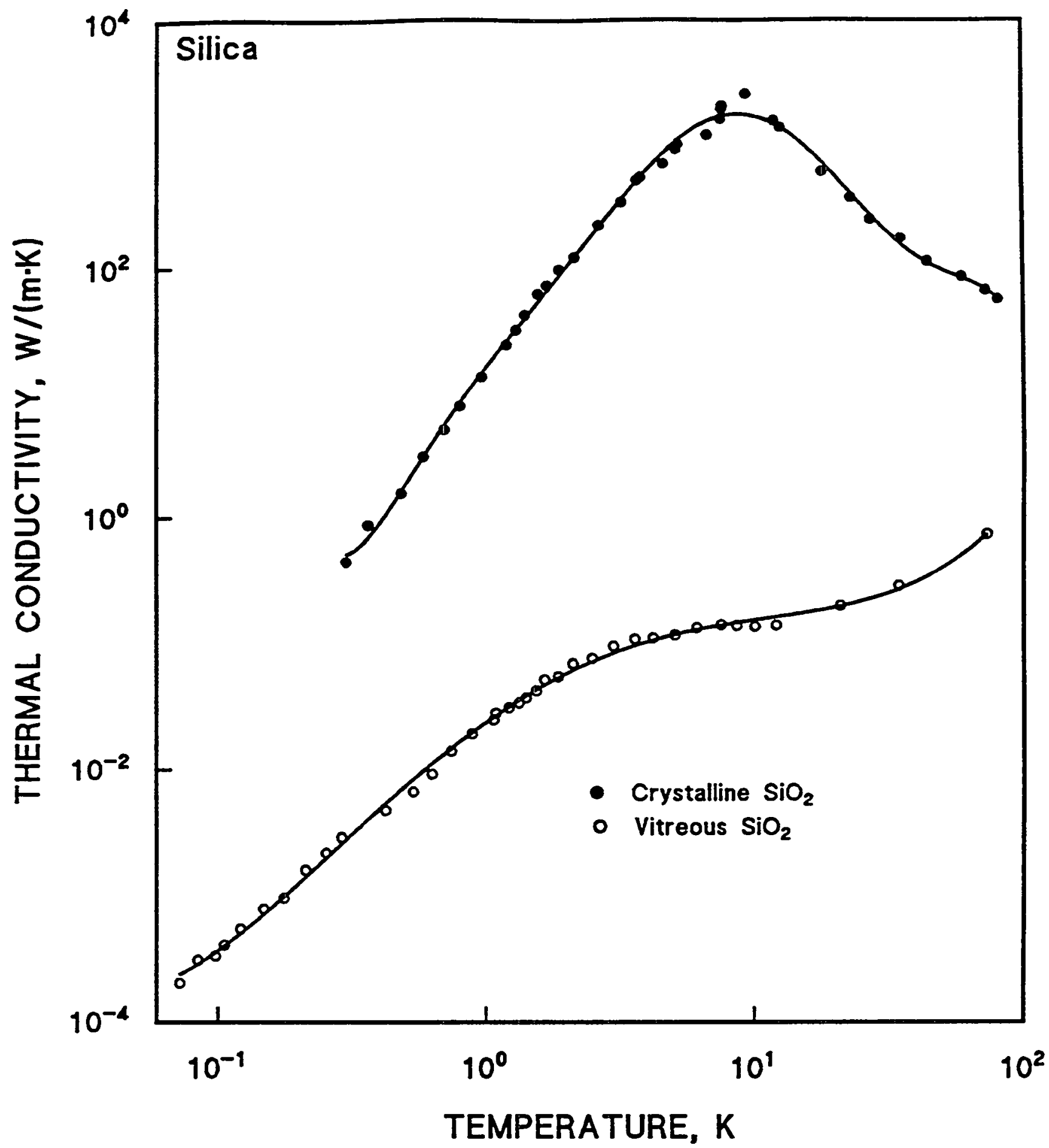

Figure 6.4.6. Thermal conductivity of crystalline and vitreous $\mathrm{SiO}_{2}$ vs. temperature. Data from Zeller and Pohl [1971]. 


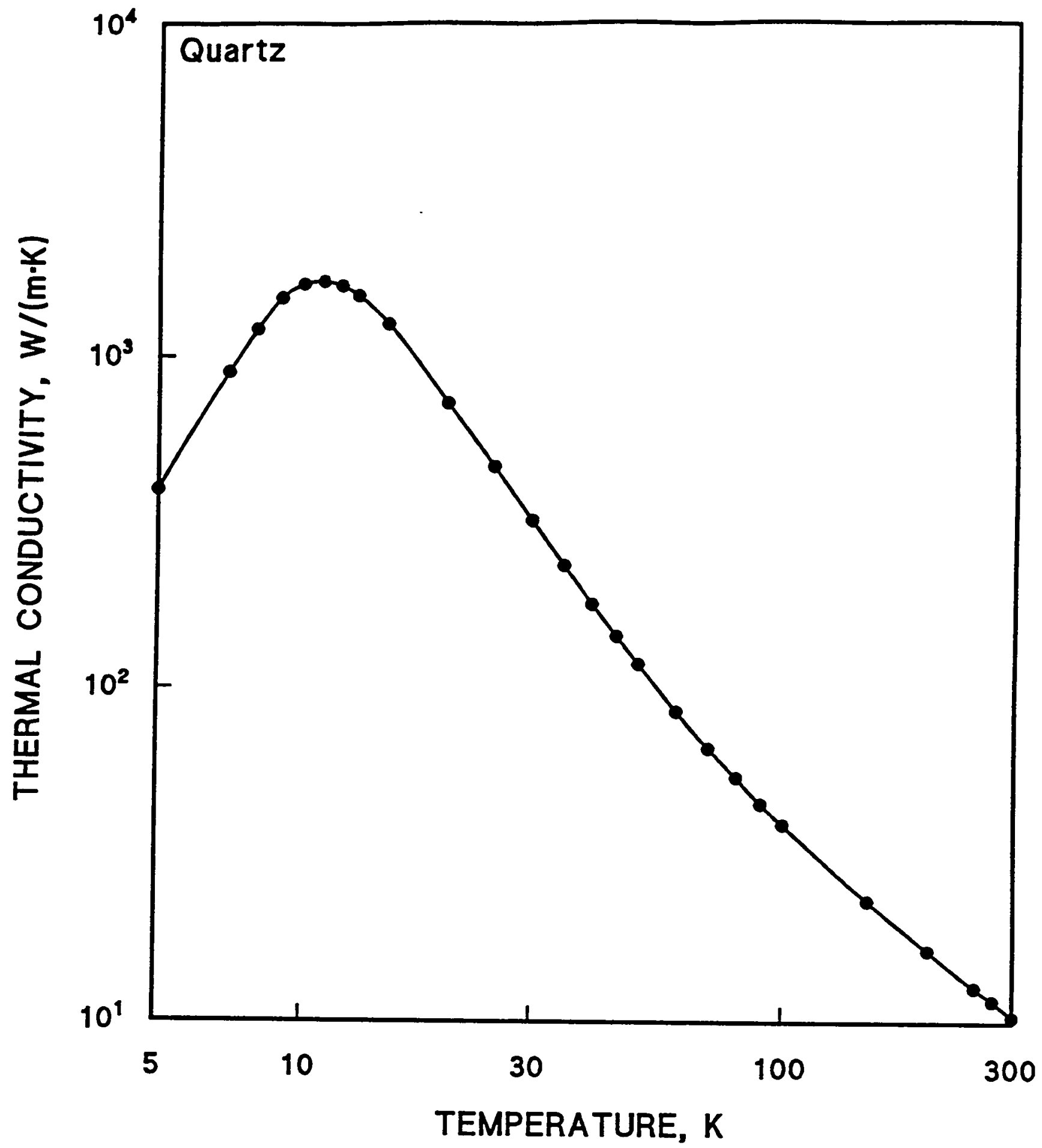

Figure 6.4.7. Recommended values for thermal conductivity of pure, annealed crystalline quartz. From Touloukian et al. [1970]. 
Table 6.4.3. Recommended values for the thermal conductivity of quartz from Touloukian et al. [1970].

\begin{tabular}{|c|c|c|}
\hline Temperature, $\mathrm{K}$ & $\begin{array}{l}\text { Thermal conductivity, } \\
\mathrm{W} /(\mathrm{m} \cdot \mathrm{K}), \quad \text { to } \mathrm{c} \text { axis }\end{array}$ & $\begin{array}{l}\text { Thermal conductivity, } \\
W /(m \cdot K), \perp \text { to } c \text { axis }\end{array}$ \\
\hline 5 & 400 & 300 \\
\hline 7 & $900^{\circ}$ & 660 \\
\hline 8 & 1210 & 860 \\
\hline 9 & 1500 & 1000 \\
\hline 10 & 1650 & 1040 \\
\hline 11 & 1680 & 1030 \\
\hline 12 & 1630 & 970 \\
\hline 13 & 1520 & 870 \\
\hline 15 & 1250 & 670 \\
\hline 20 & 720 & 370 \\
\hline 25 & 460 & 235 \\
\hline 30 & 318 & 161 \\
\hline 35 & 233 & 118 \\
\hline 40 & 179 & 89 \\
\hline 45 & 143 & 71 \\
\hline 50 & 118 & 58.5 \\
\hline 60 & 85 & 42.9 \\
\hline 70 & 66 & 33.7 \\
\hline 80 & 54 & 27.9 \\
\hline 90 & 45 & 23.9 \\
\hline 100 & 39 & 20.8 \\
\hline 150 & 23.1 & 13 \\
\hline 200 & 16.4 & 9.5 \\
\hline 250 & 12.7 & 7.5 \\
\hline 273 & 11.6 & 6.84 \\
\hline 300 & 10.4 & 6.21 \\
\hline
\end{tabular}




\subsubsection{Thermal Expansion}

The coefficient of thermal expansion of vitreous $\mathrm{SiO}_{2}$ is anomalous, falling to negative values below $200 \mathrm{~K}$. Also, considerable variability is exhibited among specimens of different thermal history. Both of these features are illustrated by data in Figure 6.4.8 from White [1973]. The figure also includes cryogenic data obtained by other investigators. Commercial glasses that contain other components in addition to $\mathrm{SiO}_{2}$ generally do not exhibit as pronounced a temperature anomaly, as indicated in Figure 6.4.9 from White [1964]. The extent of the temperature anomaly appears to vary with the percentage of $\mathrm{SiO}_{2}$ contained in the material: Vycor contains $96 \% \mathrm{SiO}_{2}$, boroilicate glass contains $80 \% \mathrm{SiO}_{2}$, and soda-lime glass contains $72 \% \mathrm{SiO}_{2}$.

Differences in the total thermal expansion of vitreous $\mathrm{SiO}_{2}$ from 293 to $4 \mathrm{~K}$ are considerable, and reflect the differences in preparation and $\mathrm{OH}$ impurity of the material. Figure 6.4.10 shows experimental data and recommended total expansion curves for three types of vitreous $\mathrm{SiO}_{2}$ : I $(1400 \mathrm{~K})$ is prepared by fusing quartz crystal powder in vacuum or a low pressure, inert-gas atmosphere, giving negligible $\mathrm{OH}$; II $(1300 \mathrm{~K})$ and $\mathrm{II}(1900 \mathrm{~K})$ are prepared by fusing quartz crystals in a flame, giving about 0.04 mass\% OH. The temperatures in parentheses refer to fictive temperatures from which the glass has been quenched. Equations for types I and II, valid from 80 to $293 \mathrm{~K}$, are as follows :

Type I (1400 K), $\Delta \mathrm{L} / \mathrm{L}_{293 \mathrm{~K}}=0.008-1.479 \times 10^{-4} \mathrm{~T}+5.458 \times 10^{-7} \mathrm{~T}^{2}-4.773 \times 10^{-10} \mathrm{~T}^{3} ;$

Type II (1300 K), $\Delta \mathrm{L} / \mathrm{L}_{293 \mathrm{~K}}-0.011-2.303 \times 10^{-4} \mathrm{~T}+9.968 \times 10^{-7} \mathrm{~T}^{2}-1.181 \times 10^{-10} \mathrm{~T}^{3}$.

Considerable additional expansion may occur between 80 and $4 \mathrm{~K}$, as indicated by the experimental data in Figure 6.4.10. However, the total expansion from 293 to $4 \mathrm{~K}$ is $\leq 0.01 \%$, which is small in magnitude compared to the contraction of typical insulators, such as 0.1 to $0.3 \%$ for crystalline $\mathrm{SiO}_{2}$ (quartz) discussed below or -0.08 for $\mathrm{Al}_{2} \mathrm{O}_{3}(\$ 2.4 .3)$. 


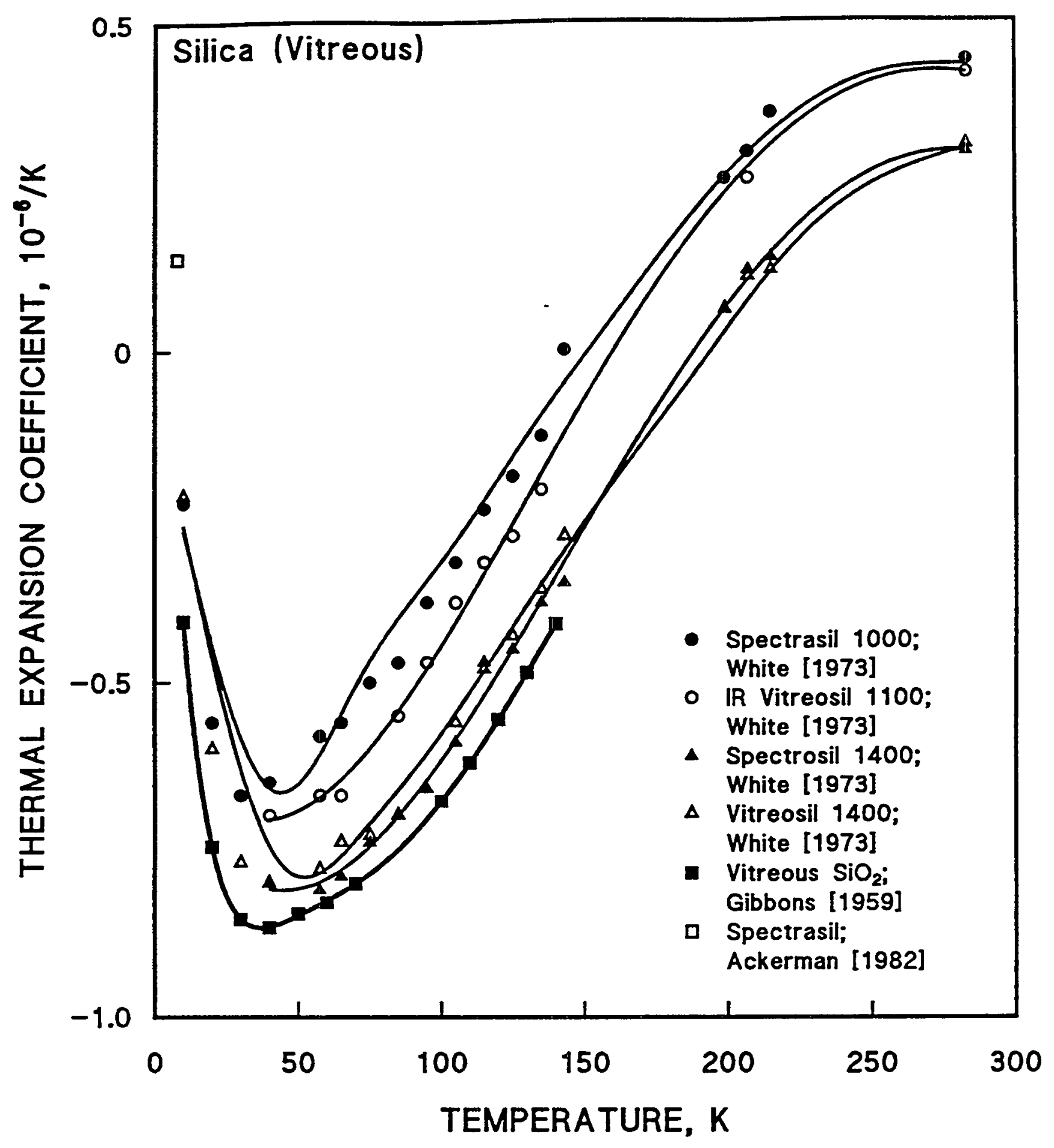

Figure 6.4.8. Thermal expansion coefficient of various types of vitreous $\mathrm{SiO}_{2}$ vs. temperature. Data from White [1973; citations therein], Gibbons [1959], and Ackerman [1982]. 


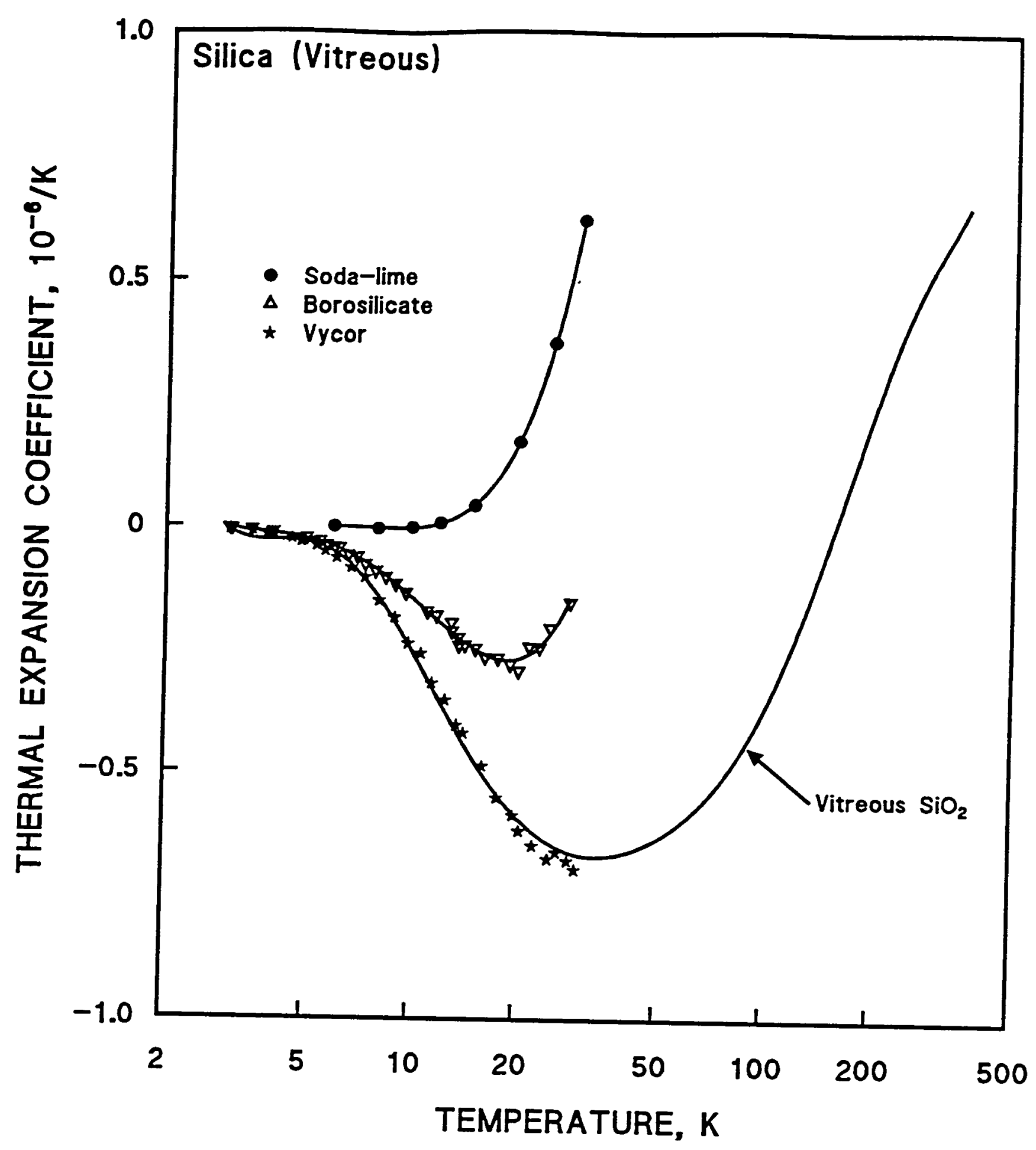

Figure 6.4.9. Comparison of the thermal expansion coefficient of various glasses with vitreous $\mathrm{SiO}_{2}$ vs. temperature. See text for $\mathrm{SiO}_{2}$ content. Data from White [1964]. 


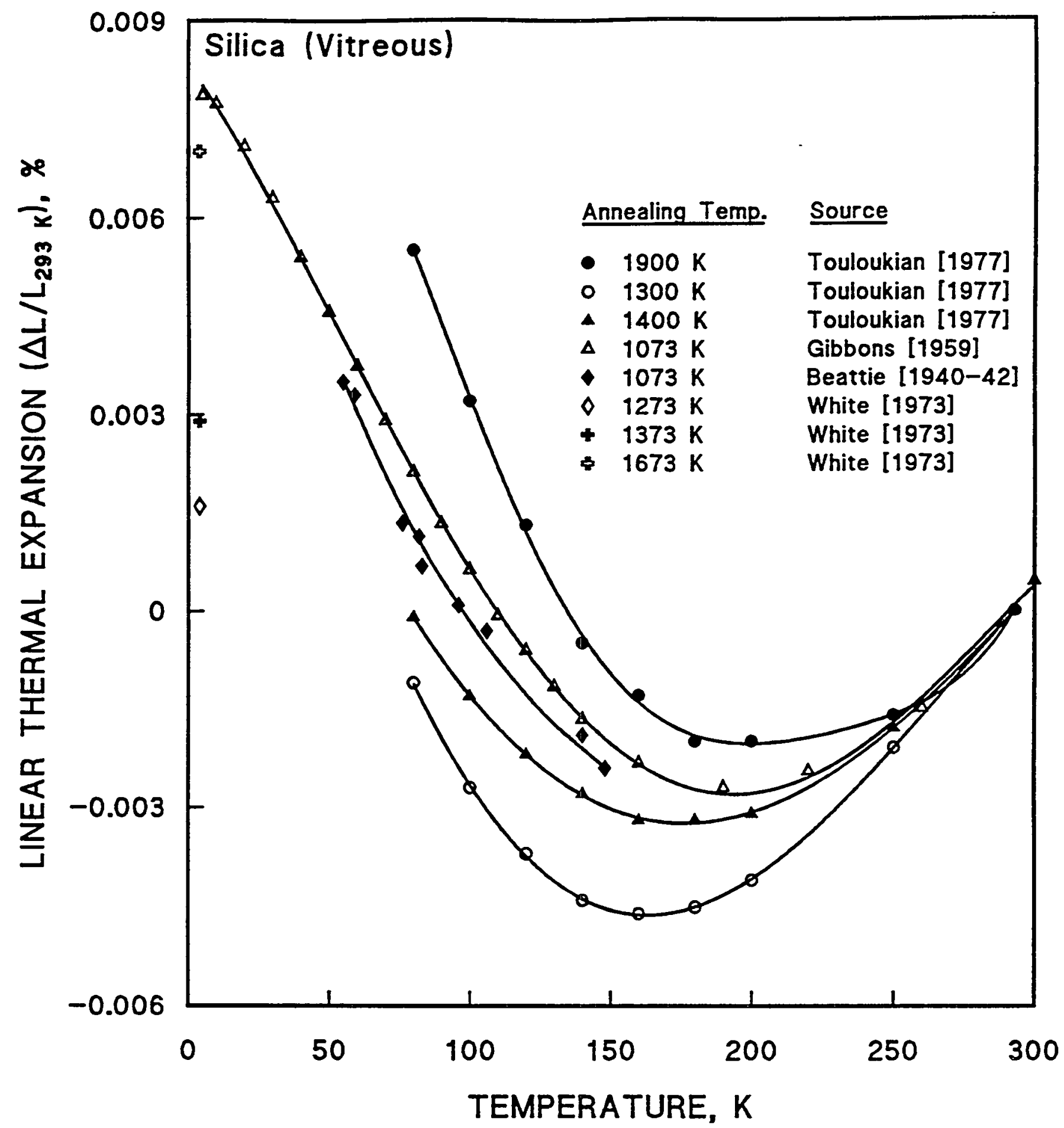

Figure 6.4.10. Linear thermal expansion of various types of vitreous $\mathrm{SiO}_{2}$ from 293 K. Data from Touloukian et al. [1977], Gibbons [1959; citations therein], and White [1973]. 


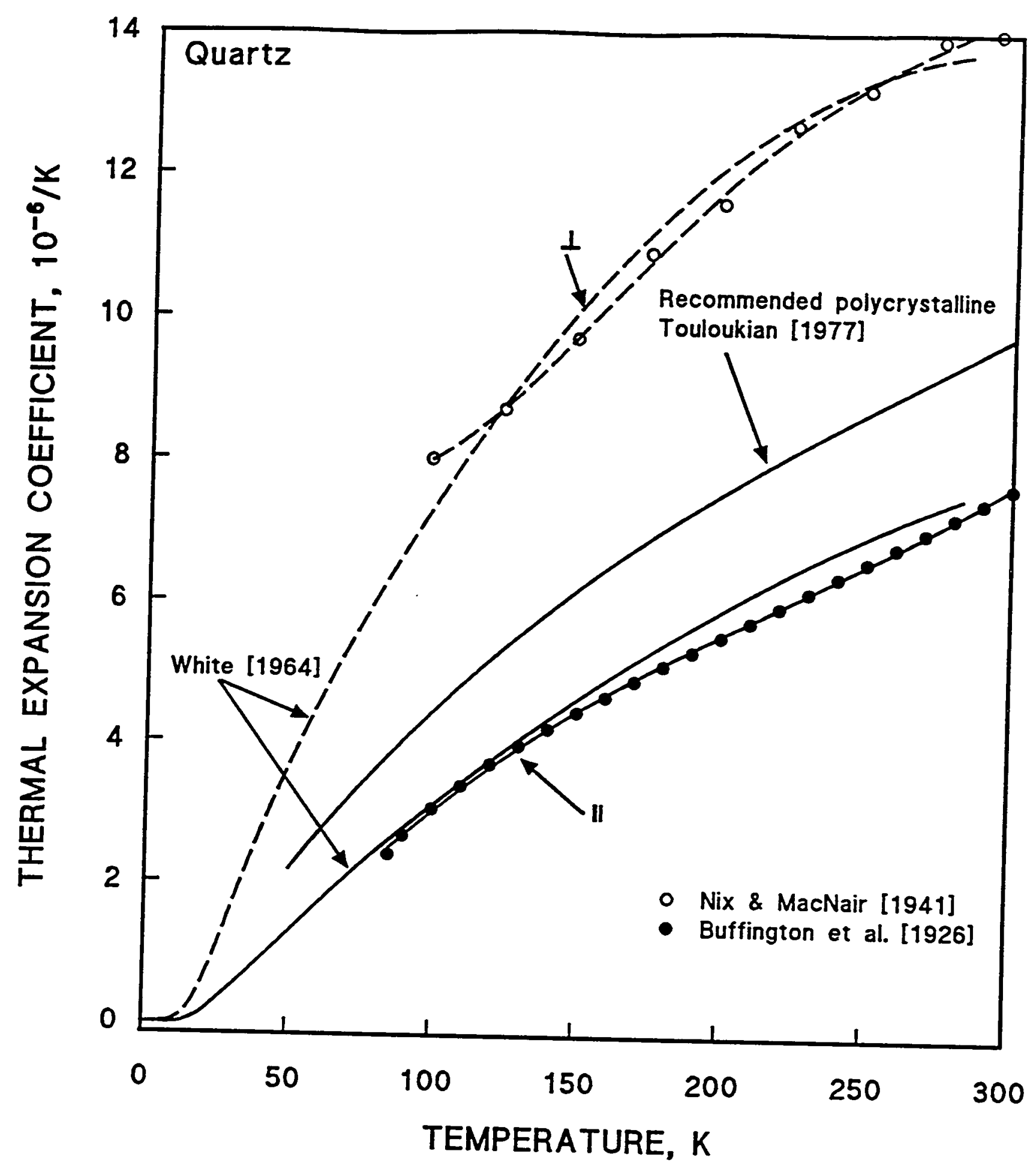

Figure 6.4.11. Thermal expansion coefficient of quartz $\perp$ and $\|$ to the optic (c) axis. Data from White [1964] and Touloukian et al. [1977; citations therein]. 


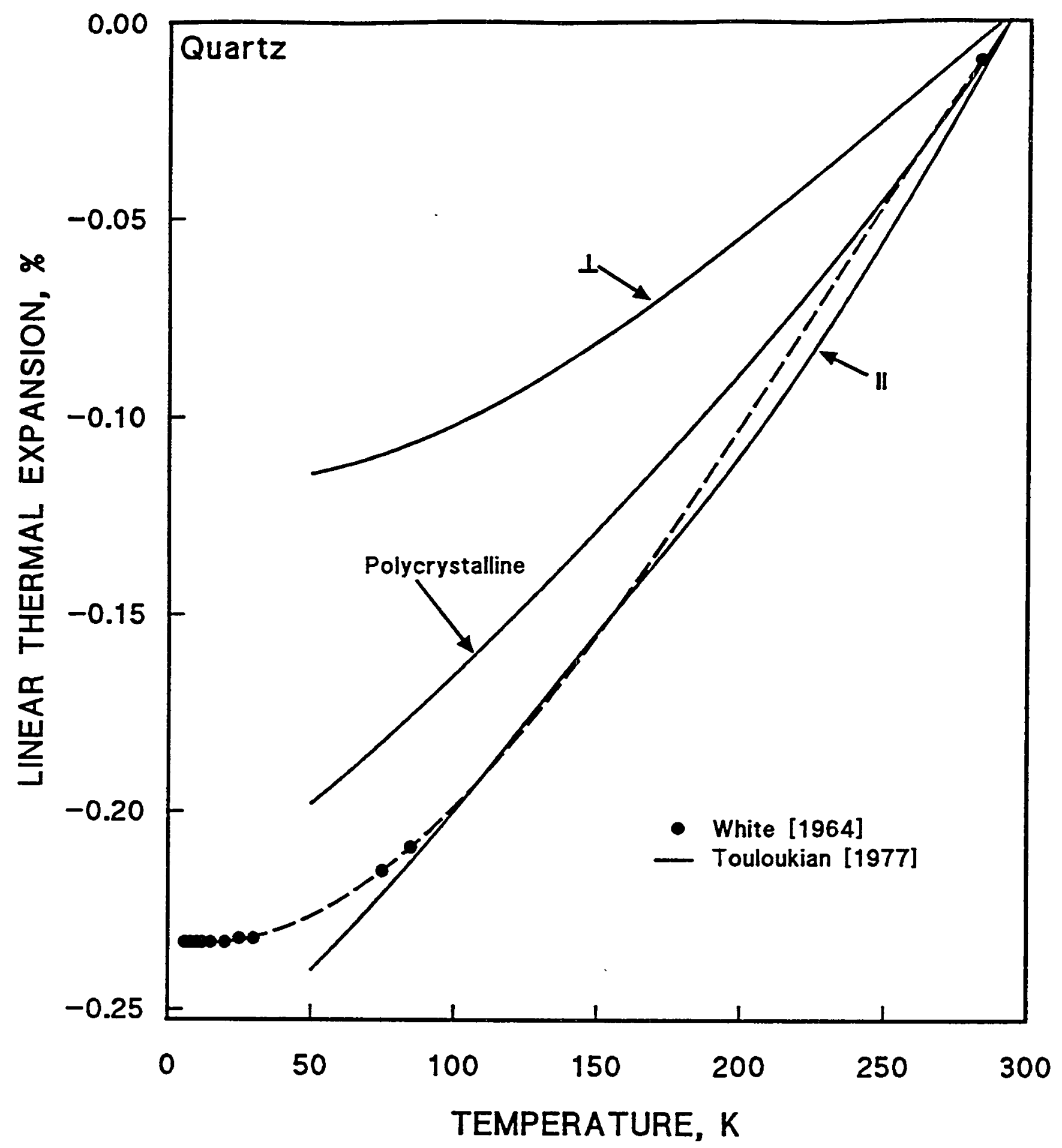

Figure 6.4.12. Recommended linear thermal expansion of quartz from $293 \mathrm{~K}$ from Touloukian et al. [1977]. Lower temperature data from White [1964]. 
Data from several authors on the thermal expansion coefficient of quartz are shown in Figure 6.4.11, parallel and perpendicular to the optic (c) axis. A more recent publication of White's group [Barron et al., 1982] presents values in agreement with those of White in Figure 6.4.11. Figure 6.4.12 shows recommended linear thermal expansion values for quartz from Touloukian et al. [1977] and some experimental data from White [1964] integrated by Touloukian et al. The equations for the recommended values for polycrystalline material, valid from 50 to $800 \mathrm{~K}$, are:

$\Delta \mathrm{L} / \mathrm{L}_{293 \mathrm{~K}}=-0.236+6.912 \times 10^{-4} \mathrm{~T}+5.559 \times 10^{-9} \mathrm{~T}^{2}+1.312 \times 10^{-9} \mathrm{~T}^{3}$ 
7. SPINEL

\subsection{MECHANICAI PROPERTIES}

Very little information on cryogenic mechanical properties of $\mathrm{MgAl}_{2} \mathrm{O}_{4}$ (spinel) was found in the literature search.

\subsubsection{Compressive Strength}

No measurements of the compressive strength of $\mathrm{MgAl}_{2} \mathrm{O}_{4}$ at cryogenic temperatures were found. Ambient-temperature measurements span a wide range. Krijgsman et al. [1989] reported values from 584 to $611 \mathrm{MPa}$ for several sintered pellet specimens, noting that these values were at least a factor of 4 above a previously published value of $130 \mathrm{MPa}$ [citation, Krijgsman et al., 1989]. The compressive strength of Krijgsman et al. was calculated from an equation, because the measurements were done on pellets. Initial particle sizes of the material were 2 to $10 \mu \mathrm{m}$, but grain size after sintering at $1873 \mathrm{~K}$ was not reported. By using the well-known factor of 8 ( $\$ 1.1 .1)$ to multiply tensile strengths obtained from handbook flexural strength values [Kingon et al., 1991], estimates of the compressive strength from 880 to $1690 \mathrm{MPa}$ are obtained. These values should be somewhat high, since the flexural strength is usually higher than the pure tensile strength, which is more difficult to measure. However, Rice [1971; citations therein] reported a compressive strength value of $2.8 \mathrm{GPa}$ for polycrystalline $\mathrm{MgAl}_{2} \mathrm{O}_{4}$.

\subsubsection{Shear/Compressive Strength}

Recently, a value of $91.6 \pm 4.7 \mathrm{MPa}$ was reported for the $76-\mathrm{K}$ shear strength of a plasma-sprayed, $\mathrm{MgAl}_{2} \mathrm{O}_{4}$ coating tested at $15^{\circ}$ (see $\$ 1.1 .6$ ) as part of a hybrid specimen [Fabian and Reed, 1994]. The compressive stress at failure was $25.5 \pm 1.3 \mathrm{MPa}$. All failures were in the ceramic layer or between the ceramic and glass. At $4 \mathrm{~K}$, a shear strength of $98.8 \pm 5.8 \mathrm{MPa}$ with a compressive stress of $26.5 \pm 1.6 \mathrm{MPa}$ was obtained for this coating, but some failures were mixed or in the composite, rather than in the ceramic. Three specimens were tested at each temperature. As noted above (\$1.1.6), failures with a test fixture angle of $45^{\circ}$ occurred in the composite, so only a lower 
limit of the shear/compressive strength of the ceramic was obtained. This value was $181 \pm 7.6 \mathrm{MPa}$ at $76 \mathrm{~K}$ and $174 \pm 9.3 \mathrm{MPa}$ at $4 \mathrm{~K}$, again based upon three specimens at each temperature.

\subsubsection{Fracture Toughness}

A fracture toughness value of $1.73 \mathrm{MPa} \cdot \sqrt{\mathrm{m}}$ at ambient temperature was reported for $\mathrm{MgAl}_{2} \mathrm{O}_{4}$ at ambient temperature [Hartnett and Gentilman, 1984]. This value was measured with an indentation technique. Loads varied from $3.92 \mathrm{~N}$ (400 $\mathrm{g}$ ) to $9.8 \mathrm{~N}$ (1-kg mass). The powder-processed specimens had a bimodal grain structure with two average grain sizes of 65 and $4 \mu \mathrm{m}$. A toughness value of 1.3 $\mathrm{MPa} \cdot \sqrt{\mathrm{m}}$ was reported for single-crystal $\mathrm{MgAI}_{2} \mathrm{O}_{4}$ [citation, Hartnett and Gentilman, 1984].

\subsection{EIASTIC PROPERTIES}

Again, cryogenic measurements were not found in the literature search. For the Young's modulus, ambient-temperature values reported in a handbook were 240 to $260 \mathrm{GPa}$ [Kingon et al., 1991]. In a comparative study, Dienst et al. [1990] reported ultrasonic Young's modulus measurements of $270 \mathrm{GPa}\left(\mathrm{MgAl}_{2} \mathrm{O}_{4}\right)$, $380 \mathrm{GPa}\left(\mathrm{Al}_{2} \mathrm{O}_{3}\right)$, and $320 \mathrm{GPa}(\mathrm{AlN})$ at ambient temperature. Hartnett and Gentilman [1984] reported a Young's modulus of $277 \mathrm{GPa}$, a shear modulus of $110 \mathrm{GPa}$, and a Poisson's ratio of 0.26 on transparent, optical quality material with a bimodal grain size distribution of 65 and $4 \mu \mathrm{m}$. The material was fabricated by powder processing methods.

\subsection{ELECTRICAL PROPERTIES}

\subsubsection{Electrical Breakdown Strength}

Cryogenic data on the electrical breakdown strength of $\mathrm{MgAl}_{2} \mathrm{O}_{4}$ were not found in the literature search. Recent dc measurements gave a value of 37.9 $\pm 6.7 \mathrm{kV} / \mathrm{mm}$ at $76 \mathrm{~K}$ in liquid $\mathrm{N}_{2}$ for a thin coating $\left(0.292 \mathrm{~mm}\right.$ ) of $\mathrm{MgAl}_{2} \mathrm{O}_{4}$ on a stainless steel disk [Fabian and Reed, 1994]. 


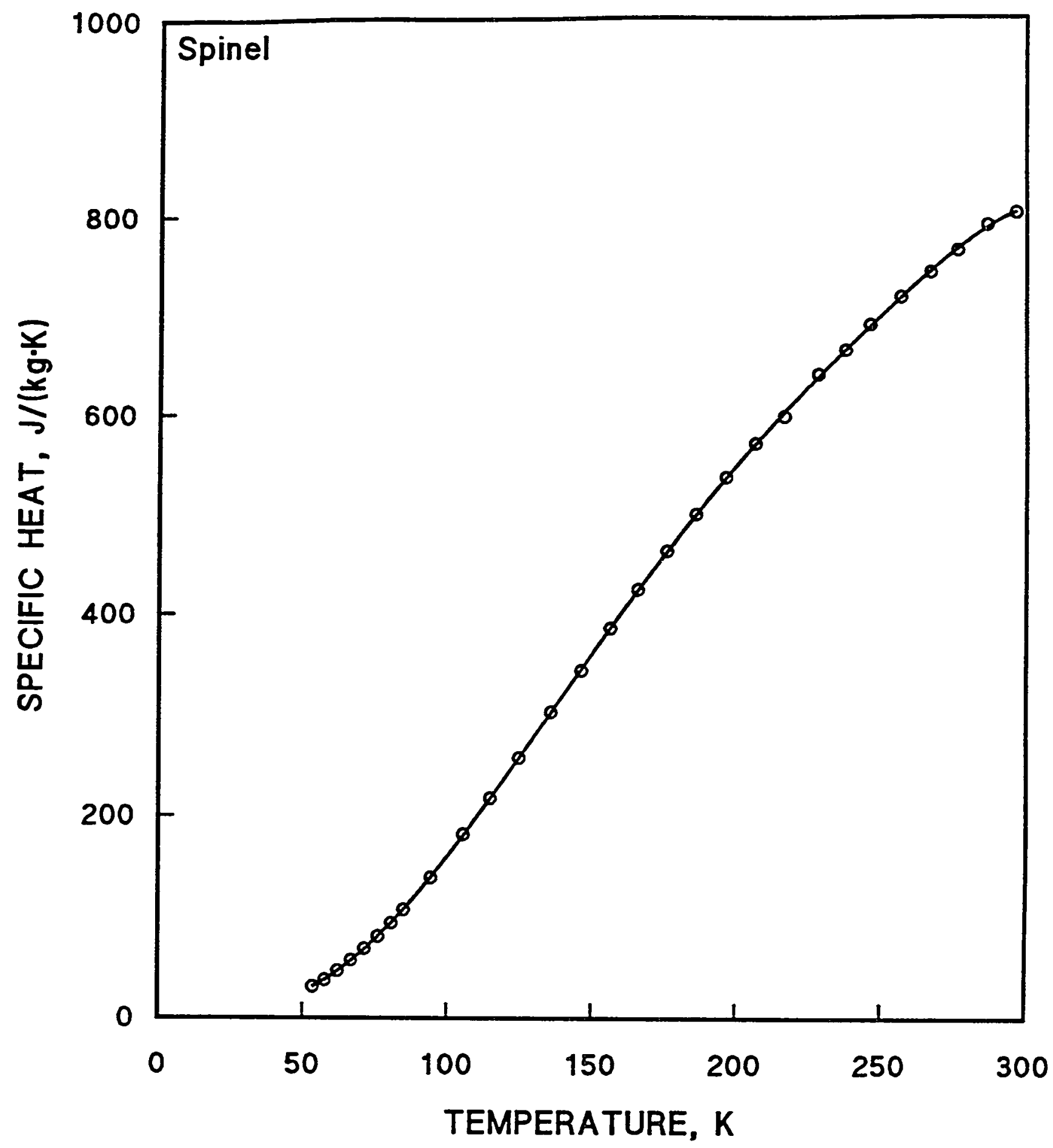

Figure 7.4.1. Specific heat of $\mathrm{MgAl}_{2} \mathrm{O}_{4}$ vs. temperature. Data from Touloukian and Buyco [1970; citation therein]. 
Ambient-temperature measurements of the electrical breakdown strength of $\mathrm{MgAl}_{2} \mathrm{O}_{4}$ specimens that were synthesized at various temperatures, but sintered at $1500^{\circ} \mathrm{C}$, were made by Totsenko et al. [1966]. The open porosity varied from 8 to $26 \%$, depending upon the temperature of synthesis. Surprisingly, the highest breakdown strength of $-27 \mathrm{kV} / \mathrm{mm}$ was reported for the specimen of highest porosity. Strengths at lower porosities were about 19 and $18 \mathrm{kV} / \mathrm{mm}$.

\subsubsection{Other Electrical Properties}

Additional measurements made on electrical properties of optical $\mathrm{MgAl}_{2} \mathrm{O}_{4}$ were not specified in detail in the resulting publication note [Briggs and Johnson, 1973], but the material was said to be an extremely low loss dielectric. Totsenko et al. reported the loss tangent to range between 1 to $4 \times 10^{-4}$ and the dielectric constant, $\epsilon$, to be 7 to 7.5 , below that of corundum.

\subsection{THERMAL PROPERTIES}

\subsubsection{Specific Heat}

Data on the specific heat of $\mathrm{MgAl}_{2} \mathrm{O}_{4}$ from 54 to $296 \mathrm{~K}$ are presented in Figure 7.4.1. Note that all the data are from one investigation. The composition was nearly exactly stoichiometric.

\subsubsection{Thermal Conductivity}

Only data on the cryogenic thermal conductivity of single-crystal $\mathrm{MgAl}_{2} \mathrm{O}_{4}$ were found in the Iiterature search [Slack, 1962]. These data on two specimens are presented in Figure 7.4.2. Comparative cryogenic studies of other singlecrystal conductivities by slack indicated that the thermal conductivity of single-crystal $\mathrm{MgAl}_{2} \mathrm{O}_{4}$ was intermediate between that of $\mathrm{Al}_{2} \mathrm{O}_{3}$ and $\mathrm{MgO}$. $\mathrm{A}$ comparative graph of the thermal conductivity of $\mathrm{AlN}, \mathrm{Al}_{2} \mathrm{O}_{3}$, and $\mathrm{MgAl}_{2} \mathrm{O}_{4}$ above $300 \mathrm{~K}$ (Figure 3.4.4) indicated that the polycrystalline thermal conductivity of $\mathrm{MgAl}_{2} \mathrm{O}_{4}$ was the lowest of the group. At $393 \mathrm{~K}$, a handbook value for the polycrystalline thermal conductivity is $15 \mathrm{~W} /(\mathrm{m} \cdot \mathrm{K})$, about half that of $\mathrm{Al}_{2} \mathrm{O}_{3}$ $(27 \mathrm{~W} /(\mathrm{m} \cdot \mathrm{K})$ ) [Kingon et al., 1991]. This value is in approximate agreement with thermal conductivity values for a ceramic specimen above $300 \mathrm{~K}$ quoted by 


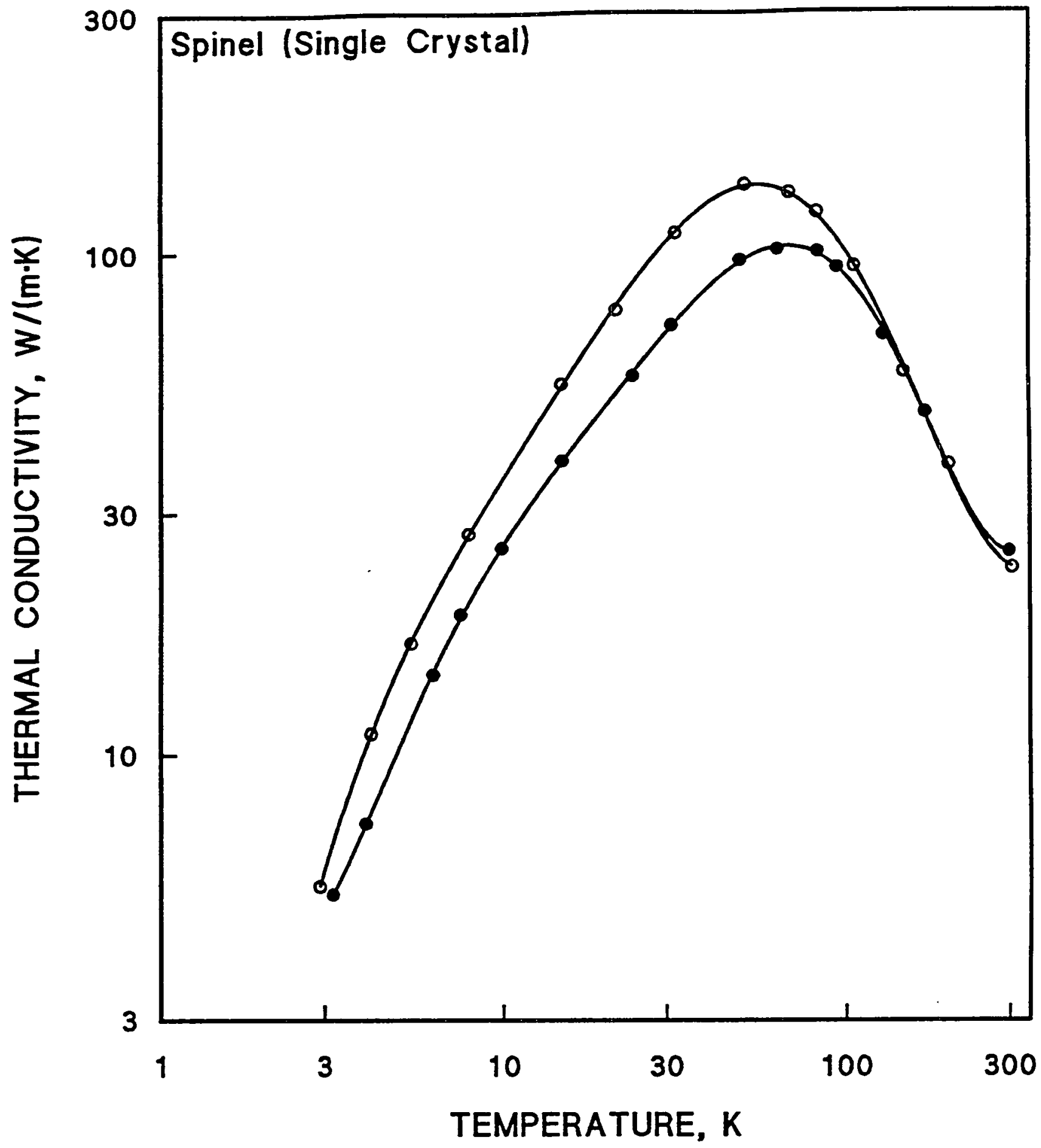

Figure 7.4.2. Thermal conductivity of single-crystal $\mathrm{MgAl}_{2} \mathrm{O}_{4}$ vs. temperature. Data from Slack [1962] on two specimens. 
slack [1962]. Since it was difficult to prepare large synthetic crystals of $\mathrm{MgAl}_{2} \mathrm{O}_{4}$, at least at the time of Slack's report, natural crystals obtained from gem sources were used. These had an impurity content of $0.2 \%$ metal atoms. Thus, the cryogenic thermal conductivity maximum would probably not be as far above that of polycrystalline material as is usually the case with single-crystal data.

\subsubsection{Thermal Expansion}

No cryogenic data on the thermal expansion of $\mathrm{MgAl}_{2} \mathrm{O}_{4}$ were found in the literature search. The relative, high-temperature thermal expansion of $\mathrm{MgAl}_{2} \mathrm{O}_{4}$ is comparable to that of $\mathrm{Al}_{2} \mathrm{O}_{3}$ and about twice that of $\mathrm{AIN}$, as shown above in Figure 3.4.5. Hartnett and Gentilman [1984] give an average value of $6.5 \times 10^{-6} / \mathrm{K}$ for the thermal expansion coefficient of $\mathrm{MgAl}_{2} \mathrm{O}_{4}$ between 30 and $200^{\circ} \mathrm{C}$ and $8.05 \times 10^{-6} / \mathrm{K}$ for the thermal expansion coefficient between 30 and $900^{\circ} \mathrm{C}$. 


\section{ZIRCONIA}

There are three well-defined structural phases exhibited by $\mathrm{ZrO}_{2}$ : the monoclinic phase is stable below about $1170^{\circ} \mathrm{C}$, the tetragonal phase is stable between about 1170 and $2370^{\circ} \mathrm{C}$, and the cubic phase is stable from $2370^{\circ} \mathrm{C}$ to the melting point of $2680^{\circ} \mathrm{C}$. Crystallographic and physical properties of these phases are tabulated in a review by Stevens [1991]. Because a large volume change of 3 to $5 \%$ occurs upon cooling from the tetragonal to monoclinic phase, elastic and fracture limits are exceeded even in relatively small grains of $\mathrm{ZrO}_{2}$, and cracking occurs. Therefore, it is not practical to fabricate large components of pure $\mathrm{ZrO}_{2}$, owing to spontaneous failure upon cooling from the sintering temperature, although some progress has been made in recent years. Oxides such as $\mathrm{CaO}, \mathrm{MgO}, \mathrm{Y}_{2} \mathrm{O}_{3}$, and $\mathrm{CeO}_{2}$ are added to $\mathrm{ZrO}_{2}$ to stabilize either the tetragonal or cubic phase. Because the tetragonal-tomonoclinic phase transformation is martensitic and stress-induced, when the tetragonal phase is retained metastably at ambient temperature, a toughening mechanism at crack tips exists from stress-induced transformation of the metastable tetragonal particles to the monoclinic form. Strength as well as toughness is improved [citations, Gupta and Andersson, 1984].

However, significant deterioration of, for example, $\mathrm{Y}_{2} \mathrm{O}_{3}$-stabilized $\mathrm{ZrO}_{2}$ occurs even at 100 to $300^{\circ} \mathrm{C}$, sometimes necessitating surface modifications, etc. [Shikata et al., 1991; Hirano, 1992]. If the martensitic transformation temperature, $M_{s}$, lies between ambient temperature and $4 \mathrm{~K}$, the excellent properties of the stabilized material will not be retained, as discussed below. Often, $M_{s}$ has not been determined for a particular system. As reviewed elsewhere [Simon, 1994], limited data on stabilized $\mathrm{ZrO}_{2}$ suggest that neutron irradiation may result in transformation to a less-desirable phase. Another problem with the cryogenic use of $\mathrm{ZrO}_{2}$-based ceramics is that the small amount of cryogenic thermal property data pertains mostly to pure $\mathrm{ZrO}_{2}$, except for some very low temperature measurements on stabilized $\mathrm{ZrO}_{2}$ (\$8.4).

\subsection{MECHANICAI PROPERTIES}

The behavior of the mechanical properties of stabilized $\mathrm{ZrO}_{2}$ depends upon the temperature of martensitic transformation, $\mathrm{M}_{\mathrm{s}}$. For $\mathrm{MgO}$-stabilized $\mathrm{ZrO}_{2}$, 
Veitch et al. [1987] showed that $M_{s}$ was about 113 to $203 \mathrm{~K}$, depending upon the grade after heat treatment. Therefore, although the flexural strength of MgOstabilized material continues to increase, down to the limit of testing, $77 \mathrm{~K}$, as Figures 8.1.1, 8.1.2, and 8.1.3 for the three grades show, the toughness, as measured by the stress intensity factor, peaks for each grade at $M_{s}$ and then declines (Figure 8.1.4).

In contrast, $\mathrm{M}_{5}$ for 3-mol\% $\mathrm{Y}_{2} \mathrm{O}_{3}-\mathrm{ZrO}_{2}$ is below $77 \mathrm{~K}$. The toughness therefore continued to increase down to the lowest temperature of $77 \mathrm{~K}$ at which testing was done. This is shown in Figure 8.1.5. The flexural strength initially increases below ambient temperature, and then, apparently, becomes about constant with temperature, as Figure 8.1.6 indicates. The grain size of the 3-mol\% $\mathrm{Y}_{2} \mathrm{O}_{3}-\mathrm{ZrO}_{2}$ material was $0.5 \mu \mathrm{m}$, whereas that of the three grades of 9.4-mol\% $\mathrm{MgO}-\mathrm{ZrO}_{2}$ was $50 \mu \mathrm{m}$. The fracture toughness tests were performed with the modified indentation technique (denoted MIT in the figures) or with the applied moment double-cantilever beam (denoted DCB). The report should be consulted for further details of the testing, including the observation of microcracking in the Mgo-stabilized material. Marshall et al. [1989] have reported the microstructural changes that occur in $\mathrm{MgO}-$ stabilized $\mathrm{ZrO}_{2}$ upon cooling to about $170 \mathrm{~K}$. Unfortunately, MgO-stabilization of $\mathrm{ZrO}_{2}$ produces the highest-toughness systems, although these systems are not stable at cryogenic temperatures.

Jikihara and Ishihara [1990] also compared $\mathrm{Y}_{3} \mathrm{O}_{3}$-stabilized $\mathrm{ZrO}_{2}$ with another material with a higher $\mathrm{M}_{s}, 12-\mathrm{mol} \% \mathrm{CeO}_{2}-\mathrm{ZrO}_{2}$. The $12-\mathrm{mol} \% \mathrm{CeO}_{2}-\mathrm{ZrO}_{2}$ was reported to have a tetragonal to monoclinic transformation temperature "from R. T. down to $77 \mathrm{~K}$." The difference in the temperature dependence of the flexural strength in three-point bending tests is shown in Figure 8.1.7. The other ceramics did not have a transformation temperature above $77 \mathrm{~K}$. The flexural strength of the $3-\mathrm{mol} \% \mathrm{Y}_{2} \mathrm{O}_{3}-\mathrm{ZrO}_{2}$ appears to increase monotonically with the decrease in temperature rather than to level off, as found by Veitch et al. (Figure 8.1.6). However, the temperature dependence of the fracture toughness of this material, shown in Figure 8.1.8, appears similar to that found by Veitch et al. [1987] (Figure 8.1.5). Jikihara and Ishihara found a very similar temperature dependence of both the flexural strength and the fracture toughness (usually estimated by fractographs). 


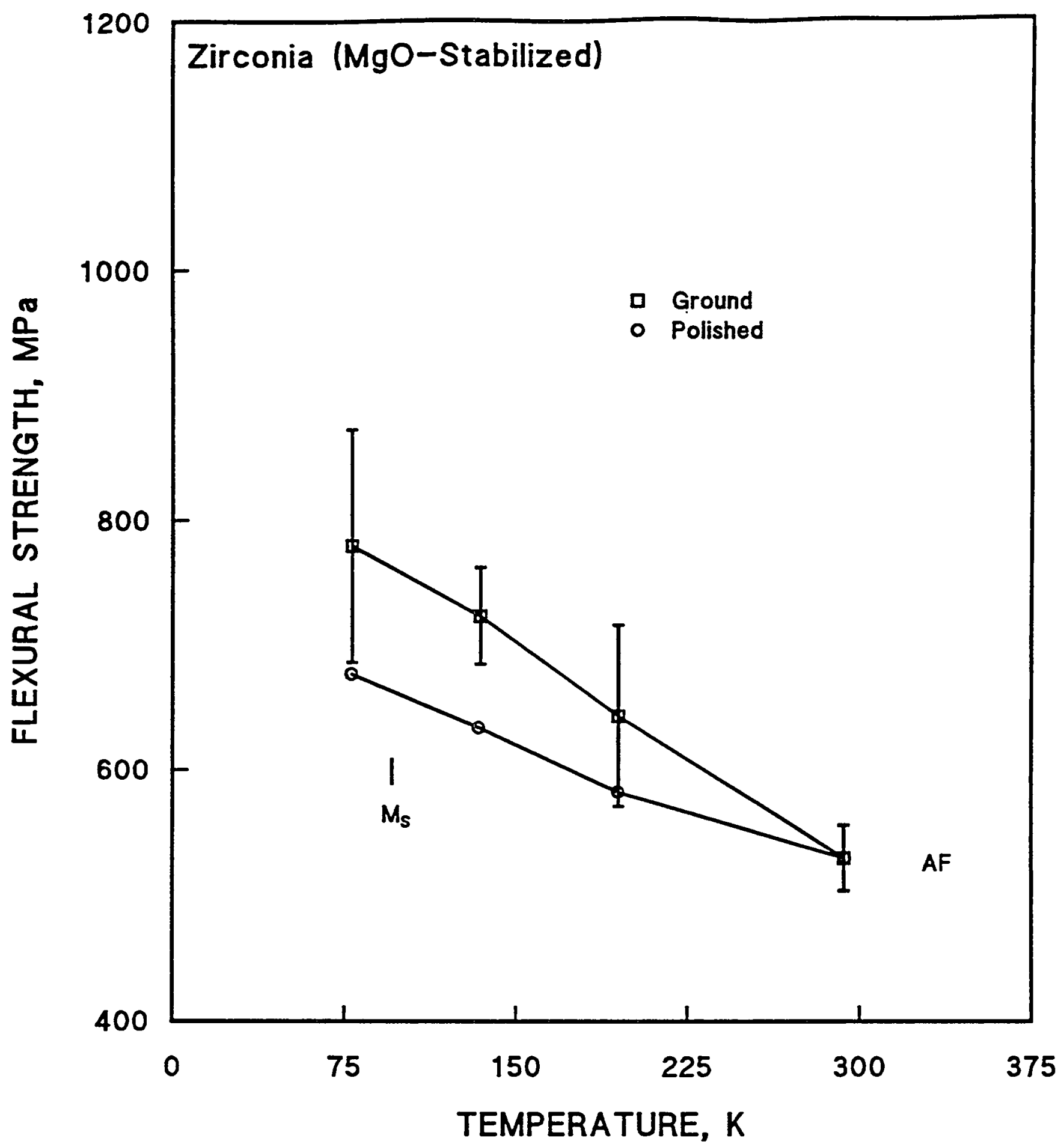

Figure 8.1.1. Flexural strength of $\mathrm{MgO}$-stabilized $\mathrm{ZrO}_{2}$ vs. temperature, for grade AF. Data from Veitch et al. [1987]. 


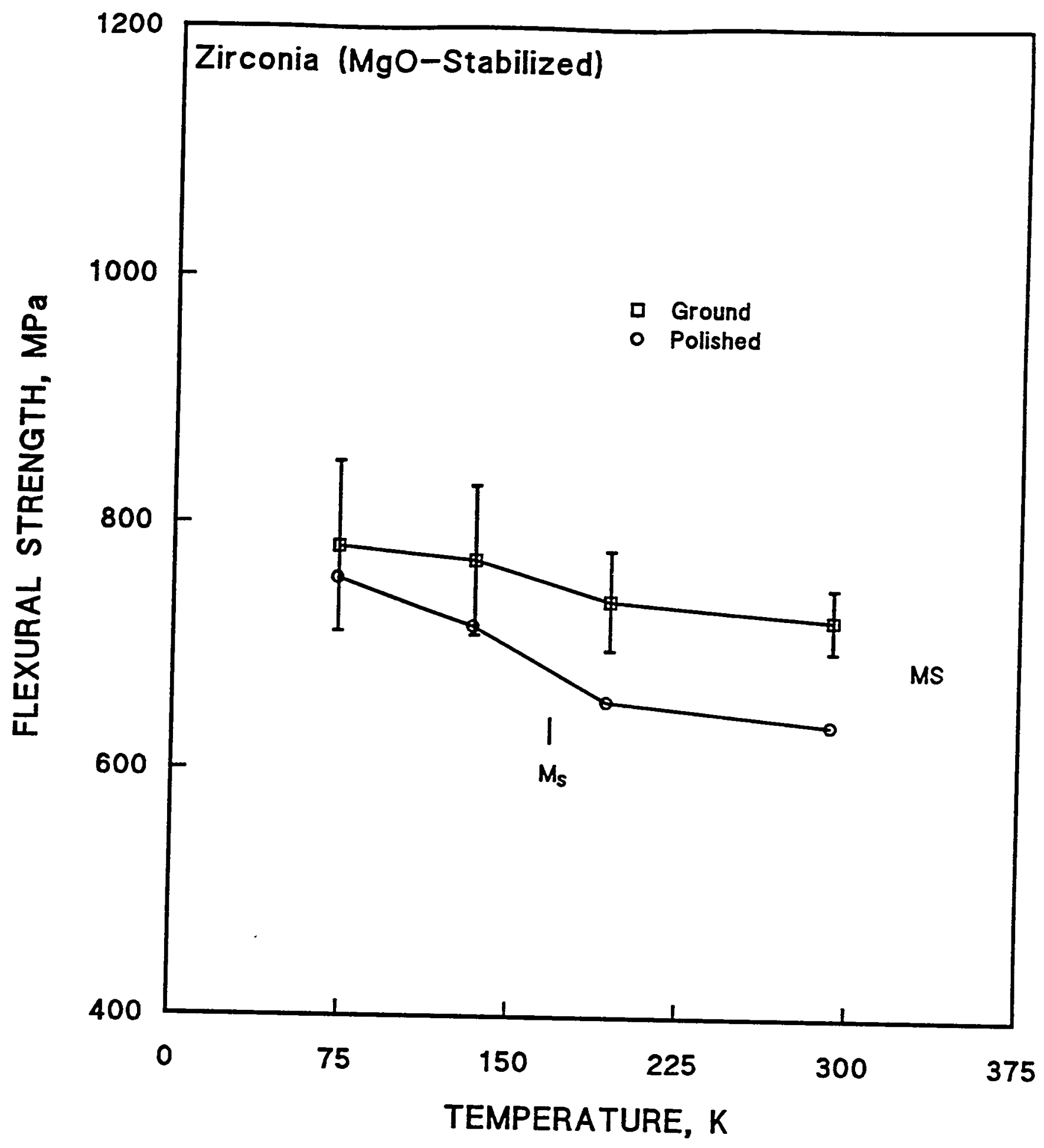

Figure 8.1.2. Flexural strength of MgO-stabilized $\mathrm{ZrO}_{2}$ vs. temperature, for grade MS. Data from Veitch et al. [1987]. 


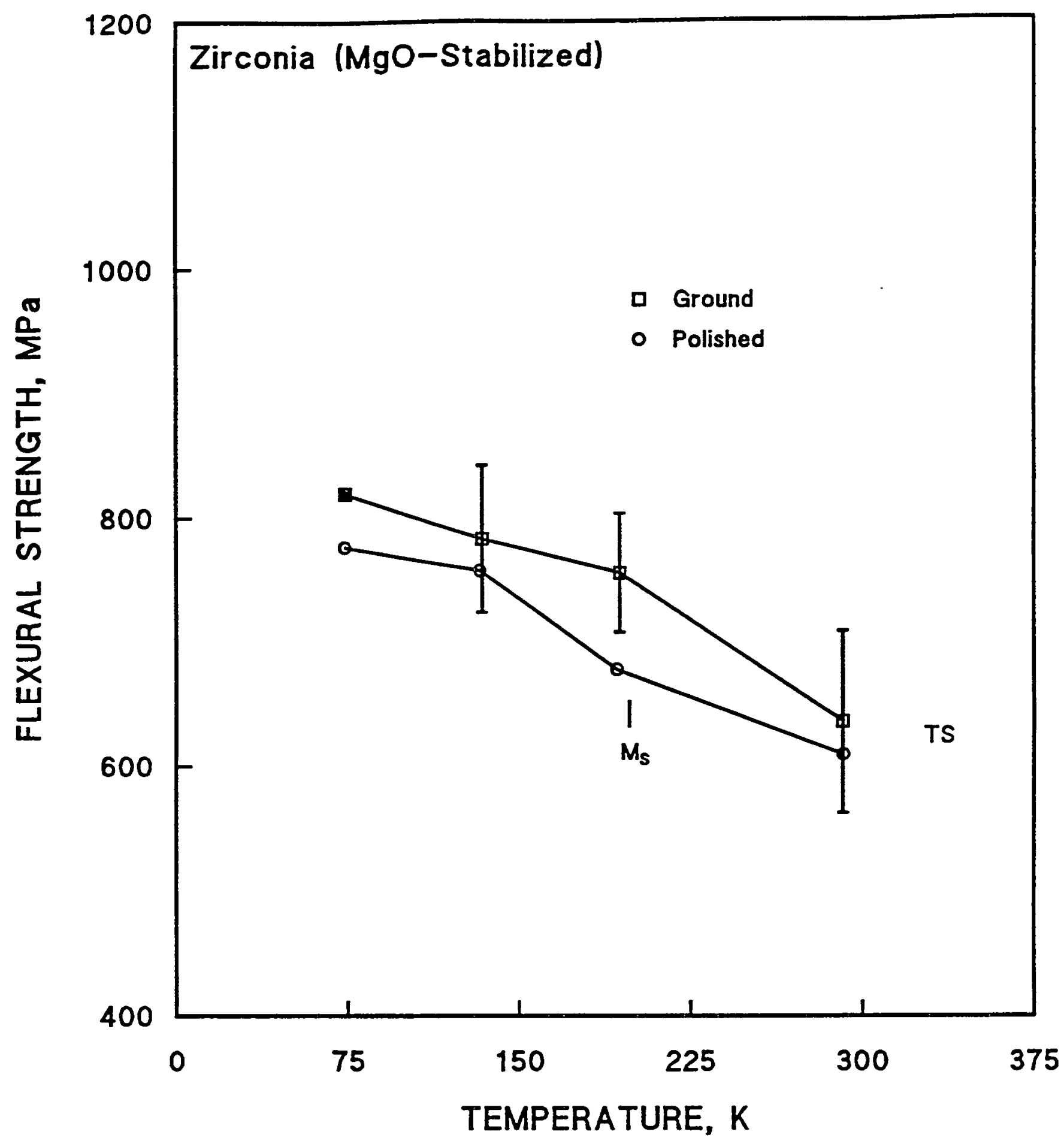

Figure 8.1.3. Flexural strength of $\mathrm{MgO}$-stabilized $\mathrm{ZrO}_{2}$ vs. temperature, for grade TS. Data from Veitch et al. [1987]. 


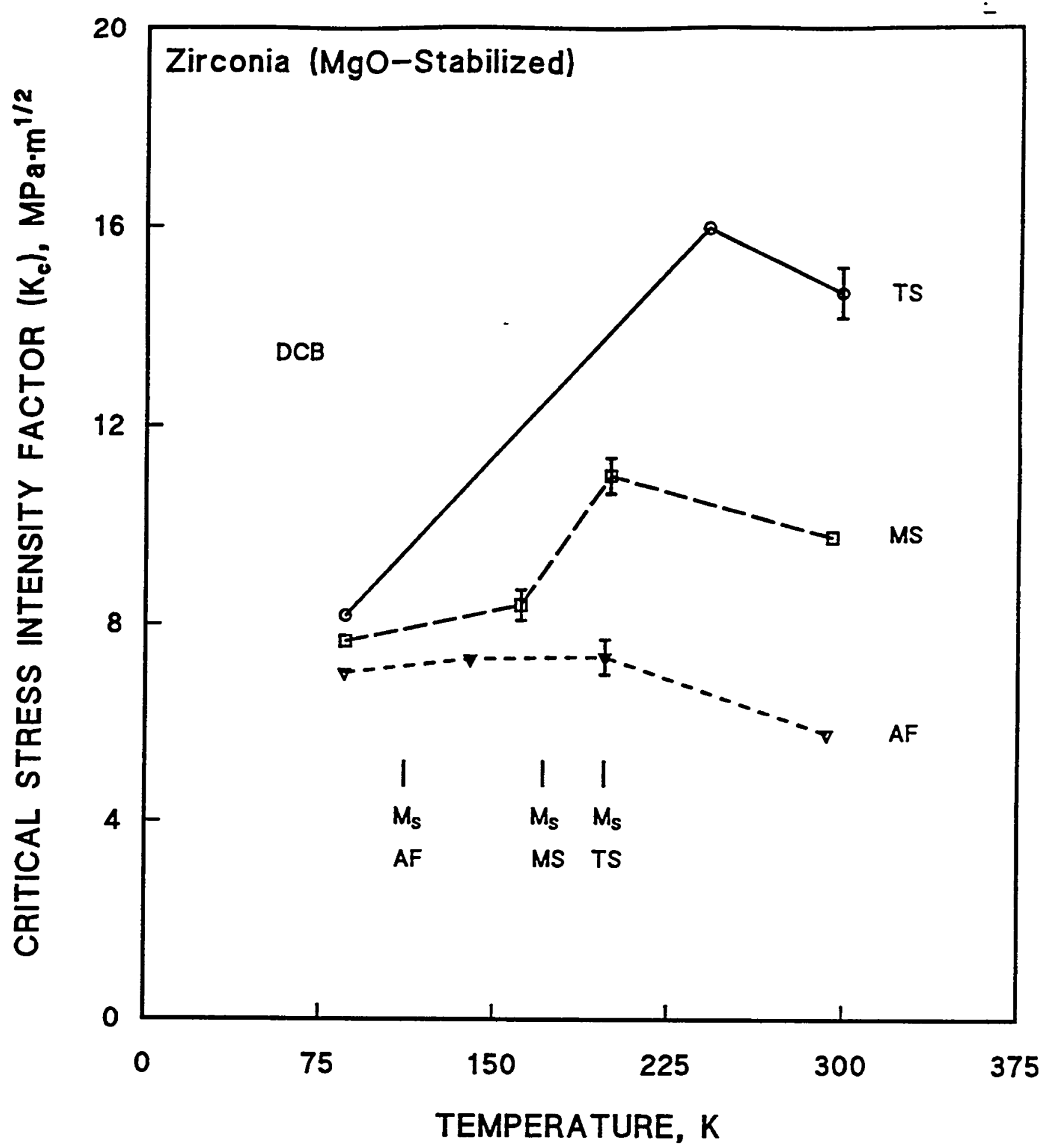

Figure 8.1.4. Fracture toughness of $\mathrm{MgO}$-stabilized $\mathrm{ZrO}_{2}$ vs. temperature for all grades, as measured by the critical stress intensity factor. Data from Veitch et al. [1987]. 


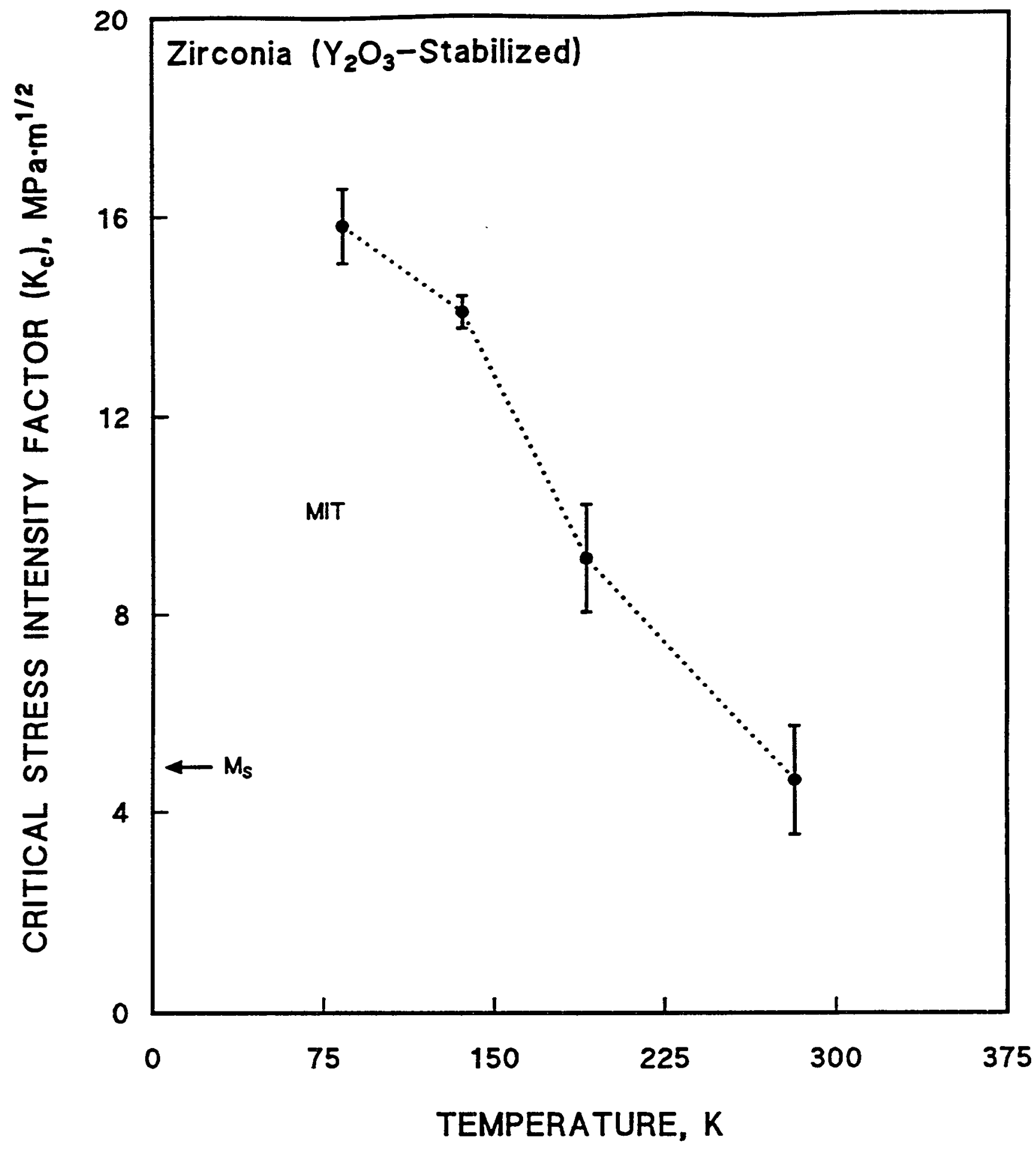

Figure 8.1.5. Fracture toughness of $\mathrm{Y}_{2} \mathrm{O}_{3}$-stabilized $\mathrm{ZrO}_{2}$ vs. temperature, as measured by the critical stress intensity factor. Data from Veitch et al. [1987]. 


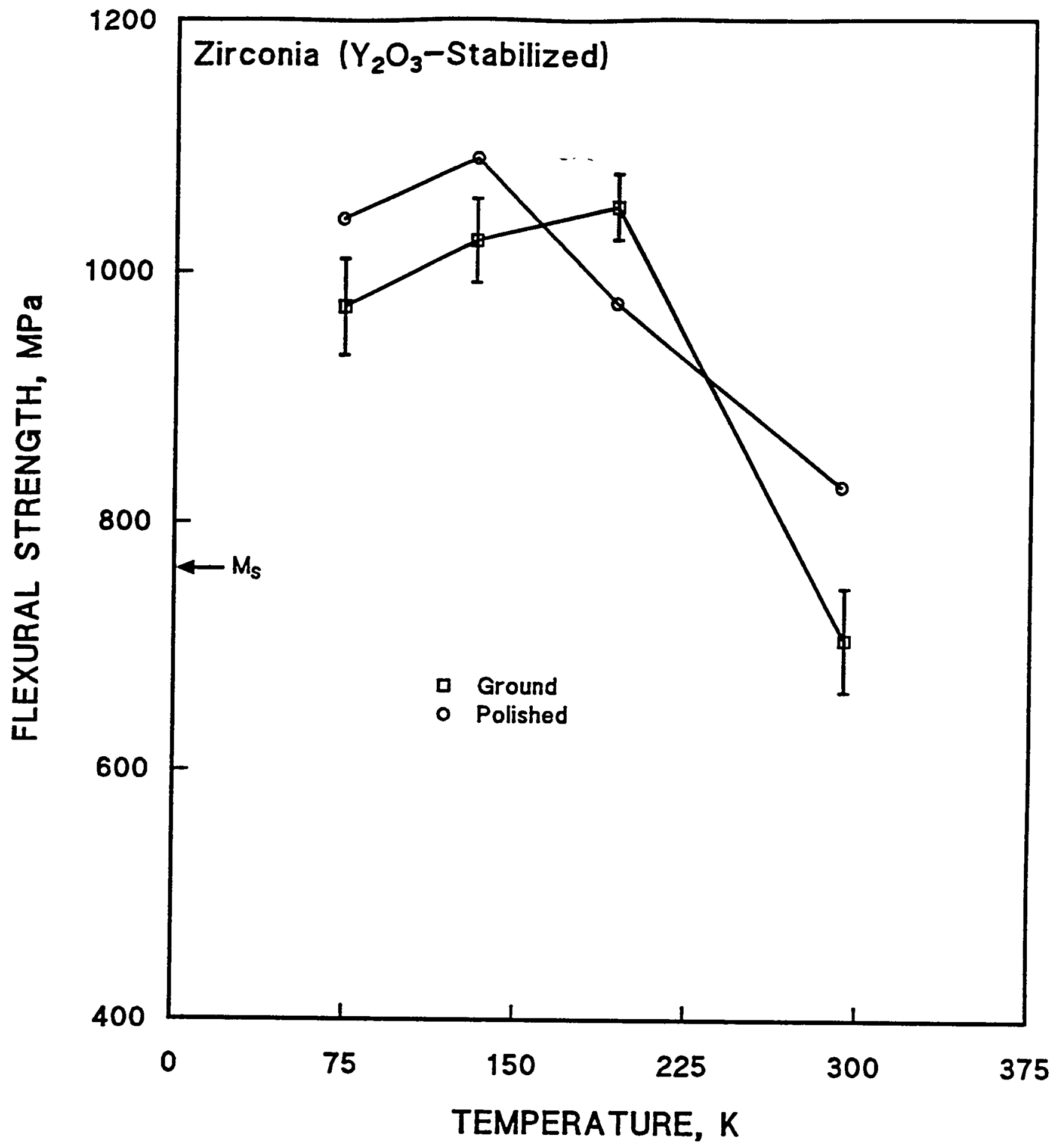

Figure 8.1.6. Flexural strength of $\mathrm{Y}_{2} \mathrm{O}_{3}$-stabilized $\mathrm{ZrO}_{2}$ vs. temperature. Data from Veitch et al. [1987]. 


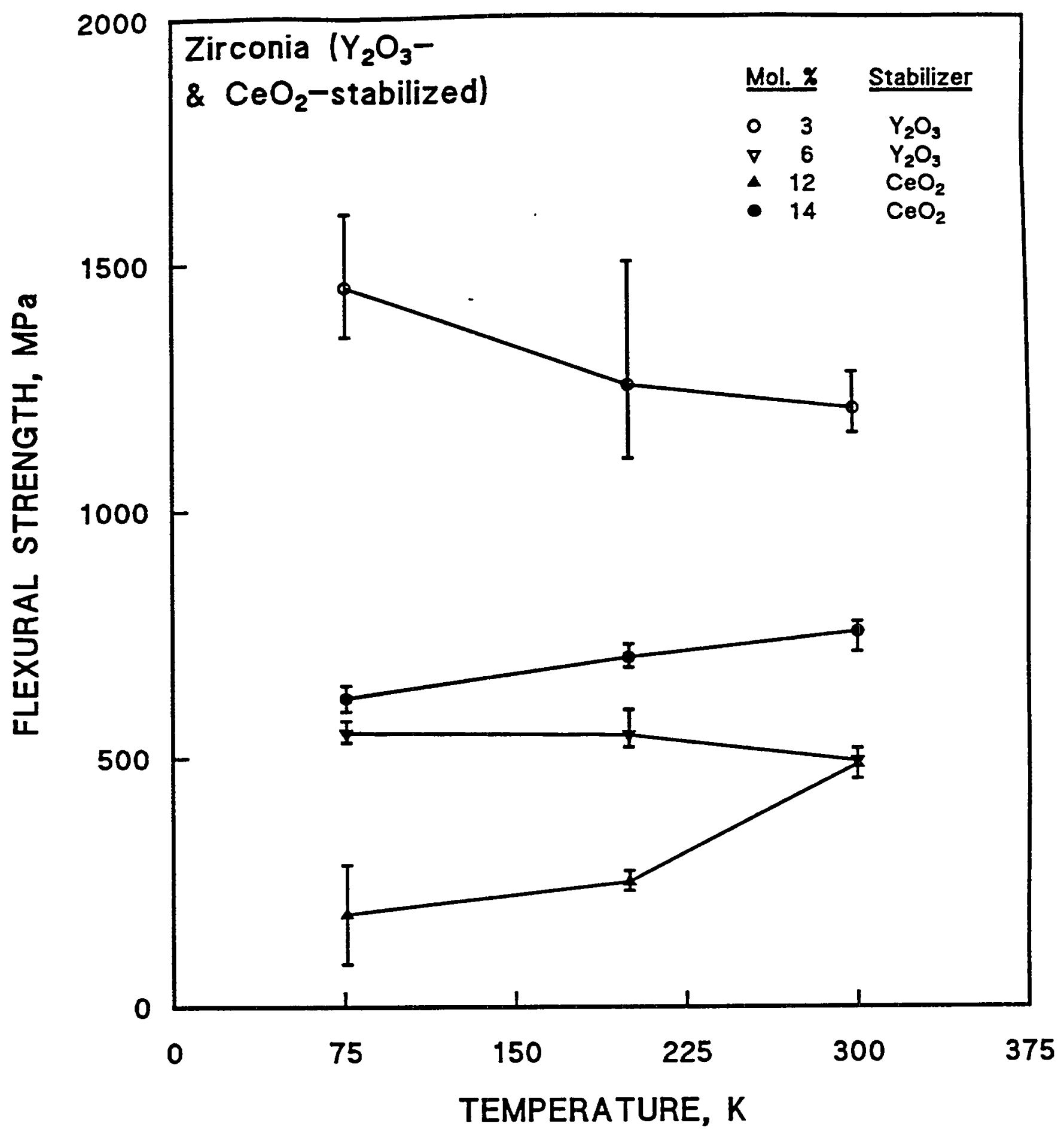

Figure 8.1.7. Flexural strength of $\mathrm{Y}_{2} \mathrm{O}_{3}$-stabilized $\mathrm{ZrO}_{2}$ and $\mathrm{CeO}_{2}$-stabilized $\mathrm{ZrO}_{2}$. Data from Jikihara and Ishihara [1990]. 


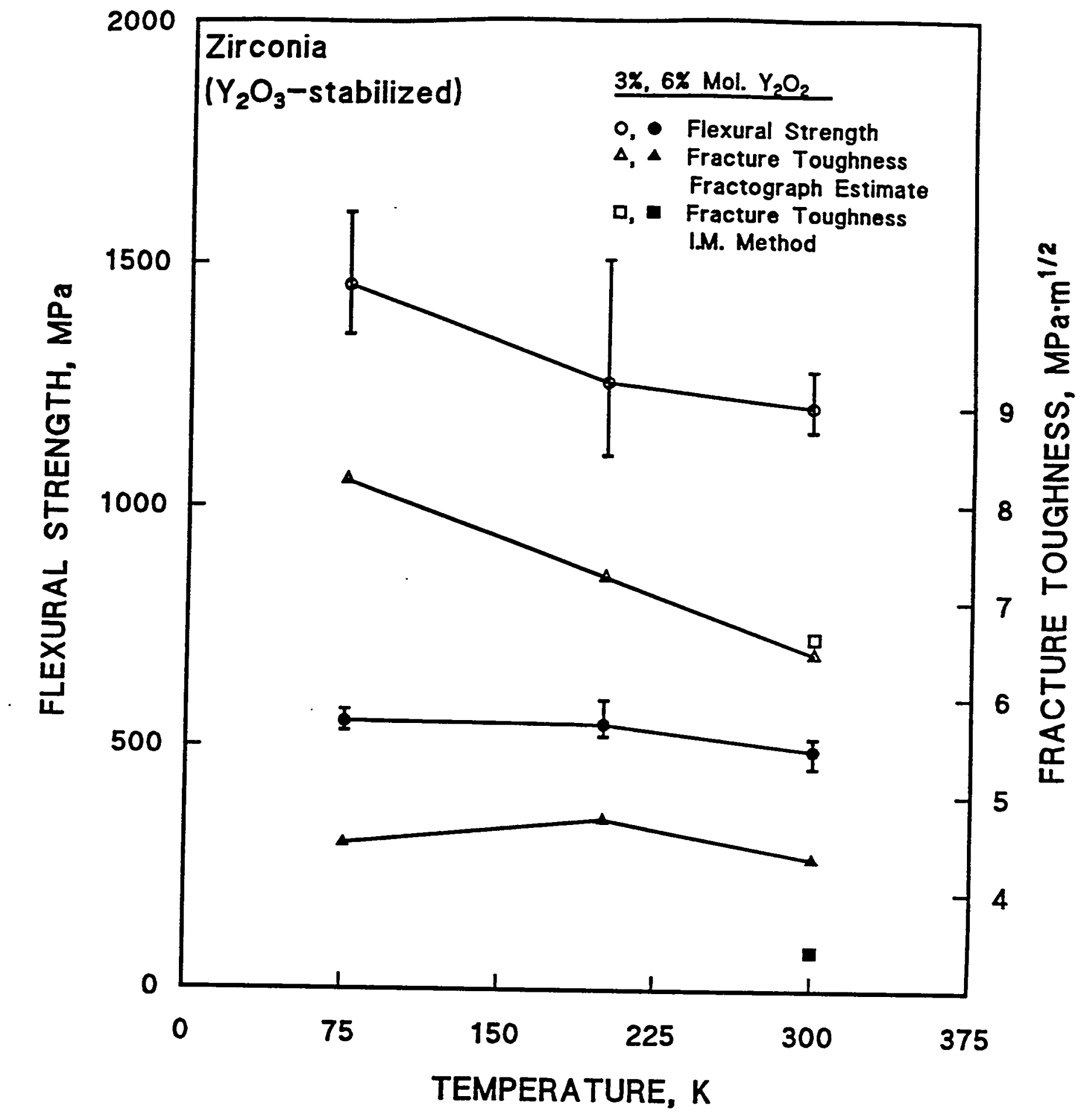

Figure 8.1.8. Flexural strength and fracture toughness of $\mathrm{Y}_{2} \mathrm{O}_{3}$-stabilized $\mathrm{ZrO}_{2}$. Data from Jikihara and Ishihara [1990]. 


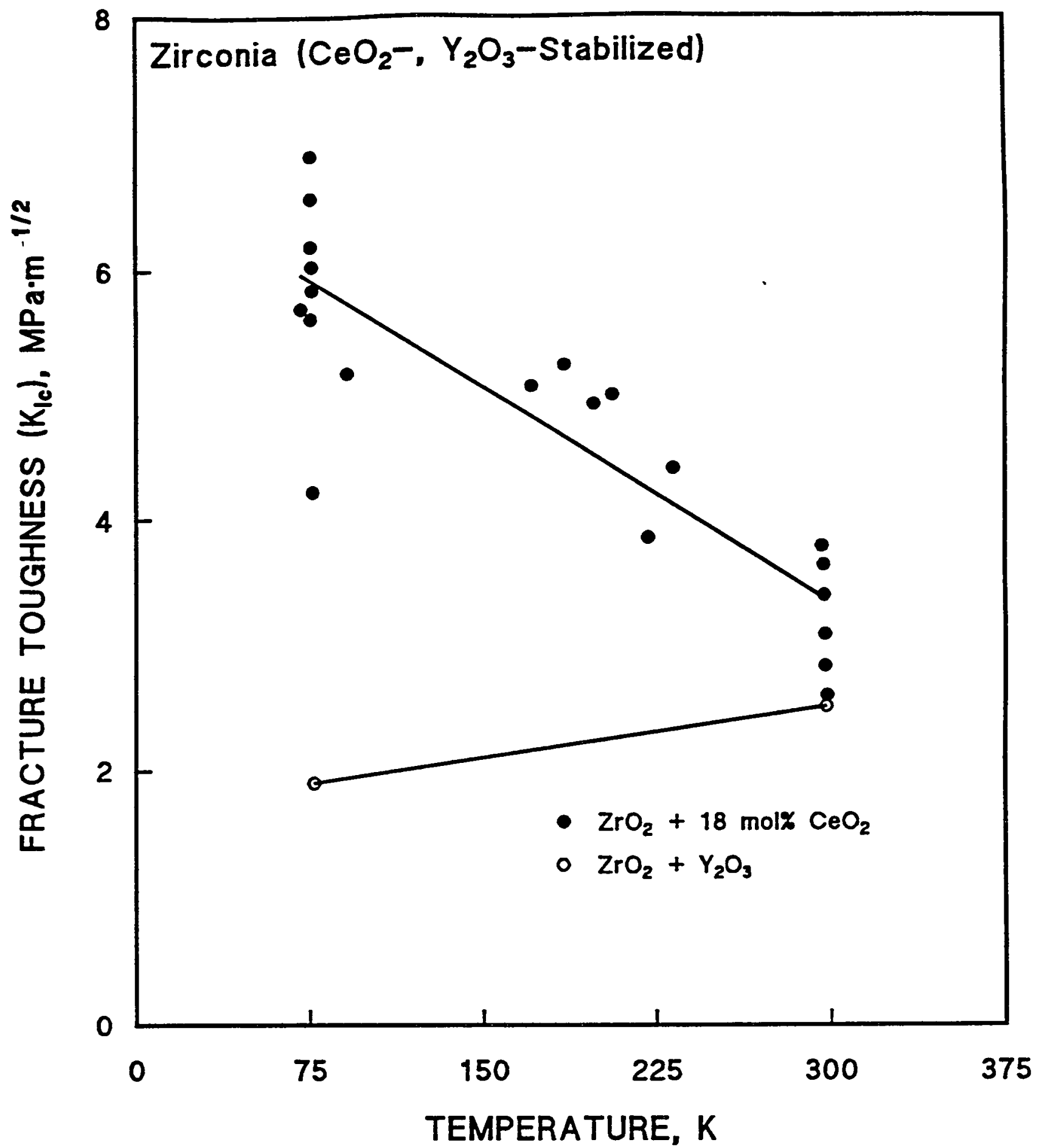

Figure 8.1.9. Fracture toughness of $\mathrm{Y}_{2} \mathrm{O}_{3}$-stabilized $\mathrm{ZrO}_{2}$ and $\mathrm{CeO}_{2}$-stabilized $\mathrm{ZrO}_{2}$. Data from Gupta and Andersson [1984]. 
Although Jikahara and Ishihara found a decrease in flexural strength of both 12- and 14-mol\% $\mathrm{CeO}_{2}$-stabilized $\mathrm{ZrO}_{2}$ below ambient temperature, Gupta and Andersson reported a large increase (54\%) in the 77-K flexural strength of $18-\mathrm{mol} \% \mathrm{CeO}_{2}-\mathrm{ZrO}_{2}$. At $298 \mathrm{~K}$, the value was $238 \pm 11 \mathrm{MPa}$ and at $77 \mathrm{~K}, 367$ $\pm 30 \mathrm{MPa}$ was observed. Three specimens were tested at each temperature. The fracture toughness (measured by the double-cantilever beam technique) also increased dramatically at $77 \mathrm{~K}$, as Figure 8.1 .9 shows. Gupta and Andersson found a narrow composition range for $\mathrm{CeO}_{2}$-stabilized $\mathrm{ZrO}_{2}$, approximately 15to 19-mol\% $\mathrm{CeO}_{2}$, in which transformation-toughening phenomena should occur at low temperatures.

Gupta and Andersson reported that the fracture toughness of $\mathrm{Y}_{2} \mathrm{O}_{3}-\mathrm{ZrO}_{2}$ (mol\% not stated) decreased at $77 \mathrm{~K}$, in contrast to the results of both Veitch et al. and Jikihara and Ishihara. In view of the differences in results of different investigators, and the variation in $\mathrm{M}_{s}$ for $9.4-\operatorname{mol} \% \mathrm{MgO}^{-\mathrm{ZrO}_{2}}$ of about $100 \mathrm{~K}$, depending upon processing techniques, caution should be exercised in using the data reviewed here. Probably, each stabilized $\mathrm{ZrO}_{2}$ system needs to be carefully investigated for processing and test method variability. Unfortunately, even for the promising systems, such as $18-m o l \% \mathrm{CeO}_{2}-\mathrm{ZrO}_{2}$ and $\mathrm{Y}_{2} \mathrm{O}_{3}-\mathrm{ZrO}_{2}$, no measurements below $77 \mathrm{~K}$ were found in this literature search. Therefore, a martensitic transformation may occur between 4 and $77 \mathrm{~K}$.

Recently, shear/compressive tests were made at 76 and $4 \mathrm{~K}$ on hybrid glassepoxy specimens with an $8 \%-\mathrm{Y}_{2} \mathrm{O}_{3}-\mathrm{ZrO}_{2}$ coating on one of the stainless-steel chips [Fabian and Reed, 1994] ( $\$ 1.1 .6)$. The test angle was $45^{\circ}$, so that the shear and compressive stresses were equal. The shear strengths for three specimens at each temperature were $187 \pm 3 \mathrm{MPa}(76 \mathrm{~K})$ and $188 \pm 3.5 \mathrm{MPa}(4 \mathrm{~K})$. All failures were in the composite and were either interlaminar or cohesive, usually at the ceramic interface.

An ambient-temperature value of $>2.9 \mathrm{GPa}$ was reported for the compressive strength of 3-mol\% $\mathrm{Y}_{2} \mathrm{O}_{3}-\mathrm{ZrO}_{2}$ [Miyayama et al., 1991]. 


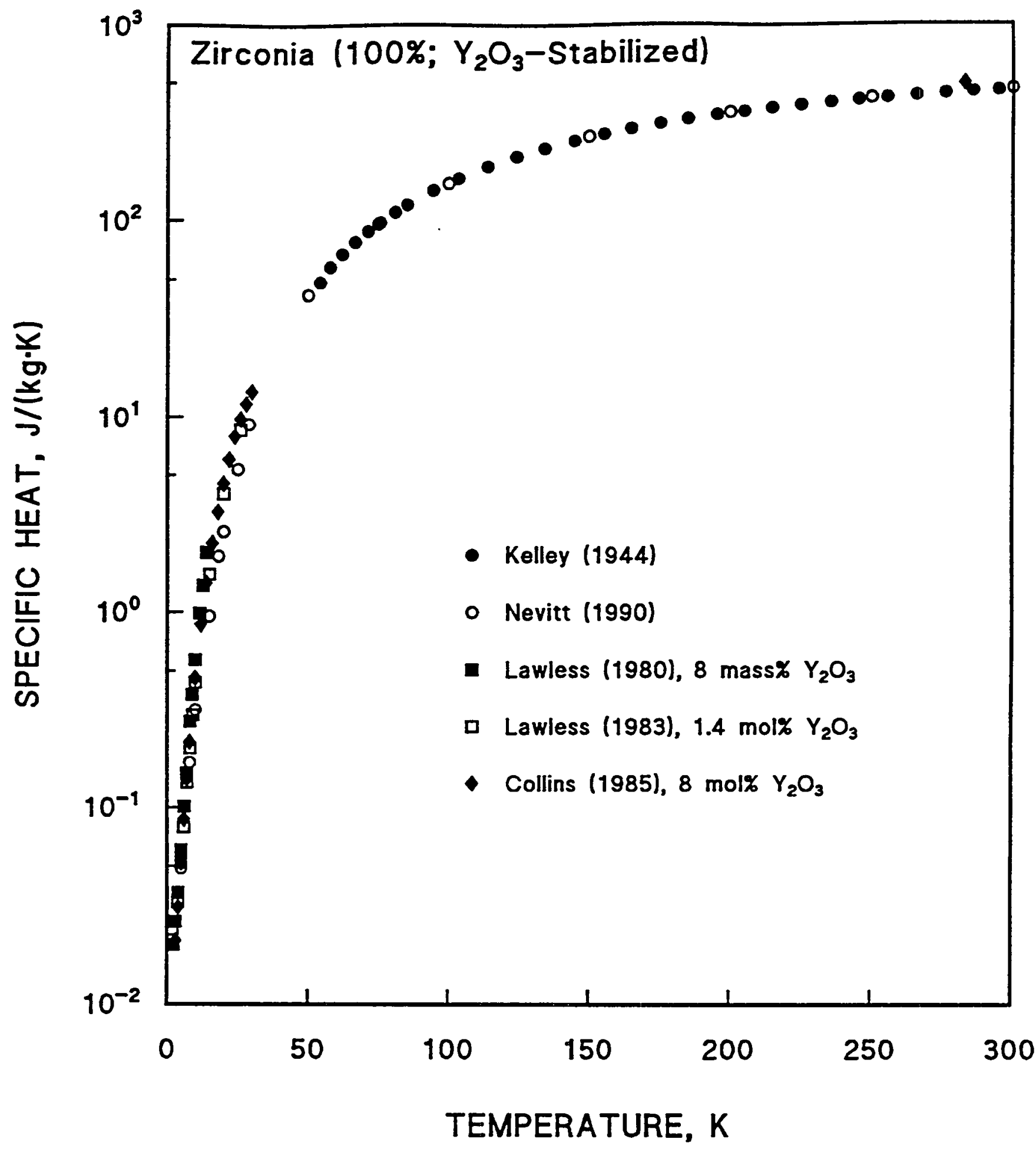

Figure 8.4.1. Specific heat of pure $\mathrm{ZrO}_{2}$ and $\mathrm{Y}_{2} \mathrm{O}_{3}$-stabilized $\mathrm{ZrO}_{2}$ vs. temperature. Data from Kelley [1944], Nevitt et al. [1990], Lawless and Gupta [1983], Lawless [1980], and Collins et al. [1985]. 


\subsection{ELASTIC PROPERTIES}

No cryogenic elastic property data were found in the literature search. For 3-mol\% $\mathrm{Y}_{2} \mathrm{O}_{3}-\mathrm{ZrO}_{2}$, the ambient-temperature Young's modulus was quoted as 200 to $210 \mathrm{GPa}$ and Poisson's ratio was given as 0.31 [Miyayama et al., 1991].

\subsection{ELECTRICAL PROPERTIES}

\subsubsection{Electrical Breakdown Strength}

Cryogenic data on the electrical properties of $\mathrm{2rO}_{2}$ were not found in the literature search. However, the electrical breakdown strength of plasmadeposited, $8 \% \mathrm{Y}_{2} \mathrm{O}_{3}-\mathrm{ZrO}_{2}$ was measured recently at $76 \mathrm{~K}$ [Fabian and Reed, 1994]. A value of $20.7 \pm 2.1 \mathrm{kV} / \mathrm{mm}$ ( $10 \%$ coefficient of variation) was found for material deposited to a thickness of $0.597 \mathrm{~mm}$ on a stainless-steel disk.

The electrical breakdown strength at ambient temperature of plasma-deposited $\mathrm{ZrO}_{2}$ stabilized with $5 \% \mathrm{CaO}$ was found to be about $10 \mathrm{kV} / \mathrm{mm}$ over a range of thicknesses of 0.1 to $0.68 \mathrm{~mm}$ [Bartenev and Navrozov, 1977]. (Comparable measurements of more uniform coatings of plasma-deposited $\mathrm{Al}_{2} \mathrm{O}_{3}$ gave values of about $16 \mathrm{kV} / \mathrm{mm}$.) Much higher values, ranging from 300 to $500 \mathrm{kV} / \mathrm{mm}$, with an average of about $400 \mathrm{kV} / \mathrm{mm}$, were reported for thin films of $\mathrm{Y}_{2} \mathrm{O}_{3}$-stabilized $\mathrm{ZrO}_{2}$ [Hesto et al., 1990]. These films were 1120- to 222-nm thick and exhibited a monocrystalline cubic phase. Flat-band voltages of these films shifted much more under a $\gamma$-irradiation dose of $50 \mathrm{~Gy} / \mathrm{min}$ if an electrical field of $25 \mathrm{kV} / \mathrm{mm}$ was simultaneously applied (see also Simon [1994], §1I).

\subsection{THERMAL PROPERTIES}

\subsubsection{Specific Heat}

The specific heat of pure $\mathrm{ZrO}_{2}$ was measured from 54 to $295 \mathrm{~K}$ by Kelley [1944] and from 3 to $350 \mathrm{~K}$ by Nevitt et al. [1990]. Figure 8.4.1 shows the data on monoclinic, pure $\mathrm{ZrO}_{2}$ and more recent data from three other authors on $\mathrm{ZrO}_{2}$ with various $\mathrm{Y}_{2} \mathrm{O}_{3}$ additions. Unfortunately, these additional data are restricted to temperatures below $30 \mathrm{~K}$. A steep increase in the specific heat 


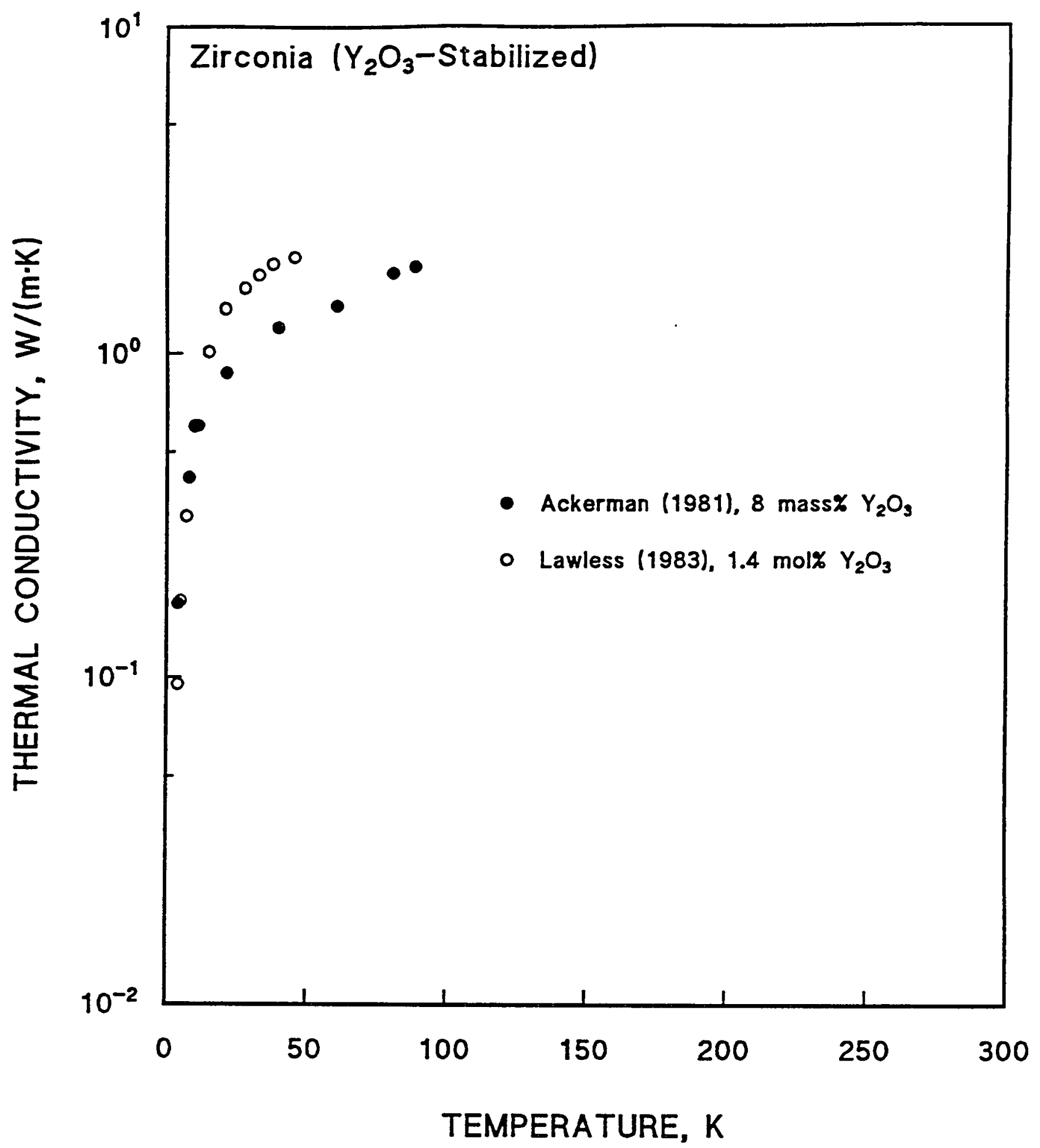

Figure 8.4.2. Thermal conductivity of 8 mass $\mathrm{Y}_{2} \mathrm{O}_{3}-\mathrm{ZrO}_{2}$ vs. temperature. Data from Ackerman et al. [1981] and Lawless and Gupta [1983]. 
below about $6 \mathrm{~K}$ was observed for 2.4- and 8-mass\% $\mathrm{Y}_{2} \mathrm{O}_{3}$ [Lawless and Gupta, 1983; Lawless, 1980], but was not reported for 16-mass\% $\mathrm{Y}_{2} \mathrm{O}_{3}$ [Collins et al., 1985]. Apparently, these anomalies are related to the Hf impurities in the samples measured by Lawless; the material measured by Collins et al. was reported to be Hf-free.

\subsubsection{Thermal Conductivity}

Thermal conductivity data on pure $\mathrm{ZrO}_{2}$ were not found in this literature search. Data from 0.1 to $100 \mathrm{~K}$ on -8 -mass\% $\mathrm{Y}_{2} \mathrm{O}_{3}-\mathrm{ZrO}_{2}$ are given in Figure 8.4.2 [Ackerman et al., 1981]. This material was probably not Hf-free. Two sets of data obtained in different laboratories showed good agreement. Data at lower temperatures for 1.4-mol\% $\mathrm{Y}_{2} \mathrm{O}_{3}-\mathrm{ZrO}_{2}$ are also shown in Figure 8.4.2.

\subsubsection{Thermal Expansion}

Data from 3 to $383 \mathrm{~K}$ on the thermal expansion coefficient of 9-mass $\mathrm{Y}_{2} \mathrm{O}_{3}$ were obtained by Collins et al. [1985] and are presented in Figure 8.4.3. Limited data (from 0.70 to $6.00 \mathrm{~K}$ ) are available on the thermal expansion coefficient of 16-mol\% $\mathrm{Y}_{2} \mathrm{O}_{3}-\mathrm{ZrO}_{2}$ and are also shown [Ackerman, 1982]. At $4 \mathrm{~K}$, the linear coefficient of expansion is $7.58 \pm 0.22 \times 10^{-10} / \mathrm{K}$; at $6 \mathrm{~K}$ it is $1.7 \pm 0.08$ $\times 10^{-9} / \mathrm{K}$. This material was probably not Hf-free. An ambient-temperature value for the thermal expansion coefficient of $\mathrm{ZrO}_{2}$ is $8.8 \times 10^{-6} / \mathrm{K}$ [Touloukian et al., 1977]. 


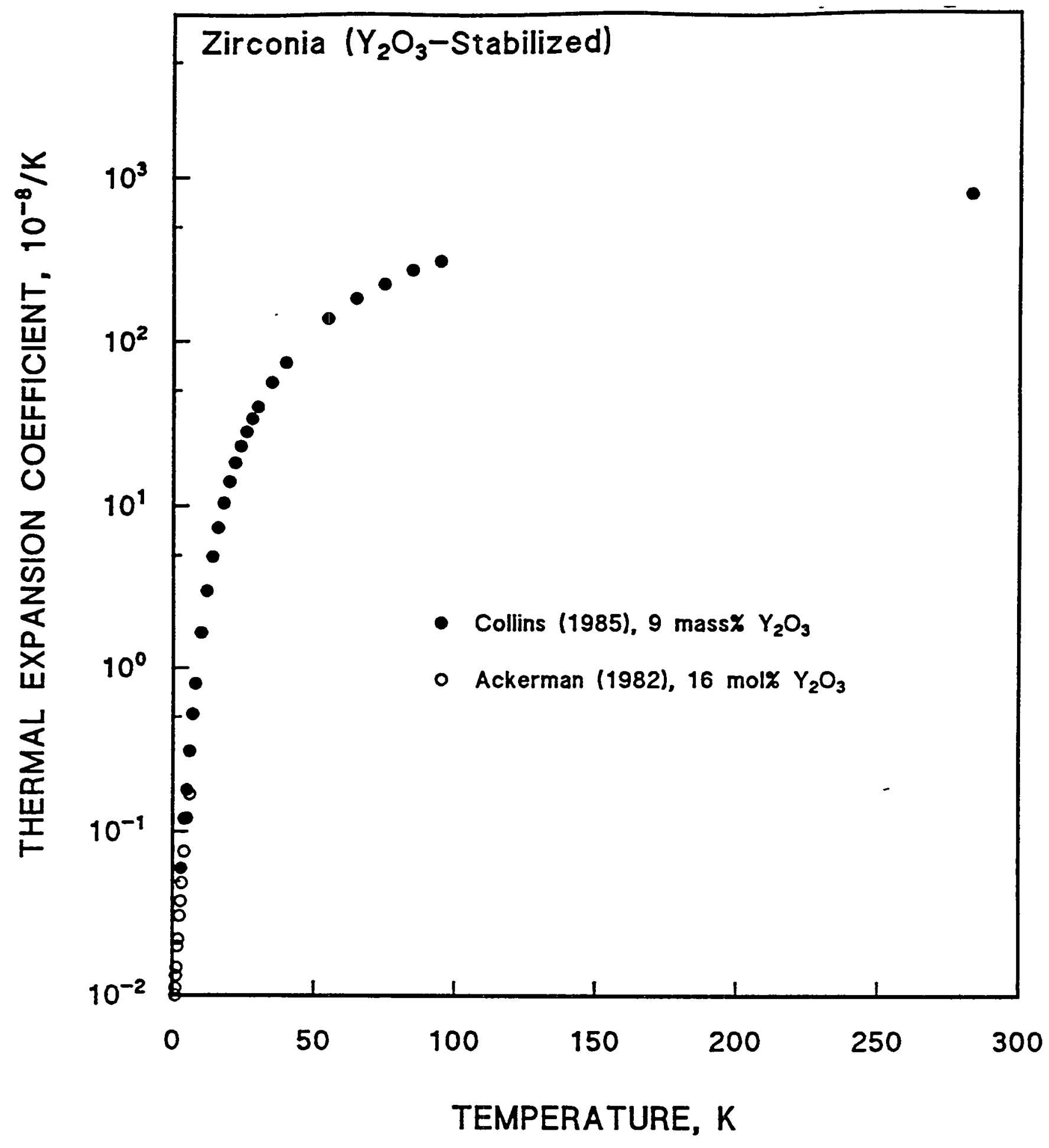

Figure 8.4.3. Thermal expansion coefficient of $\mathrm{Y}_{2} \mathrm{O}_{3}$-stabilized $\mathrm{ZrO}_{2}$ vs. temperature. Data from Ackerman [1982] and Collins et al. [1985]. 


\section{MICA}

Properties of hybrid mica insulation and glass-mica ceramics are reviewed in $\$ 10$ below; this section comprises data on mica with minimal additions.

\subsection{MECHANICAL PROPERTIES}

Ketterer [1964] describes the preparation of mica paper, a flexible product that is made without the addition of cellulose or other binders. The term "paper" refers only to similarities in the manufacturing process to that of conventional paper. The cohesive forces that hold the product together are those between parallel faces of the similarly oriented miniature flakes of mica that are recohered after separation to form the paper. Ketterer quotes a value of $14 \mathrm{MPa}$ or above for the ambient-temperature tensile strength of mica paper. Tensile strength is, of course, improved if the material is bonded to glass cloth or to an organic film, or is treated with silicone resin to fill voids. Ketterer also reported that single plies or multiple-ply stacks of mica were "more than adequate to withstand compression and shear stresses" of $138 \mathrm{MPa}$ at temperatures up to $550^{\circ} \mathrm{C}$.

Erez and Becker [1982] reported that the coefficient of friction of mica paper was 0.033 to 0.049 at ambient temperature and 0.079 to 0.092 at $77 \mathrm{~K}$. The material, also described as mica-glass, of thickness $0.50 \mathrm{~mm}$, failed in compressive fatigue at a maximum applied stress of $207 \mathrm{MPa}$ by $10^{4}$ cycles at ambient temperature.

\subsection{ELASTIC PROPERTIES}

Elastic property data on micas were not obtained in the literature search.

\subsection{ELECTRICAL PROPERTIES}

\subsubsection{Electrical Breakdown Strength}

Two extensive, careful investigations have been made of the effect of cryogenic (and higher) temperatures upon the electrical breakdown strength of thin 


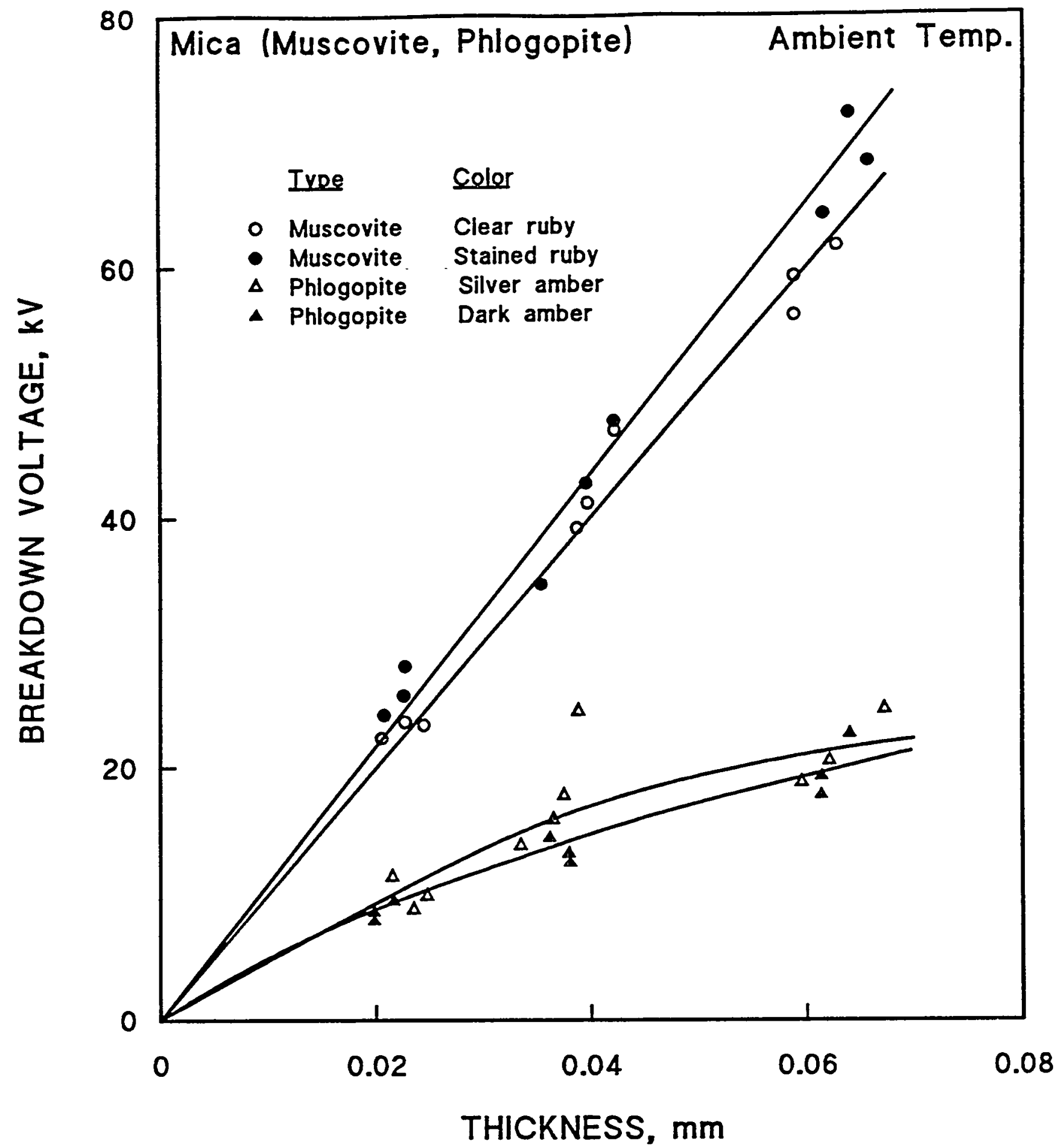

Figure 9.3.1. Intrinsic electrical breakdown voltage of phlogopite and muscovite mica vs. thickness at ambient temperature. Data from Hackett and Thomas [1941]. 
mica crystals. Comparable investigations of the flake or paper product were not obtained in this literature search. In the first investigation, Hackett and Thomas [1941] measured the intrinsic electrical breakdown strength of natural muscovite and phlogopite by using recessed specimens prepared by a special grinding and polishing technique. Ambient-temperature, intrinsic breakdown strength dependence on thickness is illustrated in Figure 9.3.1. Since the punctures were displaced from the point of contact in the phlogopite, the values obtained may not be intrinsic. However, a similar difference between breakdown strength of phlogopite and muscovite was found by a pulse technique [citation, Hackett and Thomas, 1941]. The results of measurements at different temperatures are shown in Figure 9.3.2. Not much change in breakdown strength was observed between ambient temperature and $78 \mathrm{~K}$; the average value was about $12 \%$ lower at $78 \mathrm{~K}$. Austen and whitehead [1940] also found a very limited decrease in the electrical breakdown strength from ambient temperatures down to $100 \mathrm{~K}$ in measurements on recessed ruby muscovite specimens. The immersion medium was petroleum ether.

In the second extensive investigation [Davidson and Yoffe, 1968], mica crystals that were 20 - to $800-\mathrm{nm}$ (200- to 8000- $\AA$ ) thick were tested between 4 and $520 \mathrm{~K}$ and a different temperature dependence of the electrical breakdown strength in natural mica was found (Figure 9.3.3). Breakdown in synthetic mica exhibited no temperature dependence. Davidson and Yoffe concluded that the electrical breakdown in their Fe-rich natural micas was probably thermal, from hot spots, whereas that measured by Hackett and Thomas was probably due to electron avalanche. They presented evidence to support a thermal breakdown mechanism even at cryogenic temperatures. On the other hand, the absence of a strong temperature dependence of electrical breakdown in the synthetic mica studied was attributed to a lower impurity content that favored the avalanche mechanism. The synthetic mica also showed no dependence of breakdown strength on thickness, although the usual relationship was found earlier for natural muscovite by Davidson and Yoffe [1965], as indicated in Figure 9.3.4. The geometry of these experiments was different from that of Hackett and Thomas since thin specimens were sandwiched between evaporated Au electrodes. A Au wire made a pressure contact with the top surface of the crystal when the thickness dependence was measured. Conductivity and breakdown measurements 


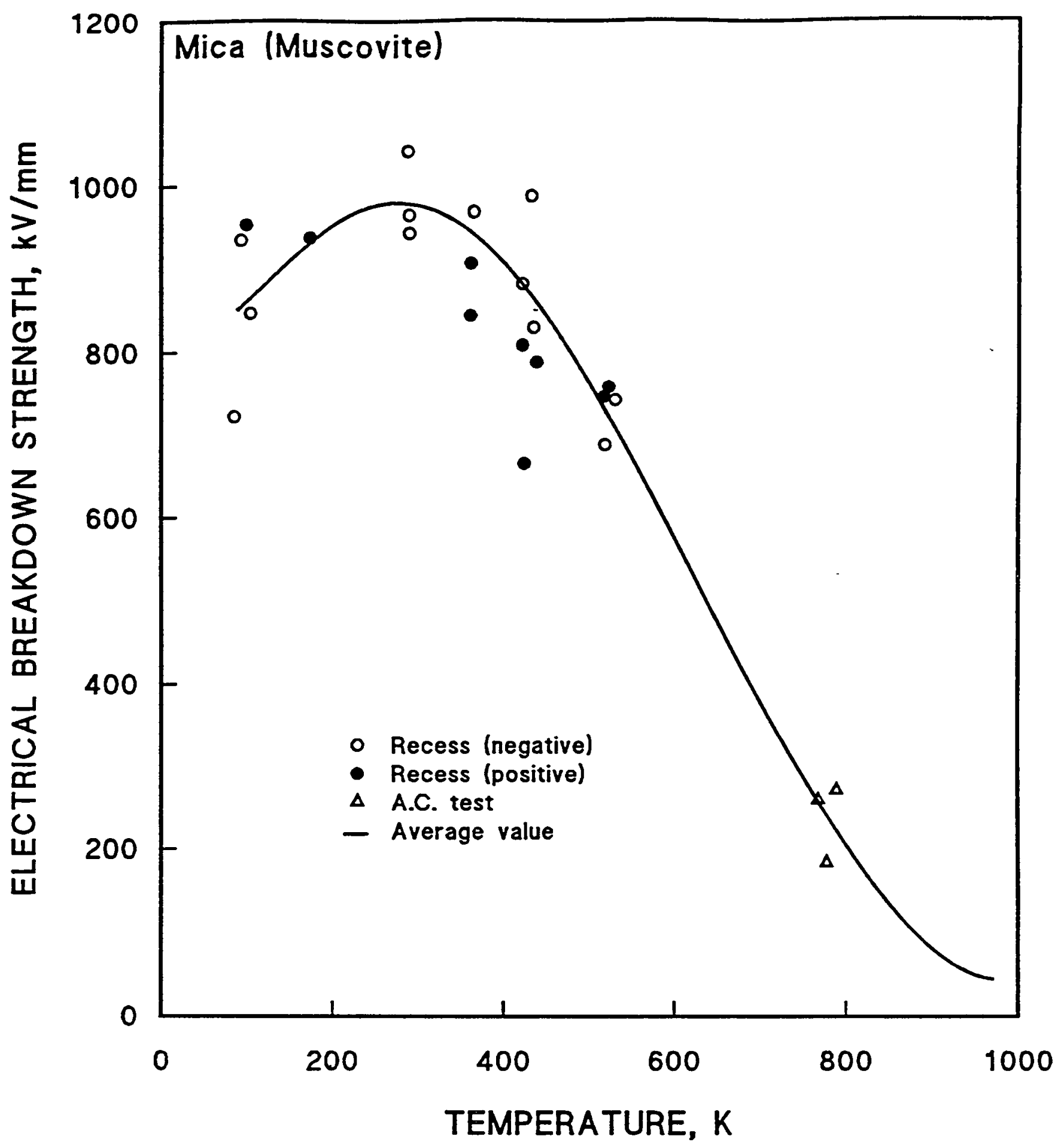

Figure 9.3.2. Intrinsic electrical breakdown strength of muscovite mica vs. temperature, from 78 to $-780 \mathrm{~K}$. Data from Hackett and Thomas [1941]. 


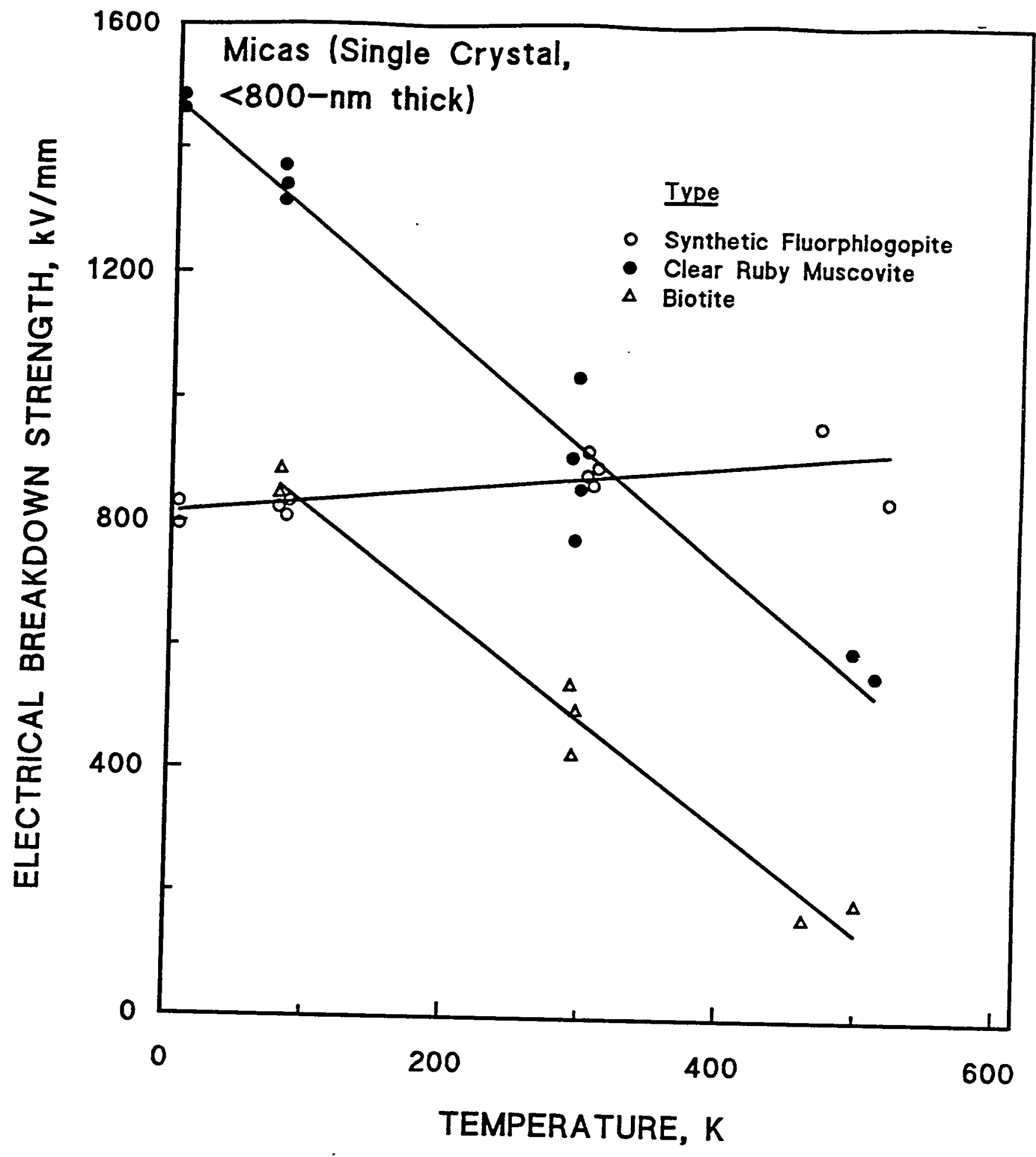

Figure 9.3.3. Electrical breakdown strength of mica crystals $<800$-nm thick from 4 to $520 \mathrm{~K}$. Data from Davidson and Yoffe [1968]. 


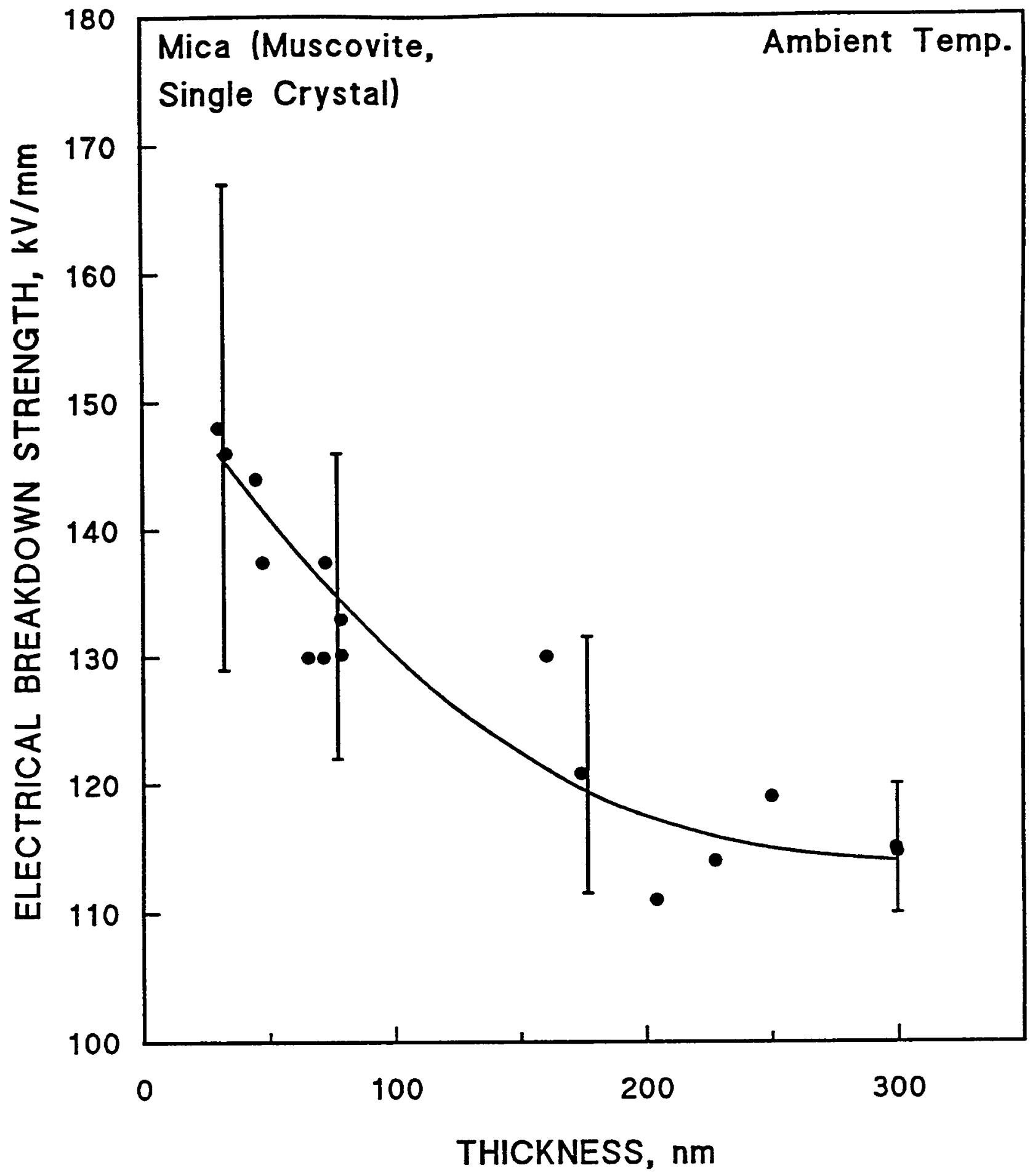

Figure 9.3.4. Dependence of electrical breakdown strength of muscovite mica upon thickness at ambient temperature. Data from Davidson and Yoffe [1965]. 
were made in a vacuum of $1.3 \times 10^{-3} \mathrm{~Pa}\left(10^{-5}\right.$ Torr $)$ with the specimen mounted on a cold finger, except for the measurements in liquid $\mathrm{N}_{2}$ and $\mathrm{He}$.

Conduction currents before breakdown were also measured. These results are shown in Figures 9.3.5 and 9.3.6. Conduction currents were stable; they could flow for long periods without damaging the specimen, except for certain instances indicated by the microbreakdown symbols in the figures. The current density just before breakdown in synthetic micas at ambient temperature was many orders of magnitude smaller than that shown for these natural micas although the electrical breakdown strength was about the same as for the best natural micas. The electrical conductivity in natural micas was found to be a bulk-controlled process determined by the concentration of transition metal atoms, especially Fe. Consult the paper by Davidson and Yoffe for details of the proposed mechanism.

As noted above, results of similar cryogenic investigations on mica flakes and paper products were not found in the literature search. Some low-temperature properties of hybrid insulations utilizing these forms are reviewed below in $\$ 10.2 .3$. However, the addition of the mica product to the rest of the insulation did not noticeably increase the electrical breakdown strength. Deutchmann and Krassnitzer [1991] showed that the electrical breakdown strength of calcined mica paper was about $30 \%$ higher than that of noncalcined mica paper. Five layers of mica paper were placed between electrodes and the $50-\mathrm{Hz}$ voltage was raised by step methods.

The deterioration of the electrical breakdown strength of mica paper and flake layers with increased bending strain is shown in Figure 9.3.7. Data were furnished at ambient temperature only. Glass tape and polyimide layers were shown to perform better than mica in this test [Aki et al., 1983]. The effect of pressure on breakdown strength of mica was studied by Tonkonogov and Omarov [1979], but tests were done only on phlogopite and muscovite crystalline material. A compressive stress of $300 \mathrm{MPa}$ produced a compressive strain of about $4 \%$ in both materials and a considerable decrease, of 40 to $50 \%$ or more, in the electrical breakdown strength. The effect depended upon the pulsed voltage duration and the insulation thickness. It was attributed to the 


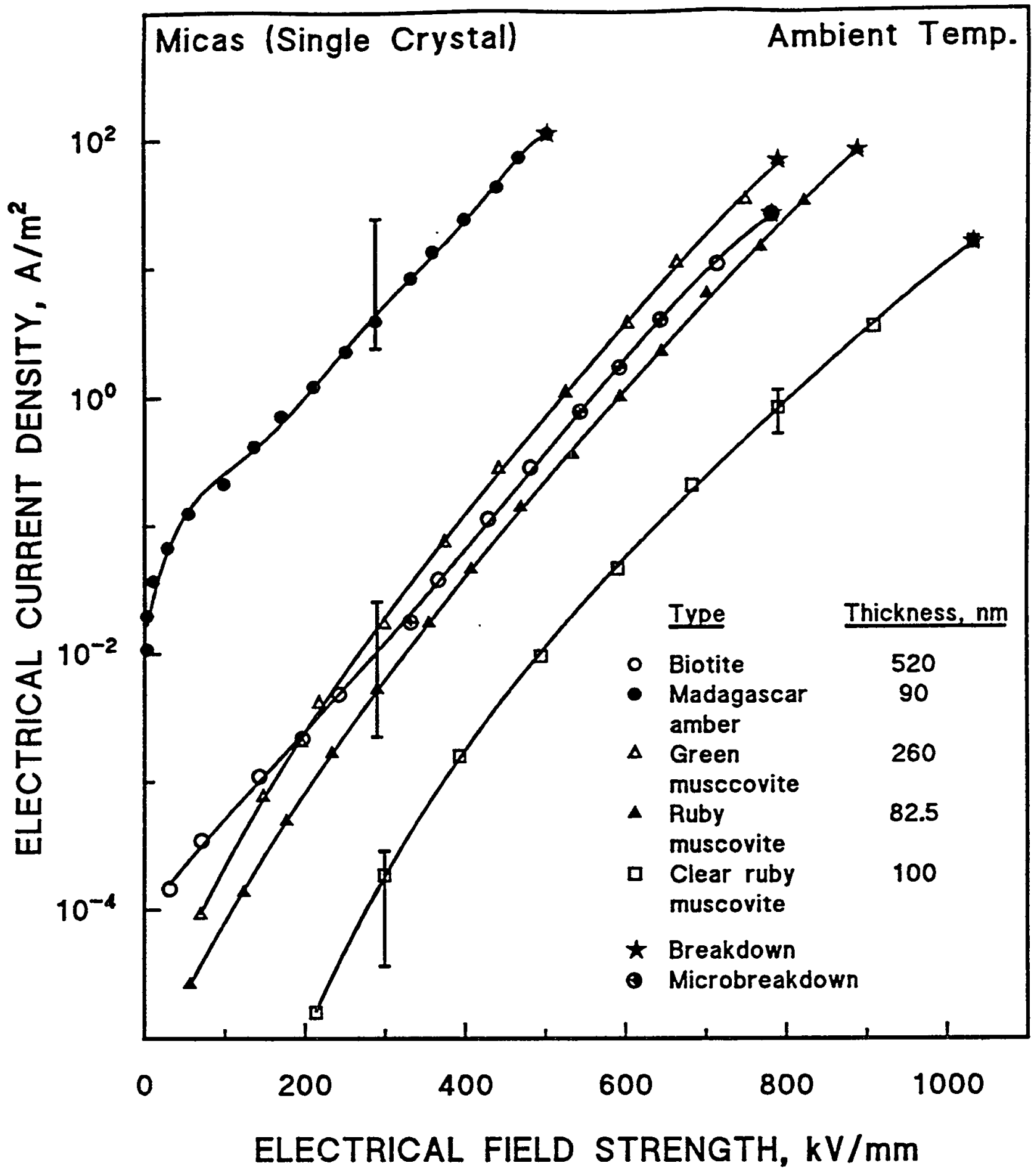

Figure 9.3.5. Conduction current in micas vs. electrical field strength. Data from Davidson and Yoffe [1968]. 


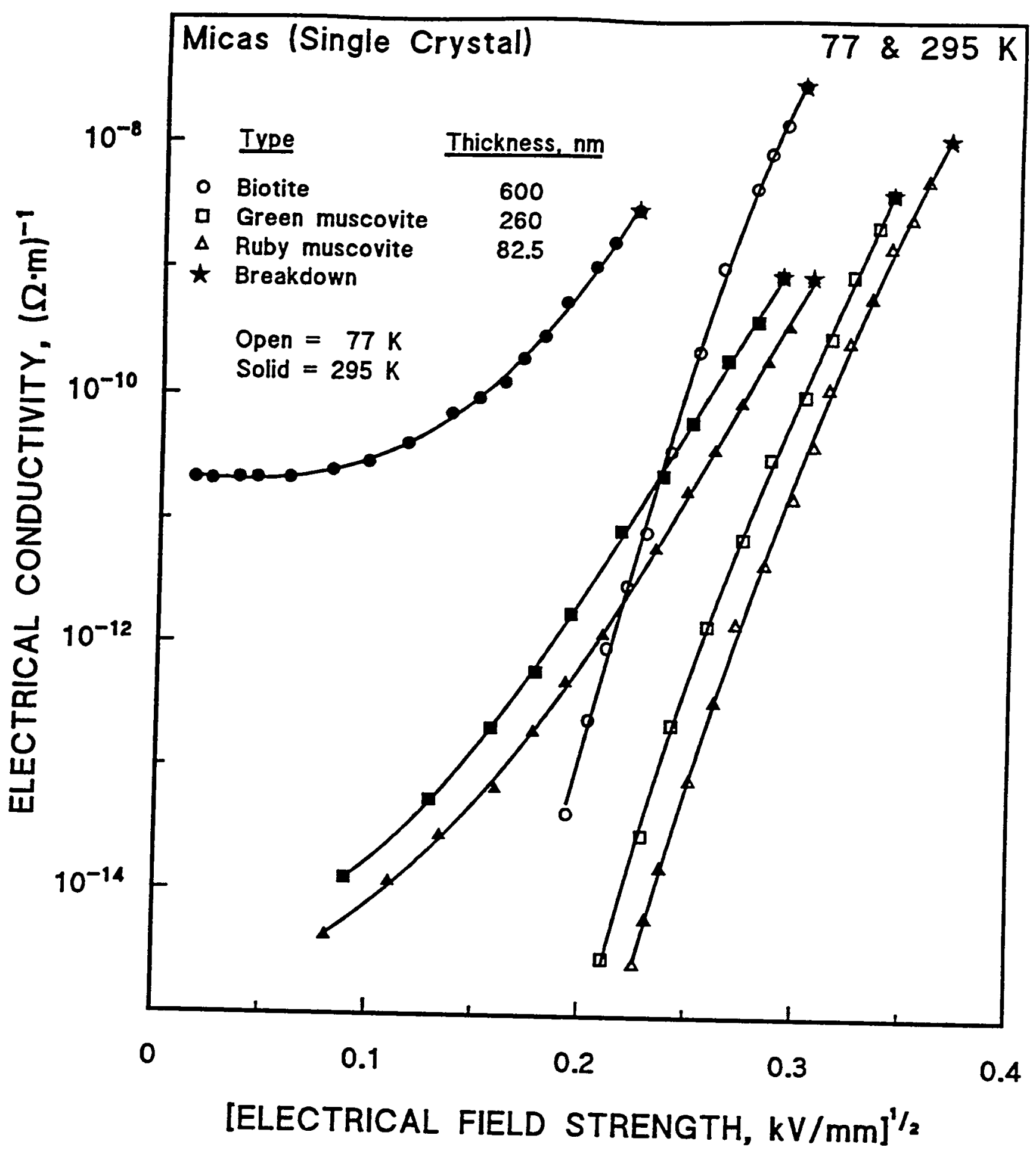

Figure 9.3.6. Conductivity in micas vs. the square root of electrical field strength at 295 and $100 \mathrm{~K}$. Data from Davidson and Yoffe [1968]. 


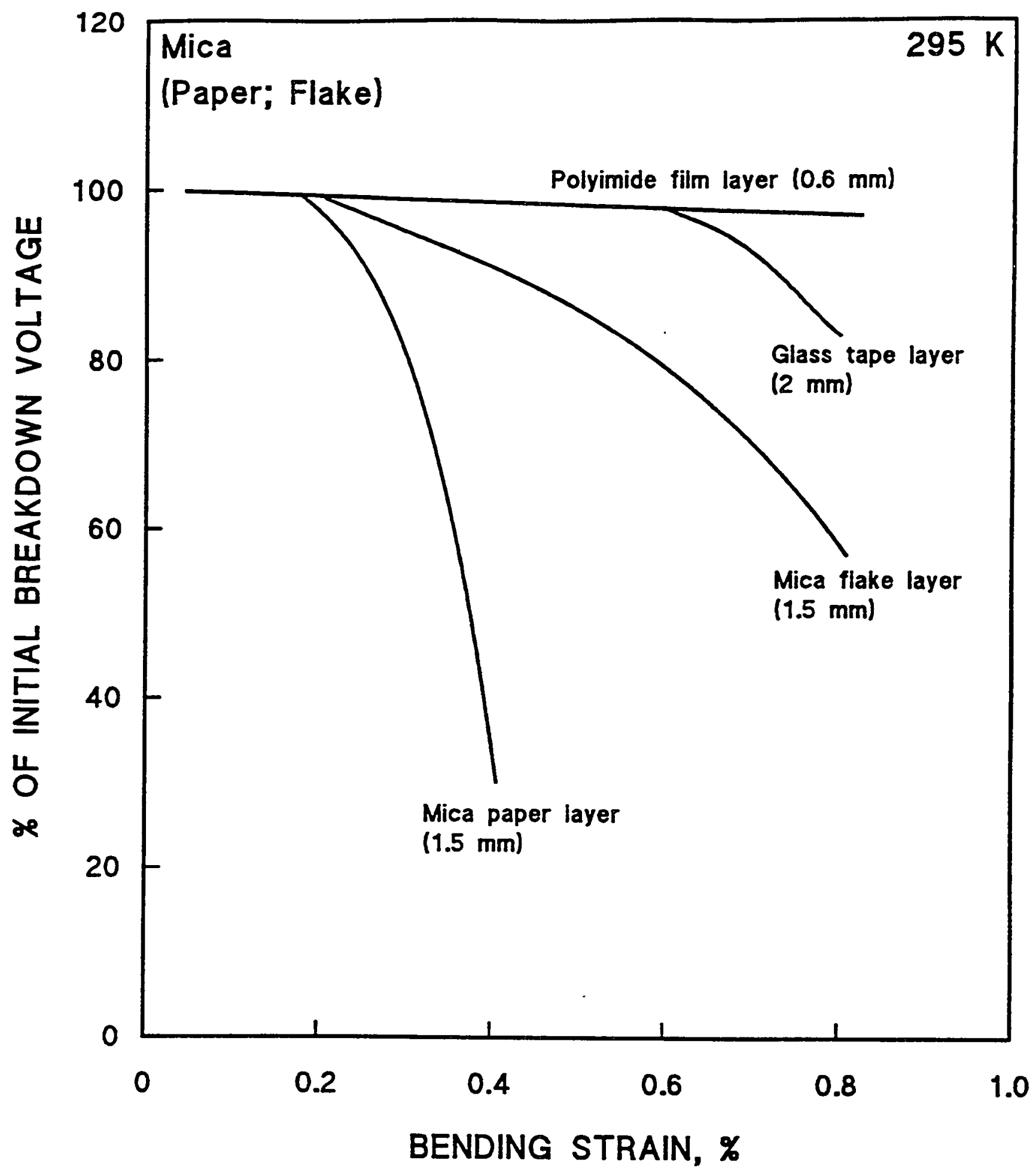

Figure 9.3.7. Deterioration of electrical breakdown strength of mica paper and mica-flake, layered insulation under static bending load, with respect to performance of polyimide film. Data from Aki et al. [1983]. 
collapse of closed laminations with a decrease in their size and density and the appearance of microcracks.

\subsubsection{Other Electrical Properties}

Dielectric loss in insulation usually contributes a negligible proportion of the total heat when electrical apparatus is operated at normal temperatures. However, the possibility of excessive heating from dielectric loss at $4 \mathrm{~K}$ has been raised [Chant, 1967]. The dielectric constant and the loss tangent of a $0.10-\mathrm{mm}$ thick, silicone-bonded mica product (Samica) from 4 to $300 \mathrm{~K}$ were measured by Chant [1967]. The results at $75 \mathrm{~Hz}$ are presented in Figures 9.3.8 and 9.3.9, together with data Chant obtained on 0.12 -mm thick polyimide (Kapton) for comparison. (The other insulations that Chant tested appear less likely to be used in ITER applications, owing to their lower radiation resistance.) Figure 9.3.10 shows the frequency dependence of the loss tangent at $4 \mathrm{~K}$. The dielectric constants were independent of frequency over the range of 40 to $1000 \mathrm{~Hz}$.

Chaudhry and Jonscher [1985] investigated the variation in dielectric properties of mica paper with humidity and temperature. These data pertain to temperatures above ambient.

\subsection{THERMAL PROPERTIES}

\subsubsection{Specific Heat}

Cryogenic specific heat data were found only for a hydrated form of muscovite mica $\left(\mathrm{KAI}_{3} \mathrm{Si}_{3} \mathrm{O}_{11} \cdot \mathrm{H}_{2} \mathrm{O}\right)$ in the literature search [citation, Touloukian and Buyco, 1970]. The data, which extend down to $52 \mathrm{~K}$, are illustrated in Figure 9.4.1. The specific heat at $295 \mathrm{~K}$ for the hydrated form is $807 \mathrm{~J} /(\mathrm{kg} \cdot \mathrm{K})$. Data from the same source (U.S. Bureau of Mines) for dehydrated muscovite mica $\left(\mathrm{KAl}_{3} \mathrm{Si}_{3} \mathrm{O}_{11}\right)$ are available only at $298 \mathrm{~K}$ and above. The $298-\mathrm{K}$ value of $746 \mathrm{~J} /(\mathrm{kg} \cdot \mathrm{K})$ for the dehydrated form that is also shown in Figure 9.4.1 is about $8 \%$ lower than that for the hydrated form. 


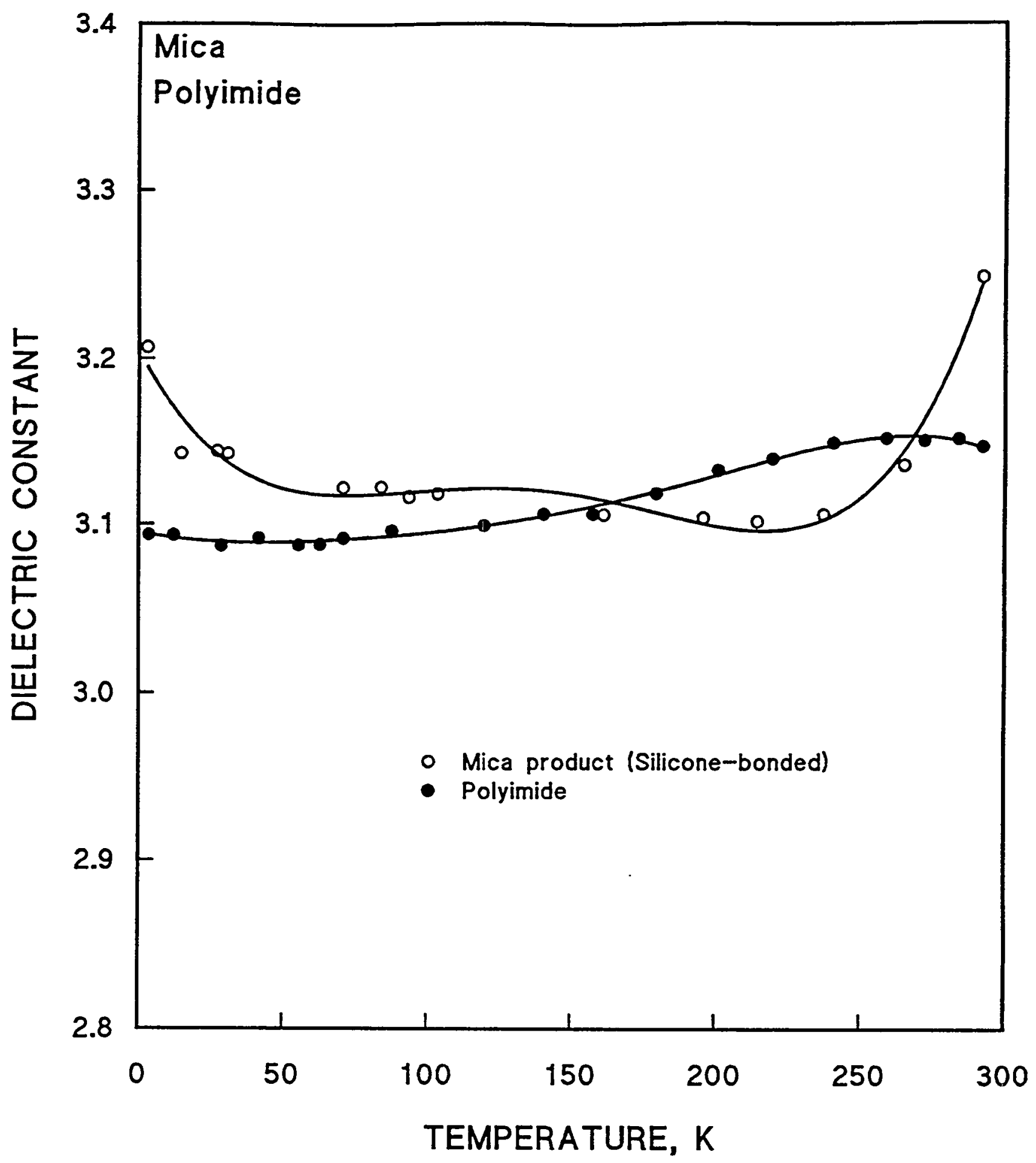

Figure 9.3.8. Dielectric constant at $75 \mathrm{~Hz}$ of silicone-bonded mica product and polyimide vs. temperature. Data from Chant [1967]. 


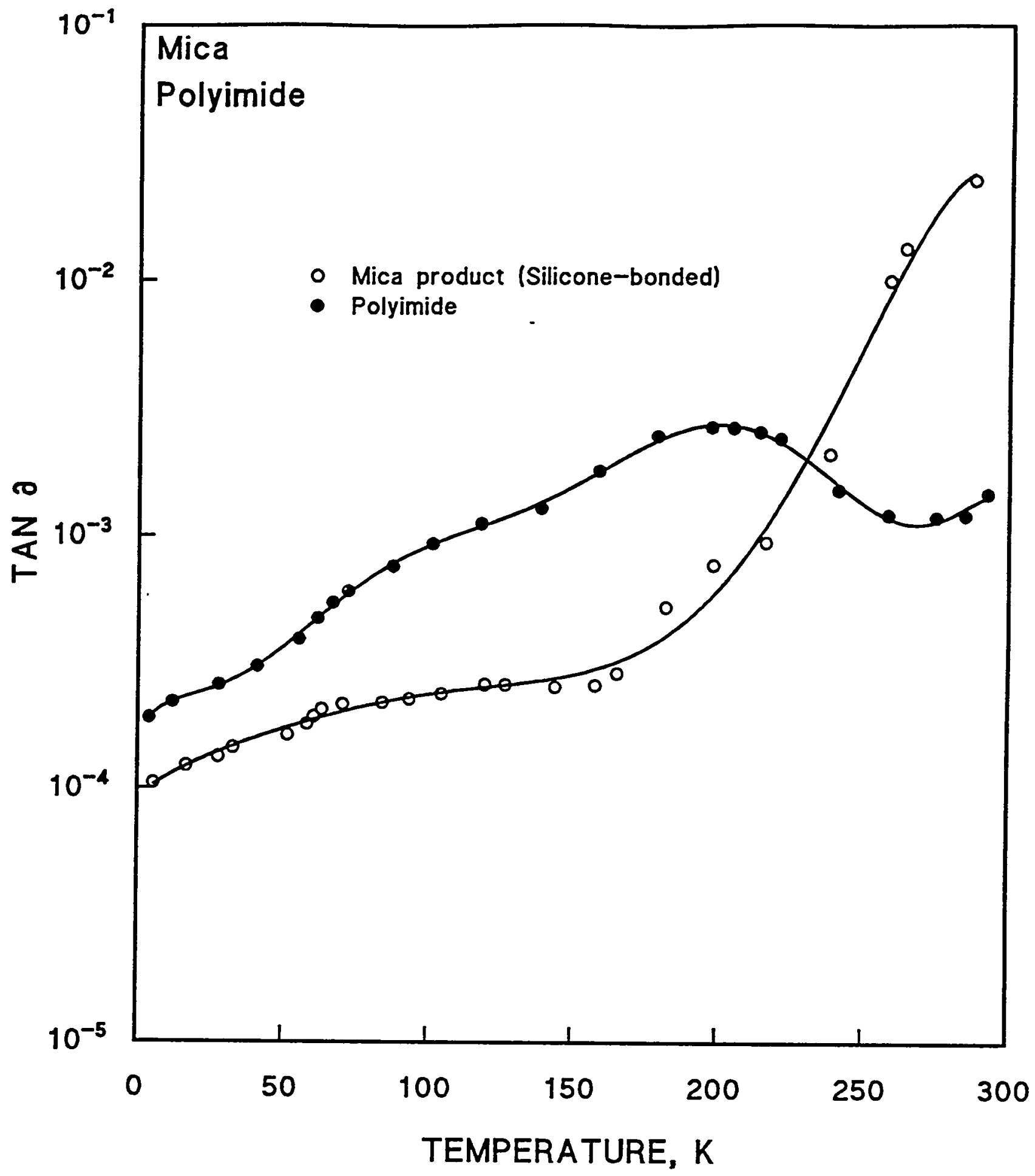

Figure 9.3.9. Loss tangent at $75 \mathrm{~Hz}$ of silicone-bonded mica product and polyimide vs. temperature. Data from Chant [1967]. 


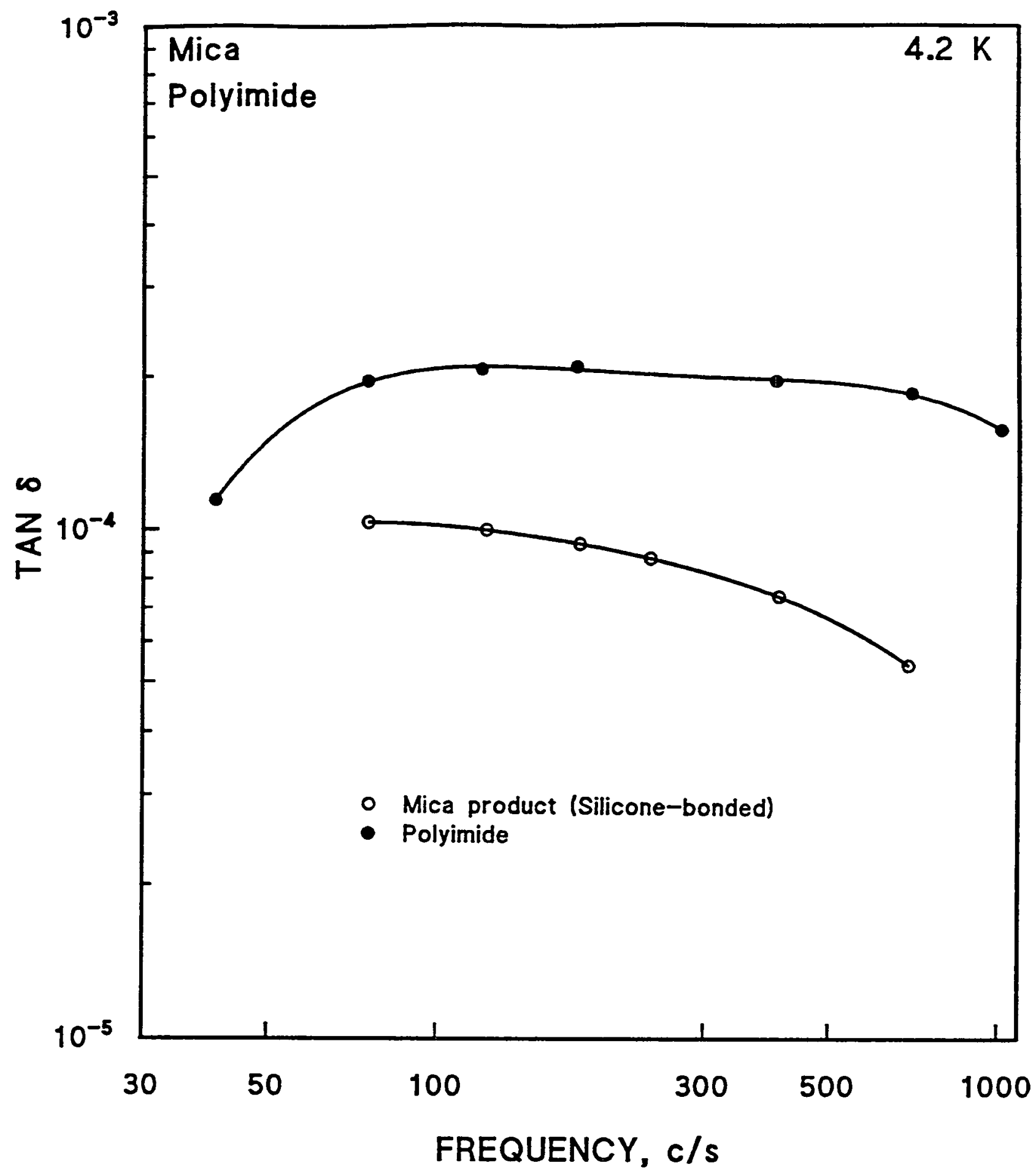

Figure 9.3.10. Loss tangent of silicone-bonded mica product and polyimide vs. frequency. Data from Chant [1967]. 


\subsubsection{Thermel Conductivity}

Thermal conductivity data of mica above $300 \mathrm{~K}$ span a range of values (see Touloukian et al. [1970]). One source of variability is the crystallographic direction. Below $300 \mathrm{~K}$, one reliable source [Gray and Uher, 1977] gives data for both muscovite and phlogopite mica, but the data are for the crystalline forms, which are less likely to be used in insulation applications. These data are presented in Figures 9.4.2 to 9.4.4. The 300-K values are in approximate agreement with the data from higher-temperature studies. Data on a mica powder are given in Figure 9.4.5, but these values do not agree well with the higher-temperature results, perhaps owing to the very low density of $0.090 \mathrm{~g} / \mathrm{cm}^{3}$ [citation, Touloukian et al., 1970]. Thermal conductivity data from two samples of muscovite mica of unknown purity are plotted in Figure 9.4.6, even though the measurements were made at and below $4.2 \mathrm{~K}$ only, because they illustrate the large variation in cryogenic properties of natural mica [Falco, 1976]. The direction of measurement was parallel to the cleavage plane. At $4 \mathrm{~K}$, the corresponding along-plane muscovite mica measurements by Gray and Uher (Figure 9.4.2) fall in between the two curves of Falco. Gray and Uher also noted considerable variability, -20 to $60 \%$, between the values of thermal conductivity that they measured at $300 \mathrm{~K}$ and those reported by others. The thermal conductivity may be very dependent upon the variable composition of natural micas.

\subsubsection{Thermal Expansion}

The thermal expansion of single crystals of ruby muscovite mica was studied by $\mathrm{X}$-ray diffraction between 123 and $423 \mathrm{~K}$ by Goldstein and Post [1969]. The change in the lattice constants with temperature is illustrated in Figure 9.4.7. The average expansion coefficient derived by Goldstein and Post for the $a$ and $b$ axes (in the plane of cleavage) for the range of 123 to $273 \mathrm{~K}$ was $5.4 \pm 0.6 \times 10^{-6}$. This is in agreement with an in-plane value of $6.3 \pm 0.3$ $\times 10^{-6}$ for the range of 83 to $273 \mathrm{~K}$ quoted by Hidnert and Dickson [1945; citations therein]. These authors also quoted an average in-plane value of $2.4 \pm$ $0.12 \times 10^{-6}$ for the range of 20 to $83 \mathrm{~K}$. Goldstein and Post noted that since the $a$ and $b$ axes expand at approximately equal rates, and since the angle between the axes is approximately $90^{\circ}$, differential thermal stress within the 


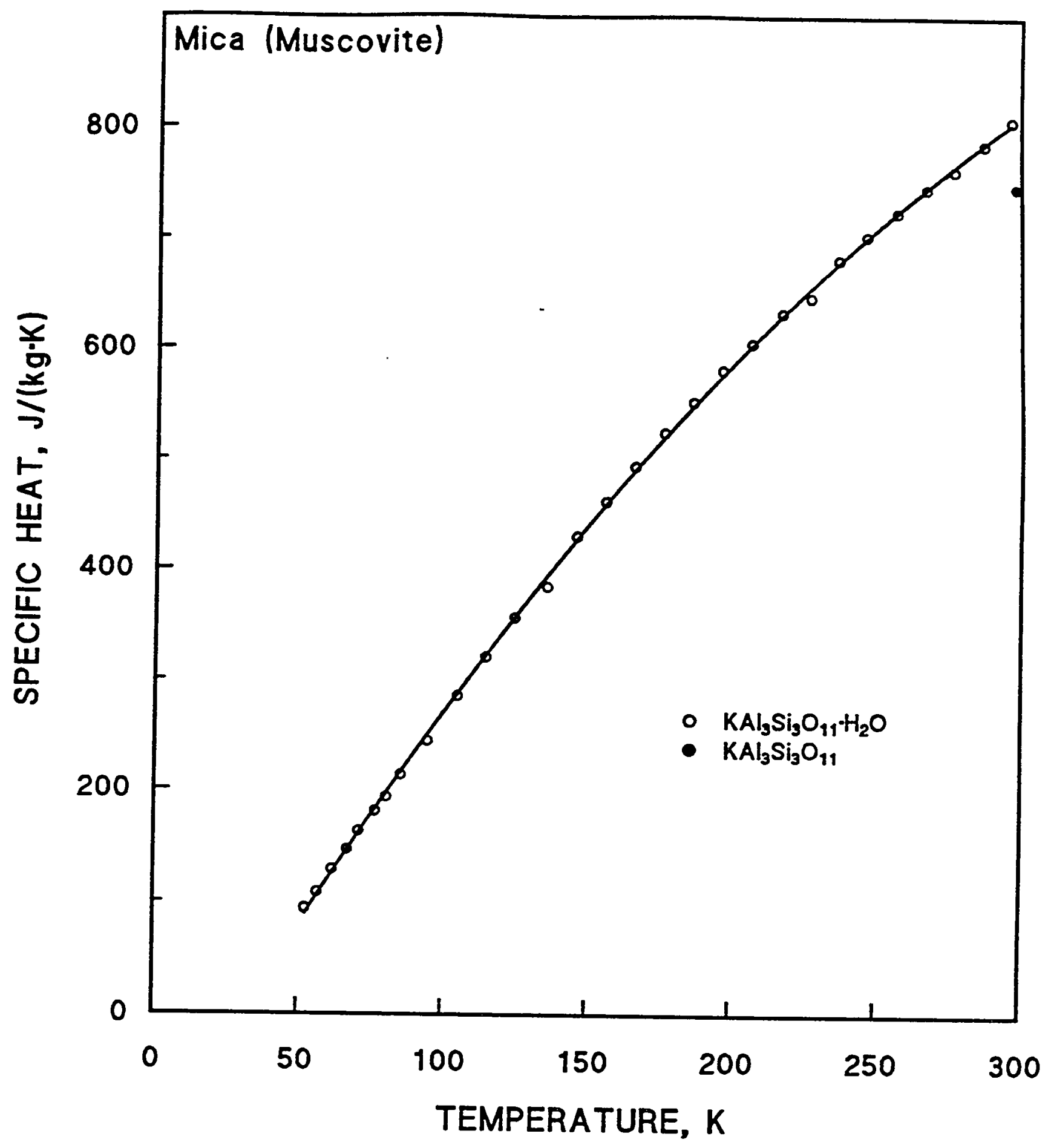

Figure 9.4.1. Specific heat of a hydrated form of muscovite mica from 52 to $298 \mathrm{~K}$. [citations, Touloukian and Buyco, 1970]. A value at $298 \mathrm{~K}$ for the nonhydrated form is also shown. 


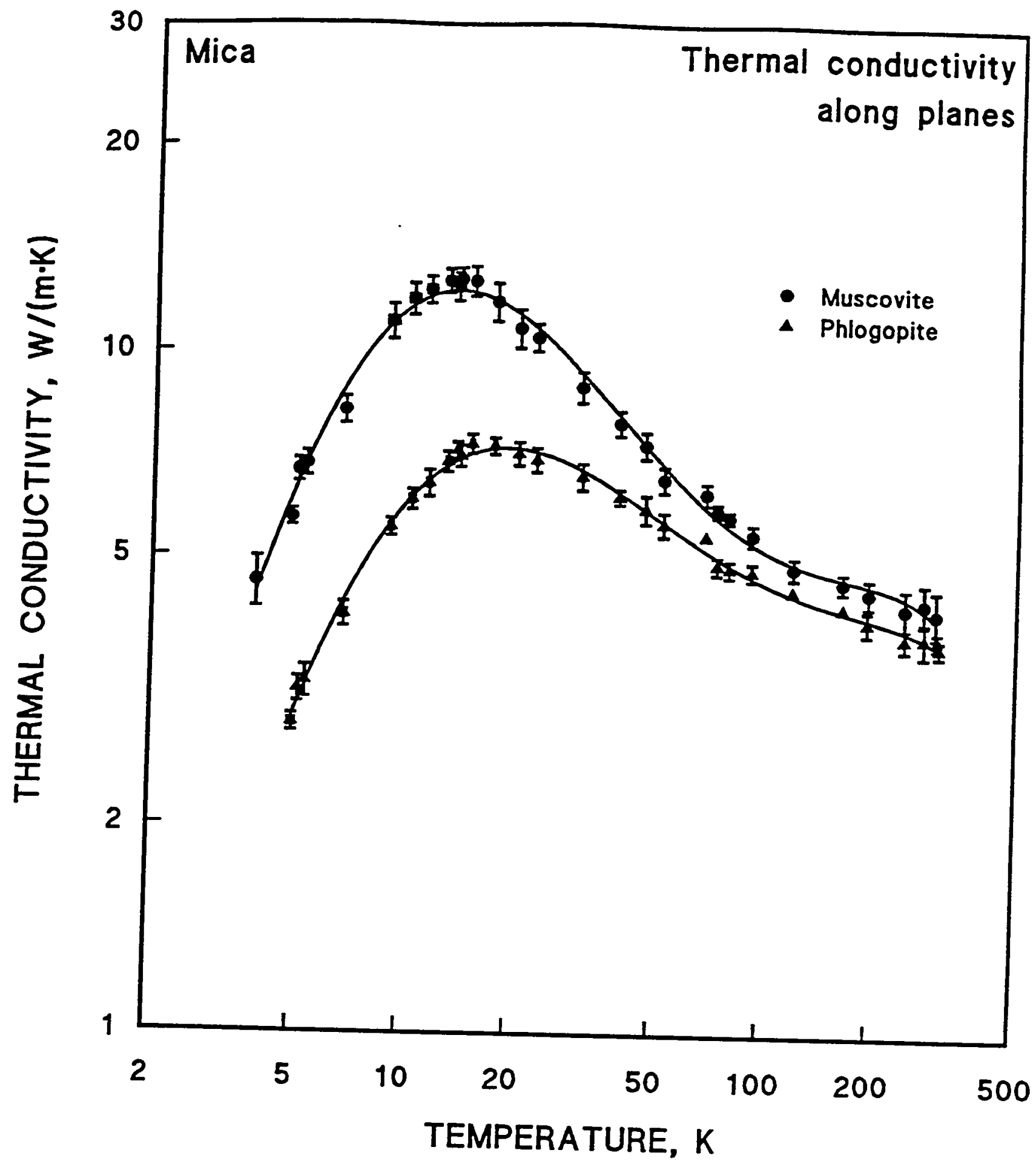

Figure 9.4.2. Thermal conductivity of muscovite and phlogopite mica along crystal planes vs. temperature. Data from Gray and Uher [1977]. 


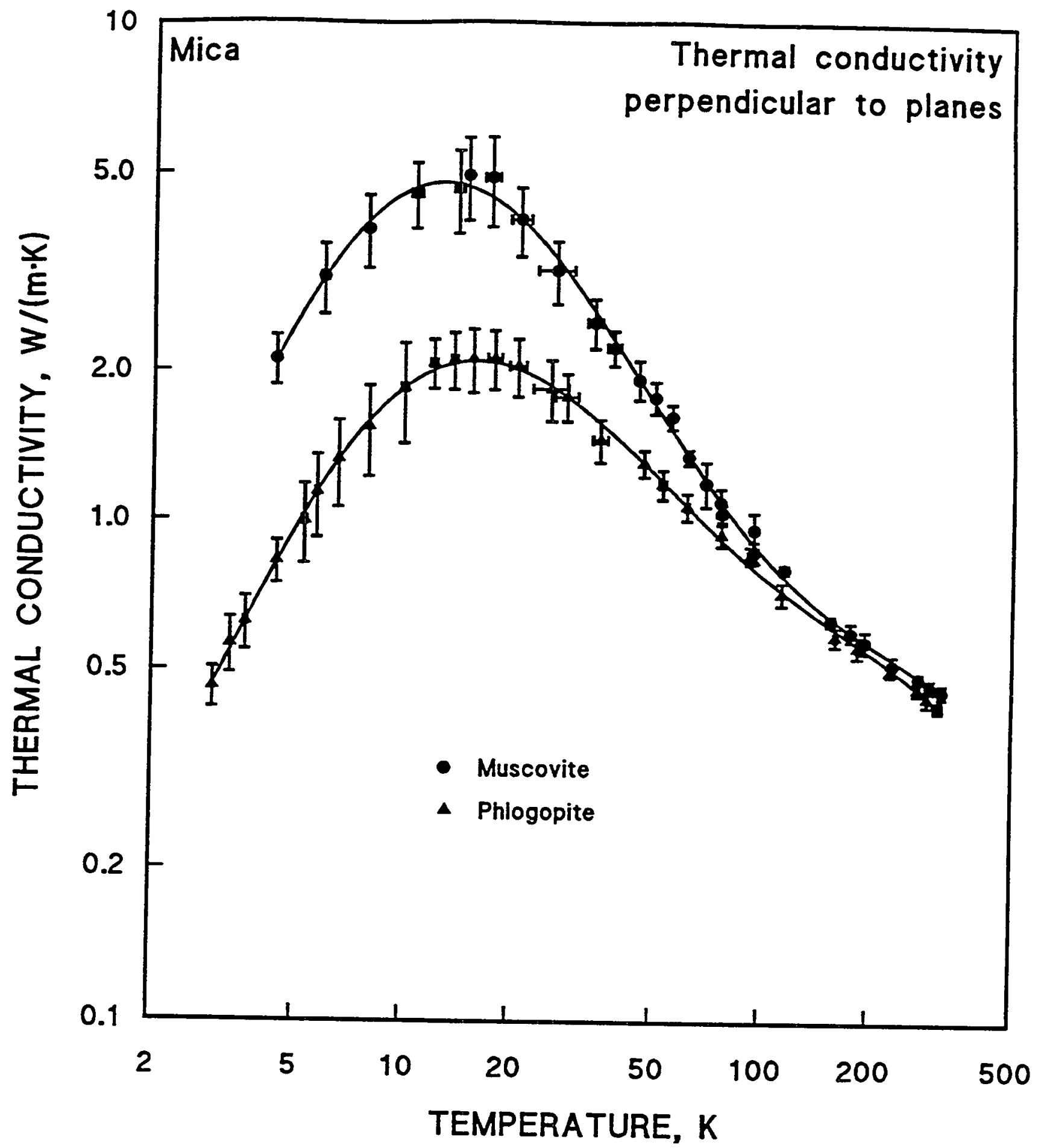

Figure 9.4.3. Thermal conductivity of muscovite and phlogopite mica perpendicular to crystal planes vs. temperature. Data from Gray and Uher [1977]. 


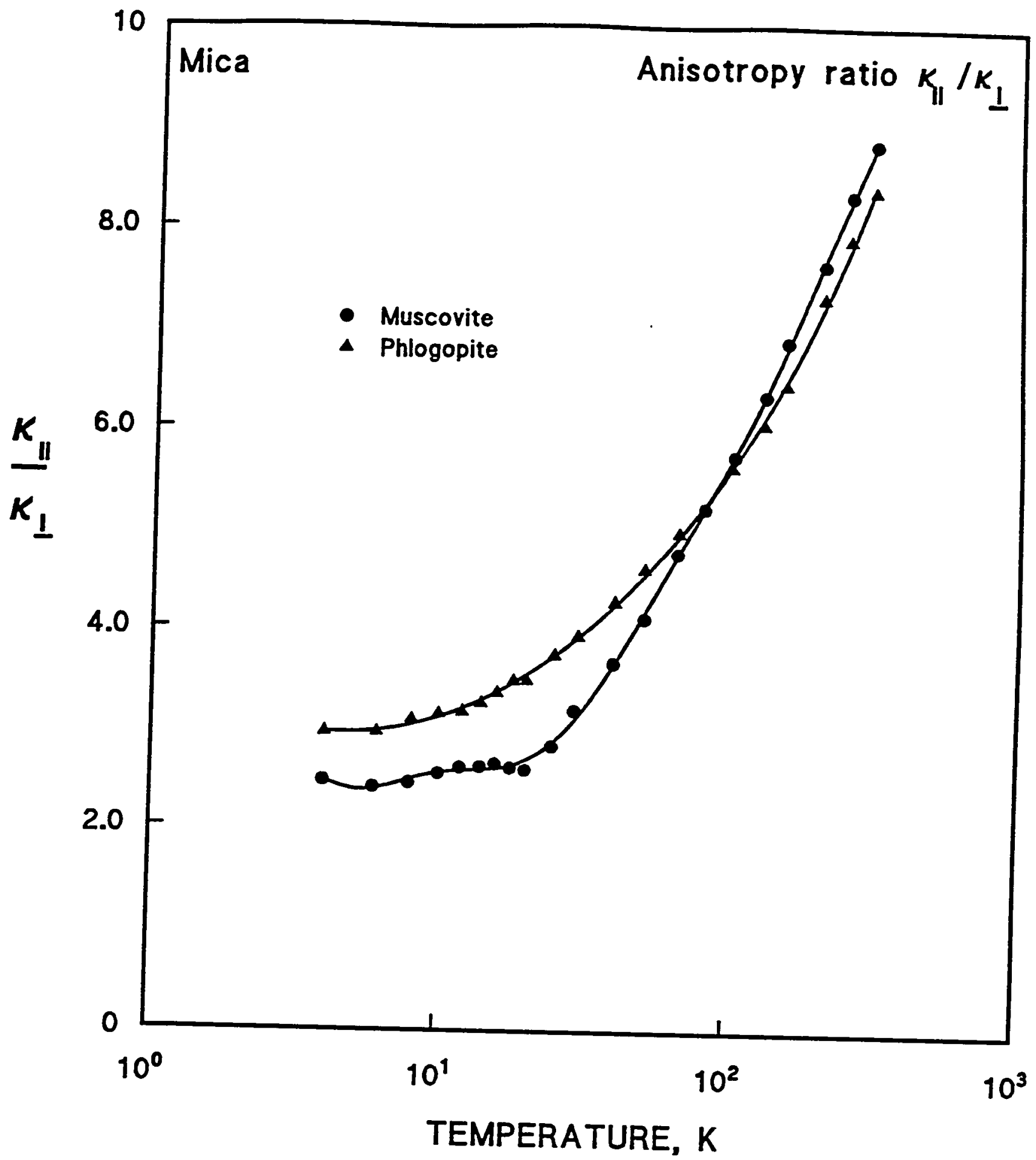

Figure 9.4.4. Anisotropy ratio of thermal conductivity of muscovite and phlogopite mica vs. temperature. Data from Gray and Uher [1977]. 


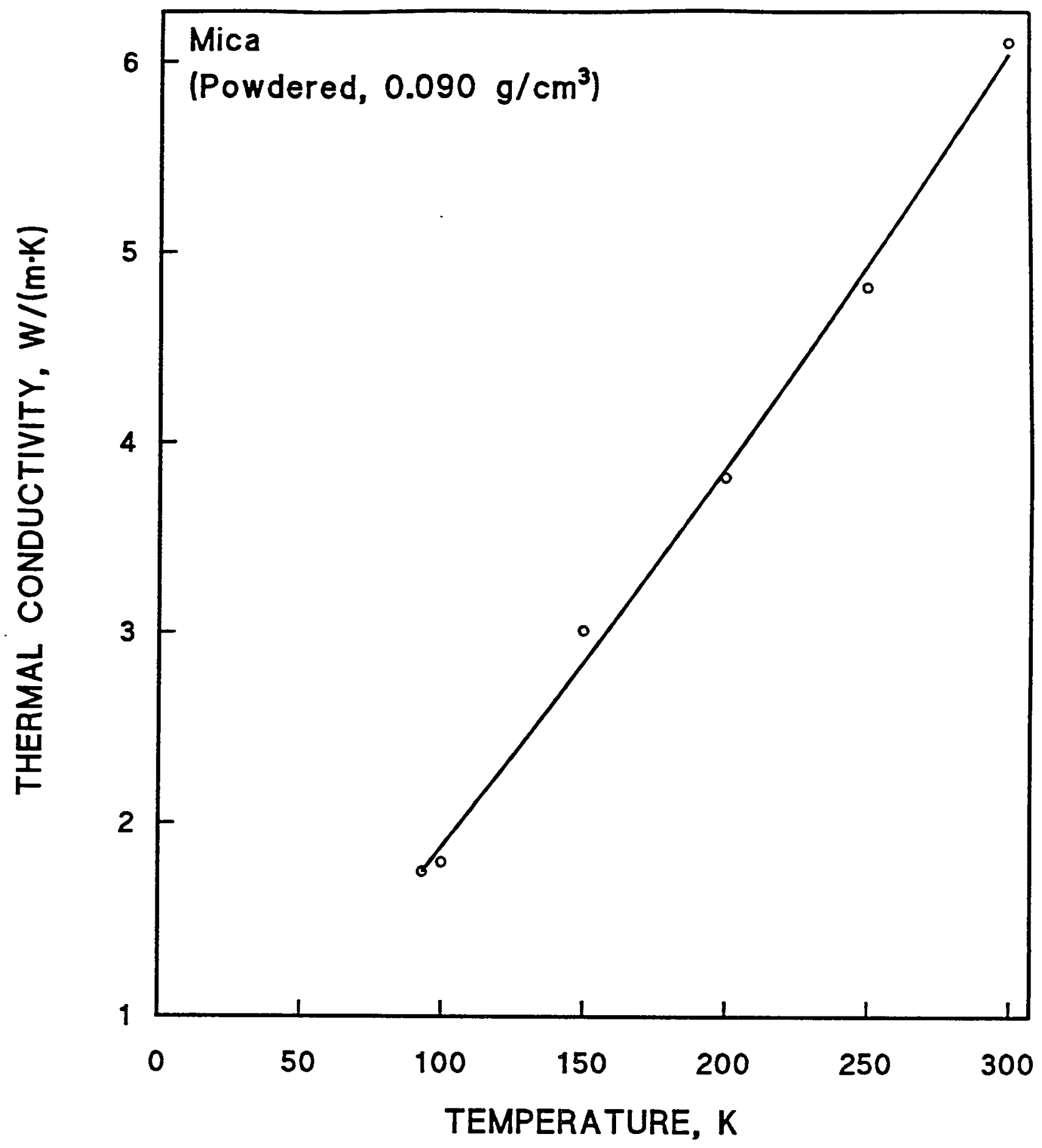

Figure 9.4.5. Thermal conductivity of powdered mica (density, $0.090 \mathrm{~g} / \mathrm{cm}^{3}$ ) vs. temperature [citation, Touloukian et al., 1970]. 


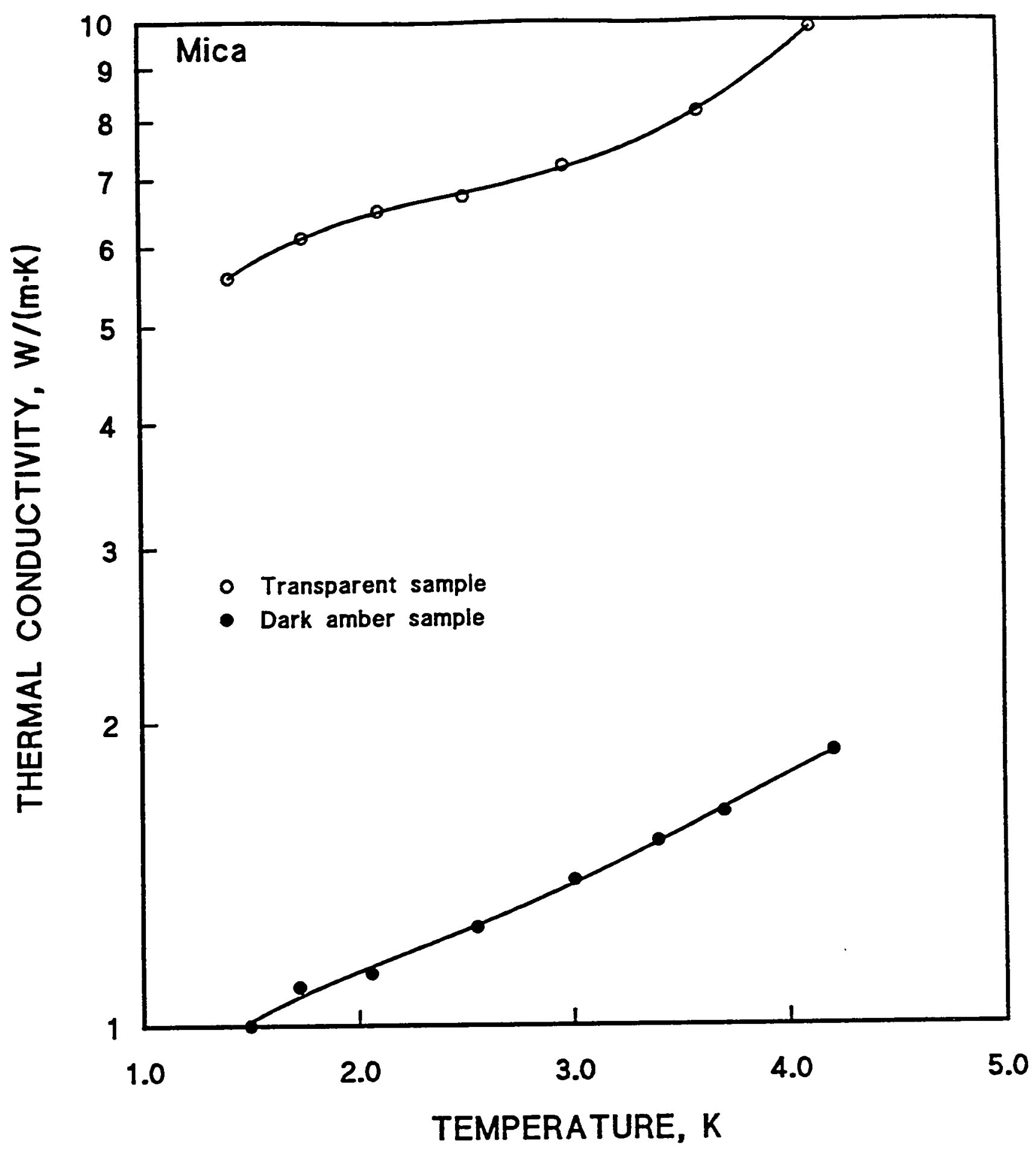

Figure 9.4.6. Difference in thermal conductivity of two samples of muscovite mica below 4.2 K. Data from Falco [1976]. 


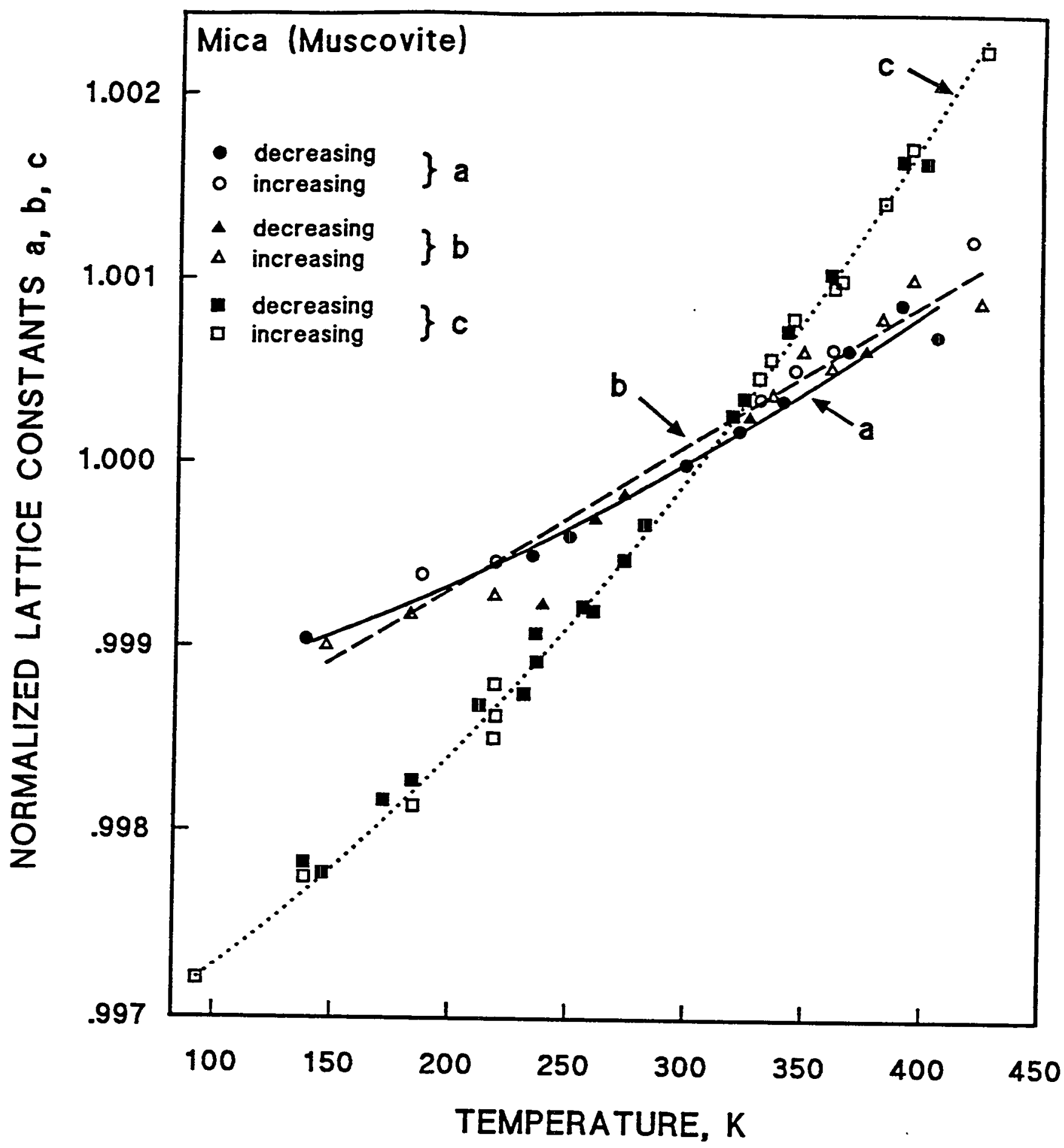

Figure 9.4.7. Change of lattice constant of muscovite mica with temperature between 123 and $423 \mathrm{~K}$. Data from Goldstein and Post [1969]. 
cleavage plane should be absent, and should not contribute to thermal stress. Thermal contraction perpendicular to the cleavage plane from ambient temperature down to $123 \mathrm{~K}$ is about 2.6 times larger than the in-plane contraction.

The in-plane thermal contraction $\left(\Delta L / L_{273} \mathrm{~K}\right)$ of a mica measured by Ebert [1928] down to $20 \mathrm{~K}$ is given in Figure 9.4.8. 


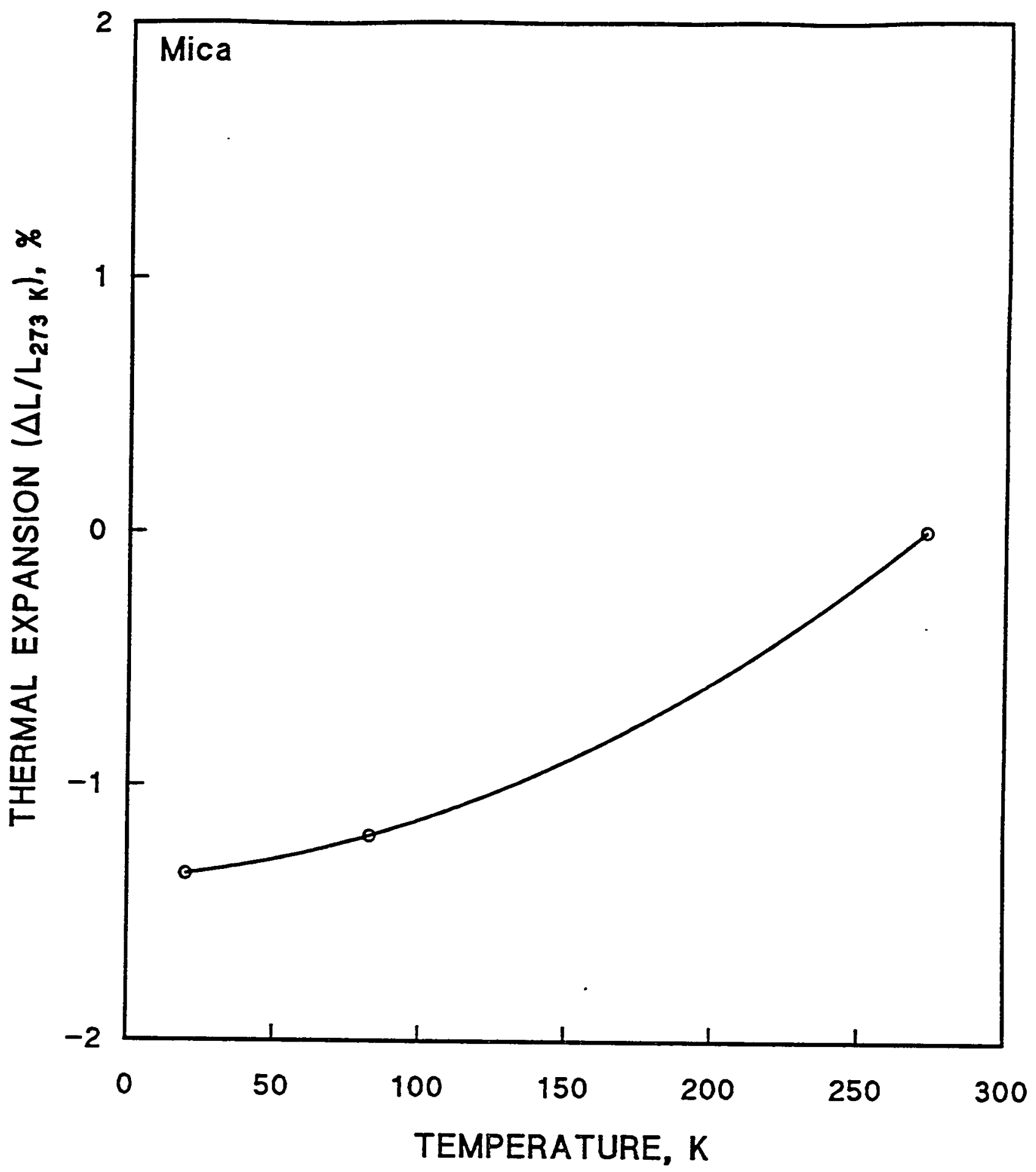

Figure 9.4.8. Thermal expansion $\left(\Delta \mathrm{L} / \mathrm{L}_{273} \mathrm{~K}\right)$ of mica from 20 to $273 \mathrm{~K}$. Data from Ebert [1928]. 
10. COMPOSITE AND HYBRID MICA INSULATION

\subsection{MICA-GLASS GERAMIC}

In machinable glass ceramics, a fluorophlogopite mica phase is crystallized under controlled conditions at 50 to 55 volumez in a boroaluminosilicate glass matrix. Crystallites that are typically 5 to $10 \mu \mathrm{m}$ in size form as mica blocks, not as individual mica sheets. Owing to the random orientation and interlocking of these mica crystallites, crack propagation is arrested, resulting in thermal-shock resistance and machinability to precise tolerances with conventional tools used for working metal. This glass ceramic is nonmagnetic, with a thermal expansion characteristic well-matched to that of metals, has zero porosity, and possesses good ac and dc insulating properties [Lawless, 1975; citations therein].

Radiation studies have been carried out on mica-glass ceramics with $14-\mathrm{MeV}$ neutrons (see Simon [1994] for a review and citations). This 14-MeV neutron energy avoids thermal-neutron activation of the B component, but B-free mica glass ceramics have also been produced in small batches for radiation studies [citations, Simon, 1994].

\subsubsection{Mechanical Properties}

Since mica flakes are easily cleavable, but are very strong in the direction parallel to the cleavage plane, the incorporation of mica flakes into a brittle glass ceramic provides strength-controlling flaws as well as fracture paths. The variation of fracture surface energy with quenching time and temperature was studied by Chyung [1974], but all data were obtained at ambient temperature. The addition of mica increased the fracture surface energy by an order of magnitude over that of ordinary glass or other finegrained glass ceramics.

The variation of flexural and compressive strength of a mica-glass ceramic (Corning 9654) with fluorophlogopite flake size was also measured by Chyung. The data, which pertain only to ambient temperature, are presented in Figure 10.1.1. Note that the flexural strength is proportional to $\mathrm{d}^{-1}$ and the 


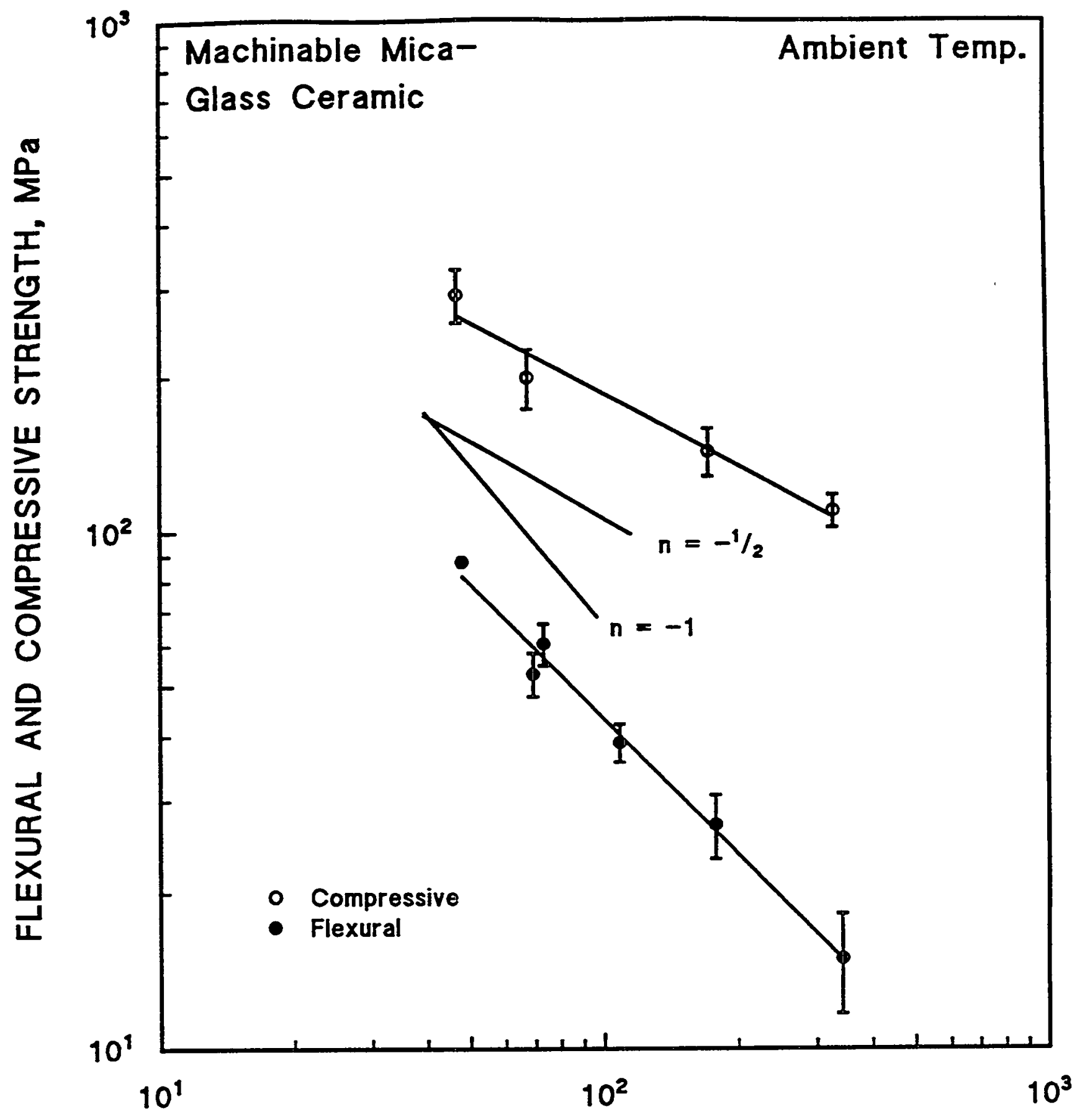

FLAKE DIAMETER, $\mu \mathrm{m}$

Figure 10.1.1. Flexural and compressive strength of mica-glass ceramics vs. mica flake diameter. Data from Chyung [1974]. 
compressive strength to $\mathrm{d}^{-1 / 2}$, where $\mathrm{d}$ is the mica flake diameter. The compressive strengths that were measured ranged from about 109 to $276 \mathrm{MPa}$. The compressive strength at ambient temperature of a phlogopite-glass ceramic of different manufacture was found to be $53 \mathrm{MPa}$ [Low, 1980]. Grossman [1972] reported ambient-temperature compressive strengths of 448 and $517 \mathrm{MPa}$ for tetrasilicic-mica glass ceramics. With 2.5 octahedral sites occupied, the $\mathrm{K}_{2} \mathrm{O}$-tetrasilicic micas are intermediate between the dioctrahedral micas such as muscovite and the trioctahedral micas such as phlogopite.

\subsubsection{Elastic Properties}

The ambient-temperature elastic modulus of specimens of different thermal history studied by Chyung [1974] ranged from 92 to $26 \mathrm{GPa}$. The Poisson's ratio varied from 0.24 to 0.10 . The density of the specimens varied from 2.614 to $2.518 \mathrm{~g} / \mathrm{cm}^{3}$. Grossman [1972] reported elastic moduli of 65 and $68 \mathrm{GPa}$, shear moduli of 26 and $27 \mathrm{GPa}$, and Poisson's ratios of 0.26 and 0.25 for tetrasilicic mica glass ceramics of density 2.61 and $2.67 \mathrm{~g} / \mathrm{cm}^{3}$. Cryogenic elastic constant data on mica glass ceramics were not found in the literature search.

\subsubsection{Electrical Properties}

Lawless [1975; citations therein] reported that the dc electrical breakdown strength of a commercial mica glass ceramic (Macor) was $145 \pm 38 \mathrm{kV} / \mathrm{mm}$ at ambient temperature. These measurements were made on a total of 42 samples that were $0.254-\mathrm{mm}$ thick. Lawless attempted to measure the breakdown strength of specimens of the same thickness at $4 \mathrm{~K}$ with voltage rise rates of $-1 \mathrm{kV} / \mathrm{s}$. However, the power supply limited the field strength to $24 \mathrm{kV} / \mathrm{mm}$, and no breakdowns were observed up to this limit.

The temperature dependence of both the dielectric constant and the loss tangent at $1 \mathrm{kHz}$ of this mica-glass ceramic from 2 to $300 \mathrm{~K}$ are shown in Figure 10.1.2 [Lawless, 1975]. The effect of the measuring frequency on the imaginary part of the dielectric constant, $\epsilon "$, and on the loss tangent were determined at 4 and $77 \mathrm{~K}$ (Figures 10.1 .3 and 10.1.4). The dielectric constant was field-independent within a few parts per million up to $7.7 \mathrm{kV} / \mathrm{mm}$, the 


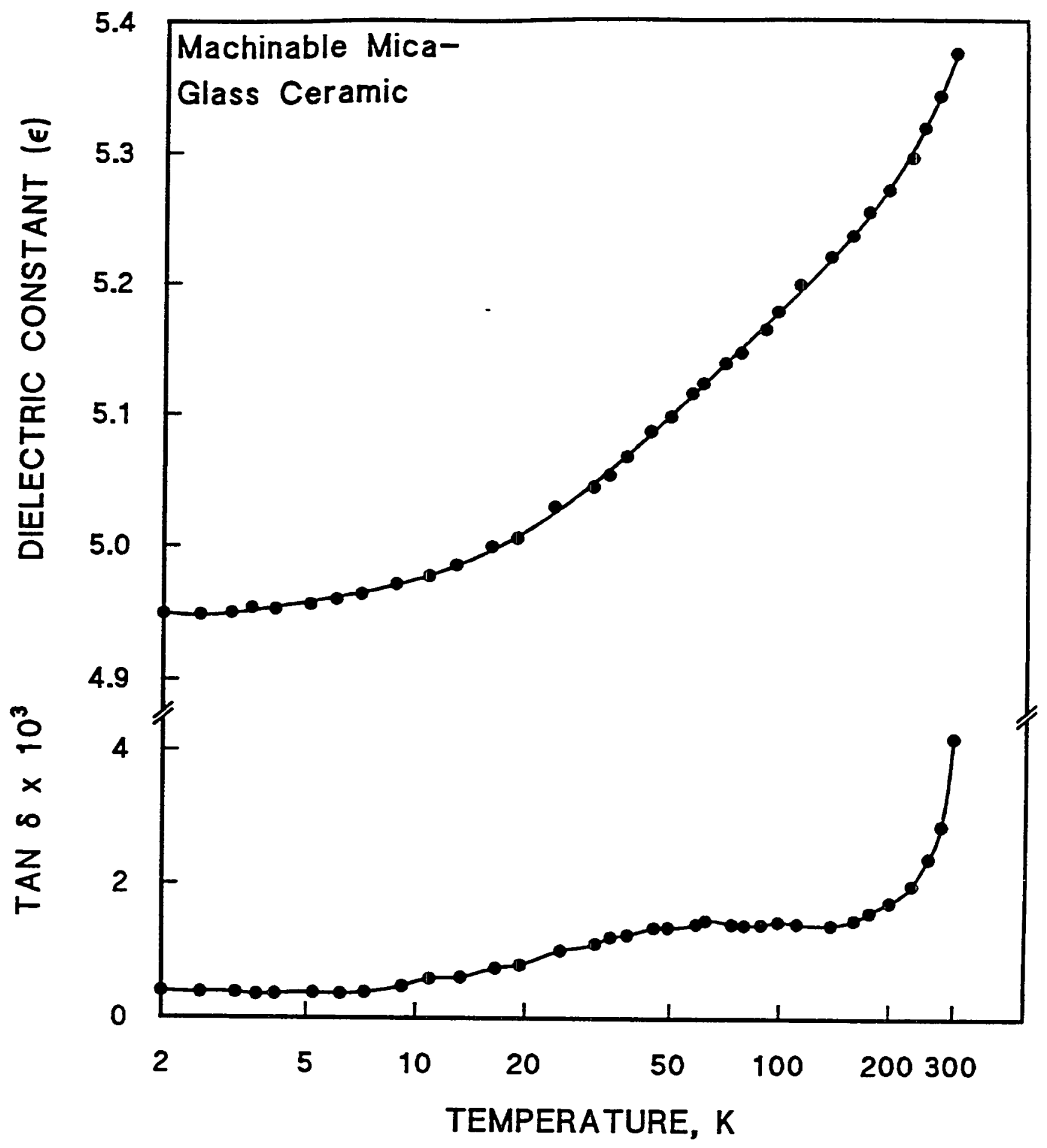

Figure 10.1.2. Dielectric constant and loss tangent at $1 \mathrm{kHz}$ of a mica-glass ceramic vs. temperature. Data from Lawless [1975]. 


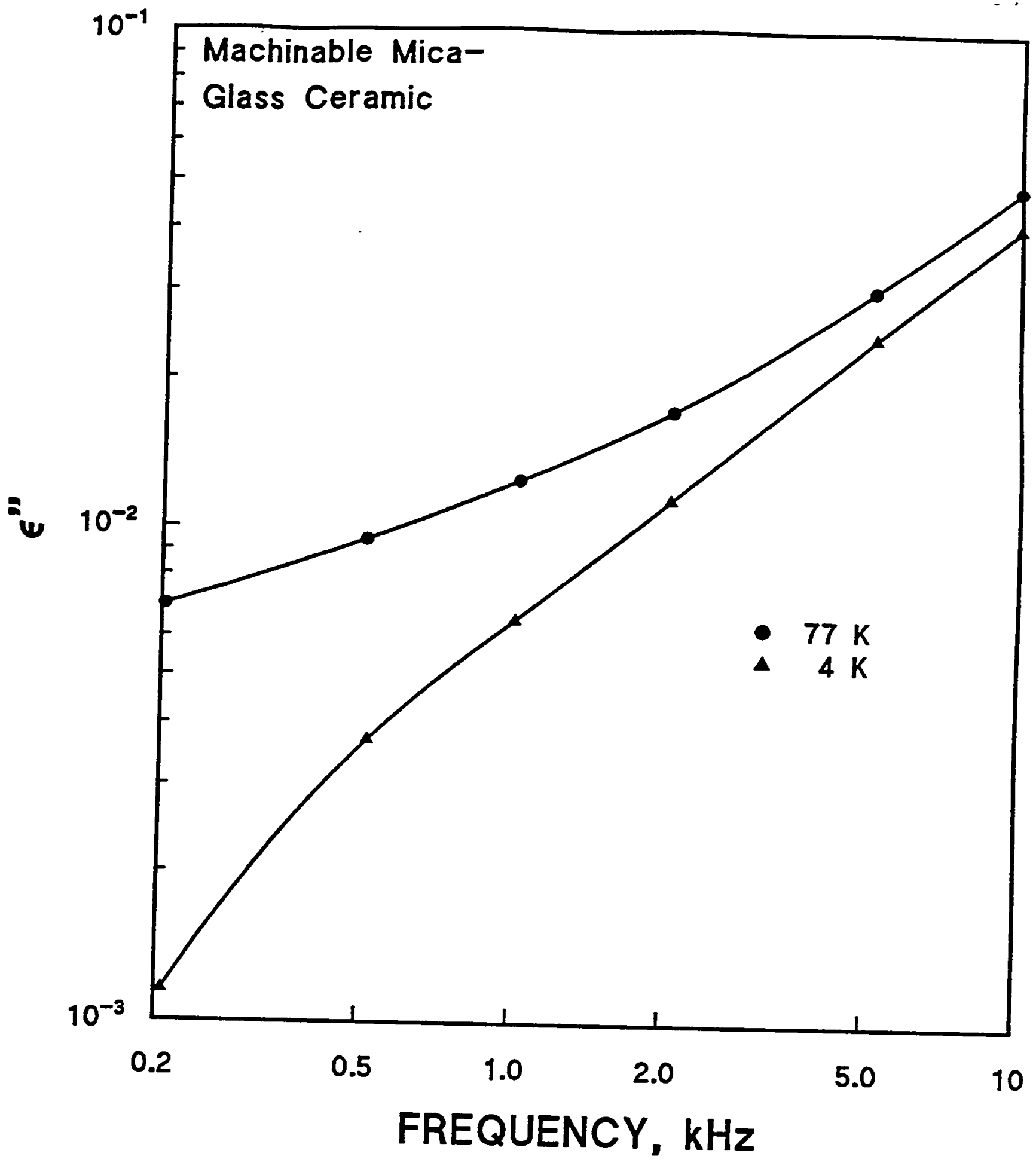

Figure 10.1.3. Frequency dependence of the imaginary part of the dielectric constant, $\epsilon "$, of a mica-glass ceramic at 4 and $77 \mathrm{~K}$. Data from Lawless [1975]. 


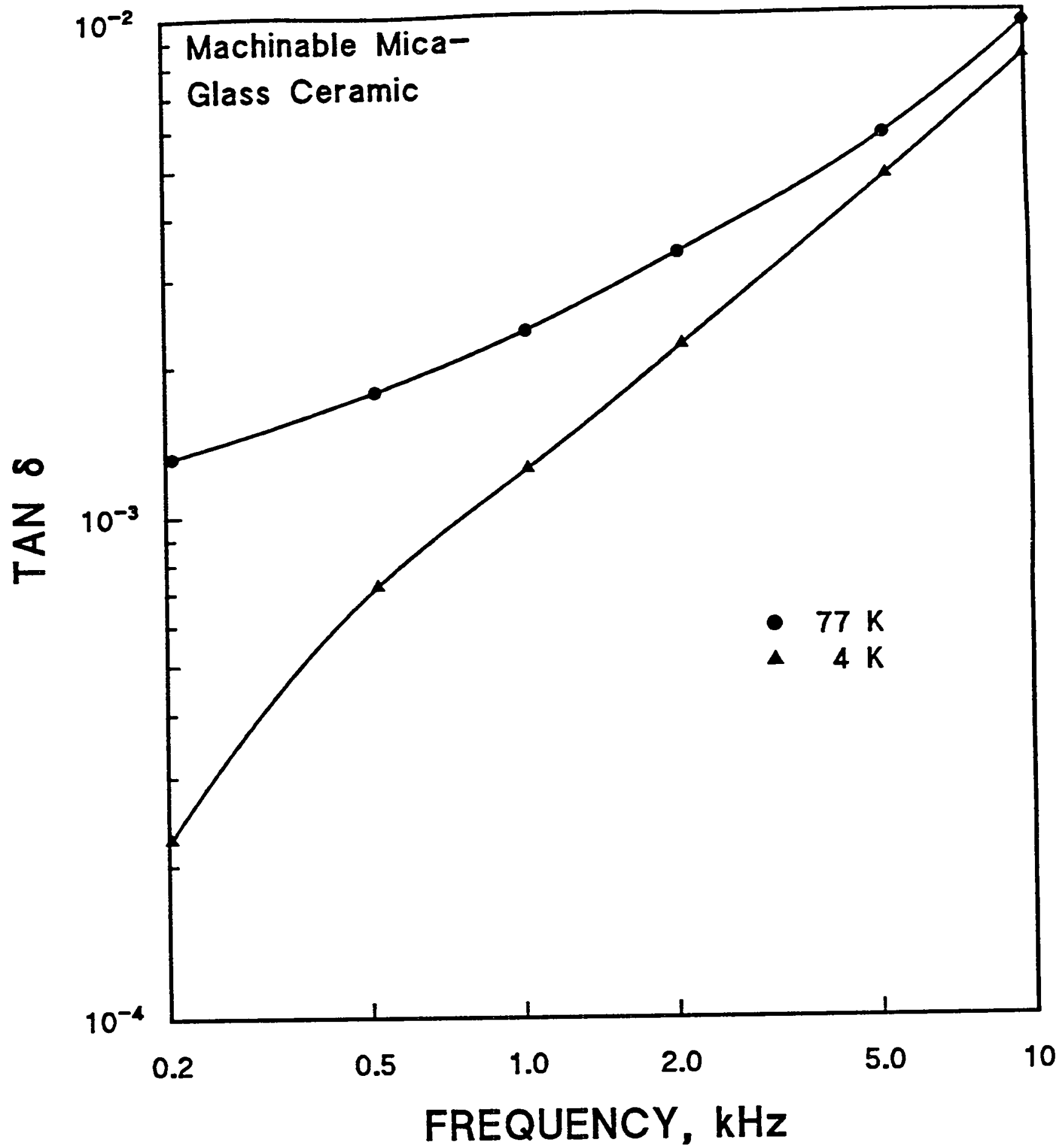

Figure 10.1.4. Frequency dependence of the loss tangent of a mica-glass ceramic at 4 and $77 \mathrm{~K}$. Data from Lawless [1975]. 
largest field applied. The loss tangent depended upon specimen thickness, which accounts for the differences between data in Figures 10.1.2 and 10.1.4.

\subsubsection{Thermal Properties}

The specific heat of a mica-glass ceramic (Macor) between 2 and $20 \mathrm{~K}$ was also measured by Lawless [1975], and compared to that of vitreous $\mathrm{SiO}_{2}$ (Figure 10.1.5). Specific heat data at lower temperatures from Roth and Anderson [1976] agree with these data, as indicated in the figure. (Only data down to $1 \mathrm{~K}$ are illustrated.) In the temperature range investigated by Lawless, the specific heat of the ceramic was very similar to that of vitreous $\mathrm{SiO}_{2}$. Roth and Anderson found that at lower temperatures $(-0.1$ to $1 \mathrm{~K})$, the specific heat of the ceramic was significantly higher than that of vitreous $\mathrm{SiO}_{2}$, but similar to specific heat data on a borosilicate glass. Thus, the presence of the mica crystals does not seem to significantly change the magnitude of the specific heat. Roth and Anderson [1976; citations] noted that the specific heats of epoxies measured above $1.5 \mathrm{~K}$ are also similar in magnitude to the specific heat of this ceramic, and that between 10 and $300 \mathrm{~K}$, most glasses and ceramics have nearly the same specific heat.

The thermal conductivity of the mica-glass ceramic from 2 to $20 \mathrm{~K}$ was also measured by Lawless [1975], and compared with that of vitreous $\mathrm{SiO}_{2}$, as indicated in Figure 10.1.6. In this case, the thermal conductivity is considerably higher above $5 \mathrm{~K}$, about where vitreous $\mathrm{SiO}_{2}$ exhibits the wellknown plateau effect (see \$6.4.2). Since there is no plateau in the ceramic data, the mica crystallites appear to raise the thermal conductivity of the composite material considerably. Some thermal conduction data of Roth and Anderson [1976] at lower temperatures are also shown in Figure 10.1.6 and appear to be in good agreement. The low temperature $(<0.4 \mathrm{~K})$ thermal conductivity of this mica-glass ceramic was also measured by Bosch et al. [1989]. High temperature heat treatment (above $800^{\circ} \mathrm{C}$ ) was also shown to affect the thermal diffusivity of mica-glass ceramics [Siebeneck et al., 1977]. According to the explanation given, the thermal conductivity would be expected to increase at lower temperatures. However, the measurements were not extended below ambient temperature. 


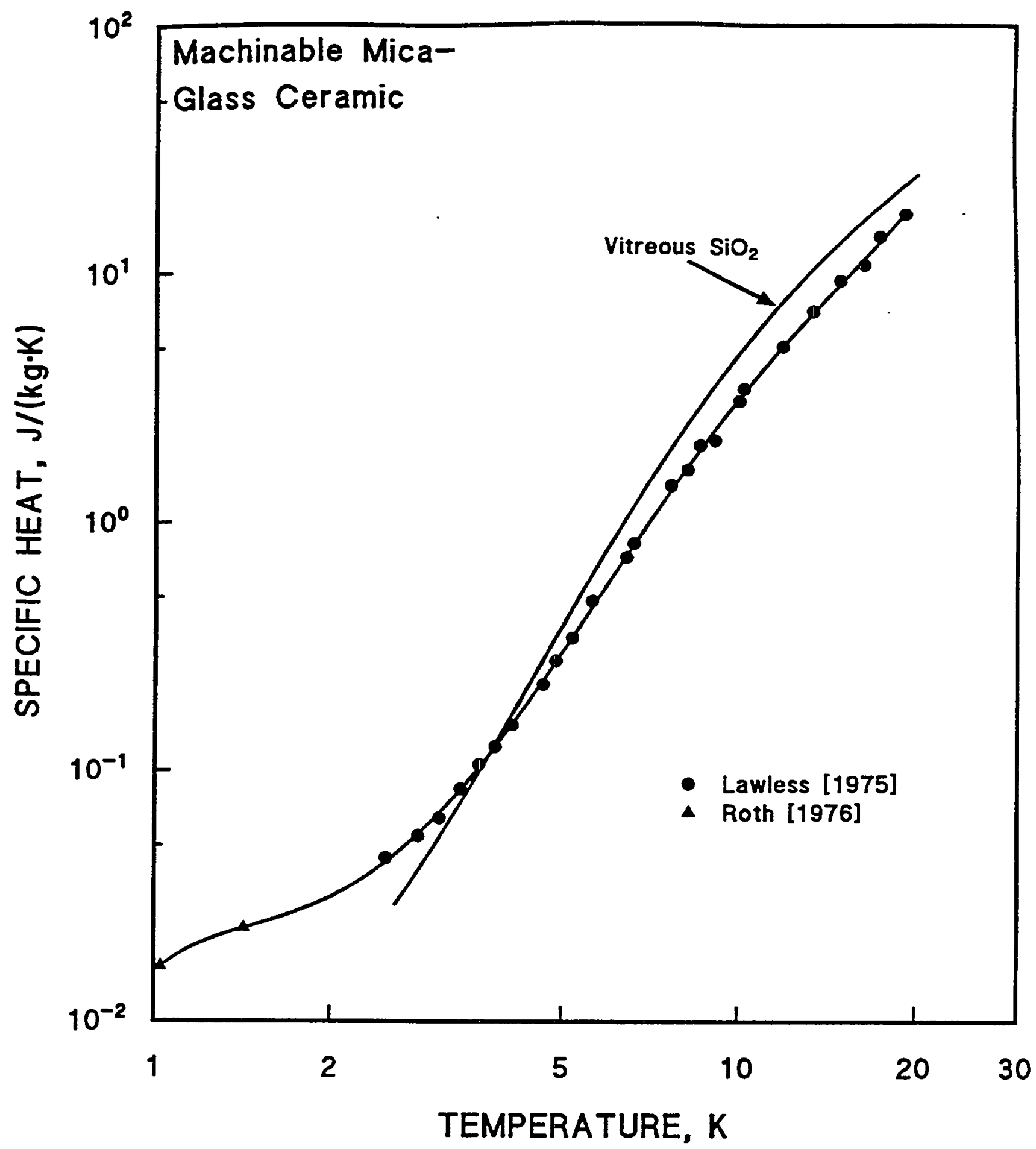

Figure 10.1.5. Specific heat of a mica-glass ceramic below $20 \mathrm{~K}$. Data from Lawless [1975] and Roth and Anderson [1976]. 


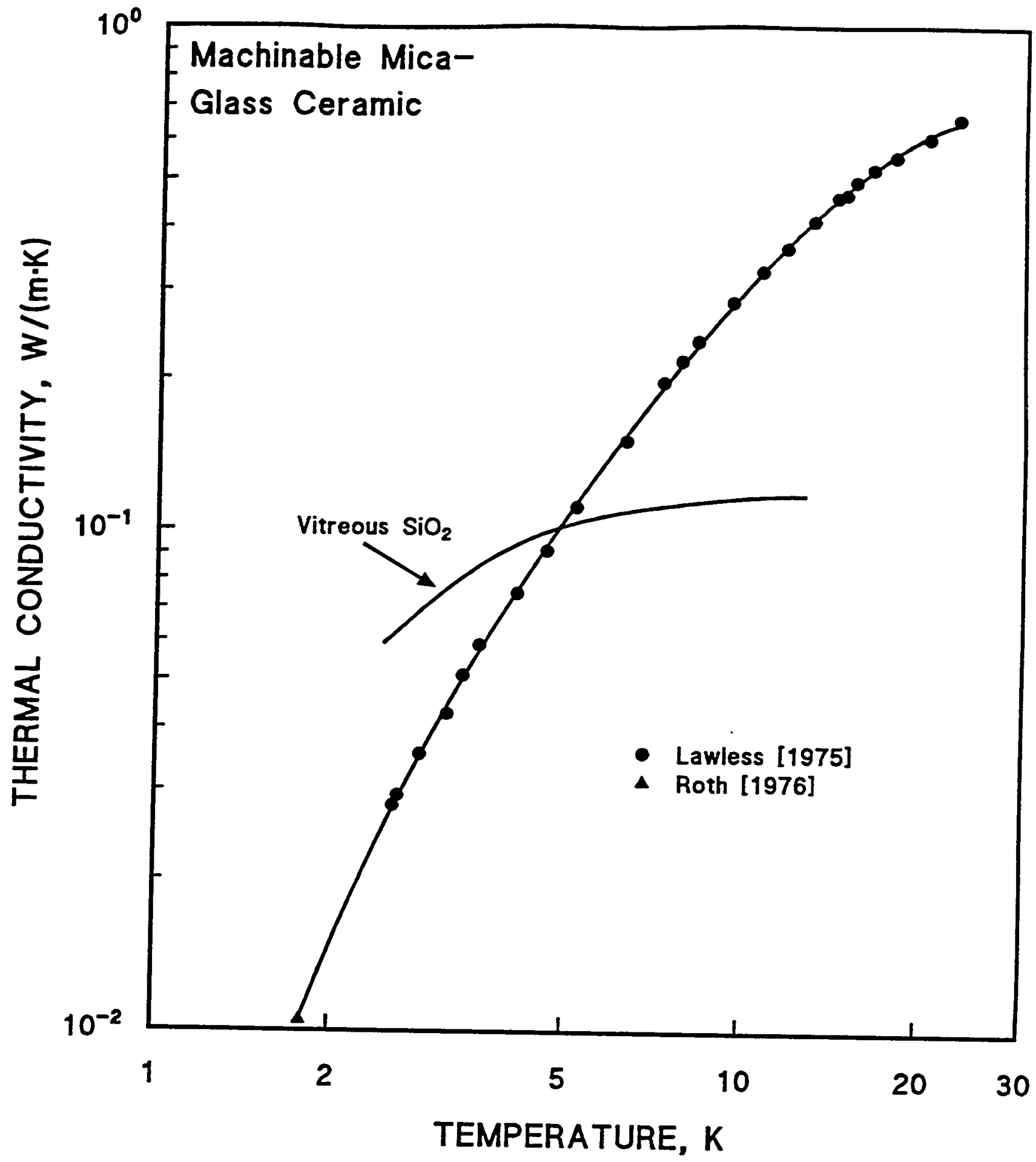

Figure 10.1.6. Thermal conductivity of a mica-glass ceramic below $20 \mathrm{~K}$. Data from Lawless [1975] and Roth and Anderson [1976]. 


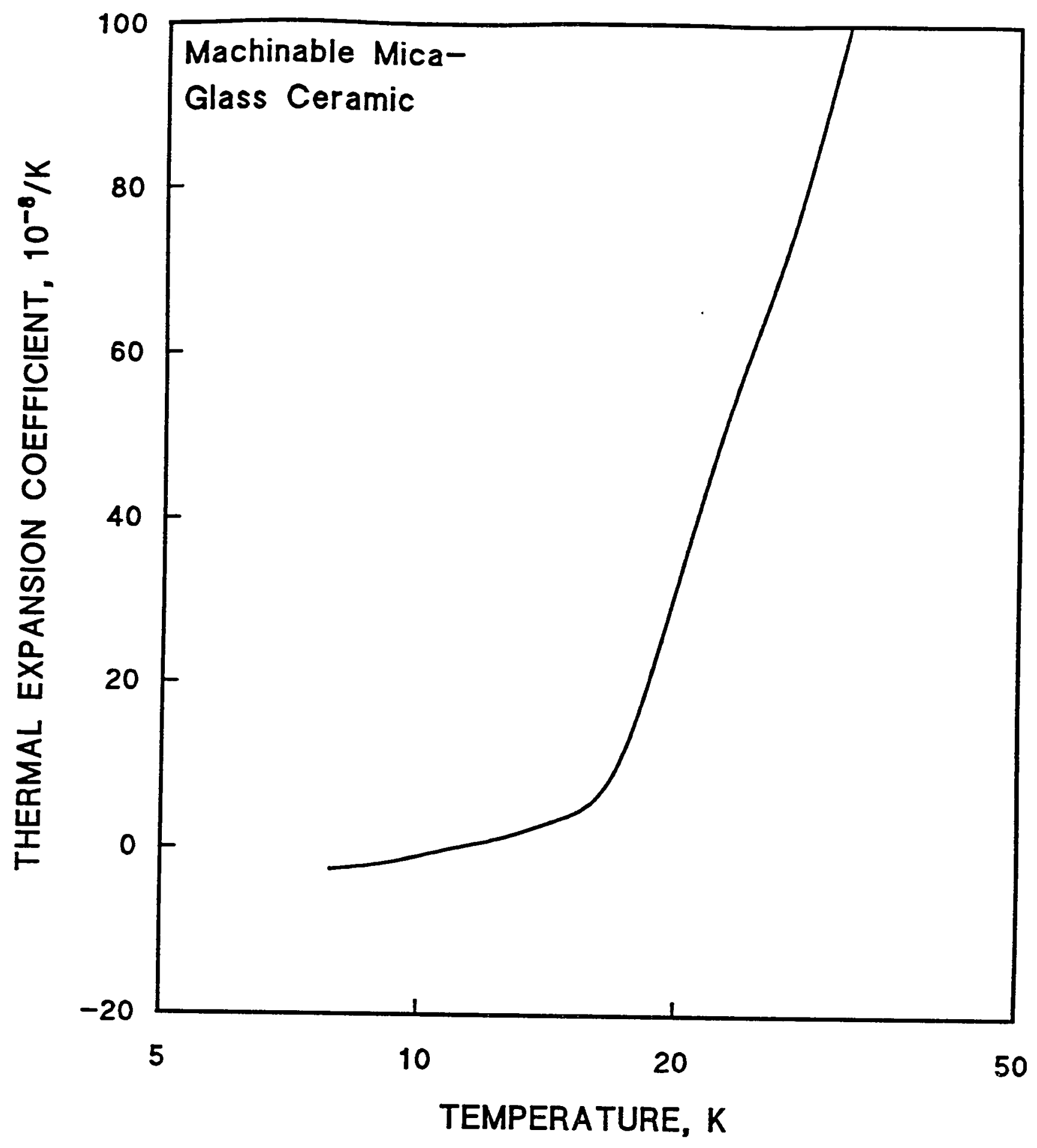

Figure 10.1.7. Thermal expansion coefficient of a mica-glass ceramic vs. temperature from $\sim 8$ to $30 \mathrm{~K}$. Data from White [1976]. 
The thermal expansion coefficient of a mica-glass ceramic was measured by White between about 8 and $30 \mathrm{k}$. These data are presented in Figure 10.1.7.

10.2. HYBRID MICA INSULATION

\subsubsection{Mechanical Properties}

Two types of calcined mica paper attached to S-2 (B-free) glass were used with a TGDM (Tetraglycidyl Diaminodiphenyl Methane) prepreg epoxy system with and without a polyimide film (Kapton) in recent tests at 4 and $76 \mathrm{~K}$ of compressive strength, short-beam shear strength, and shear/compressive strength ( $\$ 1.1 .6)$. The results are shown in Tables 10.2.1, 10.2.2, and 10.2.3 [Fabian and Reed, 1994]. The first two tables show that results from all systems were similar, in general, within the statistical error, as expressed by the coefficient of variation, $C_{v}$. All three tables show that the strengths at $4 \mathrm{~K}$ were generally similar to or slightly higher than those at $76 \mathrm{~K}$, again within the quoted statistical error. The shear/compressive test results in Table 10.2.3 are paired with results on a similar system without mica to show that the addition of mica lowers the shear strength of the system considerably. The addition of a polyimide film in place of mica seems to have a less severe effect. The compressive strengths of the hybrid systems are considerably larger than those expected for the mica products $(\$ 9.1)$.

\subsubsection{Elastic Properties}

The elastic properties at 76 and $4 \mathrm{~K}$ of the hybrid systems discussed in $\S 10.2 .1$ are given in Tables 10.2.1 and 10.2.2.

\subsubsection{Electrical Properties}

The electrical breakdown strengths at $76 \mathrm{~K}$ of the systems described above are given in Table 10.2.4, along with a similar system without mica [Fabian and Reed, 1994]. Surprisingly, the addition of mica paper or mica paper and Kapton does not increase the breakdown strength, within the statistical error (indicated by $C_{v}$, the coefficient of variation). The electrical breakdown strength was measured between $12.7-\mathrm{mm}$-diameter electrodes with 6.4-mm-diameter 
Table 10.2.1. Compressive Strength of hybrid mica/epoxy/fiberglass insulation systems. Data from Fabian and Reed [1994].

\begin{tabular}{lrrrrrrr}
\hline Material & & $\begin{array}{c}\text { Temp. } \\
\mathrm{K}\end{array}$ & $\begin{array}{c}\text { Compressive } \\
\text { strength, } \\
\text { GPa }\end{array}$ & $\begin{array}{c}\mathrm{C}_{\mathrm{v}}, \mathbf{z} \\
\text { \% }\end{array}$ & $\begin{array}{c}\text { Compressive } \\
\text { modulus, } \\
\text { GPa }\end{array}$ & $\begin{array}{c}\mathrm{C}_{\mathrm{v}} \text { \% } \\
\text { \% }\end{array}$ & $\begin{array}{c}\text { Strain } \\
\text { to } \\
\text { failure }\end{array}$ \\
\hline CTD-112P/S-2 glass (AR) & 76 & 1.22 & 1.07 & 18.6 & 7.38 & 0.066 \\
& 4 & 1.26 & 3.66 & 23.7 & 3.56 & 0.053 \\
CTD-112P/S-2 glass (AR) & 76 & 1.09 & 2.65 & 19.3 & 0.33 & 0.056 \\
IMI mica & 4 & 1.27 & 2.77 & 24.7 & 10.71 & 0.051 \\
CTD-112P/S-2 glass (AR) & 76 & 1.23 & 1.32 & 20.7 & 12.72 & 0.059 \\
MM mica & 4 & 1.28 & 8.50 & 21.5 & 5.20 & 0.060 \\
CTD-112P/S-2 glass (AR) & 76 & 1.20 & 3.93 & 17.6 & 6.55 & 0.068 \\
IMI mica & 4 & 1.19 & 2.44 & 18.5 & 8.08 & 0.064 \\
\hline
\end{tabular}

a $c_{v}=$ coefficient of variation.

Table 10.2.2. Short-beam shear strength of hybrid mica/epoxy/fiberglass insulation systems. Data from Fabian and Reed [1994].

\begin{tabular}{|c|c|c|c|c|c|c|}
\hline Material & $\underset{\mathrm{K}}{\text { Temp. }}$ & $\begin{array}{l}\text { Span } \\
\text { Ratio }\end{array}$ & $\begin{array}{c}\text { Shear } \\
\text { Strength, } \\
\text { GPa }\end{array}$ & $\mathrm{C}_{\mathrm{v}}$ & $\begin{array}{c}\text { Flexural } \\
\text { Modulus, } \\
\mathrm{GPa}\end{array}$ & $\mathrm{C}_{\mathrm{y}}$ \\
\hline CTD-112P/S-2 glass (AR) & $\begin{array}{r}76 \\
4\end{array}$ & $\begin{array}{l}5.0 \\
5.0\end{array}$ & $\begin{array}{l}67.0 \\
69.0\end{array}$ & $\begin{array}{l}3.0 \\
1.0\end{array}$ & $\begin{array}{l}29.5 \\
27.9\end{array}$ & $\begin{array}{l}3.7 \\
8.8\end{array}$ \\
\hline $\begin{array}{l}\text { CTD-112P/S-2 glass (AR) } \\
\text { IMI mica }\end{array}$ & $\begin{array}{r}76 \\
4\end{array}$ & $\begin{array}{l}5.0 \\
5.0\end{array}$ & $\begin{array}{l}18.0 \\
22.0\end{array}$ & $\begin{array}{r}9.0 \\
11.0\end{array}$ & $\begin{array}{l}22.2 \\
28.2\end{array}$ & $\begin{array}{l}0.1 \\
1.9\end{array}$ \\
\hline $\begin{array}{l}\text { CTD-112P/S-2 glass (AR) } \\
\text { MM mica }\end{array}$ & $\begin{array}{r}76 \\
4\end{array}$ & $\begin{array}{l}5.0 \\
5.0\end{array}$ & $\begin{array}{l}23.0 \\
36.0\end{array}$ & $\begin{array}{r}10.0 \\
1.0\end{array}$ & $\begin{array}{l}24.3 \\
24.0\end{array}$ & $\begin{array}{l}7.4 \\
4.7\end{array}$ \\
\hline $\begin{array}{l}\text { CTD-112P/S-2 glass (AR) } \\
\text { IMI mica }\end{array}$ & $\begin{array}{r}76 \\
4\end{array}$ & $\begin{array}{l}5.0 \\
5.0\end{array}$ & $\begin{array}{l}18.0 \\
16.0\end{array}$ & $\begin{array}{l}13.0 \\
31.0\end{array}$ & $\begin{array}{l}25.4 \\
24.3\end{array}$ & $\begin{array}{l}9.7 \\
5.5\end{array}$ \\
\hline
\end{tabular}


Table 10.2.3. Shear/compressive strength of hybrid mica/epoxy/fiberglass insulation systems. Data from Fabian and Reed [1994].

\begin{tabular}{|c|c|c|c|c|c|c|}
\hline Material & $\underset{\mathrm{K}}{\operatorname{Temp}}$ & $\begin{array}{c}\text { Fixture, } \\
\text { deg. }\end{array}$ & $\begin{array}{c}\text { Shear } \\
\text { strength, } \\
\mathrm{MPa}\end{array}$ & $\mathrm{C}_{\mathbf{v}}$ & $\begin{array}{c}\text { Compressive } \\
\text { stress, } \\
\mathrm{MPa}\end{array}$ & $C_{v}$ \\
\hline \multirow[t]{2}{*}{ CTD-112P/S-2 glass (AR) } & 76 & $\begin{array}{l}15 \\
45 \\
75\end{array}$ & $\begin{array}{r}52.6 \\
140.9 \\
188.1\end{array}$ & $\begin{array}{l}17.9 \\
12.7 \\
15.3\end{array}$ & $\begin{array}{r}14.1 \\
140.9 \\
701.6\end{array}$ & $\begin{array}{l}17.9 \\
12.7 \\
15.3\end{array}$ \\
\hline & 4 & $\begin{array}{l}15 \\
45 \\
75\end{array}$ & $\begin{array}{r}59.5 \\
150.1 \\
219.7\end{array}$ & $\begin{array}{r}27.9 \\
4.7 \\
4.2\end{array}$ & $\begin{array}{r}16.0 \\
150.1 \\
819.5\end{array}$ & $\begin{array}{l}8.0 \\
4.7 \\
4.2\end{array}$ \\
\hline \multirow[t]{2}{*}{$\begin{array}{l}\text { CTD-112P/S-2 glass (AR) } \\
\text { IMI mica }\end{array}$} & 76 & $\begin{array}{l}15 \\
45 \\
75\end{array}$ & $\begin{array}{l}12.0 \\
18.3 \\
92.7\end{array}$ & $\begin{array}{r}7.5 \\
18.3 \\
2.8\end{array}$ & $\begin{array}{r}3.2 \\
18.3 \\
345.7\end{array}$ & $\begin{array}{r}7.5 \\
18.3 \\
2.8\end{array}$ \\
\hline & 4 & $\begin{array}{l}15 \\
45 \\
75\end{array}$ & $\begin{array}{l}11.4 \\
26.4 \\
83.6\end{array}$ & $\begin{array}{r}19.3 \\
12.7 \\
2.4\end{array}$ & $\begin{array}{r}3.1 \\
26.4 \\
311.7\end{array}$ & $\begin{array}{r}19.3 \\
12.7 \\
2.4\end{array}$ \\
\hline \multirow[t]{2}{*}{$\begin{array}{l}\text { CTD-112P/S-2 glass (AR) } \\
\text { Kapton HA }\end{array}$} & 76 & $\begin{array}{l}15 \\
45 \\
75\end{array}$ & $\begin{array}{r}46.4 \\
108.8 \\
122.8\end{array}$ & $\begin{array}{r}24.3 \\
5.8 \\
9.6\end{array}$ & $\begin{array}{r}12.4 \\
108.8 \\
458.0\end{array}$ & $\begin{array}{r}24.3 \\
5.8 \\
9.6\end{array}$ \\
\hline & 4 & $\begin{array}{l}15 \\
45 \\
75\end{array}$ & $\begin{array}{r}58.9 \\
135.5 \\
106.0\end{array}$ & $\begin{array}{r}17.1 \\
9.5 \\
25.4\end{array}$ & $\begin{array}{r}15.8 \\
135.5 \\
395.6\end{array}$ & $\begin{array}{r}17.1 \\
9.5 \\
18.0\end{array}$ \\
\hline
\end{tabular}

Table 10.2.4. Electrical breakdown strength of hybrid mica/epoxy/fiberglass insulation systems. Data from Fabian and Reed [1994].

\begin{tabular}{lccccc}
\hline Material & $\begin{array}{c}\text { Coating } \\
\text { thickness, } \\
\mathrm{mm}\end{array}$ & $\begin{array}{c}\text { Breakdown } \\
\text { voltage, } \\
\mathrm{kV}\end{array}$ & $\begin{array}{c}\mathrm{C}_{\mathrm{v}}, \\
\%\end{array}$ & $\begin{array}{c}\text { Dielectric } \\
\text { strength, } \\
\mathrm{kV} / \mathrm{mm}\end{array}$ & $\begin{array}{c}\mathrm{C}_{\mathrm{v}}, \\
\text { z }\end{array}$ \\
\hline $\begin{array}{l}\text { CTD-112P/S-2 glass (AR) } \\
\text { CTD-112P/S-2 glass (AR) } \\
\text { IMI mica }\end{array}$ & 0.552 & 44.0 & 4.9 & 79.7 & 4.0 \\
$\begin{array}{c}\text { CTD-112P/S-2 glass (AR) } \\
\text { MM mica }\end{array}$ & 0.523 & 38.2 & 9.5 & 73.1 & 10.0 \\
$\begin{array}{l}\text { CTD-112P/S-2 glass (AR) } \\
\text { Kapton HA/IMI mica }\end{array}$ & 0.569 & 48.0 & 10.2 & 80.9 & 8.5 \\
\hline
\end{tabular}


flats. Specimens were about 0.50 - to $0.60-\mathrm{mm}$ thick. Tests were done in liquid $\mathrm{N}_{2}$, which is an adequate dielectric fluid that should minimize flashover (\$1.3). A dc test voltage was applied to the specimen in steps of $5-s$ duration.

At ambient temperature, Deutschmann and Krassnitzer [1991] also tested hybrid insulation with mica paper (see also \$9.3), but the procedure was the reverse of that described above, in that the electrical breakdown strength of several layers of the mica paper was measured, and then the breakdown strength of a mica-paper-containing laminate was determined. The breakdown strength (in air) of five layers of calcined muscovite paper was $24 \mathrm{kV} / \mathrm{mm}$. Breakdown strengths of 86 and $101 \mathrm{kV} / \mathrm{mm}$ were obtained for calcined paper with glass or polyester film in an epoxy novolac matrix. Specimens that were $0.3-\mathrm{mm}$ thick were tested between hemispherical electrodes under oil at $50 \mathrm{~Hz}$. Tapes made with a VPI (vacuum-impregnated insulation) showed superior breakdown strength $(42 \mathrm{kV} / \mathrm{mm})$ compared to prepreg tapes that used epoxy novolac $(28 \mathrm{kV} / \mathrm{mm})$. Results with noncalcined paper were lower. Similar results were obtained in voltage life tests $\left(12.5 \mathrm{kV} / \mathrm{mm}, 50 \mathrm{~Hz}, 155^{\circ} \mathrm{C}, 440 \mathrm{~h}\right)$.

Even though the specimens were carefully prepared, the breakdown characteristics of mica-epoxy composites were lower than those of the mica or the epoxy. The ac breakdown voltage was about one half that of the dc breakdown voltage, $-550 \mathrm{kV} / \mathrm{mm}$ at $25^{\circ} \mathrm{C}$ [Kimura and Hirabayashi, 1977]. Mica splittings were wound around $\mathrm{Cr}$-Mo steel bars $1 \mathrm{M}$ in length and a "post-impregnating process" was carried out with a modified epoxy resin [Kimura and Kaneda, 1991]. A high speed, repetitive four-point bending machine was used to fatigue the bar at a strain of 700 to $1500 \times 10^{-6}$. Little change in the breakdown voltage was seen after $10^{4}$ cycles, but by $10^{5}$ cycles, the breakdown strength was about $55 \%$ of the initial value, and at $5 \times 10^{5}$ cycles, the breakdown strength was about $25 \%$ of the initial value. The relative stiffness of the bars did not decrease as rapidly, falling to about $85 \%$ of the initial value after $5 \times 10^{5}$ cycles. Thermal aging carried out at $180^{\circ} \mathrm{C}$ before the fatigue test for periods of 100 and $3000 \mathrm{~h}$ drastically increased the deterioration of the breakdown voltage under fatigue. But measurements of the breakdown voltage without fatigue showed only a slight deterioration after $7800 \mathrm{~h}$ at $180^{\circ} \mathrm{C}$. SEM showed that delaminations and cracks vertical to the 
plane surface of the mica flakes were found after thermal aging, especially in resin-rich areas, but that the appearance of local fractures was different after fatigue: powder-like fragments were scattered around the damage. From examination of many SEM pictures and the known synergistic effect of thermal aging, Kimura and Kaneda deduced that the number of delaminations between the mica and the matrix increased during thermal or mechanical aging, but that breakdown did not occur until microcracks connected the defects. Tree-like partial discharges in the mica were thought to dominate at the final stages of multistress aging [citation, Kimura and Kaneda, 1991]. Electrical failure occurred before mechanical rupture.

\subsubsection{Thermal Properties}

The thermal contraction from $295 \mathrm{~K}$ of one of the TGDM/glass/mica paper laminates described above was reported to be $0.16 \%$ at $80 \mathrm{~K}$ and $0.19 \%$ at $4 \mathrm{~K}$ in the warp and fill directions, and $0.61 \%$ at $80 \mathrm{~K}$ and $0.70 \%$ at $4 \mathrm{~K}$ in the throughthickness directions [Fabian and Reed, 1994]. Thermal expansion was measured with a strain gage technique using the known thermal expansion of $\mathrm{Cu}$ [citations, Fabian and Reed, 1994]. Thermal contraction of the system containing mica was very similar to the thermal contraction of the same system without mica.

The thermal conductivity of the TGDM/glass/mica paper laminate was reported to be $0.535 \mathrm{~W} /(\mathrm{m} \cdot \mathrm{K})$ at $295 \mathrm{~K}, 0.313 \mathrm{~W} /(\mathrm{m} \cdot \mathrm{K})$ at $100 \mathrm{~K}$, and $0.065 \mathrm{~W} /(\mathrm{m} \cdot \mathrm{K})$ at $4 \mathrm{~K}$. The report by Fabian and Reed may be consulted for additional data. This thermal conductivity is similar to that of other laminates measured in the same program. 


\section{REFERENCES}

Ackerman, D.A. 1982. Low-Temperature Thermal Expansion of Amorphous Solids. Ph.D. Thesis, University of Illinois at Urbana-Champaign, IL. 98 pp.

Ackerman, D.A.; Moy, D.; Potter, R.C.; Anderson, A.C. 198I. Glassy Behavior of Crystalline Solids at Low Temperatures. Physical Review B 23. pp. 3886-3893.

Adams, M.; Sines, G. 1976. Methods for Determining the Strength of Brittle Materials in Compressive Stress States. Journal of Testing and Evaluation 4. pp. 383-396.

1977. Spalling and Cracking in Alumina by Compression. Journal of the American Ceramic Society 60. pp. 221-226.

Aghajanian, M.K.; MacMillan, N.H.; Kennedy, C.R.; Luszcz, S.J. 1989. Properties and Microstructures of Lanxide $\mathrm{Al}_{2} \mathrm{O}_{3}-\mathrm{Al}$ Ceramic Composite Materials. Journal of Materials Science 24. pp. 658-670.

Ahmad, N.; Matiullah. 1990. The Effect of OH Concentration on the Low Temperature Heat Capacity and Raman Scattering of Vitreous Silica. Solid State Communications 76. pp. 443-435.

Akh'yan, A.M. 1986. Electric Insulating Materials from Quartz Ceramics. Glass and Ceramics 43 . pp. 470-472.

Aki, F.; Matsunobu, K.; Kadotani, K. 1983. Developments in Coil Insulation Technology for Nuclear Fusion Equipment. Hitachi Review 32. pp. 153-158.

Alterovitz, S.; Deutscher, G.; Gershenson, M. 1975. Heat Capacity and Thermal Conductivity of Sintered $\mathrm{Al}_{2} \mathrm{O}_{3}$ at Low Temperatures by the Heat Pulse Technique. Journal of Applied Physics 46. pp. 3637-3643.

Amin, K.E. 1991. Toughness, Hardness, and Wear. In: Engineered Materials Handbook, Vol. 4: Ceramics and Glasses. S.J. Schneider, Jr., ed. ASM International, Metals Park, OH. pp. 599-609.

Anthony, P.J.; Anderson, A.C. 1976. Thermal Conductivities of Li, Na, K, and Ag B-alumina below $300 \mathrm{~K}$. Physical Review B 14. pp. 5198-5204.

Arp, V.; Wilson, J.H.; Winrich, L.; Sikora, P. 1962. Thermal Expansion of Some Engineering Materials from 20 to $293^{\circ} \mathrm{K}$. Cryogenics 2. pp. 230235 .

Austen, A.E.W.; Whitehead, S. 1940. The Electric Strength of Some Solid Dielectrics. Proceedings of the Royal Society (London) $A 176$. pp. 33-50.

Barron, T.H.K.; Berg, W.T.; Morrison, J.A. 1959. On the Heat Capacity of Crystalline Magnesium Oxide. Proceedings of the Royal Society (London) A 250. pp. 70-83. 
Barron, T.H.K.; Collins, J.F.; Smith, T.W.; White, G.K. 1982. Thermal Expansion Grüneisen Functions and Static Lattice Properties of Quartz. Journal of Physics $C$ 15. pp. 4311-4326.

Bartenev, S.S.; Navrozov, S.V. 1977. Some Technical Characteristics of Plasma-Deposited $\mathrm{ZrO}_{2}$. Journal of Inorganic Materials 13. pp. 17441747.

Beauchamp, E.K. 1971. Effect of Microstructure on Pulse Electrical Strength of MgO. Journal of the American Ceramics Society 54. pp. 484-487.

Berman, R. 1952. The Thermal Conductivity of Some Polycrystalline Solids at Low Temperatures. Proceedings, Physical Society of London A 65 . pp. 1029-1040.

Berman, R.; Foster, E.I.; Schneidmesser, B.; Tirmizi, S.M.A. 1960. Effects of Irradiation on the Thermal Conductivity of Synthetic Sapphire. Journal of Applied Physics 31. pp. 2156-2159.

Bhatia, C.S.; Guthmiller, G.; Spool, A.M. 1989. Alumina Films by Sputter Deposition with $\mathrm{Ar} / \mathrm{O}_{2}$ : Preparation and Characterization. Journal of Vacuum Science and Technology A 7. Pp. 1298-1302.

Bobo, J.; Perrier, M.; Fallou, B.; Galand, J. 1968. Dielectric Strength of Polymers at Cryogenic Temperatures under Vacuum. Vacuum 18. pp. 397401 .

Boch, P.; Glandus, J.C.; Jarrige, J.; LeCompte, J.P. Mexmain, J. 1982. Sintering, Oxidation and Mechanical Properties of Hot Pressed Aluminium Nitride. Ceramics International 8. pp. 34-40.

Borodai, F.Ya.; Suzdal'tsev, E.I. 1975. The Influence of the Technological Parameters on the Properties of Quartz Ceramic. Refractories 16. pp. 648-651.

Bosch, W.A.; Willekers, R.W.; Meijer, H.C.; Postma, H. 1989. Heat Conductivity below $0.4 \mathrm{~K}$ of the Glass-Ceramic Macor and Staybrite Stainless Steel. Cryogenics 29. pp. 982-984.

Briggs, D.D.; Johnson, D.R. 1973. Electrical Properties of Optical Spinel. American Ceramic Society Bulletin 52. p. 716.

Burk, M. 1962. Thermal Expansion of Ceramic Materials at $-200^{\circ}$ to $0^{\circ} \mathrm{C}$. Journal of the American Ceramic Society 45. pp. 305-306.

Carlström, E.; Carlsson, R. 1986. A Fractographic Study of Electrical Porcelains Containing Alumina. Journal de Physique 47. pp. C1-563C1-567.

Chanchani, R.; Hall, P.M. 1990. Temperature Dependence of Thermal Expansion of Ceramics and Metals for Electronic Packages. In: Proceedings, Electric Components Conference, Vol. 1. IEEE, New York. pp. 94-102. 
Chant, M.J. 1967. Dielectric Properties of Some Insulating Materials over the Temperature Range $4.2-300^{\circ} \mathrm{K}$. Cryogenics 7. pp. 351-354.

Chaudhry, M.A.; Jonscher, A.K. 1985. The Dielectric Properties of Mica Paper in Variable Temperature and Humidity. Journal of Materials Science 20. pp. 3581-3589.

Charles, R.J. 1959. The Strength of Silicate Glasses and Some Crystalline Oxides. In: Fracture. The Technology Press, Massachusetts Institute of Technology, Cambridge, MA. pp. 225-249.

Chaudhuri, S.P. 1974. Ceramic Properties of Hard Porcelain in Relation to Mineralogical Composition and Microstructure. III. Dielectric Behaviour. Transactions and Joumal of the British Ceramic Society 73. pp. 37-41.

Chyung, K. 1974. Fracture energy and Thermal Shock Resistance of Mica Glass-Ceramics. In: Fracture Mechanics of Ceramics, Vol. 2: Microstructure, Materials, and Applications. R.C. Bradt, D.P.H. Hasselman, and F.F. Lange, eds. Plenum Press, New York. pp. 495-508.

Clark, W.G., Jr.; Logsdon, W.A. 1974. The Applicability of Fracture Mechanics Technology to Porcelain Ceramics. In: Fracture Mechanics of Ceramics, Vol. 2: Microstructure, Materials, and Applications. R.C. Bradt, D.P.H. Hasselman, and F.F. Lange, eds. Plenum Press, New York. pp. 843-861.

Clinard, F.W., Jr.; Hobbs, L.W. 1986. Radiation Effects in Non-Metals. In: Physics of Radiation Effects in Crystals. R.A. Johnson and A.N. Orlor, eds. Elsevier Science Publishers B.V. pp. 388-471.

Collins, J.G.; Collocott, S.J.; White, G.K. 1985. Thermal Properties of Stabilized Zirconia at Low Temperatures. Australian Journal of Physics 38. pp. 617-622.

Cooper, M.T.; Littler, E.S.; Owen, V.J. 1972. The Influence of Feldspar Composition on the Electrical Properties of High-Tension Porcelain. Proceedings of the British Ceramics Society 23. pp. 1-10.

Cosculluela, A.; Cagnoux, J.; Collombet, F. 1991. Uniaxial Compression of Alumina: Structure, Microstructure, and Strain Rate. Journal de Physique IV. pp. C3-109-C3-116.

Damon, D.H. 1973. Thermal Conductivity of Vitreous Silica at Low Temperatures. Physical Review B 8. pp. 5860-5865.

Davidson, A.T.; Yoffe, A.D. 1965. Dielectric Breakdown in Thin Mica Crystals. Nature 206. pp. 1247-1248.

1968. Hopping Electrical Conduction and Thermal Breakdown in Natural and Synthetic Mica. Physica Status Solidi 30. pp. 741-754. 
Demidenko, A.F.; Koshchenko, V.I.; Sabanova, L.D.; Gran, Yu.M. 1975. LowTemperature Heat Capacity, Entropy, and Enthalpy of Aluminum and Gallium Nitrides. G10-75. All-Union Institute of Scientific and Technical Information (VINITI), Moscow. $14 \mathrm{pp}$.

Deutschmann, G.; Krassnitzer, K. 1991. Influence of Mica Paper Type and Construction on the Dielectric Properties of VPI and Resin Rich High Voltage Insulation. Proceedings of the Electrical/Electronics Insulation Conference. IEEE, New York. pp. 60-64.

De With, G. 1986. Note on the Relation between the Compressive Strength of Debased Alumina and its Use as Hot-Pressing Die Material. Joumal de Physique 47. pp. C1-667-C1-671.

Dienst, W. 1992. Reduction of the Mechanical Strength of $\mathrm{Al}_{2} \mathrm{O}_{3}, \mathrm{AIN}$ and SiC under Neutron Irradiation. Journal of Nuclear Materials 191-194. pp. 555-559.

Dienst, W.; Fett, T.; Heidinger, R.; Röhrig, H.D.; Schulz, B. 1990. Investigations on Ceramic Materials for Fusion Technology. Journal of Nuclear Materials 174. pp. 102-109.

Ditmars, D.A.; Douglas, T.B. 1971. Measurement of the Relative Enthalpy of Pure $\alpha-\mathrm{Al}_{2} \mathrm{O}_{3}$ (NBS Heat Capacity and Enthalpy Standard Reference Material No. 720) from 273 to $1173 \mathrm{~K}$. Journal of Research of the National Bureau of Standards 75A. pp. 401-420.

Dobrovol'skii, Yu.V.; Likhatskii, S.I.; Okhrimenko, G.M.; Rodichev, Yu.M.; Nikol'skii, S.G. 1984. Effect of the Dimensions of Specimens on the Strength of Electrotechnical Porcelain in Axial Compression. Strength of Materials 6. pp. 837-842.

Drexler, E.S.; Simon, N.J.; Reed, R.P. 1992. Shear-Compressive Properties of a Vacuum-Impregnated Insulation System at $76 \mathrm{~K}$. Cryogenics 32 (ICMC Supplement). pp. 22-25.

Dudko, D.Ya.; Primak, A.V.; Fal'kovskii, N.I.; Karpinos, D.M.; Morozov, Yu.I.; Zil'berberg, V.G.; Ivkin, V.K. 1982. Electrical Strength of PlasmaDeposited $\mathrm{Al}_{2} \mathrm{O}_{3}$ Coatings at $\mathrm{T}=300-1400^{\circ} \mathrm{K}$. High Temperature 20. pp. 120-124.

Durand, M.A. 1936. The Temperature Variation of the Elastic Moduli of NaCl, $\mathrm{KCl}$ and $\mathrm{MgO}$. Physical Review 50. pp. 449-455.

Ebert, H. 1928. Ausdehnungsmessungen bei tiefen Temperaturen. Zeitschrift für Physik 47. pp. 712-722.

Egorov, B.N.; Zabruskova, T.N.; Kilesso, V.S.; Kogan, Yu.N.; Kuklenko, V.G. 1991. Thermophysical Properties of Highly Porous Cordierite and Ultraporcelain. Glass and Ceramics 47. pp. 178-181. 
Erez, E.A.; Becker, H. 1982. Radiation Damage in Thin Sheet Fiberglass Insulators. In: Nonmetallic Materials and Composites at Cryogenic Temperatures, G. Hartwig and D. Evans, eds. Plenum Press, New York. pp. 59-71.

European Community representatives, 1993. Electrical Insulator Coatings on $\mathrm{Al}_{2} \mathrm{O}_{3}$. Annex 1P-2, presented at session 3, ITER Technical Meeting, San Diego, CA, May 24-28, 1993. Unpaged.

Evans, A.G.; Fu, Y. 1984. Mechanical Behavior of Alumina: A Model Anisotropic. In: Advances in Ceramics. American Ceramic Society, Columbus, OH. pp. 697-719.

Fabian, P.; Reed, R.P. 1994. Candidate ITER Insulation Materials Characterization Report. Composite Technology Development, Inc., Boulder, Co. $131 \mathrm{pp}$.

Fabian, P.; Schutz, J.; Hazelton, C.; Reed, R.P. 1993. Screening of Candidate Insulation Systems for ITER TF Coils. Composite Technology Development, Inc., Boulder, CO. 131 pp.

Falco, C.M. 1976. Thermal Conductivity of Mica from 1.5 to $4.2 \mathrm{~K}$. Joumal of Applied Physics 47. pp. 3355-3356.

Filmer, R.L.; Hochstrasser, J.; Nicoll, A.R.; Wohlen; Zambelli, G. 1990. Plasma Spray Deposition of Alumina-Based Ceramic Coatings. DVS-Berichte 130. pp. 11-13.

Fine, M.E.; Van Duyne, H.; Kenney, N.T. 1954. Low-Temperature Internal Friction and Elasticity Effects in Vitreous Silica. Journal of Applied Physics 25. pp. 402-405.

Flubacher, P.; Leadbetter, A.J.; Morrison, J.A.; Stoicheff, B.P. 1959. The Low-Temperature Heat Capacity and the Raman and Brillouin Spectra of Vitreous Silica. Physics and Chemistry of Solids 12. pp. 53-65.

Gerlich, D.; Dole, S.I.; Slack, G.A. 1986. Elastic Properties of Aluminum Nitride. Journal of Physics and Chemistry of Solids 47. pp. 437-441.

Gerson, R.; Marshall, T.C. 1959. Dielectric Breakdown of Porous Ceramics. Journal of Applied Physics 30. pp. 1650-1653.

Giauque, W.F.; Archibald, R.C. 1937. The Entropy of Water from the Third Law of Thermodynamics. The Dissociation Pressure and Calorimetric Heat of the Reaction $\mathrm{Mg}(\mathrm{OH})_{2}=\mathrm{MgO}+\mathrm{H}_{2} \mathrm{O}$. The Heat Capacities of $\mathrm{Mg}(\mathrm{OH})_{2}$ and MgO from 20 to $300^{\circ} \mathrm{K}$. Journal of the American Chemical Society 59. pp. 561-569.

Gibbons, D.F. 1959. On the Thermal Expansion and Grüneisen Factor of Vitreous Silica. Journal of the Physics and Chemistry of Solids 11. pp. 246-248. 
Gmelin, E. 1967. A Cryostat for Measuring Heat Capacities from 1.2 to $300^{\circ} \mathrm{K}$ and Measurements of the Specific Heat of Magnesium Oxide below $36^{\circ} \mathrm{K}$. Cryogenics 7 . pp. 225-232.

1969. Thermal Properties of Alkaline Earth Oxides. I. Specific Heat Measurements. Zeitschrift für Naturforschung A 24. pp. 1794-1800.

Goland, A. 1978. Insulator Irradiation Studies at Brookhaven National Laboratory. In: Proceedings of the Meeting on CTR Electical Insulation. pp. 199-212.

Goldstein, L.; Post, B. 1969. Thermal Expansion Coefficients of Ruby Muscovite Mica. Journal of Applied Physics 40. pp. 3056-3057.

Gray, A.S.; Uher, C. 1977. Thermal Conductivity of Mica at Low Temperatures. Journal of Materials Science 12. pp. 959-965.

Grossman, D.G. 1972. Machinable Glass-Ceramics Based on Tetrasilicic Mica. Journal of the American Ceramic Society 55. pp. 446-449.

Gupta, T.K.; Andersson, C.A. 1984. Low Temperature Mechanical Properties of $\mathrm{CeO}_{2}$-Alloyed Tetragonal Zirconia. In Advances in Cryogenic Engineering (Materials), Vol. 30. A.F. Clark and R.P. Reed, eds. Plenum Press, New York. pp. 367-373.

Gurevich, V.M.; Khlyustov, V.G. 1979. Calorimeter for Determining the LowTemperature Heat Capacity of Minerals. Heat Capacity of Quartz in the Temperature Range of 9-300 K. Geokhimiya No. 6. pp. 829-839.

Hackett, W.; Thomas, A.M. 1941. The Electric Strength of Mica and its Variation with Temperature. The Journal of the Institution of Electrical Engineers (Part 1) 88. Pp. 295-303.

Hamano, K.; Wu, Y.-H.; Nakagawa, Z.; Hasegawa, M. 1991a. Effect of Grain Size of Quartz on Mechanical Strength of Porcelain Body. Joumal of the Ceramic Society of Japan 99. pp. 153-157.

1991b. Effect of Coarse Quartz Grains on Mechanical Strength of Porcelain Body. Journal of the Ceramic Society of Japan 99. pp. 1110-1113.

Hannink, R.H.J.; Swain, M.V. 1984. Indentation Studies of Zirconia Materials. In: Proceedings, 11th Australian Ceramic Conference. Australian Ceramic Society, Sydney. pp. 137-143.

Hartnett, T.M.; Gentilman, R.L. 1984. Optical and Mechanical Properties of Highly Transparent Spinel and ALON Domes. SPIE Advances in Optical Materials 505. pp. 15-22.

Heard, H.C.; Cline, C.F. 1980. Mechanical Behaviour of Polycrystalline $\mathrm{BeO}, \mathrm{Al}_{2} \mathrm{O}_{3}$ and $\mathrm{AlN}$ at High Pressure. Journal of Materials Science 15. pp. 1889-1897. 
Hesto, P.; Pellet, C.; Schwebel, C.; DuPont-Nivet, E.; Le Noxaic, A. 1990. Electical Properties of Ion Beam Sputtering Grown Epitaxial Yttria Stabilized Zirconia Films on Silicon. In: Epitaxial Heterostructures, proceedings of MRS Symposium, San Francisco, CA, April 16-19, 1990. Materials Research Society, Pittsburgh, PA. Pp. 577-582.

Hidnert, P.; Dickson, G. 1945. Some Physical Properties of Mica. Journal of Research of the National Bureau of Standards 35. pp. 309-353.

Hirano, M. 1992. Inhibition of Low Temperature Degradation of Tetragonal Zirconia Ceramics - A Review. British Ceramics Transactions and Journal 91. pp. 139-147.

Hsieh, T.-C.; MacDonald, W.M.; Anderson, A.C. 1981. Low-Temperature Thermal Conductivity of Porous Vycor. Journal of Non-Crystalline Solids 46. pp. $437-440$.

Hulse, C.0.; Pask, J. 1960. Mechanical Properties of Magnesium Single Crystals in Compression. Journal of the American Ceramic Society 43. pp. 373-378.

Ibarra, A.; Heidinger, R.; Mollá, J. 1992. New Potentials for High Mechanical Strength Grades of Polycrystalline Alumina for EC Waves Windows. Journal of Nuclear Materials 191-194. pp. 530-534.

Ichinose, N.; Hazeyama, I. 1990. Thermal Properties of Low Temperature Firing AlN Ceramics. Report of Materials Science and Technology 41. pp. 11-15.

Jikihara, K.; Ishihara, M. 1990. Mechanical Properties of Zirconia Ceramics at Low Temperature. Nippon Seramikkusu Kyokai Gakujutsu Ronbunshi 98. pp. 1132-1138.

Kawai, K.; Ishida, H.; Otsuka, N. 1993. Thermal Expansion of Ceramic for Building Materials. Journal of the Ceramic Society of Japan 101. pp. 305-308.

Kelley, K.K. 1944. Specific Heat of Zirconium Dioxide at Low Temperatures. Industrial and Engineering Chemistry 36. p. 377.

Ketterer, R.J. 1964. Mica Paper Insulations - State of the Art. Insulation 10. PP. 24-32.

Kim, S.H.; Yun, M.S.; Yoshino, K. Inuishi, Y. 1983. Dielectric Breakdown of Superfluid Helium. Technology Reports of the Osaka University 33. pp. 295-299.

Kimura, K.; Hirabayashi, S.; 1977. Dielectric Breakdown of Mica/Epoxy Composite. Electrical Engineering in Japan 97. pp. 230-236.

Kimura, K.; Kaneda, Y. 1991. Breakdown Voltage and SEM Observation on Mica Insulation Systems after Thermal Aging and Mechanical Fatigue. In: Seventh International Symposium on High Voltage Engineering, Vol. 2. Technische Universität Dresden, Dresden, Germany. pp. 151-154. 
Kingon, A.I.; Davis, R.F.; Thackeray, M.M. 1991. Engineering Properties of Multicomponent and Multiphase Oxides. In: Engineered Materials Handbook, Vol. 4: Ceramics and Glasses. S.J. Schneider, Jr., ed. ASM International, Metals Park, OH. pp. 758-774.

Klakken, M.I.; Dickinson, J.T.; Jensen, L.C. 1984. Electrical Breakdown Induced by Fracto-emission. IEEE Transactions on Electrical Insulation EI-19. Pp. 578-585.

Korzo, V.F. 1968. Temperature Dependence of Electrical Strength of $\mathrm{SiO}_{2}$ Films. Soviet Physics - Solid State 10. pp. 1256-1257.

Koschenko, V.I.; Yachmenev, V.E.; Lepkov, A.A. 1981. Heat Capacity of Aluminum Nitride at 216-300 K. VINITI-2814-81. All-Union Institute of Scientific and Technical Information (VINITI), Moscow. 7 pp.

Krijgsman, P.; Becht, J.G.M.; Schoonman, J. 1989. Hydrothermal Processing of Ceramic Powders for Alumina-Magnesia Spinels. Solid State Ionics 32/33. pp. 436-439.

Kropschot, R.H.; Mikesell, R.P. 1960. An Experimental Study of the Strength and Fatigue of Glass at Very Low Temperatures. In: Advances in Cryogenic Engineering, Vol. 2. K.D. Timmerhaus, ed. Plenum Press, New York. pp. 136-144.

Langdon, T.G.; Pask, J.A. 1971. Factors Influencing the Stress-Strain Behavior of Ceramic Materials. In: Ceramics in Severe Environments. W.W. Kreigel and H. Palmour III, eds. Plenum Press, New York. pp. 283-296.

Lankford, J. 1977. Compressive Strength and Microplasticity in Polycrystalline Alumina. Journal of Materials Science 12. pp. 791-796.

1981a. Mechanisms Responsible for Strain-Rate-Dependent Compressive Strength in Ceramic Materials. Communications of the American Ceramic Society 64. pp. C-33-C-34.

- 1981b. Temperature-Strain Rate Dependence of Compressive Strength and Damage Mechanisms in Aluminium Oxide. Journal of Materials Science 16. pp. 1567-1578.

- 1991. The Compression Strength of Strong Ceramics: Microplasticity versus Microfracture. Journal of Hard Materials 2. pp. 55-77.

Lawless, W.N. 1975. Dielectric and Thermal Properties of a Machinable GlassCeramic at Low Temperatures. Cryogenics 15. pp. 273-277.

- 1980. Low-Temperature Specific Heat of a $\mathrm{ZrO}_{2}: \mathrm{Y}_{2} \mathrm{O}_{3}$ Oxygen Conductor. Physical Review B 21. pp. 585-588.

Lawless, W.N.; Gupta, T.K. 1983. Thermal Properties of Tetragonal $\mathrm{ZrO}_{2}$ at Low Temperatures. Physical Review B 28. pp. 5507-5510. 
Löhneysen, H.V.; Rüsing, H.; Sander, W. 1985. Structural Relaxation Effects on the Low-Temperature Properties of Vitreous Silica. Zeitschrift für Physik B 60. pp. 323-330.

Low, N.L.P. 1980. Formation and Properties of Glass-Mica Composite Materials. Ceramurgia International 6. pp. 85-90.

Lynch, W.T. 1972. Calculation of Electric Field Breakdown in Quartz as Determined by Dielectric Dispersion Analysis. Journal of Applied Physics 43. pp. 3274-3278.

McSkimin, H.J. 1953. Measurement of Elastic Constants at Low Temperature by Means of Ultrasonic Waves-Data for Silicon and Germanium Single Crystals, and for Fused Silica. Journal of Applied Physics 24. Pp. 988-997.

Maiti, K.N.; Kumar, S. 1992. Effect of Glass-Ceramics and Sillimanite Sand Additions on Microstructure and Properties of Porcelain. Ceramics International 18. PP. 403-412.

Mamedov, K.K.; Abdullaev, A.B.; Shalumov, B.Z.; Mekhtiev, M.I.; Aldzhanov, M.A.; Aliev, N.N.; Gumbatov, D.O. 1985. Fizika Khimiya Stekla 11. pp. 536-541.

Mamedov, K.K.; Abdullaev, A.B.; Shalumov, B.Z.; Mekhtiev, M.I.; Alyanov, M.A.; Gumbatov, D.0. 1987. Low-Temperature Heat Capacity and Thermodynamic Properties of Silicon-Dioxide-Based Binary Vitreous Systems. Physica Status Solidi (a) 99 . pp. 413-421.

Mangalaraj, D.; Radhakrishnan, M.; Balasubramanian, C. 1982. Dielectric Breakdown Properties of Aluminium Nitride Films. Current Science 51. pp. 1068-1069.

Mäntylä. T.A.; Vuoristo, P.J.M.; Telama, A.K.; Kettunen, P.0. 1985. Electrical Insulating Properties and Thermal Stability of R.F.-Sputtered Alumina Coatings. Thin Solid Films 126. pp. 43-49.

Marshal1, D.B.; James, M.R.; Porter, J.R. 1989. Structural and Mechanical Property Changes in Toughened Magnesia-Partially-Stabilized Zirconia at Low Temperatures. Joumal of the American Ceramic Society 72 . pp. 218227.

Mathes, K.N. 1963. Electrical Insulation at Cryogenic Temperatures. Electro-Technology 72 . pp. 72-77.

Miyayama, M.; Koumoto, K.; Yanagida, H. 1991. Engineering Properties of Single Oxides. In: Engineered Materials Handbook, Vol. 4: Ceramics and Glasses. S.J. Schneider, Jr., ed. ASM International, Metals Park, OH. pp. 748-757.

Moore, R.E. 1991. Engineering Properties of Nitrides. In: Engineered Materials Handbook, Vol. 4: Ceramics and Glasses. S.J. Schneider, Jr., ed. ASM International, Metals Park, OH. pp. 812-820. 
Morse, C.T.; Hill, G.J. 1970. The Electric Strength of Alumina: The Effect of Porosity. Proceedings of the British Ceramic Society 18. pp. 23-25.

Naguib, H.M.; Kelly, R. 1975. Criteria for Bombardment-Induced Structural Changes in Non-Metallic Solids. Radiation Effects 25. pp. 1-12.

Nemoto, T.; Sasaki, S.; Hakuraku, Y. 1985. Thermal Conductivity of Alumina and Silicon Carbide Ceramics at Low Temperatures. Cryogenics 25. pp. 531-532.

Nevitt, M.V.; Fan, Y.; Chan, S.-K. 1990. Journal of the American Ceramic Society 73. pp. 2502-2504.

Nielsen, L.F. 1990. Strength and Stiffness of Porous Materials. Journal of the American Ceramic Society 73. pp. 2684-2689.

O'Dwyer, J.J. 1967. The Theory of Avalanche Breakdown in Solid Dielectrics. Journal of Physics and Chemistry of Solids 28. pp. 1137-1144.

Okhrimenko, G.M. 1984. Strength of Porcelain with Biaxial Compression. Strength of Materials 5. pp. 691-697.

Olivo, P.; Ricco, B.; Nguyen, T.N.; Kuan, T.S.; Jeng, S.J. 1987. Evidence of the Role of Defects near the Injecting Interface in Determining $\mathrm{SiO}_{2}$ Breakdown. Applied Physics Letters 51. pp. 2245-2247.

Orlova, R.G.; Beshentsev, V.D.; Moroz, I.Kh.; Bogdanis, É.P. 1989. Effect of Structure and Degree of Dispersion of Alumina on Properties of Porcelain. Glass and Ceramics 45. pp. 466-469.

Owate, I.O.; Freer, R. 1988. The Dielectric Breakdown Strength of Alpha Alumina Ceramic at Room Temperature. Science of Ceramics 14. pp. 1013-1018.

- 1989. The A.C. Electrical Breakdown of Some Aluminum Nitrade Ceramics. Silicates Industriels 54. pp. 123-127.

Pawlowski, L. 1988. The Relationship between Structure and Dielectric Properties in Plasma-Sprayed Alumina Coatings. Surface and Coatings Technology 35. pp. 285-298.

Petch, N.J. 1971. Fracture Mechanisms of Very Strong Solids. In: Ceramics in Severe Environments. W.W. Kriegel and H. Palmour III, eds. Plenum Press, New York. pp. 185-194.

Pratt, I.H. 1968. Processing and Evaluation of RF Sputtered Quartz. Transactions of the Metallurgical Society of AIME 242. pp. 526-531.

Quinn, G.D. 1991. Strength and Proof Testing. In: Engineered Materials Handbook, Vol. 4: Ceramics and Glasses. S.J. Schneider, Jr., ed. ASM International, Metals Park, OH. pp. 585-598. 
Ratcliffe, E.H. 1963. A Survey of Most Probable Values for the Thermal Conductivities of Glasses between about -150 and $100^{\circ} \mathrm{C}$, Including New Data on Twenty-two Glasses and a Working Formula for the Calculation of Conductivity from Composition. Glass Technology 4. pp. 113-128.

Reed, R.P. 1993. Private communication. (Transmission from ITER EDA Naka Co-Center, July and December 1993.) Cryogenic Materials, Inc., Boulder, Co.

Rhodes, W.H.; Cannon, R.M., Jr.; Vasilos, T. 1974. Stress-Corrosion Cracking in Polycrystalline Mgo. In: Fracture Mechanics of Ceramics, Vol. 2. Microstructure, Materials, and Applications. R.C. Bradt, D.P.H. Hasselman, and F.F. Lange, eds. Plenum Press, New York. pp. 709-733.

Rice, R.W. 1971. The Compressive Strength of Ceramics. In: Ceramics in Severe Environments. W.W. Kriegel and H. Palmour III, eds. Plenum Press, New York. pp. 195-229.

Rice, R.W.; Freiman, S.W.; Bechner, P.F. 1981. Grain-Size Dependence of Fracture Energy in Ceramics: I. Experiment. Joumal of the Americal Ceramic Society 64. pp. 345-354.

Rosenberg, H.M. 1963. Low Temperature Solid State Physics. Clarendon Press, Oxford.

Roth, E.P.; Anderson, A.C. 1976. Low-Temperature Thermal Conductivity and Specific Heat of a Machinable Ceramic. Journal of Applied Physics 47. pp. 3644-3647.

Schroeder, J.E. 1978. Inexpensive High Strength Electrical Porcelain. American Ceramic Society Bulletin 57. p. 526.

Schroeder, J.E.; Guertin, J.P. 1978. Extremely High Strength Porcelain. EL-722. Electric Power Research Institute, Palo Alto, CA.

Shikata, R.; Yamamoto, T.; Shiono, T.; Nishkawa, T. 1991. Improvement of Heat Degradation in Y-TZP by Surface Modification. Journal of the Society of Materials Science, Japan. pp. 927-933.

Shutilov, V.a.; Abezgauz, B.S. 1985. Physical Properties of Vitreous Silica. Soviet Journal of Glass Physics and Chemistry 11. pp. 83-96.

Siebeneck, H.J.; Chyung, K.; Hasselman, D.P.H.; Youngblood, G.E. 1977. Effect of Crystallization of the Thermal Diffusivity of a Mica GlassCeramic. Journal of the American Ceramic Society 60. pp. 375-376.

Simon, N.J. 1994. Irradiation Damage in Inorganic Insulation Materials for ITER Magnets: A Review. NISTIR-5025. National Institute of Standards and Technology, Boulder, Co. 391 pp. 
Simon, N.J.; Drexler, E.S.; Reed, R.P. 1994. Shear/Compressive Tests for ITER Magnet Insulation. In: Advances in Cryogenic Engineering (Materials), Vol. 40. R.P. Reed, F.R. Fickett, L.T. Summers, and M. Stieg, eds. pp. 977-983.

Simon, N.J.; Reed, R.P.; Walsh, R.P. 1992. Compression and Shear Tests on Vacuum-Impregnated Composites at Cryogenic Temperatures. In: Advances in Cryogenic Engineering (Materials), Vol. 38. F.R. Fickett and R.P. Reed, eds. Plenum Press, New York. pp. 363-370.

Singh, A. 1983. Electrical Pulse Breakdown in Magnesium Oxide Capacitors. Joumal of Materials Science Letters 2. pp. 573-576.

Singh, G.P.; von Schickfus, M. ; Hunklinger, S.; Dransfeld, K. 1981. Anomalous Low Temperature Dielectric Behaviour of $\gamma$-alumina. Solid State Communications 40 . pp. 951-953.

Skripnikov, V.A.; Sanin, V.N. 1982. Low Temperature Properties of Some Single-Component Dielectric Glasses. Fizika e Khimia Stekla 8. pp. 721-725.

Slack, G.A. 1962. Thermal Conductivity of $\mathrm{MgO}, \mathrm{Al}_{2} \mathrm{O}_{3}, \mathrm{MgAl}_{2} \mathrm{O}_{4}$, and $\mathrm{Fe}_{3} \mathrm{O}_{4}$ Crystals from $3^{\circ}$ to $300^{\circ} \mathrm{K}$. Physical Review 126. pp. 427-441.

1973. Nonmetallic Crystals with High Thermal Conductivity. Journal of Physics and Chemistry of Solids 34. pp. 321-335.

Slack, G.A.; Tanzilli, R.A.; Pohl, R.O.; Vandersande, J.W. 1987. The Intrinsic Thermal Conductivity of AlN. Journal of Physics and Chemistry of Solids 34. pp. 641-647.

Slaoui, A.; Fogarassy, E.; Fuchs, C.; Siffert, P. 1992. Properties of Silicon Dioxide Films Prepared by Pulse-Laser Ablation. Journal of Applied Physics 71. pp. 590-596.

Soliman, A.; Nosseir, A.; Bakr, M.; Sakr, M. 1972. Effect of Percentage Porosity on Electrical Properties of Porcelain Insulators. Interceram 21. pp. 69-70, 72 .

Spinner, S.; Cleek, G.W. 1960. Temperature Dependence of Young's Modulus of Vitreous Germania and Silica. Joumal of Applied Physics 31 . pp. 14071410 .

Sprangle, E.A.; Andrews, J.M.; Peckerar, M.C. 1991. Dielectric Breakdown Strength Analysis of Silicon Dioxide Using a Step-Field Testing Method. Proceedings Electrocehmical Society 91-11. pp. 409-420.

- 1992. Dielectric Breakdown Strength of $\mathrm{SiO}_{2}$ Using a Stepped-Field Method. Journal of the Electrochemical Society 139. pp. 2617-2620.

Stevens, R. 1991. Engineering Properties of Zirconia. In: Engineered Materials Handbook, Vol. 4: Ceramics and Glasses. S.J. Schneider, Jr., ed. ASM International, Metals Park, OH. pp. 775-786. 
Thompson, D.S.; Roberts, J.P. 1960. Flow of Magnesium Oxide Single Crystals. Journal of Applied Physics 31. pp. 433-434.

Tonkonogov, M.P.; Omarov, K.M. 1979. Effect of Lamination on the Pulse Breakdown of Mica. Soviet Physics Journal 22. pp. 661-664.

Totsenko, S.V.; Kainarskii, I.S.; Degtyareva, E.V. 1966. Properties of Spinel and Spinel-Corundum Sintered Refractory Materials. Journal of Inorganic Materials 2. pp. 1434-1440.

Touloukian, Y.S.; Buyco, E.H. 1970. Thermophysical Properties of Matter, Vol. 5: Specific Heat, Nonmetallic.Solids. Plenum Press, New York.

Touloukian, Y.S.; Kirby, R.H.; Taylor, R.E.; Lee, T.Y.R. 1977. Thermophysical Properties of Matter, Vol. 13: Thermal Expansion, Nonmetallic Solids. Plenum Press, New York.

Touloukian, Y.S.; Powell, R.W.; Ho, C.Y.; Klemens, P.G. 1970. Thermophysical Properties of Matter, Vol. 2: Thermal Conductivity, Nonmetallic Solids. Plenum Press, New York.

Tracy, C.A. 1987. A Compression Test for High Strength Ceramics. Journal of Testing and Evaluation 15. pp. 14-19.

Veitch, S.; Marmach, M.; Swain, M.V. 1987. Strength and Toughness of Mg-PSZ and Y-TZP Materials at Cryogenic Temperatures. In: Advanced Structural Ceramics, MRS Symposium Proceedings. P.F. Becher, M.V. Swain, and S. Sömiya, eds. Materials Research Society, Pittsburgh, PA. pp. 97106.

Volger, J; Stevels, J.M.; van Amerongen, C. 1955. Dielectric Losses of Various Monocrystals of Quartz at Very Low Temperatures. Phillips Research Reports 10. pp. 260-280.

Vonnegut, B.; Glathart, J.L. 1946. The Effect of Temperature on the Strength and Fatigue of Glass Rods. Journal of Applied Physics 17. pp. 10821085 .

Wachtman, J.B., Jr.; Lam, D.G., Jr. 1959. Young's Modulus of Various Refractory Materials. Journal of the American Ceramic Society 42. pp. 254260 .

Wachtman, J.B., Jr.; Scuderi, T.G; Cleek, G.W. 1962. Linear Thermal Expansion of Aluminum Oxide and Thorium Oxide from $100^{\circ}$ to $1100^{\circ} \mathrm{K}$. Journal of the American Ceramic Society 45. pp. 319-323.

Wachtman, J.B., Jr.; Tefft, W.E.; D.G. Lam, Jr.; Stinchfield, R.P. 1960. Elastic Constants of Synthetic Single Crystal Corundum at Room Temperature. Journal of Research of the National Bureau of Standards 64A. pp. 213-228.

Wenger, L.E.; Amaya, K.; Kukkonen, C.A. 1976. The Negligible Effect of Strain on the Low-Temperature Heat Capacity of Silica Glass. Physical Review B 14. Pp. 1327-1328. 
White, G.K. 1964. Thermal Expansion of Silica at Low Temperatures. Cryogenics 4 . pp. 2-7.

1973. Thermal Expansion of Reference Materials: Copper, Silica and Silicon. Journal of Physics D 6. pp. 2070-2078.

1976. Thermal Expansion at Low Temperatures of Glass-Ceramics and Glasses. Cryogenics 16. pp. 487-490.

1984. Physical Properties: Knowing, Guessing, and Measuring. In:

Advances in Cryogenic Engineering (Materials), Vol. 30. A.F. Clark and R.P. Reed, eds. Plenum Press, New York. pp. 383-393.

Yoshimura, M.; Bowen, H.K. 1981. Electrical Breakdown Strength of Alumina at High Temperatures. Journal of the American Ceramic Society 64. pp. 404-410.

Zeller, R.C.; Pohl, R.O. 1971. Thermal Conductivity and Specific Heat of Noncrystalline Solids. Physical Review B 4. pp. 2029-2041. 